UB 400 A17

\title{
Encounters at the
}

\section{interface}

A perspective on social discontinuities in rural development

Norman Long (Editor)






\section{CIP-DATA KONINKLIJKE BIBLIOTHEEK, DEN HAAG}

Encounters

Encounters at the interface: a perspective on social discontinuities in rural development / Norman Long et al. (eds). - Wageningen: Agricultural University Wageningen. - (Wageningen studies in sociology; 27)

With bibliogr.

ISBN 90-6754-148-6

SISO 630.6 UDC $631 / 632(1-772 / 773)$

ISSN 0923-4365

NUGI 659

Subject heading: rural development

(c) Agricultural University Wageningen, the Netherlands 1989

No part of this publication apart from bibliographic data and brief quotations embodied in critical reviews, may be reproduced, re-recorded or published in any form including print, photocopy, microfilm, electronic or electromagnetic record without written permission from the publisher Agricultural University, P.O. Box $9101,6700 \mathrm{HB}$ Wageningen, the Netherlands.

Printed in the Netherlands 


\section{CONTENTS}

Acknowledgements

I. INTRODUCTION: THE RAISON D' ETRE FOR STUDYING RURAL DEVELOPMENT INTERFACE

Norman Long

II. THE SOCIAL CONSTRUCTION OF AGRARIAN DEVELOPMENT: A CASE STUDY OF PRODUCER-BUREAUCRAT RELATIONS IN AN IRRIGATION UNIT IN WESTERN MEXICO

Alber to Arce

$x$ III. SOCIAL ENCOUNTERS AND INTERFACES BETWEEN FARMERS AND INTERVENING ACTORS: THE EMERGENCE OF LOCAL ORGANIZATION IN WESTERN MEXICO

Hans Heijdra

$x$ IV. THE CHANGING LIFE-WORLDS OF WOMEN IN A MEXICAN EJIDO: THE CASE OF THE BEE-KEEPERS OF AYUQUILA AND THE ISSUE OF INTERVENTION

Norman Long and Magdalena Villarreal

$x$. KNOWLEDGE SYSTEMS, METAPHOR AND INTERFACE: THE CASE OF POTATOES IN THE PERUVIAN HIGHLANDS

Jan Douwe van der Ploeg

XVI. KNOWLEDGE, NETWORKS AND CULTIVATORS: CASSAVA IN THE DOMINICAN REPUBLIC

Louk Box

VII. IRRIGATION SYSTEMS AS SOCIAL INTERFACES: TOWARDS AN UNDERSTANDING OF IRRIGATION DEVELOPMENT AS AN INTERACTIONAL PROCESS

Jan Ubels

X VIII. INTERFACES AND JANUS-FACES: A CRITICAL APPRAISAL OF THE INTERFACE APPROACH IN DEVELOPMENT SOCIOLOGY FROM A SOCIO-LEGAL STUDIES PERSPECTIVE

Franz von Benda-Beckmann, Ab van Eldijk, Joep Spiertz and Fietje Huber

X IX. CONCLUSION: THEORETICAL REFLECTIONS ON ACTOR, STRUCTURE AND INTERFACE

Norman Long

Appendix. NOTES ON RESEARCH METHODOLOGY: MEXICAN PROJECT Norman Long

Bibliography

Notes on the contributors 


\section{Acknowledgements}

This volume is a wageningen product. It arises out of ongoing discussions among researchers and students based in Wageningen interested in developing new approaches to the study of rural development and planned intervention. Although the central issues are fundamentally sociological and anthropological, the interest in "interface" at Wageningen extends beyond the confines of these disciplinary boundaries to encompass others working in adjacent fields. The latter include agrarian law, irrigation engineering, agricultural extension, and knowledge systems. I would like firstly, therefore, to thank all those (whose names are too numerous to mention) who have been drawn into the debate for their many useful, challenging and at times combative, contributions. Chapters $V$ to VIII of this volume bear witness to the fecundity of this interchange of ideas. I would also 1 ike to thank the participants of the "Interface Workshop" organized by my department in December 1986 .

A second source of inspiration has been the team of researchers working under my supervision on Mexican agrarian development. This team was formed in late 1986 to investigate issues concerning planned intervention and farmer strategies in an irrigation region of Jalisco. The programne of studies was supported by grants from the Ford Foundation and the Netherlands Scientific Council for Tropical Research (WOTRO), and was affiliated to El Colegio de Jalisco, Guadalajara. The materials presented in Chapters II to IV constitute the first fruits of this joint research. Throughout the planning and fieldwork stages, as well as now that we begin to grapple with the analysis of data, we have continuously debated the methodological and theoretical value of an interface approach. Whilst we cannot claim to have resolved the issues satisfactorily, nor to have reached a theoretical consensus, the present book gives some insight into our journey to date. Later we intend to publish a monograph on the region which will analyse more 
fully "intervention" processes and struggles "from below". In the meantime, I wish to thank various team members who have taken an active part in the disclissions over the past two years. In addition to the authors of chapters in this book, these include Dorien Brunt, Humberto González, Elsa Guzmán, Gabriel Torres, and pieter van der Zaag. I also wish to single out for special mention, my friend and intellectual soulmate, Alberto Arce (now of the University of Hull) who, with his usual combination of critical observation and evangelical enthusiasm for this field of study, insisted that I get this volume into print.

My greatest debt, however, is to my wife Ann who, despite her own academic and other commitments, shared with me the burden of editing and putting into sound English all the contributions to this volume. At times we buckled at the pressure and sometimes sparred over phraseology or logic, but in the end we managed to finish, as we had started, the best of friends.

Finally I wish to express my gratitude to Ans van der Lande who prepared the camera-ready copy of the manuscript and who never flinched when I suggested for the $n$-th time that we still needed to make certain editorial changes.

Bennekom, 20th February 1989

Norman Long 


\section{INTRODUCTION: THE RAISON D'ETRE FOR STUDYING RURAL DEVEIOPMENT INTERFACE}

Norman Long

From time to time "new" words or expressions, deriving from other sciences or from everyday discourse, creep into the vocabulary of a particular scientific debate. This usually occurs when the need arises to convey a new idea or to emphasize some particular dimension of a problem requiring further exploration. This, I believe, is true of the central organizing concept for this book - social interface.

This opening chapter outlines briefly the essence of the concept and suggests how it relates to several important issues in the field of rural development. Although sketchy, the following account serves, as it did in our 1986 workshop 1, to lay out the terrain and to stimulate others to think through the various analytical problems which it raises. This introduction also aims to provide an overview of the contours of the chapters that follow, reserving until the conclusion a fuller discussion of the theoretical implications of an interface perspective.

The concept of interface and why it is important

The general notion of interface conjures up the image of two surfaces coming into contact or of a modern computer system whose central processing unit is linked to auxiliary equipment through a mechanism called the interface. It has also been used to characterize the situation where chemical substances interact but fail to combine to form a new composite solution. My usage differs sonewhat from these in that I wish to stress the dynamic and potentially conflictive nature of social interface. Hence I define a social interface as a critical point of 
intersection or linkage between different social systems, fields or levels of social order where structural discontinuities, based upon differences of normative value and social interest, are most 1 ikely to be found.

The concept implies some kind of face-to-face encounter between individuals or units representing different interests and backed by different resources. The interacting parties will often be differentiated in terms of power. Studies of social interfaces should aim to bring out the dynamic and emergent character of the interactions taking place and to show how the goals, perceptions, interests, and relationships of the various parties may be reshaped as a result of their interaction. However, they should also explore how these interactions are affected by, and in turn themselves influence, actors, institutions and resource-fields that lie beyond the interface situation itself. Interface analysis, then, is essentially a methodological devise for studying linkage structures and processes and should not therefore be confined to the study of the minutiae of social interaction, but should situate these within broader institutional frameworks and power fields.

\section{Rural development interface}

It is my view that we can develop this type of approach for analyzing interventions in the rural sector. Public agencies (both government and non-government) frequently intervene to implement particular development policies or programmes and much research (both "pure" and "applied") has been addressed to understanding the complex relationship between types of intervention and types of outcome. Yet we still find it immensely difficult to formulate sound generalizations about this relationship that could serve for replication purposes: note, for example, the widely differing findings and interpretations of the results of the Green Revolution in Asia or of different Land Reforms in Latin America. I believe that interface analysis could help us to resolve some of these issues more effectively, but it would require developing a systematic framework for comparison and the working out of appropriate field methodologies.

My interest in developing such an analytical framework has evolved 
from my view that there are presently three urgent areas for research on rural development.

1) We need to develop a more adequate analytical approach to understanding the relationships between policy, implementation and outcomes. The tendency in much existing work is to conceptualize the relationship between policy objectives, the means of implementation and the outcomes as essentially linear in nature, implying a kind of step-by-step deterministic process whereby a policy is formulated, implemented and then certain results follow. Clearly, as recent research and practice demonstrates, this separation of "policy", "implementation" and "outcomes" is a gross simplification of a much more complicated set of processes which involves the continuous reinterpretation or transformation of policy, both at the point of manufacture and at the "frontline" by those responsible for its implementation. Furthermore, "outcomes" often result from factors which cannot be directly linked to the development programe itself.

Following certain leads in policy research (see, for example, Grindle, 1980, and Warwick, 1982), I became interested in looking closely at the point at which planned intervention (whether initiated by the state or some non-government organization or interest group) takes place, and at studying the social consequences and peasant and bureaucratic responses to this process. Development interface situations are the critical points at which not only is policy applied but at which it is "transformed" through acquiring social meanings that were not set out in the original policy statements. As any enlightened planner or rural development worker knows through experience, it is impossible to separate policy, implementation and outcome into watertight compartments: there is considerable seepage between them and therefore a mixing of elements such that it is often difficult to say where one stops and the other begins. One solution to this problem seerns to be to concentrate one's research efforts on implementation processes so that one reaches a fuller understanding of the structural dynamics and "degrees of freedom" or "room for manoeuvre" associated with particular interface situations (see Long, 1984:11-13).

The question of implementation is close to the central problem of policy analysis, namely the "allocative dimension", i.e. how exactly are the goods and services, rewards and punishments, handed out to the 
population at large? What are the direct and indirect benefits to particular social sectors, and why are the distributive effects uneven? Only a close-up study of allocative processes and outcomes can provide the answer to these and similar questions (Batley, 1983). This, of course, entails looking in detail at interface situations.

2) We need to develop a sounder comparative analys is of the processes by which "target" and "non-target" populations respond to planned intervention. Such an analysis would ain to explore how different types of households, peasant groups and communities (including both those directly and indirectly affected) develop strategies for dealing with the new circumstances they face due to the introduction of new development initiatives. Such an approach necessarily entails contextualizing the new types of choices generated by specific interventions within the framework of the livelihood and organizational problems faced by peasants and other classes.

In order to undertake such an analysis one needs to document the differential responses of particular peasant groups to specific rural development programmes. This requires undertaking a set of controlled comparisons aimed at explaining why different groups react differently to apparently similar circumstances (Long, 1977:105-143), as well as providing a detailed chronological analysis of the relations that evolve between the target and non-target group, and the implementing agency. The latter diachronic analysis is often neglected, with the result that it is simply assumed that the key explanatory factors are endogenous to the situation (for example, existing variations in demography, access to resources, or differences in ideology or culture) rather than an outcome of how the intervention process has evolved in relation to specific social units. The issue of differential responses, therefore, requires a much more careful mapping out of how implementing agencies and their personnel interact and present themselves to local groups, and vice versa.

3) We need to resolve the serious theoretical gap in the analysis of social change and rural development that results from the tendency to formulate problems either from the point of view of how peasants react to development intervention without really analyzing the nature of the wider encapsulating systern, or from the point of view of how external 
forces determine local patterns of change without taking into account how the actions of peasants themselves or of other local groups may shape these processes. One way of breaking this theoretical deadlock is, I believe, to develop methods of analysis which focus more on the interface situations that develop between implementing agencies and local groups and actors.

While the study of interface necessarily involves giving attention to interactional processes and adopting an "actor-oriented" approach to the understanding of sociat phenornena (Long, 1977:187-190; and Long, 1984), this should not, however, blind the researcher to the effects of important larger-scale structural processes (such as integration into national or international cormodity markets or the impact of state bureaucracy and national-level power structures). Rather, I argue that interface studies reveal concretely the nature of Capital-state-peasant relations in particular localities or regions, and thus indirectly facilitate a fuller understanding of the character and significance of specific State formations (see Martinez, 1983; Geschiere, 1984). Interfaces focussing upon the role of non-government organizations or on peasant-organized strategies aimed at implementing policies that may run counter to the interests of ruling classes likewise highlight the problems and nature of the wider politico-economic system. Unlike general theories of the state, or interpretations of the role played by planned development in "accumulation on a world scale" (De Janvry, 1981), which operate at a high level of abstraction, often tending towards reification, the study of interface forces one to look closely at the interplay and mutual determinations of so-calied "external" and "local-level" processes.

The present book, then, explores both ethnographically and theoretically these various interface issues. Its principal aim is to begin the search for ways of developing a methodology and theoretical framework for dealing with the many, complex problems raised above. If it succeeds in arousing interest among social scientists and others working in the field of rural development then indeed it will have achieved its objective. 
The book begins with an ethnography of interface encounters, with what Geertz (1973:6-9), borrowing from the philosopher Gilbert Ryle, has called "thick description" to convey the many layers of social meaning implicit in the activity of ethnography itself. It ends with chapters that explore the more general theoretical and practical issues involved, including the usefulness of an interface perspective for work on knowledge systems and networks, irrigation organization, and the comparative study of socio-legal processes.

We open, then, by imnersing the reader in detailed ethnography so as to communicate both the excitement and complexity of dealing with processes of cultural construction, strategy and negotiation at the interface. The analytic struggle with field material, so evident in these opening chapters, underscores the crucial need for developing an appropriate and sensitive methodology for collecting and analyzing field data on rural development interface (see Appendix for some suggestions).

Chapters II, III and IV are based upon field studies that form part of a programue of research currently being carried out in western Mexico by a team of researchers based at wageningen. Chapter II focusses on the social processes that made possible the construction, operation and eventual demise of a small-scale irrigation unit in a Mexican ejido. The case identifies the crucial social actors and institutions involved and the different phases of the project. The analysis deals with a series of encounters between the local representatives of the Mexican agricultural bureaucracy and the producers. It emphasizes the ways in which the actors' previous experiences and biographies shaped their interaction with each other, leading to differing social constructions of the project. Yet despite these differences, the actors are nonetheless able to develop bridges between their life-worlds, even when these life-worlds represent major discontinuities within a particular social order. Hence processes of accommodation are not simply defined by the existence of differential relations of power and sources of authority in the society at large, but by the inherent capacity of the actors to process knowledge and to learn from experience, which are the hallmarks of human agency. In the end, it appears that it is those who cope best with this process of 
defining specific interface situations and utilizing their resources to the full, who come to control the organization and meaning which particular interventions take at local level.

Chapter III examines how, in another village context, farmers' organizations responded to a crisis in the future of a farmer-organized packing plant producing winter vegetables and fruits for the United States. The material is presented and analyzed using the method of "situational analysis" which analyzes the negotiations, exchanges and opposing strategies that emerge between them and officials representing different government agencies. The main theoretical interest of this contribution is to shed light on "intervention" processes from within the local arena, thus showing how actions initiated from "above", involving in this case the setting up of farmers' organizations, are reshaped by the interpretations and strategies of local actors.

The next chapter (IV) discusses a third case from western Mexico: that of a women's group that establishes a small-scale, bee-keeping enterprise. Adopting a "life-worlds" approach, it is argued that these women are actively engaged in reordering their social relations (both within their household domains as well as within the wider social environment of the village and beyond). For some, this means reconstructing their life-worlds by creating space for the pursuit of their own individual "projects", entailing a break with existing social practice and ideology on women's roles and behaviour. For others, it implies the consolidation of existing networks with female kin, affines and friends, with no attempt to challenge prevailing cultural representations of male/female relations and duties. The chapter describes the differentiated nature of these social forms and levels of consciousness. In addition, it looks at the relationships that the group has with representatives of government agencies interested in promoting women's "participation" in rural development. The analysis explores interface from the point of view of the co-existence and interpenetration or transformation of life-worlds. Such an approach, it is argued, provides important insights into processes of social confrontation, negotiation and restructuration within the context of everyday social encounters, as well as within the larger arena of State-peasant relations.

The following two chapters address the issue of knowledge interfaces. Chapter $\mathrm{V}$ analyzes the confrontation of two knowledge systems in 
the cultivation of potatoes in Peru and the consequent marginalization of local knowledge by a system of scientific knowledge. Through this process farmers are deprived of one of their major resources, since local knowledge becomes superfluous. This has profound consequences for the dynamics of interface between the "agents" of scientific knowledge, on the one hand, and the farmers, on the other. The chapter argues that the agents of scientific knowledge, who are categorized as "the experts", ignore the importance of local knowledge and agricultural practice, thus denying the peasants any significant role in rural development. In this way "development" becomes a kind of commodity that is monopolized by the expert who acquires authority over $h$ is "subjects". Further, it is argued that the processes of negotiation that occur between the representatives of development agencies and farmers must be understood within a broader social context, since the rules, limits and procedures for these negotiations and the levels of resources involved are only very rarely defined in the interface encounter itself. They are usually shaped and sanctioned by other social and institutional contexts or levels. Hence the interactions between potato cultivators and experts in the Andes are constructed on the bas is of relations of distrust and dependency that form part of the larger social framework wherein "modern" technology and science prevail. This prevents effective exchange of knowledge and experience, resulting in the creation of a sphere of ignorance that generates the types of interface we find between "the experts" and "the invisible men" (i.e. devalued local producers).

Chapter VI takes up a related theme: the segmented character of knowledge networks in relation to cassava production in the Dominican Republic. The chapter shows how sharply divided social interests and cultural values separate off the worlds of farmers, extensionists, and researchers, thus inhibiting the development of well-articulated networks of information and knowledge, and limiting the generation, spread and utilization of technology. It is suggested that here the applied social scientist can play a useful role in developing ways of linking together this segmented social systern and devising methods of stimulating the flow of information between the parties concerned. Indeed, in the Dominican case, this was attempted through organizing meetings that brought the different parties together and by establishing teams consisting of researchers and cultivators involved in on-farm 
trials. "Adaptive agricultural research", it is argued, must extend its work to cover these dimensions, which, to coin a phrase, entails "adaptive networking".

The discussion of knowledge interface is followed by two contributions from scholars from related disciplines working on rural development. The first (Chapter VII) discusses the application of the concept of interface to the analysis of irrigation projects. Such projects represent important instruments of rural development intervention, yet their design, construction and management has, until recently, been the domain of engineers. But due to increasing social, managerial, economic and ecological problems, social scientists have now become interested, though it remains difficult to combine these different approaches and types of analysis. The chapter suggests that the concept of "social interface" can serve as a focal point for the development of a new integrated approach. Such an approach would analyze irrigation development as an interactional process, linking technical and social aspects, and would also provide the means to develop a framework for tackling more effectively the practical issues of managing projects. Three cases, drawn from Ecuador, Sri Lanka and Tunisia, are presented to illustrate the practical value of this interface approach. The discussion concludes that a more dynamic perception of management processes is needed, that engineers should make explicit the social dimensions of their designs, and that research should aim at revealing the social meanings of implementation processes. This requires the integration of structural and actor-oriented approaches, as well as the use of sociological, management and engineering concepts.

The second chapter (VIII) consists of a critical discussion of the original position paper written by Noman Long (now appearing in slightly revised form as the first part of this chapter). The argument is developed by drawing upon socio-legal studies that have analyzed intervention issues, discontinuities in normative systems ("the conflict of laws"), and the interrelations between "customary" and "State" law. A number of critical points are made: one should not confine oneself simply to the interactional setting when studying implementation or interface situations; one must be careful not to posit a aualistic notion of "external" versus "internal" forces; agents should not be identified with one system as "representatives" - rather they are "janus-faced" - ; and one must resolve the issue of whether inter- 
face is an interactional and/or a structural concept. The chapter concludes by suggesting how one might develop a framework for analyzing the reproduction of structural discontinuities, using recent research on Ambon and Bali in Indonesia.

The book ends with a concluding chapter (IX) which outlines the essentials for developing an actor-oriented approach to interface and which describes the various analytical dimensions involved.

\section{Notes}

1. The first part of this introduction consists of a slightly revised version of a discussion paper prepared for the "Interface Workshop" held in Wageningen in December, 1986. The Conclusion to this book provides my more recent views on the theoretical and methodological implications of interface analysis. 


\section{THE SOCIAL CONSTRUCTION OF AGRARIAN DEVETOPMENT: A CASE STUDY OF PRODUCER-BUREAUCRAT REIATIONS IN AN IRRIGATION UNIT IN WESTERN MEXICO}

Alberto Arce

\section{Introduction}

In a previous study of State-peasant relations in Mexico, I focussed upon an analysis of the interactions between bureaucrats and rural producers in the hope of providing insight into social change from the perspective of people and their ability to modify the contents of development intervention (Arce, 1986). While I perceived the general effects of a technocratic strategy aimed at readjusting relations between the Mexican State and society (Arce, 1987), I concluded that negotiations among the actors involved in the process was a central point to which theoretical analysis should address itself. I also argued for "the reflexive consideration of empirically observed social realities, rather than the construction, generation or pseudo-validation of abstract theoretical models" (Arce, 1986:414).

The present chapter 1 develops this line of analysis - already clearly signalled in Norman Long's writings on "actor-oriented" and "interface" perspectives on rural development (see especially Long, 1977, 1984 and 1988), and in our joint contribution 2 to the study of knowledge interfaces and systems of ignorance (Arce and Long, 1987). The case-study data are drawn from recent investigations into the behaviour and interactions of government officials and peasants in the context of irrigated agriculture in western Mexico, which formed part of a larger study of irrigation organization, farmer strategies and planned intervention (Long, 1986). One of the research aims was to apply an interface methodology to the analysis of state intervention 
(see Long, 1988:121-129). Under the influence of Giddens' writings (Giddens, 1984) I came to realize the importance of $h$ is theory of structuration and the significance of human agency. Thus, although an actor-oriented perspective was the basis for the research, it could not stop at the level of actors' interactions. Actors' practices for organizing society through, for example, social networks are important, but they are an outcome, a part of a complex process, which, I think, starts at the level of actors' practical consciousness. Hence the cognitive process of actors became one of my main concerns during fieldwork.

\section{My impressions of the fieldwork area}

The first impression I had of the fieldwork area was a sense of diversity and complexity; a productive and social space, where a diversity of social actors were involved in different types of property relations (i.e. ejido 3, private property and agro-industrial enterprise) and in different labour processes (i.e. State-organized, Mexican private and ejido enterprise, and USA/transnational enterprise). These patterns represented the specific local dynamics of capital/labour relations, non-commoditized relations, and state intervention.

One salient local characteristic was the diversity of producer groups with different modalities for irrigating their lands. State intervention in this context played the role of provider of the basic conditions for irrigation through direct and indirect action. Irrigation started in 1955-1960 with the construction of a centralized irrigated system and continued during 1974-1978 with the rehabilitation of the infrastructure. In addition, other locally-managed irrigation modalities, such as 19 pumping stations and 88 artesian wells, are found in the Municipalities of Autlán, El Grullo, El Limón, Tonaya and Tuxcacuesco. The majority of these pumping stations were built around 1977-1978, and were influenced by a regional power group (the zuño Family) inside the state. This group sought to introduce the Chinese development model as an alternative to the traditional Mexican one. The artesian wells, on the other hand, were part of a project of local private entrepreneurs backed by foreign capital, who started illegal drilling of wells at the end of the 1970's. With this action, they 
opened up new economic options for agricultural production. Confronted with this fait accompli, local state representatives opted not to implement existing regulations to stop the drilling.

In all these situations, the state's presence and involvement have been important, although the degree of control exercised by government has varied according to the specific period and conditions, and according to the state agency in charge of implementation. In this way interventions have affected differently local social groups and patterns of differentiation and integration. The processual character of these interventions has also provided opportunities for shifts in the creation of agricultural commodity value. Each specific intervention has embodied a singular process of cognition for the producers which, depending on the degree to which they value and identify with it, will generate possibilities and limitations for further change. This process has affected the social construction of the producers' world and allowed the state to insert itself locally through legitimizing the consolidation of certain social groups.

State intervention in Mexico does not run counter to the processual character of the Mexican state. On the contrary, it constitutes, what one might call, a practice of governability that aims to control the contradictions arising from discontinuities in the social order. This style of intervention, on the one hand, separates interests and on the other, recognizes the legitimate right of segmentary groups to accumulate. Accumulation is an economic dynamic that relates to capitalist production and the expansion of commodity relations in the society as a whole. This dynamic provides state representatives with a framework of reference for their institutional, economic and social areas of action, influence and control.

Producers internalize these new components within their everyday knowledge and this motivates them to weave social ties and consolidate networks in which producers (ejidatarios and small private producers), government officials and rentistas (those who rent land) manage their contacts, in spite of divergent interests, in an attempt to achieve their respective social images of "progress". For instance, I observed that the planned extension of the centralized irrigation system that will come into operation after the Trigomil dam 4 is finished, today constitutes among rainfed producers an imperative for continuing as agricultural producers. They believe that when the water comes, their 
economic problems will be solved overnight; it is just a matter of holding on for a couple of years more before making a transition to a better situation. This notion of a bright future, when the producer has access to water, is now part of everyday producer technical knowledge and, at present, is widely generalized in the research area.

Producers who have access to irrigated land and who benefit from irrigation infrastructure contrast sharply with rainfed producers whose only alternative is to cultivate maize. Rainfed producers are characterized by low productivity, little incentive to invest in agriculture, constant pressure to reduce maize production costs and by their capacity to work only during a short season of production. They are constantly trying to gain access to some irrigation modality. In other words, the need to have access to water has been transformed by rainfed producers into an important ideological device. This device provides the producer with a conceptual option which makes it possible for $h$ im to dream about extending $h$ is control over a previously-restricted reality (one limited by the rainy season). This control, based on access to water, projects an image of being able to solve all the economic and productive problems faced by the producer, and constitutes an important springboard for mobilizing local producers.

The emergence of an ideology regarding access to water as a central element in the economic life of agricultural producers basically means that the experience of producers who have water is seen by rainfed producers as the "solution" for closing the inequality gap between them. In this vein, certain scientific techniques, which promote change through irrigation, have penetrated the social construction of agrarian development at local level.

The Autlán-El Grullo area is located in the hydraulic basin of the Armeria river. This area is an important agricultural location within the State of Jalisco which, from the 1950's onwards, has been the scene of a process of comnoditization which has followed cyclical waves fluctuating between different economic activities geared to internal and external markets, covering both mining and agriculture. 
After some weeks in the fieldwork area, I decided to attend the monthly meetings held between high ranking government officials of each of the agricultural agencies active in the area, and the State Governor's and the agricultural producers' representatives (Reuniones de Comité Directivo). It was at one of these meetings, in Tuxcacuesco, during producers' question time, that a voice different to the others caught my attention: "sir, we have not received fertilizers or credit during this agricultural cycle". The answer from the bank representative was sharp and clear:

"We did not give credit to El Guamuchil because the producers owe us money. Some years ago we gave credit (refaccionario) to the producers to help them buy and install an irrigation pump. To this day, we have not recovered that credit... Last year we lent money to the producers to cultivate melon. The agreement was that the profit from the melons would be used to repay the credit. We gave some money in advance to help producers with the agricultural cycle. Producers repaid part of their debt but, unfortunately, that was not good enough, and we have had to stop any further economic help to El Guamuchil" 5 .

When the meeting ended I met the ejido President from El Guamuchil. He struck me as a person who was really proud of his office and totally committed to making those important people hear his case. The voice he used in the meeting was in accordance with his black shirt, so naively decorated with small red motifs on both sides of his chest. I liked the way he was dressed, how he presented his case and how he apparently did not listen to the logical reasons put forward by the bank to justify its institutional action.

On the way back to Autlán-El Grullo with the group of bureaucrats I started to ask about the ejido of El Guamuchil. I had in mind the idea of developing a story, based on the image of water for irrigation (the producer-perceived solution to all economic and production problems), that would be an exercise for reflecting on the "social reality of progress" as I observed it at local level. I wanted insight into the interaction of different sorts of knowledge operating in the area, so as to reach an understanding of this elusive notion of "progress". Several colleagues questioned my interest in knowledge. Others, who perceived my enchantment for El Guamuchil, suggested that the ejido was not representative of the reality within the valley and, even more, some members of the research team suggested to me that perhaps my 
interest in the Tuxcacuesco area was no more than my individual anthropological obsession for the exotic.

My enquiries about El Guamuchil established that the ejido was one of the poorest ejidos in the administrative area of the Irrigation District. It was difficult to reach because of the bad conditions of the roads. The officials in charge of the District did not want to talk very much about the ejido and furthermore, in the official file, no documentation, not a single paper, existed concerning the present or past situation of the ejido. On the other hand, a number of officials critical of the District's policy mentioned to me that, through the previous team of administrative officials, the ejido managed to obtain important irrigation infrastructure. They pointed out that $\mathrm{El}$ Guamuchil received help from the District because past policies were orientated to helping the poorest producers, a situation that, according to them, contrasts markedly with the present aims of the District. People said that the irrigation infrastructure of El Guamuchil came from a period when District officials and producers had collaborated in the building of it, though it now lay idle. The irrigation unit of $E 1$ Guamuchil was thus far circumscribed by an aura of failure. Different explanations pointed to bad official decisions or to the lazy nature of the producers.

The opposition of worlds (the different actors' meanings) excited me sufficiently to go and study this irrigation unit, three years after its completion. This implied that I would have to work with the actors' memories of the irrigation unit. I was interested specifically in looking at the experiences underlying these actors' social accounts. In other words, my journey was in search of actors' cognitive processes.

I was ready to board the Foucaultian ship of fools for a symbolic voyage in search of imaginary heroes, ethical models or social types. For me these imaginary elements form part of practical knowledge (animation) and, therefore, they have a real existence through the actors' recall of the significant events they have experienced, felt and analyzed during the construction and operation of the irrigation unit. I was less interested in abstracting from this information the general properties of the different actors' social accounts. In this sense, I was not motivated to manufacture the conflict of logic underlying the processes of interaction or interface. I wanted to collect 
and bring together the different voices, images, meanings and social forms that animate the social practice of development projects.

Before going to the community I carried out some open-ended interviews with the local bureaucrats who had participated in the irrigation project. Only when I had a picture in mind of the El Guamuchil people, drawn from the District officials' accounts, did I decide to go and see for myself. The aim was to talk freely with some of the producers and to explore how they perceived their involvement in the construction of agrarian development. I wished to contrast producers' perceptions with the mental constructs of bureaucrats, because I wanted to find a realm of denotation, where $I$, as a researcher, and they, as actors, could both accept an horizon real enough to direct my symbolic voyage into the actors' past and their animations of this irrigation project.

On my first visit to El Guanuchil a child guided me and showed me the irrigation unit. The diesel engine was inside a solid stone construction which was exected a metre or so above the level of the river. This solid construction consisted of an unfinished room, without roof or windows. A complicated system of pipes connected the engine to a big diesel tank embedded higher up in the arch of an old hacienda bridge. The composition of tubes, machinery and metal containers, in contrast to the tranquility of the river, hills and forest, produced in me a strong image. I had this same feeling before. I remembered it was in Paris when a friend took me to see the Pompidou Centre. I smiled inside, because I had finally located my symbolic artifact of agrarian development.

I returned to $E l$ Guamuchil several times for day-visits before staying there continuously for several weeks, in order to experience the everyday life-situation of producers. After that I followed the case of El Guamuchil for some six months and became good friends with the producers, and their problems to a large degree became mine. 
The case of an irrigation unit: social configurations of actors and strategies across the technical and a-technical realities of agrarian development

Social configurations

This case is about the social process that made possible the installation, organization and operation of a small irrigation unit in the ejido of El Guamuchil. By means of the case I want to outline how the social configuration of people participating in the project spearheaded a process of social transformation. The project involved a number of different phases, with the social experiences of the actors acting as bridges that connect different settings and give meaning, value and identity to their encounters. The outcome of each one of these encounters led, within the limits of the contexts of both administrators and producers, to the achievement of specific ains. The actors related to each other through their interpretation of their experiences and social locations (Bailey, 1969:1-17). Thus pragmatic rules of action emerged which were culturally accepted and internalized through the experiences of the actors.

The point to stress here is the importance of previous experiences that shaped the social positions and interpretations of the actors, because it was in these events or processes that actors' identities and strategies were formed. Previous experiences strongly influence actors' ways of asking, 1 istening and signalling idions, a process that is central to the constitution of a social field wherein the social reality of agrarian development is constructed 6 . Consequently, in this section, "by social configuration" is meant an actor's cultural construction of knowledge and experience that shapes the contours of specific aggregate social forms 7 (i.e. encounters, interactions, interfaces) in bureaucrat-producer relations.

The producer's social configuration

A producer's social configuration refers to the actor's descriptive knowledge concerning the constitution of social phenomena. This is a mental construct that arises from the tension between the practical 
consciousness of the producer experiencing spatially and temporally the presence of an "ordered reality", and how others share that reality with him. That is to say, it is the knowledge employed by producers in concrete social encounters so as to direct the course of events through their definitions of the situation.

The point here is to appreciate how actor events can be understood through their links with individual biographies. In this way they come to form part of an assembled chain of previous contexts and social relations that reveal the relevant capacities of the actor in defining situations such as interfaces. This is an analytical device designed to set the "scene" or the "setting" of an interface. It uses to a maximum the participants' own social experiences and the cognitive elements of practical knowledge.

This notion of social configuration makes it feasible to examine the way possibilities are combined and achieve their meaning as alternatives, in the producer's immediate context. In the case that follows, fanily biography, community history, political relations with the state and even population pressures appear no more than separated elements until they are combined consciously or unconsciously in the actions, perceptions, presumptions, premises and statements of defined social agents. Such individual combinations are organized within the local social stock of knowledge that is familiar enough to the rest of the producers so as to "collectivize" an individual project, endorsing it as a legitimate model of social change. This process finally replaces the existing pattern of political control and establishes a new set of practices between producers and the state.

El Guamuchil is an ejido situated near the town of Tuxcacuesco, approximately two hours by jeep from El Grullo. The settlement contains about 40 families and is situated on the banks of the Armeria River. It is one of the most difficult ejidos to reach for the administrative personnel of the Rural Development Centre in El Limón. Also, it is perceived by fieldworkers as a "punishment zone" (area de castigo). The lack of roads makes access to the ejido arduous in good weather, and practically impossible during the rainy season.

This relative isolation has affected the development of economic possibilities in El Guamuchil, forcing the producers over the last 10 years to migrate to the USA or to work as labourers in irrigated 
agriculture (in El Grullo, Autlán and later Tuxcacuesco) and as producers of rainfed maize.

Javier Rivera was 37 years old at the time of the project and the son of Don Salvador, a 63 year old producer who is very respected in the ejido. The Rivera family came to live in this area 55 years ago. As Don Salvador remembers, his father Don Pedro (now deceased) and his elder brother Margarito (68), who lives today in El Grul10, were the first of the Rivera family to settle down in what was then the community of Los Mezquitez. When the first Riveras realised that conditions in this new location were good for tilling the land and working as labourers, they sent for Don Salvador. The Rivera family was originally from Toliman, a settlement in the nearby state of Colima. One of Rivera's brothers stayed behind there to work the property of Don Pedro. After Don Salvador's arrival, his other brother Pedro (60) came and settled in Los Mezquitez.

When Don Salvador arrived he was married and already had a son (Javier) and a daughter. Later his family increased with the birth of four more children. From this original family, two sons and two daughters today still live in the community. Don Salvador was active in community affairs from the beginning and he is proud to remember the agrarian fight that eventually gave them the status of ejidatarios, and that resulted in the creation of the new settlement (pueblo) of El Guamuchil. Don Salvador was elected head of the ejido from 1958 to 1961 .

This long family tradition in the area, their participation in the agrarian struggle, the network of Rivera family relationships in the ejido and the fact that Don Salvador was head of the ejido in the old days, have given the Riveras a strong local presence, political respect and power to influence collective decisions.

Javier, being the elder son of Don Salvador, inherited the prestige of the Rivera family. He married in 1963, at the age of 26, Virginia Lapuente, who belongs to one of the important families in the community. Her uncle, victoriano, was the first producer to hold ejido office from 1955 to 1958. Furthermore, in relation to the living standards of the ejido, virginia comes from an economically well-off family. Her mother, Elpidia, runs one of the two shops within the community. One of Javier's longstanding passions has been politics and he has had to overcome difficult local political circumstances in order 
to become accepted as an influential representative of ejido opinion. In my view, this situation is a direct result of the historical process by which the ejido was founded. Producers are consciously aware that access to land has not significantly modified their social position vis-á-vis the traditional landlord families and that therefore they must coexist with them economically and politically.

El Guarnuchil was created an ejido during the years 1947 to 1955. The peasants had to endure a long fight with the local landlord and $h$ is supporters, who physically threatened them and even murdered one of their leaders (1955/1956). They also had to suffer the constant dismissal of their petitions by government officials in charge of implementing the agrarian reform law. According to the producers, the officials were easily bribed by the local landlord. But, in the end, their petitions were accepted by the government and they were granted the right to organize the ejido, although government, in a totally unprecedented interpretation of the law, dictated that the implementation of the agrarian reform had to take place some 14 kilometres from Los Mezquitez. This decision was interpreted by the producers as further interference by the landlord and as a clear sign from government that winning the right to land did not mean that the political power and influence of the local landlord over peasants had ended.

This decision of the government still haunts the elders and some of them uphold the view that until they recover their old land, the agrarian reform cannot yet be considered to be concluded. Peasant producers maintain that, although the state was not totally hostile to their interests, it was not a body that they could trust. And there are some elders who still question whether the agrarian struggle, and "the sort of independence" that came with it, was really worth while. The majority of the producers today consider the price they paid for their independence too high.

These experiences have shaped a collective stock of knowledge in relation to the expression of power at local level, as well as giving rise to an ideology in which the old place "Los Mesquitez" is perceived as having an extraordinary fertile soil, an abundance of fish and chacales (river shrimps) in still virgin and deep parts of the river, and a multitude of buried treasure waiting to be recovered by those "pure" and brave enough to resist the apparition and pursuit of the wandering ghosts (espantos). 
The character of the socio-political practices revealed to producers during implementation of the agrarian reform required that they adopt a balanced political strategy in order to survive the pressure of the landlord and the reluctant support of the state. It was this constraint that enabled 13 producers from the old agrarian guard to consolidate and legitimize themselves as the political representatives of the ejido. They rotated responsibility for the ejido, and during the first years actively encouraged their families from Toliman to join the ejido. This group managed to distribute among themselves the best land of the ejido and they became the only producers with access to small riverside orchards. Internal conflicts did not reach a point critical enough to change this situation until the $1970^{\prime} \mathrm{s}$.

By the 1970's, the sons of the group of elders and their brothers had started to marry and to form their own households. This new generation of young heads of households had a common characteristic. None of them had access to land. While some people migrated to the United States as a partial solution to their economic problems, Javier Rivera, who was then 33 years old, became involved in organizing this landless group. The group demanded an increase of ejido land, and, although some older producers morally supported this position, only one of them committed himself to helping them achieve this end. Eventually in 1973 the group managed to gain access to additional land. During this period of mobilization, Javier won himself a good political reputation. His critical views about the form and content of what had been the traditional political style of leadership, and how this affected the community's lack of development, found a positive reception among producers.

In 1981, Javier presented his candidature for ejido office. In Javier's favour were the long tradition of his family's involvement in community issues, his marriage into one of the influential ejido families, and $h$ is active participation in the movenent for an increase of land. His family tradition and marriage generated a division inside the group of elders when confronted with Javier's candidature. Those related by kinship or political alliance to Javier endorsed his nomination, and with this came a real challenge to the existing power base of the ejido. For the first time, an alternative existed which could cut across generational boundaries and unify ejidatarios around the need for change. It was this last element that finally rallied behind Javier 
the support of people who had just acquired access to land (i.e. the new ejidatarios). In 1981, Javier was elected head of the ejido, and for the first time in the history of $\mathrm{El}$ Guamuchil someone who was not a member of the old guard was invested with the political representation of the ejido.

In this presentation of Javier's social configuration, I am not suggesting that Javier was able to manipulate each one of the social circumstances (family, marriage and political participation), in which he was involved for several years simply for the purpose of one day being elected head of the ejido. What I am trying to suggest is that the conditions surrounding Javier's election motivated a process of collective reflection, and that it was during this process that people gained awareness, within their own local social stock of knowledge, of the need for change. It was, then, during this process that Javier's biography acquired a concrete cultural meaning, as well as a defined social identity. In other words, it was in this process of collective cognition, and the subsequent step when this knowledge became objective, that Javier was legitimized as a real political alternative. This event reveals the importance of knowledge and belief, as practical resources, based on everyday processes, that link producers' valuations and identity with the assessment of the possibilities and limitations accompanying social change. After Javier was elected, the ejido was for the first time clearly divided into, at least, two well-defined carms.

When Javier assumed ejido office, he became concerned with the need for improving the econornic opportunities of those producers who, in 1973, had gained access to land. To achieve this, he began a personal campaign to mobilize local agricultural government agencies. This method was highly disapproved of by some of the elders and disagreement was finally stamped with strong criticism against Javier, who was characterized as an opportunist using the name of the ejido to improve $\mathrm{h}$ is own economic position. Nevertheless Javier, a producer who cannot write or read and who can hardly sign his name, succeeded in using his position to establish a new set of practices between producers from El Guarnuchil and the government agencies. 
The institutional social configuration

The institutional social configuration is fundamentally a relation between a model of the government, that is, on the one hand, a representation of an interrelated set of concepts or notions that explains and administers the supply and delivery of agricultural services to the producers and, on the other hand, the individual action of those persons responsible for the implementation of such a model 8 .

In the case of Mexico, the District is the administrative unit where national and regional programmes and the different federal and regional agencies coordinate their actions in order to implement government agricultural policy at municipal and ejido levels. The agency in charge of providing an overall rational framework for these activities is the Ministry of Agriculture and water Resources (SARH). This means that they are responsible for making the connections between the technical and political aspects of development.

District decision making has to adapt programmes and institutional intervention to local conditions but political considerations are not an extra burden for district officials who have long been involved in the regional political game. This last aspect in practice has the effect of politically enhancing the importance of the officials working for SARH at District level, since they are perceived by different types of local producers as important elements in the process of resource allocation. The field in which the implementor moves and manages is one in which he has to mediate between general administrative rules and what can be done in the field (see Grindle, 1980; and Arce, 1986, Chapter I).

The individual actions of officials in charge of implementing policies assume a central importance in those social contexts that lack the strong presence of political leaders able to mobilize the interests of the disadvantaged producers. This is also the case in situations where a sense of advocacy from professional groups, promoting policies within the government agencies on behalf of the producers, is practically non-existent. In these circumstances the administrative action of the implementor acquires a specific importance.

In this vein, Grindle's study of the Mexican implementor (1980:197223) appears to ignore that the decision-making process of the implementor (which according to Grindle is largely determined by the po- 
litical and administrative context in which he has to make decisions and maintain peace) implies a particular cultural and cognitive process, which varies according to the life experiences of the official. This missing dimension in Grindle's analysis leads her to stress a functional explanation of public officials' behaviour within the administrative structure of the Mexican government. My uneasiness with this explanation led me to examine one implementor's biography in order to analyse decisions as culturally-constructed entities that go beyond administrative state-society explanations. My approach perceives these implementors as human agents whose actions are embodied within ideologically and culturally specific meanings.

The implementor's experience

Engineer Pedro Ariziaga arrived in the Irrigation District of El Grullo in 1979. During that period irrigation was divided between two main administrative bodies, one which administered the centralized irrigation system and the other which supervised the operation of the locally-managed irrigation units.

He came to the District after being in charge of the rainfed District of Ameca. In this post he encountered strong political reactions to his decisions by fellow ex-students from Guadalajara University. This, it seems, was mainly a consequence of his political position when a university student. Ariziaga came from a humble rural family background, without resources. He saw in education his only chance to improve his economic and social mobility. He, therefore, concentrated upon achieving professional status. Contrary to the university norm in Guadalajara, he believed in hard work and dedication, and rejected politics (i.e. membership of the official government party, PRI) as the quick route to a successful university degree. He opposed official party corruption and showed his political preference for the radical left of student opinion. These attitudes brought him into conflict with students who supported the PRI, some of whom later became $\mathrm{h}$ is institutional subordinates when he was designated head of the District of Arneca.

During his university period he established a friendly and close relationship with Carlos Rojo, a fellow student. The family of Rojo 
accepted Ariziaga as one of their own family and helped him financial1y. This relationship influenced Pedro so deeply that he considers carlos as his brother. When political problems started to manifest themselves, Carlos, who at that time was Head of the Irrigation District in El Grullo, invited Ariziaga to work with him.

During his period in Ameca, Ariziaga established contacts with people working inside SARH on Producers' Organization. This group were members of different political groupings but had one point in common: they were all left-wing political supporters and adopted Marxism as their ideology. Through SARH these people were comnitted to support the organization and politico-economic development of poor rural producers. Their small number inside the Ministry of Agriculture led them to decide that if they wanted to intervene practically in the agrarian context, they would have to concentrate their few human resources on target Districts in Jalisco.

When the invitation from Engineer Carlos Rojo came, Ariziaga was informed that El Grullo was one of the Districts in Jalisco selected by the people from the Producers' Organization for a long-term initiative. This last element finally persuaded hirn to accept the new post in $\mathrm{El}$ Grullo. Thus Ariziaga arrived as District Deputy in charge of URDERAL (Irrigation Units for Rural Development). Within the institution, he was perceived as a highly efficient and technically excellent professional, an image that protected him from political reprisal from other institutional groups. Ariziaga remembers:

"When I arrived to work with Carlos Rojo, the situation was a difficult one. In spite of our great friendship we have differences in ideological terms and on how to organize institutional work practices".

(interview/Ocotlán/30 and 31/12/1987).

Nevertheless, Ariziaga overcame these difficulties and finally found, in the people from the producers' Organization, a strong ideological compatibility with his ideas, and support for his institutional position. This relation evolved to the point where Ariziaga and the people from the Producers' organization decided to form a special policy unit, made up of a network of SARH employees, but outside formal institutional channels, in order to strengthen their capacity to influence District decision-making processes. In this informal policy unit the members were free to use their Marxist categories to order, describe and analyze existing institutional policies, as well as to explore alternative views on existing problems in need of solutions. 
Contrary to formal institutional practice (Arce, 1986:204-243), the policy unit was encouraged to understand the whole District agrarian reality and the effects that $S A R H$ intervention could produce in specific localities. The group was committed to a policy which would lead to the rest of the institutional personnel recognizing them as the best technical group in the District. They organized alternative training courses among themselves and forced the District to finance their projects, because they were technically viable and socially relevant. In other words, their practice was what Selwyn (1984:13-32) calls a search for the "unobjectionable".

An important feature of this policy unit was that their members covered the different institutional levels in the District, ranging from central staff to fieldworkers. The group was made up of a wide range of different professionals (agronomists, psychologists, sociologists, rural teachers and field personnel with experience in agricultural programmes). This gave the members of the unit a remarkable capacity for gathering information and implementing their alternative views in some areas of the District. In order to exercise their influence and to control negative reactions, the members of the unit identified other officials within the formal institutional order according to the degree to which their actions might directly affect them. In practical terms this provided the members of the unit with an institutional knowledge for defining and organizing political alliances so as to influence the everyday administrative running of the District.

Later the activities of the policy unit were detected by the group of officials critical of Engineer Rojo, the head of the District. These officials perceived the activities of the policy unit as requiring institutional control, otherwise their own positions might be weakened. Carlos Rojo, too, was concerned that the unit should not undermine his position as head of the District and called upon his own inner circle of collaborators to give hin support. These latter had a proven record of loyalty to Rojo (i.e. they were his compadres). But, with the exception of Ariziaga, he could not rely on the members of the unit. He therefore opted to acknowledge the presence of the unit, though not endorse its activities. According to Ariziaga, Rojo called him, on at least one opportunity, to ask for reassurances that the aim of the unit was not to create problems for him. 
The group of staff officials critical of Rojo was composed mainly of professionals with strong local social and economic interests. Some of them had made their fortunes during the period of $\mathrm{high}$ melon production and later had acted vigorously in favour of state intervention to counteract the effects of melon decline. They now favoured agricultural production based on sugar cane that would promote local conmodity relations. They perceived the function of SARH as an essential element in achieving this and protecting their interests. They argued that control of the centralized irrigation system (El Operado) could in the end determine the extension of the area of sugar cane cultivation. The members of the informal policy unit also concluded that sugar was crucial; they, too, focussed their attention on the activities of the sugar cane producers, as well as on the institutional in-fighting for the administration of the centralized irrigation system.

During 1979 to 1980 the policy unit influenced the policies of URDERAL and the organization of producers. This was achieved largely through the personal relationship between Ariziaga and Rojo; and some of the unit's recommendation were adopted as general policies of the District. During this period, Rojo managed to keep control of the institutional situation by assigning the administration of the centralized irrigation system to one of his compadres, and during 1979 the institutional position of Ariziaga improved. A new government scheme incorporated the work of URDERAL within the administrative framework of the Irrigation District and Ariziaga was put in charge of implementing this at local level. Being perceived as a "true irrigation man", Ariziaga did not generate any opposition in the District in terms of the wider national conflict within SARH between rainfed and irrigation tendencies (Arce, 1987:3-24). As an agronomist from Guadalajara University, Ariziaga learned in URDERAL the importance of irrigation. He believed that this type of infrastructure could produce significant changes in favour of rural producers when used together with a programme that increased their level of organization.

This was the period when Ariziaga became known to the central District staff. He was seen as being committed to a progressive ideological position and gained a reputation for being a hard worker (muy chambeador) with a capacity to remain independent of powerful local pressure groups. 
In 1980, a group of important local government and private institutional representatives, plus the core of private owners of the sugar cane producers Association, came together to ask Rojo to increase the irrigation area for sugar cane cultivation by 300 hectares. This petition was supported by a group of officials inside the District. These professionals wanted explicit institutional recognition for the local cane producer group. Rojo perceived the strong political motivation behind this sugar lobby and decided to oppose the petition on technical grounds, namely that if more water was allowed for sugar cane, this would have the implication that other agricultural producers would be denied the right to irrigate and therefore would be pushed out of agriculture. In other words, Rojo was against the strengthening of commoditization through state intervention, because this would probably result in the reproduction of the existing pattern of political domination. This finally resulted in the state sugar Refinery (Ingenio Melchor (campo), with the support of the sugar lobby, initiating a bitter political campaign against Rojo and his group of collaborators. The lobby managed successfully to mobilize the small producers of some ejidos (i.e. El Chante, Lagunillas), who demanded their right to participate in more profitable agriculture (i.e. sugar cane). During this process they identified Rojo as the institutional obstacle to economic progress. With the mobilization of the ejidatarios Rojo was losing his political capacity to control the situation in the District. It was only then that he accepted a radical proposal from the informal policy unit. The members suggested that the only way to cope with the political situation in the District was to give producers the power to decide whether or not they wanted to increase the area of sugar cane cultivation. Rojo reluctantly accepted the suggestion and asked Ariziaga to prepare and implement a producer participation scheme.

Accelerating the process, the members of the policy unit quickly organized an Irrigation Users' Commission composed of elected members from each of the ejidos. The representatives from the District explained to this comission (mainly ejidatarios) that if more sugar cane production was authorized by them, severe water distribution problems would result and the District would then have to dictate crop priorities. Moreover, it was made clear that the Irrigation Users' Commission would be the body responsible for explaining the reasons for water shortages to the producers and the reasons why some producers, in spite 
of having access to the irrigation system, would not be able to cultivate. SARH's position was to act in a technical capacity, while leaving the political decisions to the producers themselves. However producers were terrified by the prospect of having to explain in their ejidos why some producers could irrigate and others could not. So in the end, as members of the political unit expected, the producers rejected the petition for an increase in area under sugar cane cultivation.

The producers' support for the District (Rojo's position) demobilized the actions of the sugar cane lobby and an agreement was reached for settling their contradictory interests. One of the outcomes of this conflict was that District personnel supporting the sugar lobby were given control of the centralized irrigation system. The other was that the analysis and solutions of the policy unit were finally accepted by Rojo. Ariziaga had clearly established $h$ is standing in relation to the head of the District and to the wider constituency of producers.

According to Ariziaga, it was the importance of this experience that strengthened the understanding between Rojo and himself bringing out the full potentiality of their relationship:

"It was the sugar cane conflict that made us realize the need to form a team. Rojo took control of the whole set of external relations of the District, principally, the political negotiations with the other institutional groups in SARH at national and regional levels. I, on the other hand, was to be responsible for the internal running of the District, so I had to generate strategies, design and implement projects; in a word, to plan intervention. I had to play the little intellectual. So it was my responsibility to write and present documents, even if it was Rojo who, in the end, would take the credit for them. It was this experience that certainly demonstrated to me the importance of using a technical language to highlight the concept of efficiency in SARH. I use this language to obtain my political aims, that is to provide autonony for the producers, so they can take control of the agricultural infrastructure, but this policy has to be presented within the general institutional search for efficiency, otherwise our positions may be blocked by the belief that producer participation is just a political strategy. Consequently we had to sell our producers' participation projects to SARH in line with the efficiency criterion, because this is the key to institutional approval." (interview/Ocotlán/30/31/XII/1987).

From 1981 onwards, Ariziaga consolidated his institutional position and played an important role in the District as a local decision maker. But the informal policy unit suffered a series of problems owing to members leaving the District area to take other posts in SARH, and also because 
some of them became too involved in the acquisition of individual benefits. There was somehow a general feeling of disillusionment among the members because their ideological Marxist principles were hardly ever used to link the administrative reality with the kinds of transformations that, according to them, agricultural producers needed. This issue led to Ariziaga taking more interest in the actual practice of transforming rural conditions rather than in the construction of an ideological model. The pressures and tensions inside the policy unit indicated that if new institutional members were not incorporated the policy unit would cease to exist. So Ariziaga tackled the weakness of the unit by devising a job-related training scheme so as to make some administrative officials more politically sensitive. The notion behind the scheme was that practical work, organized and implemented within the agricultural producer's context, could modify some of the traditional social behaviour of the professionals working in SARH.

It was at this stage of Ariziaga's administrative career, in 1983, that he met Javier Rivera from the ejido of E1 Guamuchil.

\section{From social configurations to the establishment of an official-rural producer relationship in the district}

In this section of the paper I want to explore crucial aspects of the relationship between the local government official (Engineer Pedro Ariziaga) and a producer applicant, Javier Rivera. This relationship evolved from a series of informal encounters into a more formal relation between the District and the ejido of El Guamuchil concerning the implementation of an irrigation project. The case focuses on the different actors' motives that made possible the process of transition from an informal project/idea for innovation to a programme/agenda of an agency (i.e. a process of institutionalization). The notion presented in this section is that the final allocation of resources was a social process strongly determined by the previous social configurations of the actors rather than by the administrative context per se. It was the communication between the actors that constituted the concrete circumstance that created a favourable administrative situation for the applicant. In this case, both the producer and the Dis- 
trict official reveal thernselves to be active agents in the search for elements that might facilitate social change.

The first encounters

At the end of 1983, Ariziaga received Javier Rivera, head of the ejido of El Guamuchil. Ariziaga still recalls the circumstances of this first encounter:

"Javier came into my office in the company of a friend of mine, the rural teacher Eduardo Garcia. Garcia used to work for us (SARH) as a technical drawer in the District offices during the mornings, and in the afternoons, he would teach at El Guamuchil primary school. I warmly received Javier because I believed Eduardo had invited him for some reason".

According to Javier, after some months of trying to figure out a way to improve the economic situation of the ejido, some of the producers, who had just acquired access to land (the new ejidatarios of El Guamuchil), decided informally to enquire about the possibility of bringing irrigation to their land. Their land was a compact area not so far away from the river Armeria, and the soil appeared fertile enough to the producers. Some of them suggested the possibility of having agricultural work the whole year round, as well as shifting towards the cultivation of crops more profitable than maize.

The idea that irrigation could be the solution to producers' problems evolved, according to Javier, from the experience acquired by some of them who had worked as labourers in the cultivation of melons, in the nearby Municipality of El Grullo during the 1970's. They had also seen government complete the construction of several irrigation units in Tuxcacuesco during 1977, something that, according to producers, could be emulated in their own ejido. Finally, the migration experience of some producers, who had been in contact with the highly technical and commercial agriculture of the USA, brought home some new ideas supporting the idea of change.

The different experiences of the producers provided the basis for modelling a producers' alternative. An irrigation project was seen as the solution to the locally-perceived economic constraints, although producers were uncertain and did not know how to establish a set of contacts that could provide them with the information necessary to put this into practice. According to Javier, it was his own decision to go 
to the District to enquire about the possibility of obtaining a water concession for the ejido. "I went to the District in El Grullo and there I met by chance Eduardo the teacher. I explained to him the motives of my visit and he immediately took me to see Ariziaga who was, according to the teacher, a close friend of his."

When I interviewed Ariziaga he explained that the encounter between Eduardo and Javier was an important one, because at that time the District staff were involved in a conflictive situation and if Javier had been accompanied by some other official the outcone would probably have been quite different. In strict terms, the District was not the official agency for enquiries about water concessions. And this, according to Ariziaga, could have provided the staff with the perfect, according to the book, escape route for avoiding any involvement with the producer, since staff always perceive producers as people likely to request unprogrammed intervention. Ariziaga said:

"Javier came with Eduardo and as I was a friend of Eduardo, I listened to Javier's enquiry about obtaining a water concession to irrigate their land from the Armeria river. Javier appeared to me as a trustworthy producer in need of information. I had to explain to him that I was in no position to give such an authorization. However, I told $h$ im he could take the petition to the head of the irrigation programme".

Ariziaga, as well as Javier, recall that the three of them, there in the office, wrote a petition to the Head of the Irrigation Programme in Guadalajara asking for a water concession. This was the first time that Ariziaga had been involved in a petition of this sort, so he failed to follow the proper procedures, suggesting that they direct the petition to the Irrigation section, because he thought that that was the appropriate authority to deal with the producers' request. After two months, Guadalajara replied to Ariziaga's letter saying that these sorts of petitions should be sent to the Governor of the state for authorization. Ariziaga and Javier then sent the petition to the Governor's office.

Ariziaga remembers that Javier, during this period, was in his office every seven days asking for news. This interest in the water concession permit made a positive impression on Ariziaga, who saw in Javier the determination and eagerness to gain, in spite of the linitations, the minimal conditions for improving the economic situation of the producers in his ejido. It was during these continued visits for information that Ariziaga and Javier got to know each other well. 
While this process was going on, Javier asked the state Bank (BANRURAL) about the possibility of obtaining credit to buy an irrigation pump. The bank answered that they could not proceed with the petition for credit until Javier could show then the water concession. Eventually, the Governor's Office asked the District for a technical report to assess the needs of the ejido. The head of the District passed the responsibility for the technical report to Ariziaga who, as expected, produced a report in favour of the water concession. Then, after some weeks, the Governor's Office provided a temporary authorization for El Guamuchil to use the water of the Ameria river for irrigation.

Having obtained the water authorization, Javier went back to the bank. There he contacted an ex-field agent, Luis Mendoza, who used to work in El Guamuchil and who was $h$ is compadre. With the help of Luis the petition was submitted. Javier waited a few months but received no answer to his request. Finally, worried, he went back to SARH to mobilize pressure on the bank, in order to secure a quick institutional decision. Unfortunately, however, Javier failed in this attempt. According to $\mathrm{him}$, these were real moments of uncertainty:

"I didn't know how to get through with my petition. I was in despair because I couldn't exercise pressure on the bank and this institution was not giving justice to our petition".

So once again Javier sought help from his compadre. Luis gathered information at the local bank branch and, since he knew the case and the formal procedures of the institution, suggested that the way to force a positive decision was to write a letter directly to the President of the Republic explaining the case. According to Javier, Luis then wrote a very stylish letter explaining that El Guamuchil was a real and true representative of a marginal and poor Mexican ejido. That in this isolated community producers were in urgent need of work, that they were loyal Mexicans in agreement with the national policy to increase agricultural production, but that to achieve development they needed help to buy a diesel water pump. Luis asked Javier to keep his action secret, otherwise he could be sanctioned for conspiring against the bank. This letter was transmitted by radio to the presidential Palace in Mexico City.

Two or three months went by without a reply. But, totally unexpectedly, one day a truck arrived in the community and delivered, in front of Javier's house, a water pump. It came directly from Monterrey City 
with the compliments of the Presidential office. El Guamuchil had finally obtained its water pump.

The bank did not know of this new development and when they found out, they could not believe it. Javier remembered that they were very interested to know how he had done it, but he said "I managed to keep it secret". The arrival of the water pump modified the ejido situation. The bank decided to accept the ejido application for credit, but their involvement came only after the scenario had already been set by the producers. The permission to use water from Armerîa river for agriculture had been approved; the water pump was already in the ejido, therefore the bank had to provide the credit. After this the bank started to put pressure on the producers to complete the project.

At this point Javier realised that the actual installation and operation of the water pump unit would cost them extra money that the producers did not have. The bank adamantly refused an increase in the approved credit, arguing that they did not have the economic capacity to respond. Thus Javier was confronted with a "catch 22" situation. Producers were unable to show economic capacity, so no more credit could be provided; without credit, producers could not install the pump and, if the purmp was not installed, the bank had the right to take it away from them. In this critical situation Javier went back to SARH and explained to Ariziaga the actual situation. Ariziaga was sympathetic to Javier's problems and agreed to help him.

The official-rural producer relationship

According to Ariziaga, he saw in the relation with El Guamuchil an opportunity to involve some young administrative officials in a practical situation, from which they could learn and come to know the reality of producers. Ariziaga arranged with Javier a "personal visit" to assess the actual situation in the field. Once in the ejido, Ariziaga decided to start, with the help of the producers, the topographic study. The producers agreed to provide labour for the installation of the water pump and the construction of the irrigation unit (i.e. the construction of the canal network, the construction of boxes for water distribution, the perforation and the cement coating of the receiving water cistern, the extension of the water load line, the installation 
of the diesel tank and the structural base for the irrigation pump). Ariziaga was impressed by the warm reception he received from the producers. Producers fraternized with Ariziaga and offered a typical local meal based on fish and chacales (shrimps) from the Armeria river. For this special occasion a good mescal (a type of spirits made from cactus) was bought to make a positive impression on Ariziaga.

Ariziaga assumed the responsibility for helping the producers. The project was still not part of the official programme of the District. Ariziaga went back to the ejido during the weekends to conclude the topographic study. It was only after he finished this study that he summoned a young official from the District staff. This official was his brother Claudio, who was working in the mechanical section of the District as a mechanical engineer. Ariziaga had convinced him to work for SARH, because he knew Claudio's mechanical skills were greatly needed by the producers. Ariziaga asked Claudio to go to El Guarnuchil and make a report on the condition of the water pump, indicating the costs of the installation. The report established that several vital parts for its installation and operation were missing. It was necessary to buy the check valve, the asbestos and metal tubes and several accessories relating to the water pump itself. His diagnostic concluded that it was not possible to install the pump due to the lack of these essential items.

Ariziaga then commissioned Claudio and Engineer Amorey to support the producers as much as they could. Amorey was a young professional from Guadalajara University, from a humble rural social background, and committed to helping producers. Institutionally he had had long-term experience with the URDERAL and was loyal to Ariziaga. Ariziaga was still acting informally, but he had started to organize the official base for the project. Engineer Claudio remembers:

"My brother Pedro is an idealist, that was why he became involved
with the producers of El Guamuchil. These producers were extremely
poor, so the construction of an irrigation unit was their only hope
of improving their situation and this led them to expect to be able
to cultivate more profitable crops."
(interview/El Limon/19/IX/1987)

The social conditions of El Guamuchil impressed the young District officials and, after both professionals had accepted the challenge, Ariziaga went back to the bank with Javier and asked for an extension of the credit to complete the installation and construction of the unit. On this occasion Ariziaga decided that the head of the District 
should support the petition. So, before making this move, Ariziaga institutionalized the project by having it incorporated into the Peasant Labour Programme (Mano de Obra Campesina). Producers signed a contract with SARH in which they agreed to contribute with their labour and the institution agreed to give the necessary technical assistance to complete the project. The contract legitimized the involvement of SARH and provided the project with the necessary institutional back-up to request an increase in credit. The head of the District, Engineer Rojo, accepted responsibility for the project and in a letter to the bank argued in favour of the case. In this letter Rojo stressed that producers were in need of money to buy vital components for the installation of the water pump; he also pointed out that the ejido was potentially productive and ended saying:

"the most costly part of the project was already achieved with the acquisition of the irrigation pump, so I would suggest an extension of their credit, because the economic situation in the ejido is such that the only way that I can see for these producers to repay their debts to the bank is with the benefits that the irrigation unit will bring to them in the near future".

The institutionalization of the project meant the inclusion of $\mathrm{El}$ Guamuchil irrigation unit within SARH's agenda of programmes to be implemented in the District. Javier's position, as applicant, was now consolidated and formally accepted by the District. During this process of institutional affiliation Javier was actively involved in the expansion of the original set of social relations from a group of isolated and dispersed contacts mobilized to seek information, to a complex network of people and institutions mobilized to induce allocations. In other words, this change in the social construction of the project from being informal to acquiring formal status enhanced the capacity of producers to act effectively as negotiators on their own behalf. Achieving this - itself an expression of agricultural producers' power - was the social outcome of emergent properties generated in several encounters between Javier and an administrative official, who, due to his own life experiences and ideological position in previous and different social contexts, was able to act as an intermediary voice for the producers within the administrative context. 
From the institutional dimension to the social realm of practical activities: strategies, technical and a-technical realities of agrarian development

In this section I focus on the interface generated by the practical activities of constructing and operating the irrigation unit. The case shows how communication between producers and administrative officials constitutes a heterogeneous practical activity influenced by the specific differentiation of administrative tasks, as well as by the perceptions, rationale, or recourses to rationale, of the bureaucrats (Apthorpe, 1984:127-144).

The different dimensions of the phases of construction and operation of the irrigation unit relate to the practical consequences that these activities assume. The drama of construction takes place at the point of confrontation between the producers' strategies to solve problems and the engineers' position within the producers' context. Differential relations of power are expressed culturally in the separation of the actors in terms of the tasks they perform during the construction. It is only when scientific technical knowledge shows its limits that everyday practical knowledge of the producers becomes the alternative that makes the connection between the two knowledge systems in action possible. This process has a dramatic impact on the officials in charge of implementing the project.

The operational phase shows how irrigated agriculture entails a more complicated set of agricultural practices (when compared with their previous rainfed system) and how all this makes them redefine their relations with the agency officials in charge of providing technical support. During the operational phase intervention assumes a different meaning for the actors, partly because of the nature of the administrative task itself and because the new irrigation unit is considered part of the larger network of irrigation units in the area, and also partly because of the practical discourse used by the officials in their everyday activities involving administrative organization and the allocation of resources.

The results of the intervention during the operational phase and the several failures suffered by the producers drives them finally to realize that perhaps irrigated agriculture is not the most desirable change to be involved in. But, because the process is impossible to 
reverse, the irrigation unit remains a sort of sign-post for future strategies involving change.

The construction phase of the project

Eng ineer Amorey remembers:

"Ariziaga took charge of this project with responsibility and good institutional criteria. He spoke with the bank officials and secured the credit to help with the acquisition of the needed components. Once the bank gave the cash to the producers, they were unable to organize by themselves the buying of the components. So Ariziaga assigned Claudio to support the producers. They went to Guadalajara and bought 560 metres of tubes and other accessories, like the check valve. The tubes were difficult to obtain, but eventually they were delivered near the community by a commercial company. When Ariziaga received the news that the tubes were in the community, he asked claudio to design a route for the implementation of the project. Two District departments becarne involved in the project. Infrastructure, through the civil engineering section, and supervision of the operation, through the mechanical engineering section. Finally Ariziaga designated claudio and myself responsible for implementing the project in the field. The original plan was to start irrigation during July of 1984." (interview, El Grullo/19/10/1987)

Claudio said that they had to organize several meetings with the producers to explain the project to them and he added:

"producers were not interested in the project if SARH was not present. They did not take the head of the ejido (Javier) seriously. These peasants were accustomed to being temporary labourers in El Grullo or working as sugar cane cutters in the Tala sugar refinery or just migrating to the USA. They did not know what it was like to be a producer. The project was beyond their comprehension. There was only one producer who, with the help of a small pump, irrigated a field of melons and water melons".

Claudio Ariziaga wanted to help producers but he was dubious about the consequences of the project.

Claudio and Amorey decided to live in the conmunity, as this was the only way to complete the project. Once in the community, they organized producers into different task groups. For this purpose they communicated mainly through Javiex who gave the instructions to the producers. The nineteen producers who were to receive the benefits of the irrigation unit constituted the backbone of the labour force engaged in the project. Some of these brought along relatives, but an important section of the ejido did not participate at all, and they becane alienated from the project. 
As field engineers, Claudio and Amorey assumed responsibility for the technical implementation of the irrigation unit, whereas the producers were perceived as the means of achieving the work through their contribution of labour. Producers were in charge of clearing the area of the project, moving tubes and doing the digging. On the other hand, the engineers were perceived by producers as knowledgeable people with the capacity to penetrate the incomprehensible logic of modernization. Here modernization was embodied in the construction of the irrigation unit and the linking of the separate elements that would bring it into existence. Engineer's knowledge consisted of linking the use of a diesel engine to pump river water into a tank reservoir and from this projecting the water with force into a higher distribution tank. This tank, using the force of gravity, finally allowed water to be distributed, through the network of canals, into the producers' plots.

Producers recognized in the engineers the power to transform the ir rainfed land into irrigated land, and this provided producers with a symbolic category for accepting the position of Claudio and Amorey: producers called them "los ingenieros" (the engineers), thereby denoting them as people able or with the right to give orders, while among themselves producers would use their own names or nicknames. This privileged position was also highlighted by the fact that the engineers were given food by the producers, whereas when the producers worked collectively they ate together, putting into a communal pot their individual tortillas, vegetables, salt, beans, spices and fish.

The practice of fishing impressed me from the first day I stayed in El Guamuchil and it was one of the situations the tecnicos (engineers) remembered most. I describe this practice because it shows producers' knowledge in action. Fishing implied joint responsibility - the ejidatarios working together - and was a demonstration of producers' everyday techniques of survival. The members of the fishing party moved in a semi-circle splashing the water towards small caves. The noise airects the fish into these caves (this action is called encuevarlos). When the semi-circle of producers arrives at the selected cave, a net is placed in front of it and the producers start diving and catching fish with their hands. The identification of areas for fishing and the diving operations are performed by some members of the fishing party only. The fish are gutted and cleaned by others, usually by those who 
have been in charge of making the fire. One of the producers cooks the fish in a big pot and puts in the correct quantity of salt and chile and decides when the fish is cooked. The producers usually take turns to eat because generally there are not enough dishes. In these conmunal practices the engineers were observers but, because of their special position, they could claim a part of the meal. They were always the first to be served.

The engineers learned how to live in this context and through this became aware that the construction of the irrigation unit was likely to create contradictions between producers and their households, since the repayment of the bank would force a reallocation of resources from household to institution. Claudio was keenly aware of this contradiction. He was also sensitive to the way the project had been organized:

"we designed the unit with instructions we got from the retailer who sold us the tubes, but we had to improvise. We asked for a 10 inch valve and they sent an 8 inch one. We did not have machines. In fact we lacked real support from the District".

Despite the difficulties, Claudio and Amorey became personally involved in the project. Claudio remembered:

"The main problem we were confronted with was the installation of the tubes. We had everything sorted out, but when the producers started to dig the ditch for the tubes we found an incredible number of huge rocks along the pipeline. To put in the tubes we had to remove the rocks! It was the end of February and we wanted the project finished before the winter. We did not know what to do. Paying with our own money, we rented a tractor and with this we managed to remove some of the rocks, but still, there were several rocks stopping us. We ruled out dynamite because we did not have enough money. We did not know what to do".

(interview/El Limón/19/9/1987)

For the farmer Javier Rivera, this was one of the critical moments of the project.

"We saw the engineers in trouble. They were unable to find a solution, so we decided to tell them our way of dealing with the rocks. We said that we could break the rocks with fire and water and after that we could remove the rest of the material with a lever while digging with shovels. The engineers did not see how that was possible, so we explained we had always done it like that. They did not believe it, but they accepted because they had no other alternative".

(interview/El Guamuchil/26/9/1987)

For all their knowledge Claudio and Amorey were not able to control the obstacles of the terrain. This situation showed how the technical/practical knowledge of producers provided a solution to a problem that had paralysed the techniques of scientific knowledge. Producers' knowledge 
about how to tackle the problem meant that they did not need supervision to organize and carry out what was probably the most important task of the project. Producers knew where to find firewood, and knew how to identify the precise spot for applying the fire and water which, by producing drastic differences in temperature, would break up the rock. In short, producers recovered, within the frame of the project, their independence from the specific function of just being the providers of labour. Producers' practical knowledge impinged directly on how the project had been conceptualized by the engineers and, at the same time, they provided a practical solution to an important problem. Hence the engineers' role as supervisors was made redundant during the most important stage of the project, in such a way that they had to opt to participate in the tasks organized by the producers. The process to remove the rocks was a long and slow one and this allowed a better understanding to grow between producers and engineers. The position of the engineers did not change vis-á-vis the position of the producers, but their relative ignorance made them more accessible, in human terms, to the producers. Three years after the conclusion of the project, both engineers, Claudio and Amorey, remembered the period of rock removal as the most significant event of the project - when they had to 1 isten and finally accept the producers' proposals.

By March of 1984, the tubes were in place and the engineers started to test the different sections of the unit. Due to lack of resources, Claudio and Amorey decided to irrigate only 32 hectares of the 46 planned. Producers were disappointed, but, finally, they had to accept this decision. In institutional terms, the project had now become the ideal model of SARH-producer collaboration and was the pride of the head of the District. Rojo invited the head of the Jalisco state irrigation programe to see the project.

Claudio said:

"Rojo invited the most important person in the institution to visit the project. The producers organized a social gathering and for this they killed a pig to demonstrate their gratitude to the important people, but for us, who had been sharing their difficulties, there was nothing."

(interview/ El Limón/19/9/1987)

Claudio's sentiments indicate that he felt that the project was used by the central staff of the District to improve their individual administrative careers. His resentment against the producers was because they had forgotten them as engineers, as "important persons". They had 
became part of the producers" routine ("eating fish"), rather than elements of the special occasions or social gatherings to express gratitude ("eating pork"). In my view, the original aim of Ariziaga was achieved. The young professionals felt the full impact of the experience in hand-to-hand work with the producers. Nevertheless, I an less sure about the unintended consequences of the experience. The engineers acquired a strong awareness of how different social actors operate, in reality, through the manipulation of people and resources. In this way, claudio recalled the project with a sense of disillusionment. However, in my opinion this was also an important part of the experience and one not foreseen by Ariziaga.

When the project started to operate in June 1984, a different administrative section of the District supervised it. New professional agronomists replaced Claudio and Amorey, who were transferred to other duties. The construction of the irrigation unit marked the beginning of a new phase in the relation between producers and SARH. This new operational phase was oriented towards defining a pattern of cultivation for the producers, so they could repay the credit to the bank and be integrated into the agency plans for regional production.

The operational phase of the project

Ariziaga remembered that almost immediately after the irrigation unit had been finished, Javier came into his office and argued in favour of melon cultivation. Ariziaga was genuinely surprised with this argument. He argued that the ejido was too far away from the principal centres of melon commercialization, that the production of melon would favour the middlemen and not the producers, and that melon cultivation was an expensive crop that needed a good knowledge of how to maximize the water pumped by the irrigation system. Producers agreed with Ariziaga and decided to cultivate maize. This decision pleased him. He expected that experience of the first cultivation cycle would help producers to increase their level of organization.

A SARH agricultural promotor, based in the town of Tuxcacuesco, was assigned to give technical supervision to the producers. The promotor helped the producers to get the irrigation water flowing through the canals and into their fields. Some producers remembered that they had 
to pay a mordida (a bribe) to the promotor for this service, because "the promotor used to stop working around one o'clock. So to keep $\mathrm{him}$ working, we had to pay for extra-time". Producers complained that some of this work was so bad that the water just did not flow.

Irrigated agriculture was a new experience for the producers. They soon realized that neither "access to water ideology" nor their experience as rainfed producers could provide them with lower-level constructs (see Appendix to this volume and Long and van der Ploeg, 1988) for organizing the necessary practices or resolving the problems of this type of agriculture 9. The specific solutions for operating the system, such as the irrigation trace, were located in the private sphere of influence of the local SARH promotor. In this new situation, as producers of irrigated agriculture, they had to learn how to master their relations with the sphere of local state representatives.

Local State representatives were not interested in the development of El Guamuchil. Their main centre of attention was Tuxcacuesco, where private capital expanding from Autlán was taking over producers' irrigation units in order to gear agricultural production to the export market. Local agency officials were willing to contribute to the process of "smoothing the way" for external entrepreneurs. Undoubtedly, these ventures brought substantial economic pickings for local officials but, more fundamentally, they were true believers in the principle that capitalist entrepreneurs are the only solution for bringing development to the region.

El Guamuchil was a difficult ejido to reach in social and geographical terms. During the construction of the irrigation unit, the close relationship between Javier and Ariziaga was interpreted by producers as evidence that SARH was finally giving them the importance that they thought El Guamuchil always deserved. During the operational phase of the project, the relationship between the institution and the producer became wider because the irrigation unit was incorporated administratively into a network of such units. In this context $E 1$ Guamuchil lost its previous privileged position. Furthermore, its importance was ranked low in terms of the impact that the unit could have on locallevel development. This was not an official or unofficial policy of SARH, but rather the working out of the pragmatic rules of the local agency officials responsible for the supervision of the irrigation units. 
In 1987, during my field research, I became quite close to the Tuxcacuesco promotor and with his immediate institutional superior. These two officials strongly disagreed with Ariziaga's intervention, because, according to them, his action had allowed the producers to control an irrigation unit. According to them, Ariziaga never gave any real thought to the consequences of this project, nor to how producers should be incorporated into the process of production. Both officials blamed Ariziaga for creating problens to which they now had to provide solutions. They were convinced that none of the present solutions could put right the main mistake, namely SARH should never have been involved in the first place in an irrigation project in an ejido like El Guamuchil. The institutional superior, when he had to clarify his position, always resorted to one of his favourite idions, such as "lazy guys" (flojos), revelling in his perception of producers as having an intrinsic laziness and a total lack of entrepreneurial commitment. In his view, the lack of these important properties for "progress" was reinforced by the producers' total dependency on state action (an extrinsic property), because they did not want to take responsibility for solving the problems they had created themselves.

producer recollections about the difficulties they had experienced with the operation of their irrigation unit point to a rather different version of why they have had a long history of failure, indicating that perhaps it was not the producers' irresponsible nature that was at the heart of the problem. Don Rafael recalls:

"The first year we cultivated maize, even though some of us wanted to cultivate melons. We had really nice plants that year. We expected to pay back the bank, without any trouble, the credit for the irrigation unit and the money they had lent us to finance the agricultural cycle, but near the end of the cycle a pest (the cogollero-worm) struck the maize. This worm destroyed the shoots of the corn-cobs and stopped their full growth. The corn-cobs started to rot and then it was impossible for us to control it. The ma in problem was that we realised too late the existence of the pest and this was because it is not possible to see the worm until you have opened the corn-cobs. We did not have experience with this pest and we lost our production, because nobody wants to buy rotten corncobs or corn-cobs without grain."

(Field notes /El Guamuchil/29/10/1987)

When I enquired about the reasons for the late identification of the problem, producers indicated that they had no technical supervision during the agricultural cycle and when the promotor took notice it was already too late. This version was corroborated to some extent by 
Claudio. When I asked $\mathrm{him}$ to explain the reason why the original expectations of the unit of irrigation had not materialized, he said:

"The head of the Centre responsible for giving assistance to El Guamuchil is not a methodical person who would bother training producers to use water. He never went to see what was going on in the unit. As a result producers wasted water. This increased the economic cost and probably, because they used too much water, the producers unintentionally may have triggered off the pest. The Tuxcacuesco promotor doesn't know how to provide agronomic technical assistance. Its clear that he never went to see the plants. I remember that he came to the District for assistance to control the plague. The District immediately sent into the fields the specialists who were responsible for controlling plagues, but when they arrived there it was too late. Even so they did try to fumigate. This action, in the end, was ineffective, but it did provide a way out for the promotor, who argued that he had informed the District. At the same time the ineffective fumigation gave him the opportunity to make a mockery of the District action in front of the producers, thereby saving his own reputation. In brief, El Guamuchil producers have never had the slightest chance to learn how to use the water. The failure of this first year was very important for the ejido, because producers were unable to repay the bank who suspended any further credit to the ejido until the debts were cancelled".

(interview/El Limón/19/9/1987)

In one of my conversations with the Tuxcacuesco promotor, I asked him why the technical supervision was scarce during the first year of the project in El Guamuchil and why they did not spot the plague earlier. The promotor answered that the reason was probably the lack of technical assistance. According to him, this was not his fault because he had to supervise several irrigation units. The person directly responsible for providing technical assistance was the fieldworker (extensionist), but unfortunately the latter visited the ejido only sporadically. The promotor emphasized the fact that the ejido was difficult to reach for agency personnel, and that the agency lacked resources to support an efficient agricultural extension system. In relation to the plague, he said that that was an event that took producers and SARH officials by surprise and it was just bad luck.

The consequences of this failure left the producers without the financial means to organize their next agricultural cycle. To complicate matters, at the end of 1984, Rojo and Ariziaga were transferred to La Barca District, and the new head of Autlán-El Grullo District did not consider $E l$ Guamuchil a priority. So finally the producers were alone. Confronting the economic situation, some decided to invest their own economic resources in obtaining a good crop of melons. On this occasion there was no government involvement, so this was clearly 
the producers' moment to experience their dream and achieve progress through the cultivation of profitable crops. Every producer operated individually, that is, each one decided which crop to cultivate, organized the buying of fuel, the operation of the pump and the frequency and number of hours of irrigation. However, the consequence of this attempt was utter chaos. Producers started to fight for the right to use water, and the lack of money to buy fuel meant that some producers abandoned their crop or went into personal debt with local money lenders. To complete the picture, an eruption of the Nevado de Colima volcano scattered clouds of ashes onto El Guamuchil and so the major part of the crop was lost.

After this second failure, producers came to realize that the irrigation unit was not the solution to their problems. They were forced to look for alternatives. The reality of their experiences as irrigation producers fuelled a wave of critical opinion against Javier's ways of achieving progress. Yet it was impossible to turn back or reverse the course of events. Producers tuned themselves to a reality, where in any rearrangement of their circumstances, the presence of the irrigation unit, like it or not, was going to constitute a central point for constraining or opening up possibilities for future strategies.

\section{Concluding remarks}

I chose as the subject of this chapter agricultural producers' strategies, since strategy is a flexible concept allowing for the analysis of specific concrete contexts where action takes place (see Barth, 1981:97-104). The examination of producers' strategies entails distinguishing the differential pattern of power that exists among human agents according to the techniques they use or have access to, i.e. between, for example, everyday or scientific techniques, where technique is understood as an expression of the agents' rationale or recourse to rationales when they becone involved in a process of agrarian development (see Apthorpe, 1984).

The process of agrarian development is not a dynamic which moves around different abstract models or rationalities, but is a social construction of actors, who, by linking different interactional sett- 
ings and social zones, make practical use of their own concepts and classifications, and in so doing they generate common ground where they might demand, negotiate or diffuse solutions aimed at change. The main objective of this process is to try to influence the allocation of resources so as to create "new opportunities" for the agricultural producers. In Mexico, as in the majority of Third World countries, the government plays a central role in this process of resource allocation. This chapter shows how producers' strategies were used to bridge local discontinuities and to legitimize state intervention in support of commoditization aimed at achieving producers" images of "progress".

By focusing on the several dimensions involved in the relation of local bureaucracy to producer, I have presented an ethnography of an organizational process that generates a particular form of government intervention. I have drawn methodologically from Handelman's (1976) case study on bureaucratic transactions in Israel. His contribution to understanding relations between bureaucrats and their clients is an important one since it helps to counteract the "unproblematic" perspective provided by organizational theory. Handelman's transactional approach highlights the capacity of the parties to handle the dual aspect of resources, namely rewards and constraints. This practical knowledge allows them to negotiate the properties of the relationship, the resolution of their conflicts, and the subsequent contacts and transactions between the bureaucrat and the client.

This perspective provides analytical strength for understanding the importance of emergent properties in the constitution of social relations, but it fails to relate emergent properties to actors' previous experiences. Handelman relates official-client relationships to a set of administrative "rules", the department's past and ongoing transactions and changes of circumstances that centre exclusively on the life of the client (see the opposite position in Grindle, 1980). Handelman presents us with a transactional picture, constrained within an administrative context, yet ignores the fact that the monitoring and evaluating of emergent properties within the bureaucrat-client relationship may be based upon previous experiences that actors have gained from other contexts.

In the case of $\mathrm{E}$ l Guarnuchil, we analyzed the social configurations of the actors. They bring into their encounters and relationships their understanding of existing cultural categories and ideologies, and 
different forms of practical consciousness. These constitute important resources for apprehending cognitively the constraints or possibilities of the administrative context, and they help actors to orientate the social and interactional character of their encounters and relationships. In other words, what is missing in Handelman's perspective is the recognition of how the actors' own biographies influence the process of allocation within the administrative context. While I agree that transactions expose different capacities (i.e. differential power, access to resources, and the ability to induce allocations), I suggest that it is because we are dealing with actors with, and from, different social configurations who try to achieve their own objectives within the particular social context, that we cannot consider these transactions as conforming to some tendency towards organic solidarity in society. Rather we should consider them as an essential expression of interaction involving discontinuities in values and interests. In these encounters and relationships, actors communicate concerning the existence of possible alternatives for inducing the allocation of resources (compare this with Long's concept of development interface, Long, 1984 and 1988; Long and Van der Ploeg, 1988).

Bringing into the analysis interaction cutting across social discontinuities means that we are able to understand how bridging takes place between different life-worlds or social configurations. I owe to Schaffer's perspective the suggestion that social action resulting from these interactions should not be perceived merely as the single outcome of the bureaucratic side of the equation, but that we should appreciate and give equal primacy to the character of the client side. We need a new dimension on bureaucrat-client relations, since "policy is, after all, not just a matter of bureaucratics. It shelters, within its alliances, other zones and other participants" (Schaffer, 1984:185).

Considering policy implies understanding the wider organizational capacities of the participants involved in the interaction: this involves the study of management as well as public policy discourse, concepts and bureaucratic practice, producers' capacities to arrive at agreed definitions, local stocks of knowledge and everyday concepts and social practices. It is also necessary to examine the nature of their representation of tasks, and the forms under which situational redefinition and emergent properties arise. 
The analysis of bureaucrat-client relations must recognize the significance of the administrative and political factors involved but these must be linked to the experience of the actors themselves. Their biographies will present the discontinuities of the social process. The concept of social configuration is central to understanding how actors will define an interaction (i.e. the critical point of intersection or linkage between different social configurations) and the combination of elements that define the situation. In this way, a bureaucrat-client relation is an aggregate social construction along the lines suggested by Barth (1981:119-137).

As for the project itself, the realm of practical activities determined the variations in the scope of intervention that occurred during the phases of construction and operation of the irrigation unit. The producers' lack of influence decreased their capacity to provide solutions to problems during the operational phase. Producers' lack of knowledge of irrigated agriculture and uncertainty eventually led them to a chaotic situation of production. Nevertheless, producers' strategies did embody organized social knowledge which gave thern access to irrigation. The irrigation unit represented a symbolic artifact of agrarian development, but one that finally did not bring to the producers the best of all possible worlds. Hence, we can conclude that, in this case, agricultural producers' strategies were not able to maximize their choices and actions within the framework of a pattern of centralized social change introduced by the state.

\section{Notes}

1. I would like to thank Jan Wijbe Oosterkamp for his assistance in preparing an earlier draft of this paper, the Wageningen seminar group for their useful comments, and Ann and Norman Long for help with the final version.

2. This paper was originally presented to the EIDOS workshop on Local Know1edge and systems of Ignorance at the School of oriental and African Studies, London University, 8-10 December, 1986.

3. The term ejido refers to agrarian communities that obtained land under the land reform laws growing out the Revolution of 1910. For a fuller statement see p. 99 , fn. 5 , of this volume. 
4. The Trigomil dam is expected to provide $140,000,000$ cubic metres of water. Although located in the Municipality of Union de Tula, this water will benefit the areas of Autlán, El Grullo and El Limón. This last area will be the most favoured zone. Of the 9,000 hectares expected to be irrigated by Trigomil, around $67 \%$ will be located in the Municipality of El Limón.

5. Field diary/Report 9-8-1987: Centro El Limón. El Guamuchil is a fictitious name, but its geographical location is real.

6. Turner (1974:17) defines social fields as "abstract cultural domains where paradigms are formulated, established, and come into conflict. Such paradigms consist of sets of "rules" from which many kinds of sequences of social action may be generated but which further specify what sequences must be excluded".

7. Aggregate social forms are seen here as a feature of social organization which is definitionally specific to actors' capabilities to connect partly similar "life-worlds" and to engage in social action. Action creates alternatives (opportunities) which are independent of individuals' repertoires or the institutions they represent. Individual synchronization is a process which in itself is presented as an external fact to be accepted as part of the socially constructed reality and in correspondence with the culturally-defined contents of social interaction and the social stock of knowledge, and accepted by social actors in a given social, spatial and temporal context as routine. Therefore, an aggregate social form is the generative capacity of actors in real social life to agree or disagree about what is relevant on a particular occasion and therefore to define or redefine a situation through strategies, resource management, choice and opportunity. The outcome of these simple features, which can be located in the sphere of the individual, only becomes socially significant when the individual is transformed from self into social actor, revealing through this action the types of agency that constrain or enable the social actor to define or redefine situations (see F. Barth, $1981: 129-130)$.

8. The notion of a model of the government came from the observation that State institutions, like people, need to have an existential dimension, in order to provide their actions with a concrete meaning towards the maintenance, transformation or change of nature and the social world. Models of government are specific because they carry political authority in society from which they make reference to natural science discourse and prescriptions to justify political intervention. Such models also project the future, using a simplified social science rationale about how people engage in interactions, relationships and class formation. This allows for the formulation of plans for action that consider only some aspects of social or economic life as relevant. These plans provide public policy representatives with a set of valid criteria for policy implementation.

9. Sutti Ortiz states: "I admit to no great revelation when I stress that when searching for solutions to concrete problems, farmers reason from lower level constructs rather than from generalized models. Yet, it needs to be reiterated because not all problems are resolved in similar fashion. It remains for us to determine when it is that generalized categories are used and when it is that lower level constructs impinge more directly in the conceptualization and resolution of a problem" (1981; 166; 199-173). In the specific situation of El Guamuchil, neither the general categories (from the water ideology) nor their previous experience as rainfed producers (Ortiz, 1981:167) could help producers to find a solution to irrigated agriculture. 



\section{SOCIAL ENCOUNTERS AND INTERFACES BEIWEEN FARMERS AND INTERVENING ACTORS: THE EMERGENCE OF LOCAL ORGANIZATION IN WESTERN MEXICO 1 Hans Heijdra}

\section{Introduction}

The focus of this chapter is the place of so-called local farmers' organizations in the sets of relationships that develop between outside intervening parties and local farmers. For outside agencies (who often have founded and/or legalized them), local organizations form important "entrances" to the local level, their interventions often being canalized via them. For villagers, local organizations offer access to wider institutional and economic systems. Thus it is at the level of local organizations that critical points of intersection or linkage between different social systems or levels of social order are likely to be found. It therefore seems appropriate analytically to talk about intermediate 2 (or interface) organizations, giving emphasis to their two-sided character. Local organizations (such as water users' associations, local agrarian associations, rural cooperatives etc.) are the formalized intermediate-level structures between "the state" and "the farmers".

In this chapter I aim to analyze such formalized intermediate structures from an interface and actor-oriented perspective. The local organizations in question are analyzed as constituting social arenas where villagers and outside institutions meet and attempt to realize their collective and individual goals. Like intervention itself, local organizations are best analyzed in terms of ongoing processes of interaction and negotiation between representatives of different social orders (e.g. outside agents, peasant leaders and local members) and it 
is these vivid interactional processes which shape the actual place, function and meaning of such organizations. Hence they have a dynamic and emergent character. They are not machine-type organizational structures but continuously changing outcomes of ongoing organizing and structuring processes.

In order to analyse local organizations from this angle situational case-studies can be useful. Situational case-studies aim "to provide a close-up view of social interaction and confrontation in order to elucidate how structural forms and processes (reproduction and transformation) work themselves out in everyday situations" (Appendix, p. 251 to this volume; see also Van Velsen, 1967). Here I present a situational analysis based on a series of events involving intervention from outside concerning the outstanding debts and the future of a farmer-organized packing plant producing winter vegetables for the United states market. The packing plant is situated near San Antonio 3 , a small village in an irrigation zone of western Mexico where relatively small-scale irrigation units organized by farmers' associations are found. By analyzing certain important sequences of events of intervention I set out to tackle the following types of questions: how do people interact with representatives of outside institutions, how do intervening parties act regarding existing organizations, how are actual situations of intervention structured, how are strategies worked out both within and outside formal organizations, and so forth. In this way, I aim, to provide an account of what intervention looks like, how it is organized, how it functions as an interactive process, and how these processes influence the outcomes of intervention itself.

This kind of analysis can only be satisfactorily worked out in here-and-now situations since the reconstruction of past situations of intervention will always be coloured by present-day situations and the positions people occupy. Thus, to a considerable degree, one depends on events occurring during the period of actual fieldwork, which in this case stretched from May to October 1987. This was the rainy season when people were busy sowing and cultivating their maize. It was also the period for the preparation of the next irrigation cycle: cleaning the canals (September, October), applying for permission to sow 4 and, in the case of export production, searching for contracts, credit, and plant materials such as seedlings. 
The chapter concentrates on interventions relating to the issue of the packing plant. Yet it would be incorrect to isolate these from other intervention events and social conflicts within the village going on during the same time-period. Different organizations and fields of activity are linked together because of partly overlapping memberships, personal ties, local political factions and legal structures.

Before presenting the situational case-study it is necessary to provide some background information on the location and on the foundation and functioning of the San Antonio packing plant. Then the casestudy will be presented and analyzed, and in the final section some conclusions about outside intervention and local organization will be drawn.

\section{The socio-economic setting of the village of San Antonio}

San Antonio is a small village of about 600 inhabitants close to the Tuxcacuesco River in western Mexico. Together with a number of neighbouring villages, it forms part of the Municipality of El Limón, close to the Autlán-El Grullo valley, in the state of Jalisco. Similar to other villages in El Limón, the major sources of income for the inhabitants of San Antonio are agriculture and migration.

Agriculture includes both rainfed and irrigated fields. The main crop of the area is, and always has been, maize, complemented by other dry farming crops such as beans, sorghum and chile. The coming of irrigation, however, has enabled some farmers to branch out into export-oriented production. Here the two most important crops are cherry tomatoes and melons, destined for the us market. Irrigated agriculture allows for two, and sometimes three, harvests during the year. In addition to agriculture, some farmers are involved in livestock production, with a few larger landowners practising this as their main activity.

Migration was originally seasonal for work in the agricultural estates on the pacific coast or in the larger cities of Guadalajara, Mexico and Tijuana; but, from the 1940's onwards, a process of longer term migration, especially to California in the United States, was begun. This migrant flow continues to have a significant impact on the 
villages of the area both economically and socially. Almost every adult male in San Antonio has been in el norte ("the north", i.e. the US) and/or has close relatives living there.

The landholding pattern consists of two main types of tenure: pequeño propiedad (small private ownership) ranging from 3 up to 60 hectares of land, and ejido 5 land which is divided into plots of 8 hectares each. Approximately 12 percent of the heads of households are pequeños propietarios, 33 percent ejidatarios, 4 percent own small plots within the urbanization zone, and the rest, making up just over 50 percent, do not possess any land at all, although they may have access to plots through renting (especially irrigated land).

\section{The San Antonio packing plant: contracts, conflicts and corruption}

The foundation of the packing plant

During the first years, following the introduction of the irrigation units around San Antonio in 1977, some sugar cane had been planted but very soon melon and tomato became the most important crops. Attracted by success in this type of export production by farmers in a neighbouring valley, some farmers in San Antonio introduced these crops. The produce was delivered to the nearby packing plant of El Limón and the American company working there provided credit for sowing and technical assistance. In virgin land high returns were realized which stimulated those wait-and-see farmers to introduce these crops as well. With in two years of the introduction of the irrigation units, farmers were linked into international commodity markets 6 .

Already in 1978 some producers of San Antonio started considering the possibilities of having a plant near to their village, since the $\mathrm{El}$ Limón plant could not handle the increased delivery of produce.

"Because of that we wasted time and money. Right, so one day we talked to the owner of the plant. He was the intermediary of an American company. We discussed the possibility of us making an extension of the plant nearby here, near san Antonio, right, because we had much melon. He liked the idea. We could do it, working with the same company, right, dependent on the El Limon plant. He wrote a letter for us to Guadalajara, to his office, and they assured us that it could be done. And we went to Guadalajara and the Licenciado 7 said to us: "Look for a plot and I'll come, Saturday I'll come and I'll give you the money". Well, we never saw him again, he did not show up that Saturday and never since. So the 
idea about the extension died. And I asked Pedro Cobian (a cofounder of the San Antonio packing plant, HH): "Couldn't we work with another company?" "Of course", he said, "look, in El Grullo there operates another company, let's approach them in El Grullo." From that moment onwards the work started." (Tomás Arroyo, cofounder)

so the idea in the beginning was nothing more than to have a packing plant closer to their own fields. To realize this they started contacting private companies, which led finally to the foundation of a farmers' organization that became the owner of a newly-constructed packing plant. But before this was achieved many problems had to be solved and without the involvement of different state agencies and private companies nothing would have been accomplished at all.

First of all the farmers had to organize themselves into a legally recognized organization. The owner of the El Limon plant already had recommended that they found a society of social solidarity (SSS). The attractiveness of this type of organization is that private landowners, ejidatarios and landless workers can affiliate, while group credit can be offered in the same way as with ejidos, without risking individual property.

Not knowing how to found such an organization, Pedro Cobian and Tomás Arroyo (the two initiators) went to the office of the Ministry of Water Resources (SRH) in El Grullo to get information. From there they were sent on to the office of the Ministry of Agriculture in Autlán 8:

"There the Licenciado took our case very, very seriously. Right, he took the case seriously, and looked at the Law, studied it and then called us together with all the people to explain to us how it worked."

Many people were willing to affiliate and on August $11^{\text {th }} 1979$ the "Society of the United Producers of San Antonio, San Vicente and San Matias, Society of Social Solidarity (SSS)" was founded by some 76 farmers, the majority coming from San Antonio but also including producers from the neighbouring villages of San Matias and San Vicente. Twenty members were private landowners and the rest, ejidatarios or landless farmers who cultivated on rented land. In order to fulfil the legal requirements, four committees (each consisting of three persons plus their substitutes) had to be elected: an executive comnittee, a committee of "vigilance", an admissions committee and an education committee. The two initiators, Pedro Cobian and Tomás Arroyo (now 
President and Treasurer of the executive committee respectively), continued as the leading figures.

A second problem to be solved was finding another company to buy the produce, to assist with difficult production problems and to finance part of the costs of production. Via their connections with the leaders of the Local Agrarian Association (Ascciación Agricola Local, $A A L)$ in El Grullo, which owned a packing plant in that town, they made contact with Octavio Bautista, the representative of the Grimy and Brat Company in Autlán.

"Don Octavio was interested immediately and promised to do everything he could for us to realize our ideas." (Tomás)

A third problem was obtaining the finance to construct the packing plant. Those banks consulted were not willing to invest in it. Through an employee working on credit programmes in a neighbouring village, they were put into contact with FIRA, a state financing institution providing credit, via banks, for all kinds of projects. A feasibility study carried out by FIRA officials resulted in a positive recommendation to finance the construction of a packing plant near San Antonio. They calculated the costs to be around 10,000,000 pesos (at that time about 400,000 Us dollars 9) and so via BANAMFX (Banco Nacional de Mexico) FIRA lent this amount of money to the sSS. The sss had to bring in $5 \%$ of its own capital and for that reason issued 250 shares, each of 1000 pesos (40 Us dollars), to buy a one hectare plot near the AutlánCiudad Guzman highway on which to construct the packing plant. A construction company was contracted through Octavio Bautista and by the 23 th of October 1981 the first boxes of cherry tomatoes were being packed in the San Antonio plant, and sold to the Grimy and Brat Company (represented by Octavio Bautista) with which an official contract for sale was signed.

A few months later a second organization was founded. The National Union of Producers of Fruits and Vegetables (UNPH) refused to recognize the society as a farmers' organization for the comnercialization and export of products; consequently they were not prepared to issue them with the necessary licenses. For that reason, a Local Agrarian Association had to be founded. Officials of the Ministry of Agriculture and Water Resources (SARH) strongly supported the founding of this second farmers' organization. From the beginning, some SARH people were heavily involved in the establishment of the packing plant and con- 
sidered it as "their" project, although legally sss's fall under the responsibility of the Ministry of Land Reform (SRA). Up until then the SARH could only intervene indirectly in the organization of exportoriented agriculture as supervisor of the irrigation units. But with the founding of an AAL the SARH was able to formalize their direct intervention in the project, since AAL's do fall under their responsibility.

Legally the two organizations have different objectives. The sss runs the packing plant, while the AAL is concerned specifically with commercialization and export. However, for the farmers involved, there exists only one packing/export organization (here called the SSS/AAL). The foundation of the AAL was just one of the many procedures which had to be fulfilled. Without any discussion the executive committee of the SSS was elected to lead the $A A L$ as well and, until the increase in internal problems in 1984, nobody was really aware of the existence of these two organizations. Financial and administrative affairs and minute-books of both were completely mixed up.

organized now in an AAL, the farmers of San Antonio became linked to the Regional Agrarian Union, a politically and economically powerful. regional institution which, in turn, is affiliated to the National Union of Producers of Vegetables and Fruits (UNPH).

So the desire of some villagers to have a packing plant, in close proximity to their fields, was picked up by several outside parties. This coalescence of interests finally led to the setting-up of the organizational structure described in this section. The intention to keep everything formally in the hands of farmers' organizations (and not foreign companies) was the main objective of a few enlightened SARH officials. According to a present SARH promotor, "Ingenierolo Fernandez, the then head of the District, had this vision of establishing efficient farmers' organizations so as to free the producers from the foreign companies."

The first years of the functioning of the packing plant were economically prosperous, with some producers realizing incomes of up to 10,000 US dollars a year from only one hectare. But the process and organization of production and the packing and exporting of produce resulted in a complex set of activities which it was almost impossible to supervise fully, either by the members themselves or by the assist- 
ing agencies. Thus it easily led to internal tensions and accusations. The following issues constituted the most explosive:

- the possession and allocation of collectively-owned goods and yet the possibility of using these for personal benefit;

- the near impossibility of controlling effectively market prices and financial management, and thus the continued possibility for corrupt state institutions, companies and local leaders to cheat the farmers;

- the dependence on external financing which forms a source of power for companies, banks and local leaders which can be turned to personal gain.

What started as a "simple" idea of some producers resulted in a very complex and wide-ranging organization, linking farmers to private companies, state institutions and regional political networks. This organizational complexity was not a one-off thing, planned and settled by one institution. It was rather an outcome of ongoing processes in which different parties were involved and which no one could plan beforehand. To understand the dynamics of the growth and demise of export-oriented agriculture in and around San Antonio necessitates that we underscore these aspects.

Contracts, conflicts and corruption

Pedro Cobian, the first President, was by far the most important leader of the SSS/AAL. After working for ten years as a migrant labourer in the United States, he returned in 1973 to San Antonio, where he soon came to play a prominent role in local organizations. He is an ejidatario with 3 hectares of irrigated land, which he augments by renting plots. The cobian family to which he belongs holds a number of political offices in the region. Pedro was very active as President and took his job seriously, but soon criticism arose because of his individualistic style of management.

"He managed the plant as if it were a private company. There was much favouritism towards some non-members, while some members were treated very badly, being refused credit."

Problems intensified because of increasing feelings of corruption. During the first harvest of 1982 some members had already expressed 
their doubts about the prices being paid by Octavio Bautista, the representative of the buying company, and the growing friendship between Octavio and Pedro led to even more suspicion.

"....Pedro, well, he had many good things, like Tomás, all those who initiated the movement. They did it with much sacrifice. I do admit that. For some years he worked very well, very well in the sense that he did not notice what the company was trying to do, until his eyes were opened when the company said: "Listen, isn't it possible for you to go it alone? You're a poor man. ... What would you think if we left you some five, ten dollars, or something, so that you can have something of your own, because, look, you can't be re-elected and you will be left with nothing. You can't even sow at the moment, because as President you have to attend to so many people." And well, you begin to see what's happening, right, unfortunately you notice, you find it out and, well, what do you do?" (Roberto Rios, AAL delegate for commercialization)

The relatively poor but ambitious farmer Pedro Cobian got richer every year while, according to many people, he never had good harvests.

"He was a humble man, the President, but now he has everything: a pick-up, a tractor, everything. And from what? He never had a good harvestl ... He received tractors from Octavio, and that surely was not because of his nice face."

The first protests against Pedro's leadership came from the cofounder, Treasurer Tomás Arroyo. Tomás, who is 60 years old and much the senior to Pedro, is the eldest son of the founder of the ejido of San Antonio. He has a total of 8 hectares of land, of which 1 is irrigated. Together with his wife, he runs a shop in the village and sells gasoline. He is one of the very few people of his age group with post-secondary education (he is trained in book-keeping) and consequently has occupied a prominent position within several local organizations since his twenties. In February 1982, he had complained that effective financial control was impossible and, during an assembly in August the same year, he withdrew as Treasurer. This took place shortly after the publication of the first external accountant's report, which concluded that:

"...the data about most of the expenditure are missing. Therefore we limit ourselves to saying that the financial system of the Society is not reasonable."

The next season the protests increased and by April 1983 open and more organized opposition began with the sending of a telegram to the President of the Republic of Mexico 11, which stated:

"We apply for your intervention via the Ministry of Land Reform. Millions are at stake. Bad functioning, anomalies, arbitrary acts, caciquismo 12." (signed by Tomás Arroyo) 
In a corresponding letter to the Ministry of Land Reform an independent financial inquiry and new elections were demanded.

A full year of increasing conflicts followed. Problems arose about everything; about the allocation of credits, about the private use of the sss pick-up, and about the representation and voting at the elections of the Regional Agrarian Union. Finally, on May the 5th, 1984, new Sss elections were held, as the legal period of the executive committee had expired 13. Although Pedro had been able to consolidate his position using $h$ is extended contacts with companies, banks and state institutions, "his" candidates 14 lost the elections by 22 against 34 votes for the candidates of the heterogeneous opposition headed by Tomás Arroyo. The new President became the ejidatario René Villa, godson of Tomás and politically not a "strong" person, but respected because of $h$ is reputation for honesty. During the same Assembly a financial inquiry into the affairs of the previous executive committee was requested.

It was the staff of the Ministry of Agriculture and Water Resources (SARH) who reminded members that elections had to be organized within the AAI. René Villa, the new sSS President, explained that it was at this point that:

"We discovered that there were two organizations. We did not even know about the existence of the Association. So we had to quickly put up candidates."

Once again the opposition group won (30 as against 19 votes). But to avoid concentration of power, the members decided that the two interwoven organizations should be separated and headed by different persons. Hence a different president (Cesar olivera) was elected to lead the AAL.

Because of Pedro's individualistic style of management and his use of all kinds of personal contacts, it was difficult for the new and inexperienced leaders to take over leadership. Most problematic of all was the fact that Pedro Cobian and $h$ is group did not accept their defeat, and were therefore not willing to subordinate themselves to "those innocents" who "do not know anything". Declaring themselves to be a "solidarity group", they claimed the use of the facilities of the sss packing plant while operating independently of the SSS/AAL, and, in addition, they wanted direct credit for their group and their own selling contracts. Of course the SSS/AAL did not accept this proposal and so the "solidarity group", firmly bent upon not giving in, started 
their own small packing plant in an unoccupied barn in the centre of San Antonio. This was financed by Pedro's good friend, Octavio Bautista.

At this point the President of the National Union of Fruit and Vegetable producers and high-ranking SARH officials came to San Antonio to induce the two factions to unite again, but even their powerful intervention was of no avail. The division worsened when, in January 1985, the Ministry of Land Reform in Mexico City made public the results of the financial inquiry. It emerged that during Pedro Cobian's administration some twenty million pesos (over 100,000 us dollars at that time) had disappeared, spent without the permission of the SSS (on personal credit, for example) and without receipts for expenses. The Assembly decided to expel pedro cobian and a few of his friends from the SSS (they had legally remained as members) and requested that further legal steps be taken against them. These decisions however were never acted upon by the corresponding authorities because, according to many villagers, Pedro Cobian successfully bribed them. The requests for expulsion somehow got "lost" in the bureaucratic chaos of the Ministry of Land Reform and the Public Prosecutor's office.

A more effective strategy was then adopted to expel the "dissidents" from the AAL. It emerged that the existing AAL was never in fact officially registered in Mexico City. So simply by "refounding" it, one could exclude all unwanted elements. Moreover, official registration was necessary since the dissident group was trying to legalize their "solidarity group" as a cooperative society 15, which would be impossible so long as a legalized AAL existed in the village.

During two seasons (1984/85 and 1985/86) two packing plants were functioning in San Antonio which caused continual and intensive tensions in the area. San Antonio itself became heavily divided. Violent confrontations and robbery of documents were reported and it is a miracle that these conflicts did not escalate to bloodshed 16. The conflicts extended to embrace many aspects of social and political life. Other local organizations became arenas for the conflict; and the same factions mobilized people for the ejido and Municipal elections. This was also the case in San Matias, although the division was not so widespread as in San Antonio, where both packing plants were located.

Extended conflict of this kind led to increased state intervention. It is in the interest of state institutions, such as the SARH, to 
promote officially-recognized organizations instead of privatelyoperating groups which they cannot so easily control. For this reason, but also because of personal relations and ideology, the new leaders of the SSS and AAL got a lot of support from a few SARH officials, who eventually became their close friends.

On the legal level, considerable mobilization took place. The SSS/AAL, supported by SARH officials, tried to hit the others in their achilles tendon of export agriculture, namely the supply of irrigation water. In 1984 the sss had served as guarantor for a loan from BANAMEX to electrify the purping stations of four irrigation units around san Antonio and San Matias. In the agreement signed by the water users, BANAMEX, the Ministry of Agriculture and water Resources (SARH) and the Ministry of Land Reform (SRA), the water users bound themselves to deliver all their produce for export to the sss packing plant so that the sss would be able to repay BANAMEX. Article 6 of the agreement stated that if a water user did not fulfil the agreement, water could be refused him. Referring to these agreements (actually drawn up by Pedro Cobian himself!) all the Water Users' Associations were mobilized to refuse water to those who took their produce to the "illegally" operating packing plant. In this way the conflict concerning the organization of the packing plant threatened to spill over and affect the organization of the irrigation units. However, refusing water to Pedro Cobian's group was never actually put into effect. With the help of $h$ is connections ( $h$ is brother being the President of the Municipality and a graduate of law), Pedro Cobian immediately started legal procedures and was able successfully to secure his water supply: the internal electrification agreement was, it seems, partly in defiance of the Federal water Law and legally it was also very difficult to refuse water to persons who rented their land las most of the Pedro cobian group $\mathrm{did}$ ), so long as the landowners were paying the repayments for the electric pumps and had official permission to sow crops.

The failure to stop the "illegally" operating group, even though they had the full support of SARH (up to State level) and a written agreement, had a very negative impact on most of the farmers, who concluded that good contacts and bribery were more effective.

However, the existence of the other packing plant was only one of the problems the new leaders of the SSS/AAL, faced. All kinds of internal problems arose. First, there were conflicts over the competen- 
cy of the two Presidents of the SSS and AAL, which ended in the election of a new AAL president. He turned out to be a very inactive leader, and so once again it was the President of the sss who became the de facto leader of the AAL, assisted by the AAL President of the Vigilance Comnittee and by the two new and active AAL delegates dealing with commercialization. Second, the position of Tomás Arroyo became a problem. Tomás was indeed the motor behind the anti-Pedro campaign, but because of his dubious reputation as a former ejido secretary, many "comrades" did not trust him. Nevertheless,

"He knew the way things stood, and the most important thing was that Pedro should leave. Although there was distrust of Tomás, we were also dependent on him. Tomás knew the way. We used him as an instrument."

But to prevent further escalation within the village (Tomás had been threatened several times by Pedro and his followers) his comrades convinced $\mathrm{him}$ that it would be better not to play a part in the new executive committee. So instead he pushed his good friend and godson, René Villa, as President, hoping in this way to retain some influence. However, later when he asked René to take him on as the new bookkeeper in the SSS office, the distrust surfaced again. The rest of the SSS/AAL leaders were unable to agree, so René had to refuse his request. Tomás felt he had been used and so, when the time was ripe, he headed a campaign against the new leaders of the SSS/AAL, supported by a growing number of disappointed members.

A third problem facing the leaders was the diminishing attendance at meetings. Many members experienced conflicting loyalties and preferred to avoid situations where they were forced to take sides openly and thus exacerbate already tense relationships. Complete families were divided between the two, and later three, factions. Compadrazgo (coparent) relations were also destroyed. More and more meetings had to be postponed because there was no quorum 17 and this again frustrated those willing to attend. The sSs and the AAL had to fulfil strictly all the legal requirements. Every mistake made could be used by Pedro Cobian and Tomás Arroyo as a powerful argument against them. This kind of opposition frustrated organizational development. Assemblies became rarer, which, in turn, led to complaints being made against the official leaders.

Even worse than the internal problems, were the problems the sSS and AAL faced in the execution of their proper functions, such as the 
managing of the packing plant and the commercialization of its products. Barely one week after the elections, in 1984, BANAMEX informed the sss that they would block further credit for sowing unless the outstanding debt of $40,000,000$ pesos (then some 200,000 us dollars!) was paid within one month. Octavio Bautista, the representative of the buying company, also presented an unpaid bill of 35,000 US dollars. The new leaders were certainly not given the same treatment that Pedro Cobian had received when he was President! 18

However, in spite of their distrust in Octavio Bautista, the new executive committee was obliged to continue with the company he represented for they lacked the experience, time, contacts and capital to switch over to another one, in time for the start of the next season. So again a contract was signed with the Grimy and Brat Company.

One year later the Assembly decided finally to break with Octavio Bautista. He continued to support the group of Pedro Cobian and from calculations made by the new AAL delegates on commercialization, the prices they were paid for their products were very low and unfair. Yet breaking with octavio was not easy; outstanding debts had to be negotiated and all kinds of services and contacts would be lost. In an attempt to save an attractive contract, Octavio waived a large part of the debt, without conditions, and promised to waive the rest, providing the SSS/AAL continued to operate with the Grimy and Brat company. He even promised to end $h$ is support of Pedro Cobian. However, the Assembly did not at all trust him, and so they decided to cancel the contract.

In order to find a new buying company, the AAL asked for recommendations at the office of the National Union of Fruit and Vegetables producers (UNPH). This resulted in the signing of a contract with the Moon Valley Food Inc. (Texas, USA). The cherry tomatoes were sold on a consignment basis, with the company receiving a 128 commission on the US-selling price and the AAL taking care of transport and export. This new contract meant, on the one hand, more control by the AAL over the process and costs of commercialization, but on the other hand, more difficult procedures. For the first time the AAL had to take care of all the export arrangements, without the involvement of regional intermediaries, such as Octavio; and only with the increasing help of one or two SARH officials was it possible to arrange everything in time. 
The number of farmers willing to cooperate however was decreasing. Some preferred to work with Pedro Cobian, who offered lower prices but immediate payment, and others did not want to sow at all. The attractiveness of production was considerably reduced by low market prices and because pest control became an increasing problem. Also the bankruptcy of the El Limón plant in the previous year (1984/85) had its impact on the decisions of the farmers around San Antonio who saw many of their colleagues facing unpayable debts.

To make matters worse, a year later, the Moon Valley deal ended in a total fiasco. The company had paid in advance some 23,000 us dollars and within 45 days of the last shipment the rest of the money was to be paid. Yet, when the AAL received the final balance it appeared that instead of receiving money, they in fact owed the company some 3,000 US dollars! The company had sold the products in the USA far below the prevailing market price. According to average market prices, the AAL calculated that the company owed them at least 50,000 us dollars. strongly supported by SARH officials (who felt partly responsible), a long process of reclamation was started. A huge number of letters were sent and trips made to the company in Texas, to the headquarters of UNPH in Sinaloa, and to Mexico City (to the President of the Republic, Farmers' Union, and Ministry of Foreign Affairs). They strongly suspected that they had become the victims of "dirty" practices operating between the buying company and UNPH leaders.

In 1987, reclamation was still continuing. Legal procedures had been started via the Committee for the Protection of Foreign Trade of the National Bank of Foreign Commerce, and via the Ministry of Foreign Affairs. But for the farmers of San Antonio everything was already lost. The consequences of this apparent fraud were catastrophic. The AAI/Sss could not pay the farmers, who lost up to two or three thousand dollars each.

The commercialization of melons was also a fiasco. Here the buyer (a Mexican Company) did pay correctly, but because some farmers who had received credits for sowing did not produce anything for did not bring the products to the SSS packing plant) the AAL was not able to repay the rest of the producers the money they owed them.

This was all grist to the mill of the opposition. The incapacity of the new leaders was proved and the rumour was easily spread that the us company had surely paid, but the members of the executive committee had 
simply lined their own pockets. A general atmosphere of distrust and disorientation was created. The already diminished confidence in export-oriented production, in US companies, in State institutions and in local leadership reached its lowest point. Only a very few members continued attending the rarely-held Assemblies.

The next season $(1986 / 87)$ no new contract was signed, and the packing plant remained closed. Lacking attractive alternatives most of the producers did not know what to plant in the irrigated fields, and more than half of the area within the irrigation units lay fallow. This in turn had negative effects on the organization of irrigation units. Participation at the meetings dininished, repairs were postponed and more and more water users had problems with the half-yearly repayment of bank loans. Also the credit programme for the ejido tractor came into danger because the diminishing amount of work meant that the ejido tractor group did not receive enough income to pay back the bank. This caused all kinds of internal conflicts about who was responsible for this.

Thus five years after the inauguration of the packing plant, export oriented production had collapsed and the farmers had to fall back on maize production and cattle raising. San Antonio was no longer the same as before:

"The people are distrustful of everything, daily they are and always have been, but now with this difference, that before everybody cooperated. With a festival, for example, everyone paid some money and there was trust that the tasks would be fulfilled. You felt good to be on the list of contributors. Not now! Now they say: "Mnumm, they are going to steal half!" Now there is that excuse. Now there is a reason to say: Not me."

In 1987 San Antonio was still heavily divided. Pedro Cobian and his comrades were still trying to register their cooperative (although they had also stopped their packing activities because of low prices and crop disease). René Villa and some of the other leaders of the AAL/SSS wanted to prove their innocence and were trying to defend their organizations. Tomás Arroyo was very disappointed and was generally seen to be the leader of the in-between group. Yet, the majority of the people did not want to belong to anybody or anything at all. They felt deceived and never wanted to affiliate themselves again.

A large and ever-growing debt remains with the bank. BANAMEX and FIRA are trying to recover their money, and, beyond the scope of most villagers, several parties are lying in wait hoping to gain control of 
the packing plant (see next section). This struggle for control must be seen in the light of the planned expansion of the irrigation system in the El Limón area due to come into operation in 1989. The plant is located at the border of this virgin area, in which tomato and melon production will, once more, be attractive, especially during the first years of irrigation.

The future of the existing irrigation units are also at stake. within a few years the pumps will have to be replaced. If the ssS remains paralyzed, a new struggle for control over the units will start, and it is not unthinkable that, by offering the necessary investment, private companies will win (as happened in a nearby irrigation zone).

This background to the situational case study that follows provides us with a general but dynamic picture of ongoing structuring and organizing processes. I use the concept "structuring" to emphasize the ways in which legal and administrative frameworks are activated and redefined; and "organizing" to give a sense of the continual process by which actors construct their own (often informal) sets of social relations in an effort to resolve the problems they face. Hence the transformations described above were not determined by the strategies of a single group or party, but arose from a coalition of objectives and struggles among many parties (see also Berry, 1985:7). In the next section we will elucidate how these structuring and organizing processes work thernselves out in here-and-now situations.

\section{Social encounters and interfaces between farmers and intervening actors: a situational analysis}

The case study presented in this section is made up of a sequence of events of intervention concerning the outstanding debts of the Society of Social solidarity (SSS). It deals with bank people visiting the village and with the SSS Assembly. Attention will also be paid to the actions and reactions of villagers before and after the events. Leading villagers play an important role, since they are the ones who above all interact directly with outsiders and who mobilize local farmers. Yet, some attention is also given to those who are not active in the local 
organizations and who occupy a more distant position towards the intervening parties.

During the period of research several conflicts of varying importance, apart from those relating to the outstanding debts of the packing plant, existed. For example, there were financial problems within the ejido tractor group, problems within the irrigation unit over scarcity of water during a dry period of the rainy season, and conflicts between ejido leaders and some landowning families about the extension of ejido land. These simultaneous conflicts and the significance of the multiplicity of local organizations will be briefly discussed.

since the research was undertaken at local level, intervention and organization are mainly analyzed from the viewpoint of the villagers themselves. One disadvantage of this is that I was not always aware of the coming visits of outside institutional personnel (1ike many of the villagers themselves), and so I was not always prepared to record (or even to be present at) situations of intervention. A further implication is that the opinions and interpretations of the intervening agents are largely missing 19 .

June the $25^{\text {th }}$ : bank people in the village

By far the most important public place in San Antonio is in the shadow of a large tree, just in front of the church where several tree trunks serve as seats. One day in June I passed the tree and noticed a pick-up with some "strange" people around it. After greeting them I crossed the street, where, sitting on the ground, under a smaller tree, I met some farmers who are usually to be found under the large tree. "Who are they?", I asked. "They are from the bank."

A few moments later Pedro Cobian appeared and went straight to the pick-up, without greeting us. Pedro never came to the large tree to sit and talk like many others, so it was strange to see him over there, scon accompanied by his close friend and brother-in-law, nicknamed "the Fox", and another comrade. More people passed by, took notice of the scene under the tree, and walked on or joined us at the other side.

Then a red Volkswagen drove up. The driver greeted us and went on to join the group under the large tree. 
"It is the director of the bank."

"Why is he here?", I asked.

"How do I know. Maybe he wants to sell the packing plant to Pedro Cobian."

"The Government sent them to help us.", said another.

"And, do they help?"

"Yes, they do, like this." (He makes the gesture of stealing)

The group at my side was growing. Silently we observed the happening under "our" tree, now occupied by "the others". The San Antonio division could not be visualized more perfectly.

Suddenly the bank people entered their vehicles and left. Pedro took his place next to the director of the bank. When he passed us, he just smiled at us.

"Where are they going to?"

"How do I know."

June the 26th: the Sss Assembly.

The day after this mysterious visit, an Extraordinary Assembly of the SSS was held. A first effort to bring together the members had been made but since the legal quorum for first meetings is 758 and only $15 \%$ of them showed up, the Assembly had had to be postponed. Announcements for the second meeting, complete with the signatures and stamps of the executive committee of the SSS and the Ministry of Land Reform (SRA), were found nailed to the large tree and on the doors of some of the shops and pubs in San Antonio, and in San Matías and San Vicente. According to the agenda as included in these announcements, the main objective of the Assembly would be to elect a new executive committee (the existing one had already been operating for a year longer than the legally prescribed period) and to present the results of the financial inquiry into the functioning of the retiring executive committee, which had been carried out by employees of the SRA office in Mexico City. Although all this seemed to be very important to me, I did not notice any form of preparation, or vote soliciting, during the days before the Assembly. Many people did not appear even to know of the Assembly, when I asked their opinion about it.

That Friday, the $26^{\text {th }}$ of June, at eleven thirty I went to join the few villagers sitting under the large tree, the usual meeting place prior to Assemblies. Half an hour later a pick-up arrived. In it were 
three men and a woman, representatives and secretary of the Land Reform office (SRA) in Guadalajara. Without their attendance the Assembly would not have been possible, since the SRA has to legalize the Assemblies and the resolutions they make 20 .

When the pick-up stopped next to the ejido house (opposite the large tree), the routine of avoiding direct contact with outsiders took place. The farmers under the tree remained where they were, observing from a distance the people near the pick-up. Even the present SSS leaders, Lupe Vazquez (the sSs Treasurer and President of the ejido) and René Villa waited a while before greeting them 21 . The SRA people and the SSS leaders went into the ejido house (it is more a store for fertilizers) and through to the other side, where, in the inner court (where the ejido tractors and equipment are kept), the meeting would be held. It took at least fifteen minutes before the rest of those present started to enter.

The inner court was as messy as usual. The SRA people went to seat themselves behind the tables, with the big red tractor behind them. The members, entering one by one and taking with them a chair from the ejido house, chose where they would sit. As always, an extended halfopen circle was formed. Most of the members kept a distance from the officials at the head of the table. The SSS/AAL leaders took positions in between except for Rene Villa, the sss President, who was invited by the SRA representatives to take a place behind the table, which he did, although he apparently disliked doing so. Some of the members preferred not to sit down at all and continuously walked around.

Just before the meeting began, the bank people of the day before came in, and went to sit down close to Pedro Cobian, who seemed to be the only "member" of $h$ is faction present at the Assembly.

Then the Assembly started. One of the SRA representatives, licenciado Paz, acting as chairman opened the meeting:

Lic. Paz: "Are all those present members of the sSS?"

Member: "No, there are some two, four who are not."

Lic. Paz: "All right. Is there anyone representing an official institution?"

Bank I: "Yes, I do."

Lic. Paz: "You three, excuse me, where are you from?"

Bank I: "This ingeniero comes on behalf of BANAMEX, and we two on behalf of FIRA."

Lic. Paz: "Good, let's have your opinion. Does the Assembly agree to their being here? (meaning the bank people) I don't know what your objectives are. Are you just participating or interfering?" 
Bank II: "May I, please? It seems that, look, we were in contact with your office in Guadalajara, with ingeniero Ricardo, about today, about this Assembly. We have been waiting for this Assembly for two months, right? We agreed that you would invite us, because we have interests in the SSS. We have certainly got a vote, therefore you ought to have invited us. We only wanted to be here as observers, listeners if you want, but we didn't receive an invitation. We want to participate, that's to say, listen, because we have interests, haven't we?"

Lic. Paz: "Well, so far as I am concerned there is no objection, right. But it is the señores, the Assembly, who decide, the word is theirs."

\section{silence}

Lupe 22: "I say, for my part, that you leave please."

Before others got the opportunity to express their opinion, Pedro Cobian put forward his first objection.

Pedro: "But there is no legal quorum."

Lic. Paz: "This is the second meeting, so it doesn't matter how many members are present."

Pedro: "No, because the Law on Societies of Social Solidarity says very clearly that in the case of Extraordinary Assemblies $60 \%$ of the members have to be present."

Lic. Paz: "Did somebody bring the Law, please, because I forgot mine, but article 19 says very clearly.... The Law doesn't say that in the case of a second meeting you need $60 \%$ of the members to change the executive committee. From that angle we are not going to suspend the work, because we are basing ourselves on the Law, so, do you agree that those who are not members, like the representatives of these institutions, should be here?"

Repeating this question, René Villa for the first time spoke:

René: $\quad$ You have the floor, comrades, are we going on?"

Nobody answered. Then Tomás Arroyo started to object, also referring to legal arguments. He suggested that to conclude anything about the legal requirements for a quorum, it was first necessary to make clear who exactly were recognized as members of the sSs. René, Pedro and Tomás started to discuss this, blaming each other for never registering officially the $20 \mathrm{applicants} \mathrm{Tomás} \mathrm{referred} \mathrm{to.} \mathrm{Since} \mathrm{not} \mathrm{one} \mathrm{of} \mathrm{these}$ applicants was present, Lic. Paz decided to go on:

Lic. Paz: "Well, with the comrades of the other institutions, is there a problem?"

Lupe: "I say that it is better that they leave."

Pedro: "Why do they have to leave?"

Jesús 23: "Because this place is for members only."

Pedro : "Why, it has never been like that."

Bank II : "We are here to $l$ is ten, nothing more."

Lic. Paz: "Good, let's vote, raise your hands those who want them to participate as observers, nothing more." 
silence "It is you who decide, señores."

Only Tomás Arroyo and Pedro Cobian raised their hands.

Bank I: "It seems that there is no majority, so we have to withdraw."

Lic. Paz: "It seems so."

Another bank representative tried to convince Lic. Paz:

Bank II: "The objective of our intervention, our presence is only to listen. We did not bring data about debts or anything like that."

Lic. Paz: "I agree, yet I can't do anything. But we can send you a copy of the results, if you leave me your names."

The bank people deliberated among themselves and with Pedro Cobian. For the last time they tried to convince the chairman:

Bank II: "A declaration please, you are from the authorities as well. We, of the FIRA, do we have to do all our dealings via them, the producers? We are from the same Government!"

Lic. Paz: "That's right."

Bank II : "Jesus! .. Our objective in coming here is not to make trouble, on the contrary, only to listen, we are here to make progress."

Lic. Paz: "Yes, I understand, but we will send you a note. Señores, excuse me, good bye."

The bank people then left. All those present remained silent.

Lic. Paz broke the silence by reading out the memorandum of the first meeting which was postponed and the agenda of the Assembly. But before Lic. Paz could start the actual Assembly, Tomás, again, started to put forward legal objections.

First, he asked about the locality for the meeting, the ejido house. Officially sss Assemblies have to be held at the office of the packing plant, and since no formal paper was signed about the switchover to the ejido house (requested by the members thenselves!), Tomás had a powerful argument later to annul any decision he did not like. Second, he put forward the argument that to fill all the vacancies of the different sss comittees 24 persons were needed, while only 22 members were actually present. This last argument appeared to be very powerful and the SRA agreed that they had to postpone the Assembly for the second time. Most of the members present listened resignedly to these legal interventions by Tomás. Then Tomás started to express $h$ is own ideas about the future of the SSS. He argued for the formation of a committee to prepare for the official dissolution and liquidation of 
the SSS. However, Lic. Paz declared that that point was not on the agenda, so it could not be discussed.

A new date for a third meeting had to be found. Some people declared that sufficient members would never show up. Tomás and Pedro kept accusing the sSS leaders of being responsible for the actual lack of interest and participation of the members. The postponement of the Assembly also meant that the financial inquiry covering the period of the present leadership carried out by the Ministry of Land Reform would not be made public during the meeting. Yet, both Tomás and Pedro could not wait to express their charges against René villa and their doubts about the results of the inquiry. Referring to the man who had carried out the inquiry, Tomás said:

Tomás: "But we have never seen that man in San Antonio beforel"

Lic. Paz: "We took all the documents. We can't stay here to work in the countryside, we haven't the gasoline to do so. That's why you never saw this man before."

Tomás: "So that means that everything is already arranged, the inquiry and the change of the committees."

Lic. Paz: "Do you think it is like that, señor?"

Tomás: "No, because it shouldn't be like that."

Lic. Paz: "I am asking if you believe that things are like that?"

Tomás: "No"

Lic. Paz: "Good, so please I beg you to..."

Tomás: "We indeed are in a process of reclamation against the Ministry of Land Reform (SRA)."

Lic. Paz: "Very good, you are free to do so..."

Tomás: "For one year and two months the executive committee has not functioned because of the pure inactivity of the SRA.."

Lic. Paz: "That's your right.."

Tomás: "Yes, we have got the documentation."

Lic. Paz: "Very good, take your right and go as far as the Law will take you, that's your right. I do not say yes or no. You have your opinion, so go ahead. But we are here for one objective and that which you are talking about, we are not going to discuss here, right? Good! Well, what are we going to do? We can't fill the committee places."

Pedro then started to accuse the leaders of using the sSs pick-up for personal purposes and defrauding them over the sSS fire insurance. "All those cases will never be mentioned in the official documents", he argued, "so the financial inquiry surely will miss the point." A few members started emotionally to attack the "hypocritical" Pedro Cobian. However, the majority kept silent (including leaders such as René villa). Some of them stood up and walked around the inner court. René made clear to some friends that it made no sense to go on discussing things since the Assembly was postponed. Lic. Paz interrupted these 
quarrels, urging the members to suggest a new date. Finally they decided to hold the next Assembly on Sunday the $9^{\text {th }}$ of August.

During these deliberations the Ministry secretary had started to type the formal minutes, which had to be signed by those present, noting the lack of sufficient participants to fill the committee places. As usual, Pedro did not wait to sign, and contrary to most other members he went directly to his house. The meeting ended in a disorderly fashion (as usual). People split up into small groups, and, after signing the minutes, they left as they had arrived, one by one. The leaders were the last to leave, along with the Ministry of Land Reform people. The licenciado who had carried out the inquiry said to me, in English: "Those people just like to fight, don't you think so?"

\section{Evaluation of the Assembly}

My first conclusion after this meeting was that these kinds of events do not clarify anything. On the contrary, for me, things seemed at first even more incomprehensible, since I could not understand why people acted the way they did. It seemed clear that attitudes and strategies could not be understood by simply recording events like this one. Nevertheless, on reflection, some aspects do become clear.

First, the meeting tells us something about the nature of the organization itself. Because of the obligatory presence of representatives from the Ministry of Land Reform, and the detailed legal rules which regulate the course of the meetings, the sss does not appear to be a farmers' organization where members discuss freely their own problems, on their own terms. The meetings seem to function as a "neutral space" (as one of the local leaders explained to me) where farmers and officials meet but where, in fact, only a few of the former are able to communicate effectively with the latter. Some of the lesser experienced members talked and even shouted, for example accusing Pedro of being a hypocrite, but they lacked the skills and knowledge to express their criticism in a more acceptable way and thus they were not able to influence the course of the meeting.

Second, those who do know how to interact with officials (like Tomás Arroyo and Pedro Cobian by appealing to legal arguments), do this in a very strategic way. For them, legal frameworks (the abundance of 
rules, laws and regulations) are not only obstacles, as they are for many others, they are also instruments which they can apply to realize their own objectives.

Third, this was not the first Assembly which had to be postponed because of the lack of quorum; and this raises questions about whether the SSS can be considered an organization at all. Formally, the sss is indeed an organization made up of 76 members. However, sociologically you can hardly talk about organization. People do not interact collectively as a group (during official meetings), nor do they interact informally outside official meetings with reference to each other as members of the same organization. This stands in sharp contrast to the Assemblies held during the first years, when it appears that between 60 and 908 of the members regularly attended the meetings and when the themes that were discussed directly influenced the daily situation of the farmers involved (e.g. the growing of tomatoes and melon). Nowadays, the SSS and its Assemblies seem more like an arena for political factions and leaders to fight out their quarrels, instead of an organization concerned with the production and packing of fruit and vegetables.

Fourth, the Assembly highlights something of the heterogeneous nature of the state apparatus intervening in local processes. Farmers can see for themselves the lack of coordination between different government institutions. Here it is interesting to keep in mind that this was exacerbated by the change over of SRA to the Guadalajara office. As a result, the close informal ties between the bank people and the land reform officials working at the regional office in the nearby town of Autlán are now largely of no use.

\section{Reactions in the street}

One advantage to the researcher of interventions of this kind is that afterwards it becomes far easier than before to discuss topics raised by the intervention. After the meetings one can record reactions that provide additional insight into the attitudes of participating actors. Let us then briefly explore some of the reactions of key actors at the village level. 
Cesar Olivera, a small landowner and the AAL President, who was elected in 1984 and expelled in 1985 due to the problems concerning competence between $h i m$ and the sSS President Rene Villa, was present at the Assembly, but he did not say a word. Directly after the meeting we drank a beer together and he showed me a small piece of paper with some questions on it which he had planned to pose. They were all about the misuse of SSS/AAL money and properties. He explained that it did not make any sense to pose his questions, because the Assembly had never been opened officially. It would only have favoured the leaders, who could then have prepared their answers for the next Assembly. Two months later cesar did indeed put forward some of these questions during an official (legalized) AAL Assembly. His example demonstrates that the silence of participants does not always imply that they have nothing to say. Strategically it may be better to keep silent.

\section{Pedro Cobian}

Pedro first of all explained to me that the Ministry people did not know their own laws. He emphasized that for Extraordinary Assemblies really 608 of the members have to be present. Asked why he was the only "member" of his group present at the Assembly, he answered that he had not wanted the elections to be held before the leaders now in office had made their statements about the charges of embezzlement and fraud. $\mathrm{He}$ therefore convinced $\mathrm{h}$ is comrades not to participate, thus making sure that they would never get a legal quorum. He stressed that he could easily mobilize 20 members and maybe even win the elections, but he did not want to take over responsibility for the outstanding debts.

Lupe Vazquez, René Villa and Jesús Cárdenas 24

The above leaders, whom I met during an interview with Lupe, said, first of all, that the only thing they wanted was to organize the elections and then leave. Lupe explained that Tonás wanted to liquidize because he owns 50 shares of the plot where the packing plant is built 
25, and that, if the plant were sold, he would receive some money. On the other hand, Pedro does not hold any shares. He can only enrich himself by being the leader of the packing plant and by obtaining lucrative commissions from the companies, as he did before. Since he will never be able to win the elections he tries to paralyze all the SSS activities so that the bank will finally seize the plant and, with the help of Oscar Bautista of the Grimy and Brat Company and the bank itself, he will then be able to take it over.

Concerning the expulsion of the representatives of the bank, Lupe said:

"Look, the bank is like your father, you owe to the bank. Well, when the bank is present, many people don't talk openly, they don't say anything. We want to talk about the debts, if we are going to pay or not, and when. If they are there, many things will not be said. That way you lose things. It has already happened many times. Besides, they were here the day before. They could have asked permission to participate then, but they were only interested in talking with Pedro Cobianl"

They were all very content with Lic. Paz, the SRA representative, because he favoured nobody and just followed the rules, an enormous contrast to the SRA officials from Autlán who came to legalize the meetings before, they said.

These snap-shots give us some insight into the attitudes and opinions of key actors on the ongoing processes. It was hoped that on the $9^{\text {th }}$ of August the issues would be discussed in public again, during an official meeting of the sss.

\section{6th of July: the return of the bank people I}

Three weeks after the SSS Assembly, the impasse over the packing plant and its financial and political problems seemed far from peoples' thoughts. They were busy sowing and cultivating their maize, and other problems (delays in the supply of credit for maize production and the conflicts of the ejido tractor group) dominated discussions in the streets.

I myself spent the days interviewing people about the history of the packing plant and the irrigation units 26 . On the afternoon of Tuesday the $16^{\text {th }}$ of July I was in the pub of Pedro Cobian's brother-inlaw ("the Fox"), trying to obtain information about the "illegal" 
packing plant. As usual I could not approach the subject systematically as Pedro was there drinking and joking with some of his comrades. Suddenly the pick-up of FIRA passed and went on towards the centre of the village. Pedro jumped up, went directly to his house across the street and left a few moments later, now washed and "properly" dressed. He went straight to the large tree where the bank people had stopped. I waited a while before following in the same direction.

Under the large tree I saw René Villa (also "properly" dressed), some other farmers and some strangers, among them a tall, older man, apparently the boss, and three young ingenieros, all employees of FIRA. We talked about all sorts of things 27 until the tall man (Lic. Alto) concluded that apparently no other persons would come, so he started to put his points:

"The packing plant has been out of use now for more than a year, we have to solve that problem..."

However he did not get the opportunity to finish his discourse properly, since Pedro and René immediately started to accuse each other of being responsible for its collapse. Lic. Alto tried to continue:

"...everybody has intervened, Land Reform, SARH, the Governor of the State, but nothing has changed. You are the only ones who can solve the problem, not those in Guadalajara or in México City, but here, right under this tree! And we want to help you. We have thought out some alternatives and it is up to you to choose. We think it is not necessary to work united; the organization is too big, so we thought it would be better to split it up into groups of about ten persons each, composed of people who trust each other. They will get credit facilities directly from the bank, thus not via the Society. To supervise the packing plant each group can appoint a representative to the executive committee, or you can contract an external manager, if you prefer that. There will be more internal control and thus more mutual trust this way. ... If you do not want to opt for one of the alternatives, then we will have to seize the packing plant. But that will be very detrimental for you and for us. You will probably go to the Ministry of Land Reform, to the CNC 28, and your and our lawyers will struggle for five, maybe eight, years. And when finally the plant is sold, the returns will never be enough to repay the everexpanding debts, so we probably will have to seize the irrigation pumps and your private pick-ups and cows as well."

Lic. Alto was frequently interrupted by Pedro Cobian, "the Fox" and René, who continued to accuse each other of being responsible for all this. The bank representative tried to calm down the fighting cocks:

"Señores please, we are here to help you, we are all from the same nation!"

Since his threats did not impress those present at all, he continued: 
"And if you do not want to arrange anything, that is alright by us. We have already written instructions to all other banks saying that the ejido of San Antonio should not receive any further credit facilities. Tomorrow we will post them 29. Please, rethink the case. Don't you remember, it was so beautiful, everybody was working, there was a lot of money, festivals..."

Saying this he put the spark to the tinder once again. Pedro responded:

"Yes, everything was alright, until the change of the presidency, bad administration entered, therefore everything failed."

Rene Villa started to defend himself, referring to the fraud by the us company and, again, old wounds were opened. Being the only member of the Executive Committee of the SSS at hand, René received open support only from Roberto Ríos, the AAL delegate responsible for commercialization. Pedro was supported by some of his closest friends, who really started to provoke René and Roberto. At a distance a growing crowd of villagers observed what was going on. Little by little Roberto took over René's role in the discussion, René himself keeping silent. Above all it was Pedro who dominated the occasion.

Then two other cars arrived. I recognized the official from BANAMEX (Ing. Lopéz, "Bank man I" at the SSS Assembly) and another who was apparently his boss, a little fat man (Lic. Gordo). Lic. Alto and the other ingenieros greeted them and said they were one hour late. In the meanwhile the quarreling between the two opposing camps went on, and, after observing it for a while, Lic. Gordo attempted to intervene:

"Señores, it seems that liquidation will be the only solution. However, we have elaborated an alternative to continue with the packing plant, working in small groups. But if you do not want to, that is alright. Then you should liquidate the enterprise. The outstanding debt is about 50 million pesos. The plant could be sold for 150 million pesos 30 , so you will still earn some money."

The FIRA director (Lic. Alto) protested, stating that they were legally not allowed to keep any eventual profit. Lic. Gordo replied that they could always arrange something, whatever the law says.

The BANAMEX representative put forward the same alternative as $\mathrm{h}$ is colleague from FIRA had done. But again Pedro cobian protested, saying he did not want to cooperate in paying back debts that he was not in fact responsible for. "Besides", he said, "the legal quorum will never be realized to formalize these or any other kinds of decision". The other BANAMEX representative, Ing. Lopéz, suggested that at the next SSS Assembly, on the $9^{\text {th }}$ of August, everything had to be arranged, and 
he emphasized they had already forgiven them for the way they were treated during the last Assembly. His boss, Lic. Gordo, however, stressed that he did not want to wait another three weeks. He suggested holding a meeting the next week, without the presence of the Land Reform office ("they are of no use"), nor the presence of any other authority, and that the meeting should be right there, where they were standing, under the same tree. He emphasized that it made no sense to discuss the past:

"it is the future that counts, think about your children! what are you going to tell them, we had a packing plant, but we lost it?"

He continued talking in a very deliberated and conciliatory manner. For the first time the villagers kept quiet for a while. René said it was alright with him, next week, same place, same time. This of course pleased Lic. Gordo, who now asked:

"And you Pedro?"

"I'11 not be there, let them solve their own problems."

And again the whole discussion returned to who is, and was, responsible for what. Dispiritedly Lic. Gordo concluded that apparently liquidation was the only solution.

"But you have to liquidate yourself, because if we start such a procedure it will cost us eight, maybe ten, years, and in the end you will lose everything you have. You can also sell the packing plant and then the bank can provide the credit for those of you who want to go on with it. It is all up to you."

In the anonymity of the falling darkness more people started to intervene in the discussions. An enormous crowd was observing and commenting on what was going on. The three junior representatives of the FIRA were clearly bored with it. Several times Lic. Gordo tried to fix a date: "next week, under this tree, all right?" Roberto Rios agreed: "We will discuss the alternatives and next week we will be here to let you know our decision." More people approved. Visibly satisfied, the bank people made ready to leave. Aga in it was Pedro who objected:

"I'11 not be there."

"Pedro please, don't start again. We need people with solutions, not people with problems!"

Once more Lic. Gordo and Ing. Lopéz started to talk Pedro into participating. Pedro kept silent, without really promising anything, but anyway this was taken as an affirmation.

It was 8 o'clock in the evening. The representatives of the two financial institutions left the scene: "Next week, same time, same place", and off they went to their cars. Pedro and his friends directly 
went to their pub. Rene followed the bank people to ask something and then left for the pub where $h$ is friends usually meet, leaving the researcher in a dilemma as to which pub he should go.

\section{The next week: evaluation, complexity and devising of strategies}

Recording these kinds of interventions is difficult, especially when they arise so unexpectedly. But recording the private discussions and the way strategies are devised afterwards, is near impossible: Where to go? When to go? Yet for the researcher interested in situational analysis and strategies vis-á-vis external intervention these events are a godsend. The bank people had suggested some alternatives and had made some severe threats. During the course of the coming days I would have the opportunity to gain insight into how different villagers would deal with this, what they would decide to do and finally to examine the relationship or discrepancy between words and action.

In describing the events of the week that ocurred between the two bank visits, I highlight three different aspects of intervention and local organization:

- the complexity and multiplicity of local organization and intervention;

- the differences in knowledge and interpretation of these interventions by the parties and individuals involved; and

- the devising of decisions and strategies during that week by the key actors.

\section{Complexity and multiplicity}

The following day, having in mind the need to talk with villagers about the events of the night before, I became acutely aware of the complexity and multiplicity of interventions and organizations with which the people of San Antonio are continually confronted. The morning after the bank visit two other state representatives, Ing. Mares (local extensionist of the Ministry of Agriculture and Water Resources (SARH)) and Ing. Tocayo (local representative of BANRURAL), independently of each other, came to San Antonio to settle some things concerning the 
irrigation unit and the tractor credit group of the ejido. Two days later Ing. Mares returned again to San Antonio for an Assembly of the AAL. Later that same week other SARH officials (from the EL Grullo office) were in the village at the request of the municipal delegate to investigate the possibility of repairing the very bumpy road from the village to the highway. All these interventions dealt with other matters and concerned somewhat different groups of people, different local organizations (ejido, irrigation unit, AAL, village) and different outside institutions. Villagers, then, must acquire the ability to deal with these multiple interests and interventions which they experience almost daily.

One way of dealing with them is through avoidance, as Ing. Tocayo (BANRURAL) discovered. The financial problems concerning the ejido tractors crosscut the factions involved in the packing plant and so when Ing. Tocayo visited San Antonio he was confronted with more problems than he anticipated. The President of the tractor group told $\mathrm{him}$ that the people did not want to receive $\mathrm{him}$ in a group and so in the end he had to visit the members, one by one, to collect the data (and money!) he needed from them. It was impossible, the day after the confrontation, to discuss collectively a problem concerning multiple interests and factions 31. Not having the slightest idea about what had happened the night before, Ing. Tocayo could not understand why the farmers failed to respond to his "simple" request.

At the AAL Assembly planned for that week, which in fact was postponed because only 38 of the membership showed up, the future of export-oriented agriculture was again to be discussed. During the conversation that took place at that time between two AAL leaders and Ing. Mares (SARH) the lack of coordination and the opposing interests of state institutions became clear. Ing. Mares knew nothing about the intervention of the bank or their proposals. He argued that the two organizations (SSS and AAL) were "completely" different. Though formally correct, San Antonio people see them as one organization and so they became quite confused when hearing state agents talking about the same issue but expressing completely different proposals. René Villa commented on this:

"Even they aren't united, the institutions like the bank, SARH, and Land Reform, and they have a lot more education. And yet they tell us that we have to work together. What about that!" 
Another aspect of the complexity of local organizations became clear during the speech of the FIRA director (Lic. Alto), who threatened to seize the irrigation pumps (in fact an irrigation unit matter, not that of the AAL or SSS), and to prevent the further supply of credit to the ejido (an ejido matter). If this were to occur, then, water users and ejidatarios not belonging to the sSS would also be affected and, furthermore, BANAMEX and FIRA would be directly interfering in the politics and fields of activity of the SARH, the Land Reform office and BANRURAL.

These threats were discussed in the village afterwards, and also with Ing. Mares (SARH) and Ing. Tocayo (BANRURAL), who are better known to the villagers because they regularly visit San Antonio. From this it emerged that in the case of such complex legal situations it makes no sense to investigate precisely the legal basis for such measures. In the jungle of rules and laws of the Mexican rural sector, there will surely be found supporting evidence for both parties. These formal aspects seem to be a matter of negotiation and strategy. Unlike some less experienced villagers, the SSS/AAL leaders were not impressed at all by such threats. Since they know how and who to mobilize, they were sure they could prevent any such sweeping measures. "They are just bluffing", was the comment of one of them.

\section{The "ordinary" Sss members}

During the visit of the bank people, it was once again the leaders and ex-leaders who participated in the discussions. Later that week I tried to get some insight into the perceptions and opinions of the "ordinary" SSS members. As stated before, for most of them the SSS was already a dead dog. And if it had a future, they did not feel that they had any grip on it. Inmediately after the departure of the bank officials one member was heard to say to a friend:

"The packing plant is of everybody, and thus it is of nobody. ... It is of us all, they say, but I can't do anything with that plant, can you?"

The next day I stayed a long time near the large tree, just listening and participating in the discussions about the events of the night before. It was striking that the future of the packing plant was hardly brought up. Those present merely evaluated and commented upon the argu- 
ments and words that Pedro Cobian and René Villa had used to attack each other; and past situations of conflict were revived in detail. About the future itself most of them were very pessimistic, one saying to me:

"Write down: it is a bitter history, a lost future."

Some older men recalled a similar problem of unpayable debts. In the fifties when San Antonio received electricity, the villagers were likewise unable to pay back the bank loan for the costs of the installations. That problem was finally solved when a new President of the Republic came to power and, as a gesture, cancelled all outstanding debts in the rural areas. In 1988, a new President would aga in be chosen and so they predicted that the present problem would be solved just as easily; and so they would not lose their packing plant or their private properties.

From the many conversations I had during that same week, it appeared that, for many villagers, the issue of the packing plant, the outstanding debts, the legal aspects of liquidation, the reclamation procedures and the links with other local organizations and intervening institutions were far too complicated. After listening for half an hour to a discussion about these topics between Ing. Mares (SARH) and some AAL leaders, Joel, an inactive member, said:

"I don't understand. Before I was a member of Pedro Cobian, you know, of the packing plant. Now you are talking about Association and Society, I don't know what I am, Association or Society, I don't understand."

Jesús Cárdenas then explained the differences, referring to the related institutions and reclamation procedures. But the complexity staggered Joel even more:

"And is there no institution that can control everything, explain everything and pay everything, like a guide?"

On another day that week, Roberto Rios was found under the large tree talking to another inactive nember of the Sss. The man was one of the more optimistic farmers who thought that the boom period would return:

"We've got land, we've got water, we've got a packing plant: we have to work, take profit from it."

He went on to state that with a nucleus of some twenty or thirty farmers who were willing "to work", it would be easy to start again. He was ready to do so and suggested selling the packing machine for cherry tomatoes to pay back the bank and to continue with the production of 
melons 32. Roberto explained that to take any decision about expulsion of members you need $60 \%$ of them present at an Assembly, and if you try to arrange it otherwise, Pedro Cobian would immediately go to the judge. The other man did not agree:

"But we are the ones who work. There are many who don't sow, don't work, they never come to the Assemblies. They're not members!"

Roberto reproached him:

"For the government only bloody lists count. For them we are all equal, we are all members, we all signed."

This anecdote perfectly reflects the growing discrepancy between the formal organization as recognized by the authorities and the experienced organization or "group", which is recognized by the people involved (and which differs over time and between individuals). A prerequisite to successful comnunication with intervening parties is knowing and using appropriate legal concepts and formal procedures when talking about organizational issues. It is above all leaders, such as Roberto Rios, who can articulate this type of discourse and can handle the differences in meaning that may arise in dealing with local people and intervening parties.

\section{Devising answers and strategies}

By and large it was the leading figures who had to devise appropriate answers and strategies before the bank people would return. During the week in between I tried to get some insight into their opinions and internal deliberations, although of course it was impossible to oversee all that was going on within the different factions. Here I present fragments of the interviews I had with some of them.

Jesús Cobian 33

When Roberto was talking with the other villager (see above), Jesús Cobian came along and started discussing the coming bank visit. He said he was not present during the last visit of the bank people because he had to visit a relative in another village. Later, somebody told me this was not true. Jesús just did not want to be confronted 
openly by $h$ is brother or "the Fox", and so probably left the village as soon as he noticed the presence of the bank people. Regarding the coming bank visit, Jesís told Roberto that there was no official announcement. It would be an informal discussion among the leaders and other interested people, therefore he did not want to push the members into attending, as Roberto suggested. "What for?" he said, "we cannot take any binding decisions at all1"

Lupe vázquez

Lupe Vázquez, the President of the ejido and Treasurer of the sss, had also not been present at the meeting with the bank people. When sowing and cultivating maize he always lives near his plot, beyond san Vicente, where he has a cottage. When I went to visit him he had just returned from his temporary home and apparently did not know anything about the intervention of the bank. I explained what had happened, and when I had finished, the first thing he asked was if there was an official announcement signed by the Land Reform office for the coming visit of the bank. I said no. He said: "Then I'll not be there, because they cannot take official decisions. It will just be a quarrel. That does not make sense." When he heard about the threats to refuse further credit to the ejido he just laughed. "The ejido and the society are different organizations, only a few villagers belong to both".

\section{Jesús Cárdenas}

During the first bank visit Jesús returned late from his fields, so he only participated in the very last minutes of the discussion. Yet, he had clear opinions about the problem:

"The others (referring to Pedro Cobian) and the bank people are just one group", he said. "The proposal to split up the society into smaller, independently operating groups is their strategy to get the packing plant into the hands of Pedro cobian and Octavio Bautista. The bank will require individual guarantees from the members of each group, and, because of external financial support, Pedro Cobian will be the only one who can take that risk".

He explained that until now the society had protected individual members against the bank, since it functioned as a collective guarantor. By splitting up, the sss would lose this function. Jesús was 
not afraid about an eventual seizure by the bank: "It is hard for the bank, they must have very strong arguments and besides there are many authorities involved: Land Reform, SARH, Regional Agrarian Union, CNC. It is a huge problem for the bank."

René Villa

René Villa carne to visit Jesús while we were having the above conversation. Thus I was able to witness Jesús' effort to convince René not to go to the meeting with the bank people.

Jesús: "The Assembly for next Thursday doesn't have a legal character." René: "I'1l go, but I'll not take responsibility for anything. I won't sign anything."

Jesús: "W'll all go, or nobody goes. Don't go alone; they will judge you. Those meetings are not sane. ... The bank is in favour of Pedro Cobian. If we have to work in groups of ten persons, we will have to give a guarantee. And from "them' they will not ask for a guarantee. What they want is to dethrone us, that's their strategy, to ensure that Pedro Cobian and Octavio Bautis ta will be left with everything.

René: "I am not going to participate in such a deal. What day is it today? Wednesday already. Tomorrow those bloody people will come aga in."

Jesús: "I am not going, nor Gabriel 34."

René: "There are responsible people in the bank. We can't refuse them."

Jesús: "But the bank cannot ensure that "the others' are absent. You are the one responsible. You, as a revolutionary (1), you must not go to talk with that other party. They are two in one, the bank and them."

René: "I can't go alone, because they will say: "Where are your people? You have no support", just like last time."

Jesús: "But that is their trick. They know that people don't support us. On the other hand, at the Assembly nobody was in favour of the bank either. The people are not in favour of us, nor of them. Why don't you tell them that your people don't want you to talk with them? ... What made us fail was that bloody company that didn't pay us."

René: "It is the same politics."

Jesús: "Why do they want "them" there as well? It is not in our interests to have them present. They have another reason. We must talk alone with the bank, not together with them."

Then they started discussing the threats of the bank and again agreed that they were bluffing. Then when Jesús and I went into the legal details of these possible measures, René kept silent, and soon left, still puzzling about what to do.

The next morning, the day of the bank visit, I saw Jesús Cárdenas and Lupe Vázquez going to visit René at his house. I could only con- 
clude, as others did, that they were trying to convince Rene not to go to the meeting.

\section{Peàro Cobian}

That same day I went to Pedro Cobian to hear his opinion about it all. He started by stating that the leaders are not at all capable and run away from their responsibilities. They did not know (or did not want to know) what was hanging over their heads. He said that the bank could indeed seize the irrigation pumps, and that during the legal procedures to realize this they could forbid the use of the packing plant and the pumps. He also affirmed that the Presidents of the ejidos of San Antonio, San Matias and San Vicente had all signed a kind of declaration of guarantee when the SSS was founded, so the sss indeed is formally linked to the three ejidos. "And", he said, "I know this because I started everything here!" Pedro repeated his opinion about the coming bank visit:

"Let them solve their own problems. We will end up with the packing plant anyway. How much did he say the SSS owed him, 50 millions? Well, I have stolen 20 millions as you know, plus the interest over three years, that will make fifty! We can pay it all, ha ha ha..."

\section{3th of July: the return of the bank people II}

I was still with Pedro Cobian when finally, one hour late, the pick-up of the BANAMEX representatives arrived in the village. Pedro immediately went into $h$ is house and did not reappear. I went to the large tree where I met Lic. Gordo and Ing. Lopéz of BANAMEX. The only representative of FIRA (one of the younger ingenieros) had 'ready been waiting there for one hour. In addition to the officials, only Roberto Rios and $\mathrm{his}$ father were present 35. Even the older men who are usually to be found under the tree had abandoned their favourite place.

Ing. Lopéz said he had already visited René's house, but that he was not there. He also had come across Jesús Cárdenas, who had told him he did not want to come. According to Roberto, nobody wanted to be present that afternoon, because of the unofficial status of the meeting. "Besides", he said, "half of the villagers will never come when 
Pedro Cobian is present, and the other half do not want to hear René Villa, so, what can one do?"

Without showing any sign of anger or disappointment, the three bank people immediately left, saying they would be back on the 9 th of August, the next SsS Assembly, as Jesús had suggested.

Later that night I went to René and asked why he had not been there. He said:

"Well, my maize looks very nice, I didn't want to spoil it, therefore I had to cultivate all day. It is a lot of work. I did not return until eight $o^{\prime}$ clock to my house. That is more important, isn't it?"

For the following two days, pro forma, he also stayed in his plot until seven or eight o'clock in the evening.

\section{Epilogue}

Unfortunately a detailed follow-up of the interventions discussed earlier cannot be presented and analyzed in detail. The week before the $9^{\text {th }}$ of August, the day of the next sss Assembly, no announcements for the meeting were posted in the usual places and that sunday nothing happened at all. The sss leaders sheltered behind the authorities (the Land Reform office (SRA) of Guadalajara) who had not sent an official announcement of the Assembly. Apparently the leaders themselves were not interested in having an Assembly either, since they did not go to the SRA office to extract the announcement, although Jesús Cárdenas had been to Guadalajara to settle some things about the extension of the ejido. The other sss members seemed to have forgotten all about the planned Assembly.

At the end of August, it became clear that the bank had arranged "something" with the SRA office in Guadalajara and around the 9 th of September René Villa and the other sss leaders were invited to Guadalajara to discuss the impasse with the bank and the SRA. The SSS leaders did not tell anybody in the village about this. During that period there was a general air of distrust and conflict. Because of an application for an extension of ejido land, the tensions between the ejido leaders and some of the local landowning farmers were at a climax: Jesús Cárdenas (the most prominent advocate of the extension) left his house only when adequately armed. The normally quite open 
discussions between friends of René Villa now took place more in secret, and not in their favorite pub. Neither I, nor many other villagers, could comprehend exactly what was going on.

Later they told me they did not want go to Guadalajara because they were afraid to be overruled by the officials there, and that they expected they would be pressed to sign unattractive agreements. They decided that they only wished to negotiate with the bank in San Antonio, during a public meeting and in the presence of representatives of all the other institutions involved, such as the SARH and the Regional Agrarian Union. These last two institutions, linked more to the AAL than the SSS, are more on the side of the SSS/AAL leaders, because Pedro and $h$ is supporters are not members of the AAL and because the existence of the "cooperative" of Pedro Cobian undermines their legal point of intervention. Although the bank again had threatened the leaders that if they did not come, they would seize the plant, the leaders were convinced that nothing could be arranged without their presence. Therefore they felt safe to reject the invitation.

In October 1987, when I left San Antonio, nothing had been arranged about the outstanding debts. The negotiations were surely going on, yet they were unobserved by most of the villagers, as well as by the researcher!

\section{Intervention, interaction and local organizations: conclusions}

This paper has described a sequence of events involving intervention by banks and other institutions, such as the Ministries of Land Reform and Agriculture and water Resources. I would have liked to present other situations and forms of institutional intervention taking place during the same period, involving some of the same people. Comparable data were collected but we lack the space to examine these.

My concluding remarks are organized around the following topics:

- The nature of situations of intervention and interaction. What does intervention look 1 ike? How is it to be effected?

- The nature of local organizations: How must they be conceptualized in relation to outside interventions and peasant strategies? 
- The multiplicity of organizations, intervening parties and social conflicts: How do informal organizing processes become manifest in situations of intervention?

The character of intervention: interaction at the intermediate level.

One of the objectives of this chapter has been to provide insight into what exactly intervention is about, how it is actually structured in here-and-now situations. Different settings emerged for discussion: a formal, legalized Assembly, less formal public visits by the bank officials to the village, and contacts with institutions which occurred outside the scope of most of the villagers. During this sequence of interventions regarding the future of the packing plant, the more informal and frequent visits of agents, such as Ing. Mares (SARH) and Ing. Tocayo (BANRURAL), also came into the picture. Let us now derive some general conclusions from this account.

In all cases it is primarily the leaders who play the important role of "intermediaries". They are the ones who dominate the conversations and negotiations with the outsiders and who before and after the meetings pull together with them (although they sometimes try to minimize this). A greater cultural and cognitive distance exists between the intervening parties and the other villagers, which is also reflected physically during meetings.

The leaders are able to handle the discourse of negotiations at Assemblies by appealing to the images and rules of the outsiders. Most striking is their ability to exploit organizational and legal frameworks. On the one hand, legal frameworks and relations with outside institutions (via credit for example) may be both obstacles for peasants and provide the means by which institutions can intervene, but on the other hand, they can also be used as instruments to impede or at least delay unwanted interventions. Thus they are both obstacles to, and instruments of, strategic acting.

The word "intervention" suggests something determining and penetrating and to a certain degree it is. However, the setting, the discourse, the outcome of the intervention, and sometimes even the composition of the intervening parties are co-determined by the villagers, particularly by their leaders. The latter are able to prevent 
the de facto intervention through boycotting (the second bank visit) or by appealing to legal regulations and formal rules (expelling the bank people from the sSS Assembly). Thus we see how the outcomes of interventions are a "product" of ongoing interactive processes. Notwithstanding legal structures, rules and regulations, the de facto processes of intervention are socially constructed.

In the situation described, different outside institutions intervene at local level. The lack of coordination between these institutions and their sometimes contradictionory interests is striking. Hence peasants are certainly not confronted with a huge, over-powering and well-coordinated apparatus, and peasant leaders, familiar with the differences and mutual competition, are able to manipulate this strategically. For example, they may refuse to come to a meeting if certain institutions are not represented as well (such as the SRA during the bank visits, or the SARH and Regional Agrarian Union when they were invited to Guadalajara). These findings throw new light on Benvenuti's TATE model which posits how farming enterprise is gradually taken over by external institutions (Benvenuti, 1975). In San Antonio, indeed, farm enterprises become increasingly integrated into a wider technological and administrative environment. The introduction of irrigation, the production of tomatoes and melons and the development of credit programmes did lead to an increasing externalization of agricultural production; and the foundation of several farmers' organizations resulted in increased "vertical integration". Yet, contrary to what Benvenutti suggests, we cannot conclude that outside institutions and development agencies involved in "constructing" the farmers' institutional and technological environment present a frontal attack on the autonomy of the farm enterprise and local organization (Long, 1987:16). In San Antonio the "technological and administrative task environment" is far from a coherent and well-coordinated system. Because of this farmers are able to make strategic use of inter-agency conflicts, competency and lack of coordination.

The nature of local organizations

Another central question of this chapter concerns the nature of local organizations. How can we best conceptualize them and analyze them in 
relation to both outside intervention and farmers' strategies? A relevant point of the chapter is of course whether situational case studies provide new or different perspectives on local organization?

In evaluating the SSS Assembly, some tentative answers to these questions have already been formulated. Formally the sss is a local (even sub-regional) organization for the production and packing of vegetables and fruits, recognized and thus treated as such by the authorities. However, looking at the degree of participation in internal discussions (when there are any) and the de facto actions of the Sss, then the society is certainly not being used for the purpose for which it was set up. It appears as an organizational shell surviving from the past, which is used nowadays by two, or three small factions of politically-oriented villagers who compete for control and power in the village. Most of the members do not wish to be involved in these and therefore avoid all the sss meetings, observing them only from a distance.

The same kind of picture emerges of the AAI. Its only activity in the sumner of 1987 was an Assembly, held at the instigation of SARH officials. The AAL President was obliged to present an annual report during this Assembly, otherwise the AAL would automatically lose its legal registration and be dissolved. The attendance was extremely low (14\%) and those present were more interested in the confrontation between the two factions 36 than in the annual report. At the end when the SARH official present started discussing the future of the AAL, only five members were 1 istening. It has principally been the SARH that has tried to save the AAL, which is a farmers' organization. For the members themselves the AAL seems of lesser importance than the sSS (which is, after all, the owner of something concrete, the packing plant). For the "ordinary" members both organizations belong to the past. It is the intervening parties who have an interest in their continuation. One of the reasons for this is that local organizations provide important "points of entrance" for institutions needing to carry out development programmes, and who consequently aim to strengthen their position at the local level as well as within the bureaucratic system itself.

The data and general approach presented in this chapter highlight, then, some essential shortcomings of so-called participatory approaches to rural development planning. In projects based on such approaches 
outsiders set-up or use existing local organizations to realize their objectives more efficiently (Esman and Uphoff, 1984:26). Yet, these participative structures inevitably become part of the strategic mechanisms used by individuals and groups pursuing their own collective and personal goals. Thus they will try to use these new "spaces" created by outside intervention. Indeed Esman and Uphoff (1984: 22) state that their "purpose in focussing on local organizations is to increase knowledge of how their potential contributions can be tapped". Yet, this tapping is not a one-way process. Local organizations may be "tapped" by outsiders but, equally, they may provide the means by which local groups or actors can "tap" the contributions by external institutions and personnel. Furthermore peasants not only participate in the implementation of projects established by outsiders, but outsiders also participate in the personal and collective "projects" of the peasants themselves. The final outcome and meaning of the participatory organizational structures will differ, therefore, over time and according to the different parties involved. An understanding of these processes can only be tackled adequately by adopting a processual, "organizing" approach, rather than an institutional, "organizational" approach.

The meaning of organizations, such as the sss, differs according to the persons involved, and this of course, changes over time. Representatives of state institutions hold a quite formal view of such organizations, whereas for the membership itself there exists a discrepancy between "formal organization" and organization "as experienced". As stated earlier, it is the local leaders who must be able to manage these discrepancies; otherwise they cannot interact successfully with both the formally-oriented, State agents and the informallyoriented, local members.

Such differences in meaning and the indifference now existing within the AAL and SSS, of course, cannot automatically be applied to other local farmers' organizations such as the ejido or the association of water users. We lack the space here to present intervention situations involving these other organizations. But, generally, one can conclude that participation in the meetings and discussions of these organizations is more intensive. The supply of credit and water are activities which directly influence the daily life of all members. The -jido, especially, is experienced in dealing with formal authorities 
(SRA, BANRURAL) and usually plays an assertive role in any meetings that take place. For example, during a quite conflictive meeting concerning the outstanding debts of the ejido tractor group (3th of September 1987), many of those present (over 708 of members) participated in the deliberations, whilst the BANRURAL representatives did not. The latter could not, it seems, dominate the meeting. It was the bulk of the members, who were in debt to three fellow members, who had to solve the problem.

The degree of doninance and influence over local farmers' organizations by outside agencies therefore differs from organization to organization. Nevertheless, experience of outside domination in one organization does influence the image peasants have of farmers' organizations in general. The recording and analyzing of concrete situations of intervention enables one to gain insight into such differences and similarities as they are experienced by particular local groups.

Multiplicity of organizations and interventions

This chapter has concentrated mainly on the intervention of the bank and SRA officials concerning the future of a packing plant. The introduction stated that such interventions cannot be analyzed in isolation from other processes of intervention and social conflicts going on during the same period of time but involving other organizations and activities. In the previous sections we therefore referred explicitly to the complexity and multiplicity of interventions and local organizations with which the farmers are confronted.

It is very important to keep in touch with the totality of processes occurring. Sometimes "strange" behaviour, or tensions at a meeting, can only be understood by taking into account conflicts that relate to other problems. This simple point has very important consequences for rural development projects. In projects on irrigation organization, for example, villagers are defined and approached as irrigation-farmers, while in reality irrigation is likely to be only one of their productive or economic activities, and irrigation organization just one of the organizational entities to which they belong. Consequently problems, conflicts and constraints that emerge over irrigation may not be adequately tackled solely from the perspective or "logic" of irriga- 
tion itself. But to take this point of view is to create problems for the intervening parties or "developers" too, since they normally intervene in only one or two "spheres" of local life, mostly formalized around a specific local organization (such as the ejido, the tractorgroup, the irrigation unit, the sss etc.), whereas there usually exists a multiplicity of intervening institutions at the local level. On the other hand, however, unlike most of the intervening institutions, local organizations often consist in large part of the same people or set of close relatives and/or neighbours. Formally and superficially they may appear as separate organizations (and are treated as such by intervening parties), but in reality they constitute an interwoven complexity which can only be fully understood by analyzing the organizations (activities and members) in an integral way, including informal organizing processes, such as the formation of factions, social networks and family relationships.

The different factions sketched out in this chapter became manifest during the situations of intervention but, above all, during the periods in-between when decisions and strategies were being devised. We lacked sufficient data to show how these factions precisely functioned but one thing which emerged was that most decisions concerning formal organizations and the answers formulated for the intervening parties were made within these informal factional groupings and not during the interface situations themselves. For intervening parties, it is therefore difficult to get a grip on decision-making processes at local level. This is reinforced by the pattern of informal coordination among local institutions. Since agents of the state normally only deal with one "domain" at the local level, it is difficult for them to comprehend, and usually impossible for them to control, the totality of processes going on at the same time. It is, above all, the informal organizational structures and relationships that are central to understanding this complex totality, since they constitute the most important decision-making entities. Interface analysis, therefore, should not focus exclusively on the detailed study of the patterns of face-to-face interaction that take place between the key actors representing the different parties, as Long (1988:129) argues. However, these social encounters do provide us with a valuable window on the structuring and organizing processes operating on at village level. 


\section{Notes}

1. This paper is derived from Chapters III and V of Heijdra (1988) "Local Organizations: Outside Intervention and Peasant Strategies". A case-study at the intermediate level in an export-oriented irrigation zone of western Mexico. (Master's Thesis, Agricultural University Wageningen). The fieldwork for the study formed part of the research project "Contrasting Patterns of Irrigation Organization, Peasant Strategies and Planned Intervention: Comparative Studies in Western Mexico", a programme of collaborative research undertaken by the Agricultural University Wageningen, The Netherlands, and El Colegio de Jalisco, Guadalajara, Mexico (see Long, 1986). This research was carried out in The Municipalities of Autlân, El Grullo and El Limón, the State of Jalisco. In the elaboration of this chapter I am again indebted to Norman Long for his continuing inspiration. His involvement and incisive suggestions have facilitated the revision of earlier drafts. The critical comments and corrections of Alberto Arce and Ann Long are also very much appreciated.

2. See Esman and Uphoff (1984), for an extensive survey of the types and performance of such organizations.

3. This and other names of villages, companies and key actors are pseudonyms.

4. In order to sow in the irrigation cycle one has to apply for permission to do so from the Ministry of Agriculture and Water Resources, and in the case of export crops from the National Union of Vegetable and Fruit Producers as well.

5. Bjidos are corporately organized agrarian comnunities which have received and continue to hold land in accordance with the agrarian laws deriving from the Revolution of 1910. The land is received as an outright grant from the government (which legally remains the owner). The beneficiaries of this right to farm land of the ejido are called "ejidatarios". While ejido land legally cannot be sold, rented or mortgaged by individuals, plots of land are cultivated individually. Also usufructuary rights are inheritable, but cannot be divided (Whetten, 1948:182; Grindle, 1977:13). Within an ejido several credit groups can exist, for example, for cultivating maize or for maintaining a collectively-owned tractor.

6. The famers were already heavily involved in regional and national commodity markets at that time, and most of them also in the international labour market.

7. A Licenciado is a university graduate. The term is used as a general form of address for representatives of official institutions.

8. These two ministries were later fused into a single Ministry of Agriculture and Water Resources (SARH).

9. For the exchange rate for the Mexican peso see International Financial Statistics (November 1987:348-351).

10. Ingeniero signifies "engineer" or "agronomist". Like licenciado, it is used as a general form of address. Promotor is a field technician or extensionist.

11. It seems typically Mexican to start such procedures by appealing to the President of the Republic (see also Glantz, 1979). In San Antonio several vilJagers expressed their thorough distrust of the bureaucratic system, but all 
of them hoped that "somewhere" at the top justice would be found:

"The Government is very crooked, but not the President. It is the mafia around him."

12. This is a form of political control exercised by caciques (bosses) based upon personalistic loyalties.

13. Legally, elections must be held every two years, so Pedro Cobian was already in office too long.

14. As with most formal organizations in Mexico, the President cannot be reelected for a second term.

15. Cooperative Societies fall under the responsibility of the Ministry of Labour Affairs, the STPS (Castanos, 1987: 438). By applying for recognition as a Cooperative Society Pedro Cobian tried to bypass the Ministry of Agriculture and Water Resources (SARH), which was trying to stop his "illegal" packing plant.

16. Several times the SSS/AAL leaders were threatened with guns: especially Pedro Cobian's brother, then Municipal President of El Limón, had a bad reputation for this.

17. For first meetings this is $75 \%$. In the case of Extraordinary Assemblies, also for second meetings, the presence of $60 \%$ of the members is required.

18. Many informants suggested that the bank people were loyal to Pedro Cobian because he bribed them at the expense of San Antonio producers.

19. Other members of the research team operated more at the level of the intervening parties. However, so far the information of the different researchers has not been brought together.

20. Before 1985 officials of the regional SRA office in Autlan represented the SRA at the SSS Assemblies, but because the director of that office appeared to be on the side of Pedro Cobian (for example he prevented Pedro from officially being expelled as a member of the SSS after the publication of the financial inquiry in 1985), the actual executive committee applied for direct intervention from the Guadalajara office. Ever since it has been the relatively unknown (and frequently changing) officials from the capital city who have come to San Antonio to legalize the SSS Assemblies. Hence the composition of the intervening party is partly influenced by the local leaders themselves.

21. This routine of avoidance and waiting is very typical in these kinds of situations. It forms part of a "culture of intervention". For a moment the differences between "we the locals" and "they the outsiders" is very sharp, and it certainly brings about uncertain feelings among the outsiders.

22. Lupe Vázquez, Treasurer of the SSS and President of the ejido.

23. Jesús Cárdenas, President of the AAL Committee of Vigilance, Secretary of the ejido and a close friend of René Villa.

24. Lupe Vazquez is President of the ejido and Secretary of the SSS. Jesús Cárdenas is Secretary of the ejido and President of the AAL Comittee of Vigilance. René Villa is President of the SSS. 
25. Tomás indeed owns about 50 shares. He himself says he bought them, others maintain that he just appropriated them being the SSS Treasurer.

26. See Hans Heijdra (1988).

27. Unfortunately, as a foreign researcher, I always became the topic of conversation during these kinds of informal talks, since the visiting outsiders were, of course, very curious about me and my objectives.

28. That is the Confederación Nacional de Campesinos (National Farmers Confederation), the farmers' union affiliated to the PRI (Institutional Revolutionary Party), the dominant political party.

29. Almost all the rural credit programmes are financed directly or indirectly vi.a FIRA,

30. July 1987: 1,000,000 pesos $= \pm 750$ us dollars.

31. On other occasions, to avoid direct confrontation or unwanted unity concerning other issues, the wives of key actors would attend meetings, such as, for example, the meetings of the parents' committee at the school.

32. More people stated that they wished to specialize in the production of melon, because this product can be sold in national as well as international markets ("double option"). This implied that they were not dependent on US markets completely, as is the case for cherry tomatoes.

33. Jesús Cobian is President of the Conmittee of Vigilance of the SSS and second Municipal delegate. $\mathrm{He}$ is one of René Villa's close (political) friends.

34. Gabriel Michel, Treasurer of the SSS, and also one of the close political friends of Rene and Jesús.

35. A few weeks later Roberto told me that he was present because nobody had told him not to go!: "In my opinion, we had to be present. And if not, the leaders would have informed everybody, one by one in the street, saying: "Look, don't go, we are not going for this or that reason." But nobody told me anything."

36. This confrontation during the AAL Assembly had many similarities to the SSS meeting. It was above all the leaders who discussed and, again, legal arguments were used to obstruct the meeting (by Pedro Cobian and his brotherin-law). 


\section{THE CHANGING LIFE-WORIDS OF WOMEN IN A MEXICAN EJIDO: THE CASE OF THE BEE-KEEPERS OF AYUQUIIA AND THE ISSUE OF INIERVENTION}

Norman Long and Magdalena Villarreal

Like Chapters II and III, this study forms part of a larger Mexican project aimed at analyzing the interactions that develop between local groups and intervening actors representing external institutions such as government development agencies (Long, 1986). We start with the assumption that "intervention" is a highly complex process which is continuously being reshaped by the negotiations and strategies that take place between the various parties involved. This means that planned intervention aimed at establishing a particular project becomes the catalyst for the emergence of several, often contradictory, interpretations of the aims and significance of the so-called project (for a similar viewpoint, see Elwert and Bierschenk, et. al.,1988; also Long, 1984:177-179). This arises because different actors accord different social meanings to the events and visualize different trajectories for the project. These different social constructions are formed through a process of internalization by which the actors attempt to locate their experiences of the project in relation to their own life-worlds and aspirations. Given the heterogeneity of both local groups and intervening parties, there will necessarily arise differences in the ways in which the project and its benefits or penalties (both individual and collective) are evaluated. These social constructions change over time as new evidence drawn from new encounters with "external" or "internal" actors is processed.

The analysis of intervention processes, then, throws up a number of complex issues concerning strategic action involving "intervening" actors vis-à-vis "target" and "non-target" groups; the construction of 
the social meaning of "projects"; and the significance of different types of interface for shaping both action and interpretation. In order to explore some of these dimensions, we take the case of a women's group that establishes a small-scale bee-keeping enterprise in a village in Western Mexico. Although the idea for the enterprise came originally from outside, namely it was part of a policy initiative undertaken by government departments, the project was taken up and significantly shaped by the actions and ongoing discourse of the group and its individual members. The chapter concentrates, therefore, upon two key aspects: first, the significance of the group and the project for reshaping the Iife-worlds of its members, emphasizing the differentiated nature of this process; and second, the ways in which the social meanings of the project change over time as new interface situations arise and as new decisions are taken by the actors involved ${ }^{l}$.

\section{The research location}

The events that we describe took place in Ayuquila, a settlement of 174 households located along the main road linking the Municipal capital of El Grullo to the State capital of Guadalajara. Ayuquila is one of the oldest settlements in the area and is built upon the remains of the largest hacienda of the Autlán-El Grullo region. About one third of the arable land of Ayuquila is irrigated, where sugar, maize and a variety of vegetables are grown. The rest lies on the hillsides and is used for cattle grazing. The land is ejido 2 property, divided into many small plots under the management of 47 officially registered ejidatarios. Not all of these ejidatarios, however, live in Ayuquila: many are resident in the United States whilst others live in the nearby towns of El Grullo and Autlán. Apart from the ejidatarios, the population of Ayuquila is made up of those adult children of ejidatarios and their families who have no land rights, and of in-migrants (avecinados), most of whom work as day labourers for the tomato companies or for local farmers. In addition to agriculture and small-trade and transport, many households depend on income derived from outside, mainly from relatives in the United States. 
In 1980, a social worker from the Mexican Ministry of Agrarian Reform (SRA) presented herself to the head of the ejido of Ayuquila, the camisariado ejidal, hoping to organize an Agrarian and Industrial Unit for Woman (UAIM), following the guidelines of the national law of agrarian reform. A number of women attended a meeting arranged by the comisariado for the social worker, at which the names and signatures of those interested were 1 isted; and in this way they became recognized as a group that could receive aid under the government scheme. In accordance with the law, the ejido is compelled to provide a piece of land for any such new UAIM initiative, with the government matching this with credit for the enterprise.

Two years passed (during which time the women never ever met as a group) until another social worker, this time from the Government Rural Bank (BANRURAL), came to offer the women credit to raise goats, pigs, chickens, or to establish whatever economic activity they wanted, so long as it fitted the formal requirements. The group now had 22 members. In the intervening period, some had married and were not permitted by their husbands to continue, and others had left Ayuquila to work or study. The group finally chose bee-keeping, as it did not involve a daily commitment. They now laugh at this decision, saying that they picked the worst activity because they are always being stung by the bees.

In 1984 the project was formally initiated by a loan of 775,000 Mexican pesos (approximately 1550 US dollars) from BANRURAL for the purchase of the bee hives, bees and basic equipment. They started with 50 hives, which they bought in a nearby village with the aid of the same social worker, who also helped them to buy equipment and explained how they should keep their accounts and minute book. In addition, they received some fornal training in bee-keeping from a bank extension worker, although the women say this was not enough and was too theoretical. Once they began working they encountered major problems which they solved by contacting experienced bee-keepers in the vicinity, who gave them other more practical courses and much advice. 


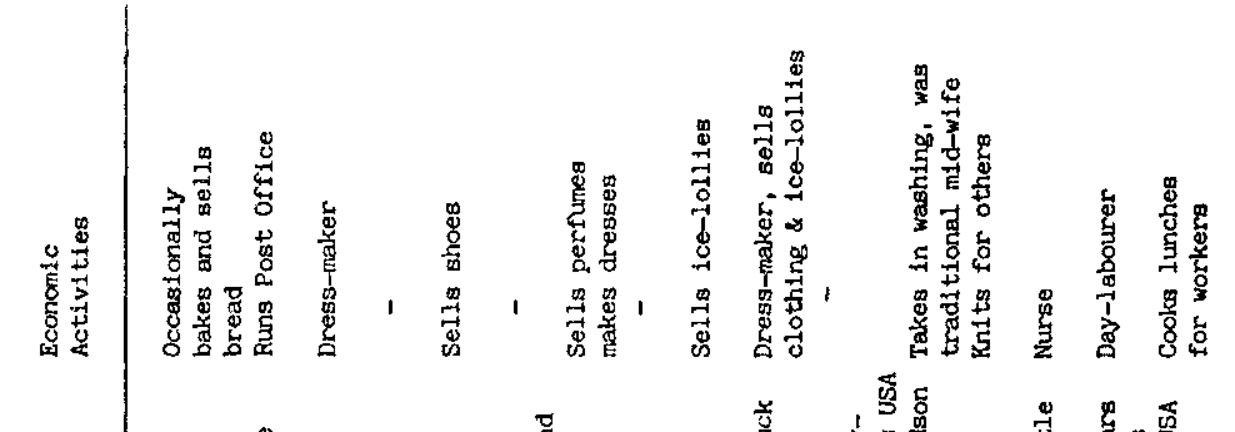

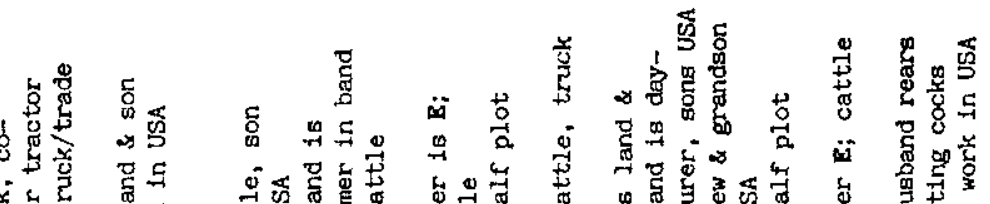

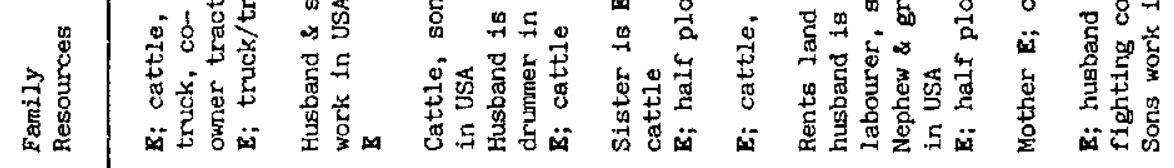

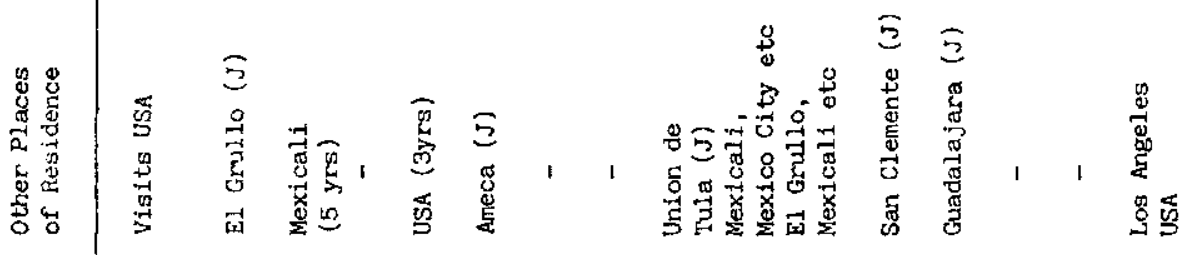

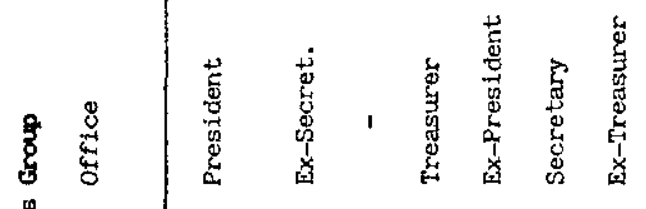

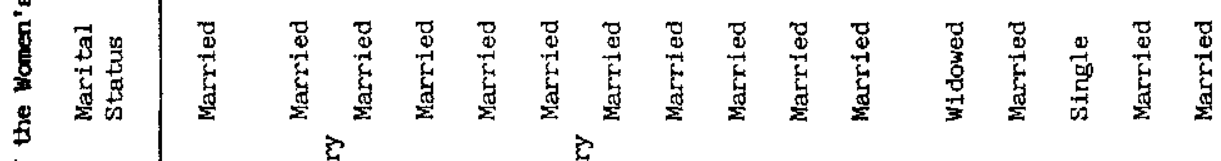

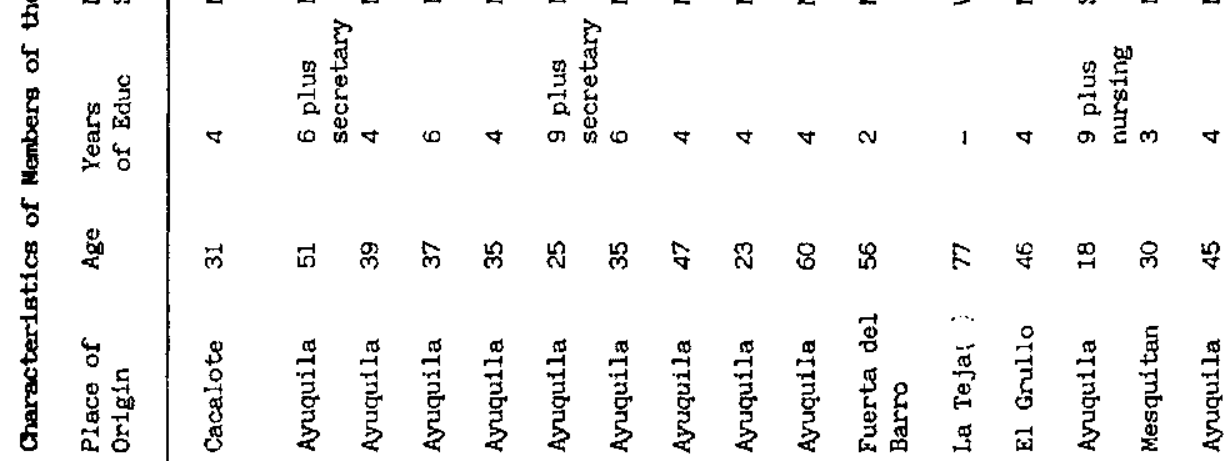

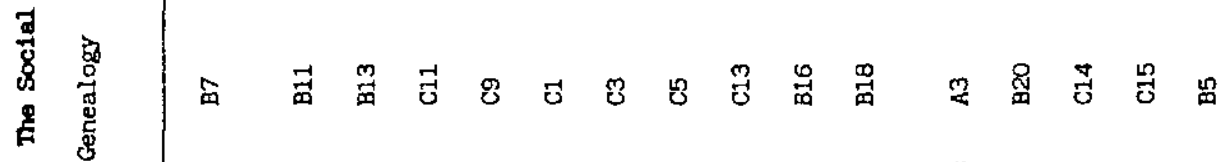

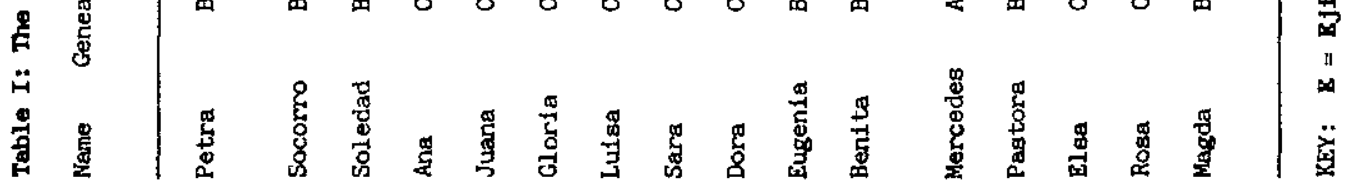

$$
\begin{aligned}
& 106
\end{aligned}
$$




\section{Genea logy}
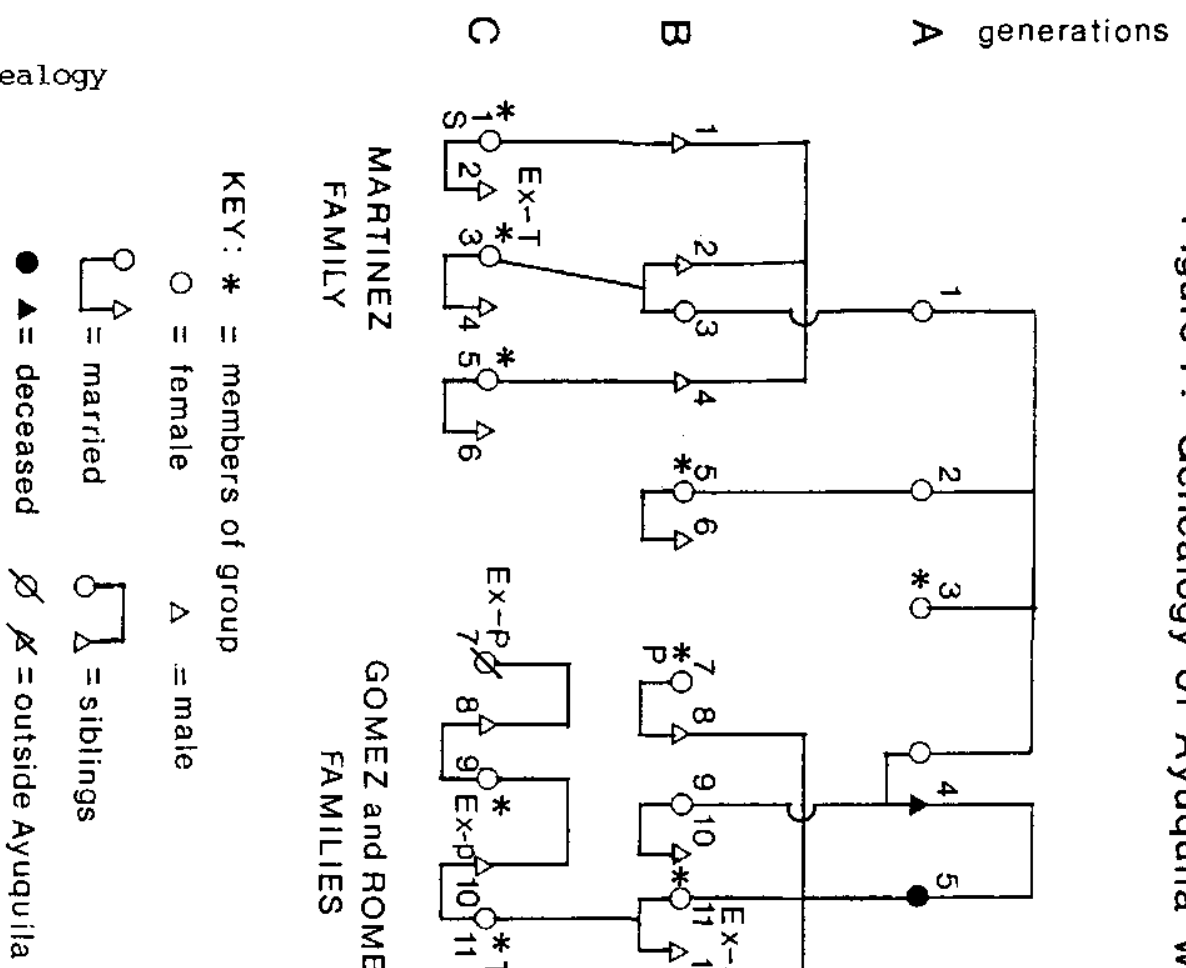

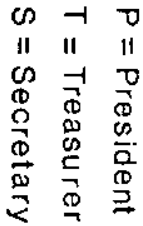

$\begin{array}{ccc}m & m & m \\ \times & \times & x \\ 1 & 1 & 1 \\ 0 & -1 & 0 \\ 11 & 11 & 11 \\ m & m & m \\ \times & \times & \times \\ 1 & 1 & 1 \\ 0 & = & 0 \\ 0 & 0 & 0 \\ 0 & 0 & 0 \\ 0 & 0 & 0 \\ 0 & 0 & 0 \\ + & 5 & 0 \\ 0 & 0 & 0 \\ 2 & 9 & 2\end{array}$
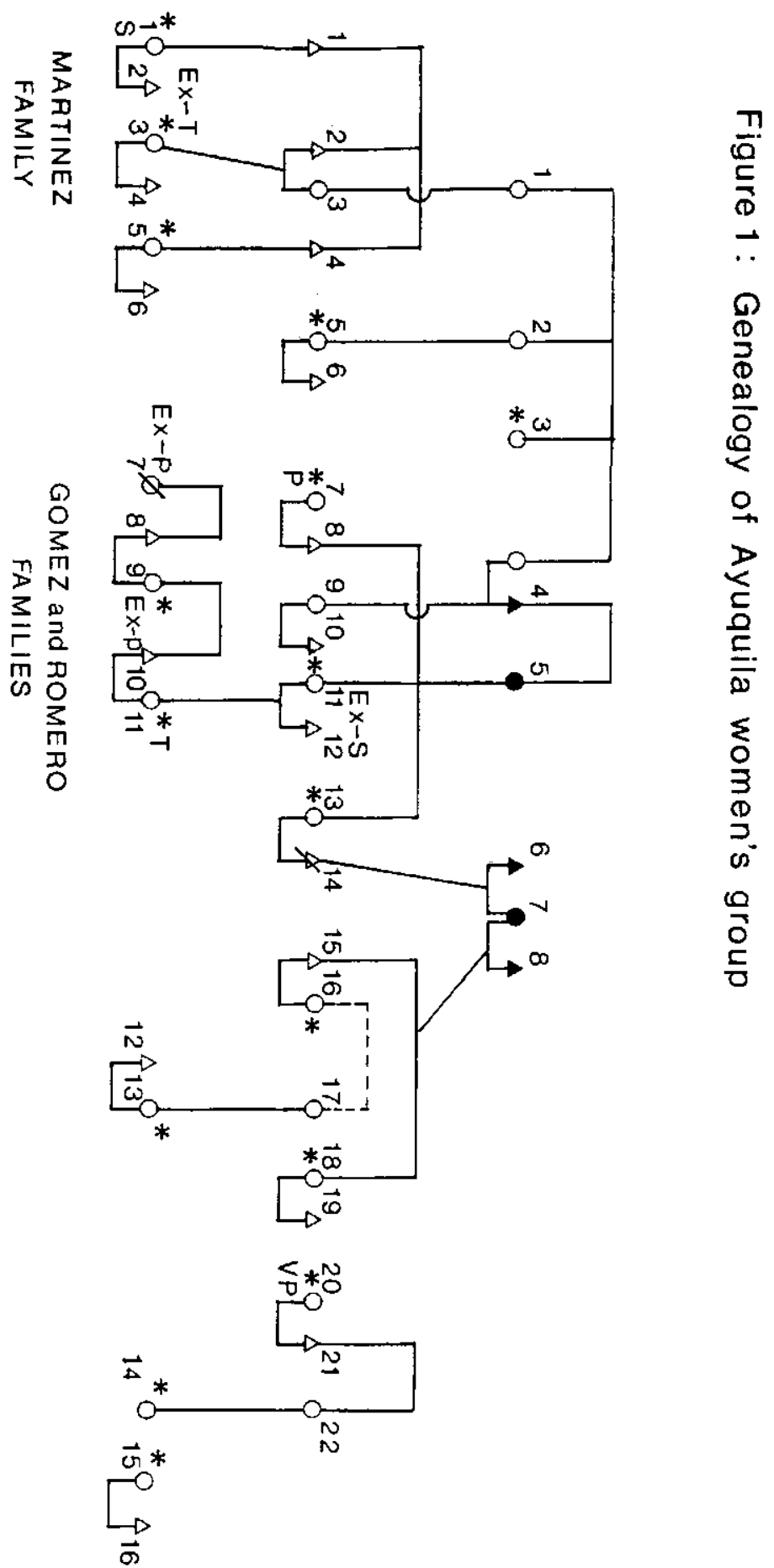

足 
By this time, because of the difficult and time-consuming nature of the work, the group had been reduced to 16 members. Also in one or two cases, personal conflicts among the women were also involved. Table I gives a breakdown of the social characteristics of present members. Fourteen of them are married. Their ages range from 18 to 77 , the majority being between 30 and 50 years old. One of them, the oldest, cannot read or write; 11 have finished the first primary school grades, and three have received some post-secondary training. The majority are from Ayuquila or have lived there most of their lives, and most of them are related by kinship or affinity to two big family groupings, the Martinez and Gomez-Romero families (see Figure I: Genealogy of Ayuquila's women's group) 3, and several are linked by compadrazgo ("ritual kinship") relationships. Even though most of them have regular family incomes, be it from their crops, cattle, or husbands' and sons' jobs, all but one of them are, or have been, involved in complementary economic activities, such as dress making, day labouring, and selling clothes, perfumes or shoes. We first had the impression that the women were from an economically marginal group in the village, but our findings obliged us to abandon this idea 4.

The criteria that appear to facilitate members being elected to hold office in the group are: having useful political and social networks, older children (which frees them from the ties and worries associated with some household chores), a degree of economic stability (which enables them to give time to group activities), a knowledge of bee-management, the boldness to go into men's worlds and move around in government offices and travel to different towns, be it by bus, in the extension officer's pick-up, or through asking for a lift. They must also display some skills in discussing and negotiating with government officials of whatever level, and must have a husband and a family who will allow them to undertake these duties.

The group has a small store built with money from the first honey harvests, which they use also as a meeting place. This entailed an investment of 1,113,000 Mexican pesos (approximately 1113 Us dollars). Currently, with the threat of an African killer bee invasion and the high prices of necessary inputs, they are encountering new challenges, needing to increase their production and look for better markets. On the other hand, different departments of the Ministry of Agriculture and water Resources (SARH) have offered on two separate occasions, 
first to build them a larger store, and later to install a honeyprocessing plant. This implies a much greater commitment on the part of the women - for they would have to invest their limited resources in paying the labour for construction - and it entails a different project altogether from the one many of them thought they were undertaking.

The women get together to work at least once a week. They meet at the house of the President of the group or at the store. There they prepare their instruments: fumigators and the dried dung, corn-cobs, pine chips and petroleum for lighting them; antibiotics for the bees; wedges to open the hives and clean them of the surplus wax; machetes and pichoacas (i.e. different types of knives used for cutting down weeds); and the large wooken boxes that serve as breeding chambers. Sometimes they also have to carry 20-litre cans of water with sugar to feed the bees when there are too few natural flowers around, together with small jars for supplying each hive with a portion of this. They walk or hopefully hitch a lift to where the bees are, along the main canal some two or three kilometers from the village.

We first met the group and its president at such a work session. They all came dressed in trousers, some worn under a dress and tied up with string at the bottom or secured with socks to prevent the bees from getting in. The outfits were completed by long-sleeved shirts, maybe inherited from their husbands, and home-made protective masks. Some masks resembled professional gear with specially shaped eye pieces, others wore local sombreros with improvised black netting tied around the headband, and one woman sported "appropriate technology" in the form of a green nylon net shopping bag. Some had taken along drinking water, fruit and biscuits to share in the field. They began work immediately, dividing themselves into several small groups with specific tasks: cutting down the grass and cleaning up the area around the beehives; putting bricks and rocks under some of the hives; fumigating the hives when opening them up for examination; removing the frames and cleaning off the surplus wax in order to observe the state of the bees and the well-being of the queen; and then, when replaced, making sure the lids of the hives were properly secured. That day they had not been given a lift and had walked, carrying the heaviest things on their heads.

Other important activities are the monthly meetings, which take place at the store on the first day of each month. The President takes 
the roll-call, the Secretary reads the minutes, the Treasurer informs them of the expenditures they have incurred, and then, under general business information, the President gives an overview of the work to be done, visits to government offices, etc. At the end of the meeting, each member signs to prove attendance and pays the monthly fee to the Treasurer. After this come the snacks, which members take turns to prepare. The latter is probably the most important activity of the meeting, for, besides being the one they devote most time to, they plan it ahead and always try to make something special.

The group also arranges solidarity activities, such as sending flowers when relatives of members die, and organizing "baby showers" or birthday parties for members.

\section{Key analytical issues}

This brief account of the history, social composition and activities of the group, provides a background for exploring in more detail issues relating to changes in the life circumstances, perceptions and aspirations of the women.

Understanding the processes by which particular women reconstruct their own "life-worlds" (Schutz and Luckmann, 1973: 3-20; and Appendix to this volume, pp. 245-256) through creating space for the pursuit of their own "projects", and the consequences this has for both gender and other relationships and for changes in social consciousness, is a highly complex matter. It is also difficult to pinpoint how far their experiences with the group have contributed to any such changes. Also our data bring to light the highly differentiated nature of these processes. Nevertheless, it is possible, we believe, to show the significance of the group and its encounters and activities for shaping the life-worlds of these women. This manifests itself most clearly in the ways in which individual women use the group and its sense of "belongingness" to reconceptualize their own life circumstances and expectations, and to sustain them in any changes in social relationships or strategies they might wish to effect.

The following discussion examines these aspects, first, as they emerge in the profiles of two members of the group and, second, through an account of the history of the "project". We have tried to indicate, 
though we are unable to analyze them in detail, the critical social interfaces involved. As suggested in "Notes on Research Methodology: Mexican Project" (see Appendix to this volume), our interest in "interface" arises essentially from a desire to understand and analyze the co-existence and interpenetration or transformation of different lifeworlds. The notion of "life-world" derives from Schutz who uses it to describe how everyday life is experienced as an "ordered reality" by individuals. This "order" appears both in the ways in which people manage their social relationships and in how they attempt to give social meaning to their everyday experiences of "the world around them". Hence it implies simultaneously both action and meaning. It is a "lived-in and largely taken-for-granted world" which, however, "we modify through our acts and which, on the other hand, modifies our actions" (Schutz and Luckmann, 1973:6).

Such an analytical approach, we believe, can provide important insights into processes of social confrontation, negotiation, and restructuration not only within the "small world" of everyday encounters in a peasant village, but also within the broader arena of statepeasant, or state-peasant-private company, relations. The formation and development of the women's group, for example, entailed not only changing patterns of social commitment within the village, but also the manaing of relationships with significant outsiders and externallybased institutions (e.g. in order to register the group and obtain credit from BANRURAL, and to learn the techniques of bee-keeping). We also wish to point out that, although our observations took place mainly in the village, the life-worlds of the individuals concerned are not confined to the particular locality or local group. They extend both backwards temporally to link them with earlier periods and generations, and outwards spatially to persons who live in other milieux. (What Giddens, 1984:132, has characterized as the "intersections of presence and absence in the "fading away" of time and the "shading off" of space"). Our unit of analysis, then, is not the local group or situation per se but the complex set of relations that constitute the intersections of life-worlds as revealed in the everyday lives of women in Ayuquila. Although we cannot present here a full and systematic treatment of the types, constitution and restructuring of women's lifeworlds, we emphasize that these social forms must be "discovered" through mapping out the social networks, social practices and cultural 
constructions of specific social actors, and not by assuming a priori the centrality of particular contexts of, what Habermas has called, "communicative action" such as the family or local community. 5

Ideally it would be better to present more than two women's profiles so as to provide a fuller and more differentiated picture of the membership, but shortage of space prevents us from doing so. The two cases represent a contrast, the first being the leader of the group and the second, someone who is marginal to the leadership core and an object of much criticism. They are similar, though, in that both women come from outside Ayuquila. They are also close neighbours.

The profiles that follow focus upon:

a) their experiences and participation in the women's group;

b) the significance of membership of the group for the pursuit and realization of their own "social projects" and aspirations; and

c) the intersection of their particular life-worlds with those of the ir husbands.

\section{Profile of Petra, the President of the wamen's group}

We first met Petra (B7 in the genealogy, Figure I) in 1987 at the workday described above. She introduced herself as the president and invited us to accompany them to see how they work with the bees. She had with her a notebook in which she recorded the names of the members who had turned up to work that day. The regulations of the group state that if one misses three workdays and/or monthly meetings in succession then one loses the right to a share of the earnings and one risks being expelled from the group. Petra, we learnt later, is very meticulous in recording attendances and is considered hard ("muy dura") by the members for the way in which she organizes people and runs the affairs of the group. During the work session Petra, assisted by the Treasurer, Ana (C11), assumed a directive role, answering any queries that came up and making sure personally that each beehive, its queen and bees, was in good condition. She also kept up a running commentary for our sakes, explaining the details and routine of managing beehives and pointing out to us particular features or problems as they were encountered (for example, how to recognize sick bees, an old queen, and 
too many drones). Throughout Petra projected herself as being both in charge and knowledgeable about bee-keeping.

This impression was further reinforced when later the same day we met the group at their bodega (store and workshop) to discuss the formation and objectives of the group. This meeting took place early evening, after the members had returned to their homes to cook for their families and to carry out any necessary domestic or other tasks. They joined us at the bodega around 5 o'clock, smartly got up in brightly coloured dresses or blouses and skirts: some wore stockings, high-heeled shoes, and underslips; most were wearing make-up and a few, earrings and other forms of jewelry. Like the rest, Petra was well dressed but wore no make-up. She arrived with the Treasurer, her niece (i.e. the daughter ( $\mathrm{Cl1}$ ) of her sister-in-law (BII) in the group) who was, perhaps, the most engagingly dressed, wearing a pink, low-cut dress, with earrings and a necklace. The two sat together throughout the meeting, silently giving each other moral support.

After some minutes of general discussion Petra gradually assumed the central role in answering questions, clarifying points and conducting the meeting. She conveyed an enthusiasm and commitment to the enterprise, despite the difficulties the group had encountered in getting the project off the ground (it took about five years before they were formally recognized and given a loan by BANRURAL), and she explained their plans for the future. They would, with the help of SARH and bee-keeping experts, ward off the expected attack by the African bee; they would eventually acquire a truck for transporting the honey and for moving beehives to new locations (none of them could yet drive); and their earnings from honey might later be invested in some other activities, such as establishing a maize grinding mill in the village. They had attended courses, taken notes from the blackboard and had studies hard to learn the techniques and science of bee-keeping and hoped to increase their knowledge through membership of the newlyformed Regional Association of Bee-keepers. At one point, when one member was explaining the enjoyment they received from bee-keeping"it being a break and a change" - Petra intervened to insist "but we work hard in the break". Thus for her, it is not simply an amusing pastime it is a serious business that requires dedication and study!

There was, Petra emphasized, the need to learn more about "the society of the bees". They had, for example. discovered that during the 
nuptial flight, it was not one brave drone that fertilized the queen but about eight. This provided the queen with sufficient sperm to produce for about three years. And another eye-opener came when they learnt that the worker bees were not destined simply to perform one single type of work during their very short life-span of about three months, but that they passed through different "sociological ages" ("edades sociologicas"), starting first with domestic duties, such as cleaning out and ventilating the hives, then moving on to defending the beehive from invading insects, assisting with the elaboration of the honey and wax and with the feeding of larvas, and then later making expeditions beyond the immediate vicinity of the hive to collect nectar. When speaking of the techniques and science of bee-keeping, her face lit up to communicate her engagement and genuine interest in the subject.

\section{Petra as "tough manager" and "local expert"}

Organizational ethic

Petra, then, shows an involvement in both the organizational and scientific aspects of bee-keeping. Before becoming President she had already established a reputation for herself among the group as one of the "experts" in bee-keeping and as a good organizer of work parties, which she did as part of her job as Vice-President. In return for devising a division of labour among members, Petra claims she is allowed to do less work because she is involved in so many "bits and pieces" ("porque me traen de un lado $y$ otro"). Once elected to the Presidency (early in 1987) she assumed a tough management line, earning the label of being very hard ("mry dura") and insisting upon maintaining discipline in the work ("tener orden en el trabajo"). She points out that looking after 100 or so beehives could be handled by as few as four persons, but since all sixteen members have the right to work and share in the benefits they can, with good organization, finish cleaning out the beehives in only one hour. In contrast to Petra, the previous President, Juana (C9), is said to have been much too flexible and easy-going, which she herself openly admits: "When I was President I was not so strict, but now we are fine". 
Since becoming President, Petra has initiated a discussion of the rights and duties of members and of what should happen to those who do not fulfil their work obligations or pay their quotas each month. As she explained:

"We are following rules given to us by those from the bank though
previously no one ever paid attention to them. Non-active members
do not have the right to a share of the honey production, even if
they have someone standing in for them. Recently, somebody (from
the bank) has been to read the new set of rules but some members
don't want to follow them. All they want is to be given the money,
but that is not what it's all about, it's about doing the work and
fulfilling your commitments. Luisa (C3) was annoyed with me on one
occasion because I told her off for not attending a collective work
day. The group expect and ask me to impart justice. If someone
doesn't go I consult the majority about what to do so as not to
impose, especially when it concerns going into the fields. Anyway
one is never right, for there are so many ideas... . this new set of
rules for instance, I studied it and consulted them to see if we
should apply it. Now they are calling it "Petra's law" and I don't
like that. One has to put laziness (la flojera) aside and get out
there to supervise the bees, otherwise, what with the black ants
and the frogs and sickness, within 15 days they would be finished.
One has to be as organized as the bees." There are presently two categories of women that do not strictly comply with the requirements of the group: those who are infirm or pregnant, and those who work as day labourers or have other duties that interfere with their obligations to the women's group. So far this matter remains unresolved since the group is divided as to how strict one should be, but Petra continues to pressure them to come to some agreement, however difficult, on how to handle these cases. For example, there is the case of Doña Mercedes (A3) who is poor and old. She is therefore unable to make much of a contribution either to the work or to the operating funds of the group. Petra comments:

"Doña Mercedes has never helped or been of service. I don't think there is any justice in considering her an active member and it would be better to have something in writing, something to the effect that she has not accumulated sufficient work to have earned the right to pass on her membership to someone else. Because of her bad legs she is unable to go out to the fields and so cannot even fumigate. It feels bad to cut her out and some of them have said as much. It would be better if she resigned, but she enjoys being in the group and is cooperative. Maybe we should also put that in writing for we don't want her to think we are just cutting her out and announcing her dead. She has some nieces in the group who, when a meeting was held to find out the group's opinion, said we should not throw her out. But she is not so poor. She has a grandson of 15 who works and other sons, although they are all a long way away." 
However, as Petra's assessment of the case of Doña Mercedes clearly brings out, it is one thing to recognize a good law or principle, and quite another to implement it to the satisfaction of all. She hopes that one day such anomalies will be ironed out.

The thirst for knowledge

As revealed in our first meeting with Petra, she possesses a considerable interest in improving her knowledge of bee-keeping and other practical skills. Before joining the group she had been a regular attender of courses on weaving and macrame at the DIF (Family Development Unit) and Caja Popular (Community Fund) in Ayuquila, and for a period had been the President of the DIF committee. Since joining the group (she was invited to join for her skills) she has participated enthusiastically in any courses that have been provided. She showed a lot of interest in the courses specially organized for them by BANRURAL on organizational and book-keeping procedures, and particularly in those given by a number of experienced bee-keepers who came to teach them the basics of bee-keeping.

Petra enjoyed these meetings and took copious notes on most topics. She began reading carefully the pamphlets on bee-keeping that were circulated and watched a series of TV programmes on the subject. She recalled how the group itself would each week prepare a particular chapter of the book they had on bee-keeping and would be expected to answer questions based on the text at a group meeting. She enjoyed this type of study session, which, it seems, resembled the way in which her father (a Jehovah's Witness) had instructed them in the Bible. Petra characterizes her father as having been a morally upright man, and a successful baker and shopkeeper:

"My father was not a drinker, nor smoker, nor a womanizer. He was a god-fearing man who found time from his business affairs to read the Bible to us and this has left us with the urge ("la espinita") to read and keep to the Bible. It is lovely to have a religion and believe and not behave like an animal."

Petra - herself a practising Jehovah's Witness - therefore sees a connection between moral rectitude and abstinence and seeking Godly knowledge. The organizational skills and dedication of the witnesses in achieving this are qualities that are also essential for succeeding in a new group venture, such as bee-keeping that entails the acquisition 
and utilization of new forms of technical and other knowledge, as well as a degree of personal commitment to, as she puts it, her companions ("sus compañeras"). Many of the attitudes and values of the Witnesses can be seen at work in Petras approach to her work and compañeras. We have learnt since that Mercedes was finally expelled from the group. So petra got her way.

\section{Developing her own "project"}

These courses and study sessions are, in Petra's eyes, important not only for the technical knowledge they impart but also for the way in which

"they help us, not only with the bees, but as women, to face life. It's a bit of everything, we learn new things and are able to get out of the house for a while and it fills us with the desire to know more."

Petra combines this desire to develop a life beyond the domestic scene with a strong sense of enterprise. She wants the bee-keeping business to become a sound money-earning venture. This will give some degree of economic independence to the women and, with careful nurturing and financial management, lead to increased profit: "by getting the fire started we will harvest more" (haciendo la lumbrita, si vamos a cosechar mas). Later she envisages that the group may be able to diversify into other economic ventures. They already sell to local livestock owners the pasture from their hillside plot donated to them by the ejido for keeping their bees; but they could also, she suggests, grow plums and nopales (cacti) in their coamil 6 and, with additional capital, open a grinding mill in the village (at present there is not one).

In many respects Petra's interest in seeing the women's project develop into a successful economic enterprise reflects her general background and orientation to life. As well as being a Witness, Petra's father was a well-known and relatively successful businessman. The father and family had at one time lived in Ayuquila but "there arose envy and he received anonymous threats", so they left for the neighbouring village of Cacalote where they established a bakery and small shop, and where several other Witness families live. Several surviving family members still live there. This background gave Petra the taste 
for commerce. As she puts it, "I very much like business because it provides for daily necessities".

It also seems that, though she herself never expressed this explicitly to us, she wishes in some way to vindicate her father's reputation and her family (they were probably driven out of Ayuquila because of their religious persuasion). She herself has "returned to the fold" with in the past five years. This sets her somewhat apart from the rest of the people of Ayuquila who are staunch Catholics and resent the evangelizing of Protestant sects. Although she is careful not to proselytize in the village - some members of the women's group intinated that if she did there would be trouble! - from time to time her religious beliefs show themselves. For example, after becoming President of the women's group, she has put a stop to using raffles for fund-raising, which she regards as the same as a lottery and therefore gambling, which is prohibited by her sect. She also acknowledges that from time to time she has conflicts with her husband over religion, as he is not of her faith.

A further element influencing Petra's personal project is her relative social isolation in Ayuquila, due mainly to her family background and religious conviction. Except for her neighbour, Rosa (C15 and our second profile), she has no close friends in Ayuquila in whom she confides. However, being married into the Gomezfamily, which is closely linked into the Romero family (see Figure I), gives her some social support and probably made it possible for her to join the women's group in the first place. She was invited by her Gomezfamily "niece-in-law" and ex-President Juana, when several women of the founding group withdrew due to the slowness with which the formalities were concluded. It took some years (some say as many as five) to decide upon the type of enterprise and to complete the "tramites" (paper work) for obtaining official recognition and credit. During this period, the Romero and Gomez families controlled the main positions within the group and had close relations with the ejido authorities, who played a crucial role in promoting the group with outside government bodies. Petra, then, was only invited to become a member once others had dropped out.

Petra's work for the women's group and her growing expertise in bee-keeping is helping to consolidate her ties with women from the Gomez group, of whom several presently hold or have held positions of 
responsibility. All but one of them commented favourably on the work of Petra and they all stressed the importance of "solidaridad" within their group. Another of her sisters-in-law in the group and a senior woman of the Gomez family, Socorro (B11), is a devout Catholic who belongs to Acción Catolica and participates regularly in various church activities; yet even she praises petra for her diligence and knowledgeability about bee-keeping. Also recently when one group of bee-hives was inundated when the Ayuquila river burst its banks, the main organizers of the rescue operations were these Gomez women - Petra, Socorro and Juana ( $\mathrm{C} 9$ ). On hearing of the flood, they quickly mobilized those members who were available and, together with the help of some husbands and sons, went down to the river area to save the hives. They used trucks owned by Socorro's and Petra's husbands.

All this suggests therefore that Petra's "project" includes the building of better relations with her sisters- and nieces-in-law and thus consolidating her position within the women's group and her network within the village as a whole. How far she succeeds in the long-run will, of course, depend very much on the fortunes of the group itself. Hence the success of Petra's personal project and the destiny of the women's group are inextricably intertwined.

The clash of two worlds: Petra and her husband

Petra's involvement in the women's group has generated new opportunities and interests for her. Although in certain respects one can see her activities as complementing those of her husband, her increasing commitment to the group leads to some separation, if not incompatibility, between their two social worlds. This process has, it appears, been exacerbated by their different religious views. Some of the other women we interviewed commented that they once came close to divorce.

Petra's husband (B8) is an ejidatario possessing a total of eight hectares of land. Originally he had 10 hectares but lost two as result of the construction of the canals and the road to El Grullo. He devotes most of his time to agriculture, although recently things have gone very badly for him: 
"Concerning the maize, the river made two hectares into ponds and swept away the soil. The previous harvest of tomatoes brought disease."

He also operates a truck transporting and buying and selling maize cobs. In addition, he has been given credit by BANRURAL through the ejido, once for a tractor which he operates in partnership with a friend, and once as a member of a group specializing in livestock production, whose members each received nine cows and two calves (three years ago), and now have some young bulls for slaughtering.

Until recently, these various agriculturally-based activities have been the basis for their household econony, but during the past few years Petra's husband has devoted more time to commerce and trucking than to production as such. According to Petra, agriculture is now a big risk: "water and pests destroy us." Nevertheless, Petra's household could not by any means be regarded as lacking in resources or as struggling to make ends meet: their livelihood is based upon a diversity of income sources, and the network that her husband uses for maintaining these, feeds directly into the main group of ejidatarios.

Her husband shows little interest in her bee-keeping activities, and certainly does not think of honey production as contributing much to the household budget. Only in emergencies, like the recent flooding of the hives, is he prepared to lend a hand, certainly not on a regular basis like Luisa's (C4) and Eugenia's (815) husbands. For him, "this is women's work". Petra explains,

"People who help are much admired, for example, Luisa's husband, who of ten goes out with us and fumigates and helps us down with the heavy hives. Don Marcelio (B15) is another who helps... my husband is not keen since he was once stung. When the river threatened to flood the hives though, the bravest and pluckiest was Pastora (B20), not the men. She threw herself into the current to rescue the boxes."

Also, according to Petra, her husband is tired of having his house cluttered with bee-keeping equipment. Moreover, like many of the husbands, he objects to her attending the bees and not being available to prepare supper for him and the children. Petra herself recognizes this as a point of difference between them and the double standards that operate for men and women. Husbands, she commented,

"they arrive home at one or two o'clock in the morning, because of their work or other reasons, not always true, drunk or whatever."

Membership of the women's group, therefore, has also generated friction between Petra and her husband. As she increases her standing among the 
women and comes to realize her own "project", so relations between them become more strained. This, it seems, is exacerbated by her moralistic Jehovah's Witness ethic, which, as her friend Rosa (Cl5) puts it, "deprives her of many things".

A further dimension is the fact that, in recent years, her husband has been extremely unlucky with his own productive investments, whereas "her" bee-keeping enterprise has achieved good results and has excellent prospects for the future. This simply heightens the significance of her project, even if her husband continues to relegate it to the realm of "women's things".

\section{Profile of Rosa, the dilemma of a day labourer in the women's group}

\section{Our first impressions of Rosa}

We first met Rosa ( $\mathrm{Cl5}$ ) when we attended the workday for cleaning out the beehives near the canal. We do not remember her very clearly on that occasion, since she did not participate in the inspecting of the hives but instead worked, together with a couple of other women, chopping down the long grass and clearing the area of ants. She seemed to be somewhat separated from the active core of members. Moreover she did not attend the afternoon meeting we had with members of the group, although during the discussions she was mentioned as a day labourer working for a tomato company.

Later, during interviews with individual members, her name came up regularly as someone who had difficulties in fulfilling her obligations to the group because she worked as a caba (chargehand) for the Leones Company, and because of her husband's negative attitude towards her membership of the women's group, which he claimed took time out of her duties towards the family and himself. He was reputed to be particularly worried about the possible loss of earnings when she chose to work for the women's group rather than for the company. It was said that

\footnotetext{
"she worked in the tomato company to help her husband, sometimes taking a child out of school to go with her... Members of the committee had told her once when she said she couldn't go and work with them that she would either have to fulfil her obligations or leave the group. She could give a quota of 2000 pesos. She said she wasn't going to donate her labour. It isn't right that she doesn't go and work with us."
} 
Despite these criticisms, however, Rosa continues to work as a day labourer and has not yet been expelled from the group. She attended a workshop on the "History and Problems of the Group" that we organized, but she misses many general meetings. She also missed the "babyshower" party organized for one of the members, Dora (Ci3), whose first baby was due soon. Dora had suffered several miscarriages and had "officially" been excused from work for several months.

A glimpse of her family situation

wishing to talk to Rosa, we went in search of her. Petra, the President had pointed out her house directly across the street from her own. Rosa received us in the patio in front of a room with a $\mathrm{TV}$, a not uncommon feature of rural househoulds that have electricity. In the patio were two dogs and many cages containing fighting cocks. The area was unkempt and crammed with fruit trees and animals. During the interview eight young women arrived to watch the TV soap opera. Rosa explained that these were women friends from the work group (cuadrilla) of toma to workers. Also twice people called to buy mangos and avocados: her daughter attended to them, only interrupting her briefly to check the prices. Then her husband arrived on a motor bike with a friend of his. With barely any greeting, he proceeded to mix food for his prize cocks. He spoke little and gave some of the mixture to his friend who then immediately left. The rest of the time the husband stayed within the house and, although invited to join us, he refused. He only once came out to ask Rosa whether she had turned off the mango drink she had been cooking on the burner. Later we learnt from others of the women's group that Rosa's husband had been very jealous because his wife was interviewed by a man.

Rosa's involvement with and views of the women's group

Like Petra, Rosa joined the group as a replacement for someone who dropped out. She had no previous experience with village clubs or groups, nor had she been a nember of any church association. She was invited to join the group by her sister-in-law (who has since 
resigned), during Juana's Presidency, at the same time as Petra. Like the majority of members she had no previous experience or knowledge of bee-keeping. She attended the courses given by BANRURAL and by Beto, the bee-keeper from Puerta de Barro, who had been invited through Petra's sister who is his neighbour in Puerta de Barro, to advise them on bee-keeping techniques. But, as Rosa explained, she faced some opposition to her joining the group:

"I had to ask permission from my husband and although complaining, he accepted. The small amount of money from the collective earnings pacifies him. It's a lot of work but being together is nice. My relatives joked about it in the beginning but they have become adjusted to it".

Although she has never participated one hundred percent since joining, she is enthusiastic about their activities. She finds working in a group

"nice, because we give each other support and it is beneficial for oneself and there are also earnings... The solidarity between us is great."

She went on to give the example of pregnant Dora who was going to quit because she could not fulfil her work quota. But, after consideration, the members decided to excuse her from duties for eight months because of her pregnancy. She also mentioned the surprise "babyshower". She compared this with the women's group in Mesquitan (a village in the same region) that had kept chickens, but

"they quickly got tired of each other and quarrelled and shared out the chickens. Our group is united but at times the burden of the work and the lack of earnings cause friction among us."

She supports the views of her friend, Petra, the President, that they must be punctual and that there should be good control of the absentees and late-comers who must be recorded each month in the minute book:

\footnotetext{
"It is good to have order. We put forward points and discuss what was gossiped about at the dances, and things concerning the group, but we never involve ourselves with other things, such as the village fairs."

She also acknowledges that she herself has some problems with the group. Her daughter once overheard the Secretary, Gloria (Cl), criticize her for her irregular participation, and this remains a difficulty for her and for the group. Recently the same secretary described her case as

"inconsistent. Because she works in tomato production, she doesn't like rules much, but she has to accept them. She prefers working in tomato production because she has more friends, and what's more one of them is a man!"
} 
On the other hand, when the President and Treasurer recently reviewed the situation of "the delinquents", they did not particularly pick out Rosa. Hence they do not wish to make it too hard for her, especially as Rosa herself proposed to pay for her lost days in order to retain her rights in the group. Others, though, stress that they not only need quotas and payments in lieu, but hands to work! This indicates that there is presently some dissent among members as to how to handle her case. During Juana's Presidency, Rosa was able to send her son to substitute for her but under Petra's regine she is expected to fulfil her obligations herself. If she does not, then she has to suffer the consequences. They may leave her share of the work undone, so that she can do it on her own the next day. Not only that, but she is made to feel ashamed because they read out at the monthly meetings the names of those who have not completed their obligations.

Rosa has few close friends in the group, although one of them she calls her comadre ("co-mother" or "ritual kinswoman") Elsa (Cl4). As she explains, her closest friends and comadres are people from the nearby villages of Corcovado and Mesquitan, from where she herself originates. Her only trustworthy friend, it seems, in Ayuquila is Petra who, as we mentioned earlier, lives opposite her. Like Rosa, Petra is also married into Ayuquila, and likewise suffers a little from being a "foreigner". Petra has a positive attitude towards her working for the companies: at one of the group's meeting she said that the companies were a good thing for they brought regular work.

Rosa says she would not want to be chairperson of the women's group. She thinks she is hopeless at expressing herself. In the workshop we organized she found it difficult to introduce Elsa (Cl4), her neighbour and comadre. "My companion is a nurse", she hesitated, and then after a long pause, "she is very young". She also took a very minor part in the role-playing drama that depicted the history and problems of the group. She believes that one day she will have to take her turn as an officer but she hope they will give her a low-level position. In any case, "the years are long and many" and therefore it will be a long time before they call upon her. It is the same situation with the bee-keeping activities: she takes a back-seat role, preferring to be told what to do by the experts, Petra and Juana. In striking contrast to this, she says she likes to be in charge of tomato production. She is the chargehand (caba) for one of the work squads based in 
Ayuquila, and has worked as a day labourer with the companies since she was about fifteen. She is therefore very knowledgeable and experienced in the various production tasks. She argues that with tomatoes there is more of an atmosphere: they are running around, sharing and gossiping all day, whereas "with the bees, it's just a short time and that's why I don't like it".

"You with your group of cock fighting men and me with my group of beekeepers"

As our first encounter with Rosa's husband suggested, their conjugal situation is fairly divided. He takes care of his affairs and she is expected to be both the dutiful wife and a second income-earner.

The husband is an ejidatario possessing some five hectares of irrigated land and an orchard with about seventy fruit trees near Chacalito. He has been cultivating sugar cane for the past fifteen years or so, and hopes to retire as a cane grower. Cultivating sugar gives him access to credit for farming and the family the right to social security. Even so, in Rosa's opinion, those from the sugar refinery control everything and "they pay my husband as though he were an unskilled labourer". Apart from sugar cane and mango trees, he also raises cocks for cock-fighting. Presently he has some 120 cocks ready for fighting, many of which are kept in cages near the house.

of these various activities, cock-rearing and cock-fighting are $h$ is great love. Like himself, many of his friends are cock fighting men (galleros). Several of them, who come from several villages within the valley, are also his partners in cock-rearing. They meet regularly to discuss their cocks and to attend cock-fighting sessions in the valley towns and villages. They often place bets themselves and sometimes make good winnings. He moves in a circle which is regarded as essentially macho.

Rosa's husband and friends often drink together ana turn up at the house expecting to be served food. Rosa finds this very irksome. She also complains about the way in which he expects the children and herself to look after and feed the cocks when he is away (not only those kept around the house but also those kept in the farming plot): 
"This martyrdom began five years ago; it's enough to drive one mad. But he likes it and it earns money. The other day he sold one for about 50 dollars."

However, his involvement in cock fighting gives Rosa some excuse for developing her own interests. She tells him:

"You with your cock fighting group and me with my group of beekeepers."

Although she can earn about 4000 pesos (in 1987, approximately 4 US dollars) a day working for the tomato company, she judges that sometimes it is more worthwhile to join in the activities of the beekeeping group where she can find "togetherness" and "solidarity". But, according to her, this has frequently sparked off quarrels with her husband who

"complains because I have lost a day's work, and I feel bad to see that at the end of the week I have less salary than the others in the work squad."

Rosa, then, is caught in a dilemma: she enjoys the women's group and is able to use it in her attempts to assert a little independence from her husband, but if she were to participate more fully, then the result would be less income for the household as a whole. The beekeeping enterprise has not reached a point where the earnings from it can compete with those from agricultural wage labour. Also increased participation simply exacerbates the conflict of interests between her macho husband and herself. Keeping a balance between day labouring and the women's group appears to be the best option so far. By combining the two, she can benefit from the camaraderie of her work friends as well as the social support of the women's group in Ayuquila.

These two profiles serve to illustrate differences that exist in the ways in which members of the women's group actively reconstrue their social worlds to create space for their own projects. Petra emphasizes the necessity of developing an "efficient" enterprise, capable of generating income and giving the women in the group some basis for economic independence. She stresses the need for organization, cormitment and moral rectitude: she is a stickler for rules and authority. Most of the other women do not take rules so seriously (they talk about "Petra' law"), but several share her aspirations for the enterprise's future, summed up by the secretary Gloria's (Cl) hope that one day they will have their own label for the jars of honey with "made in Ayuquila" on them. A further interesting point is that, although Petra's entre- 
preneurial initiative and commitment to the project have sometimes caused friction between her and her husband, she has managed to negotiate a modus vivendi that provides a space and some legitimacy for her bee-keeping activities within the diversified economy and social order of her household. This has been, on the one hand, facilitated by the fact that she shares with her husband an entrepreneurial attitude, but is, on the other hand, threatened by his present lack of success in his own ventures.

Petra's participation in the group has therefore resulted in her achieving more personal space within her family-household. It has also enabled her to consolidate her relationships with her sisters-in-law (BIl and Bl3) and nieces-in-law ( $\mathrm{C} 9$ and $\mathrm{Cl1}$ ), all important members of the group, and thus to gain the general respect of her in-law families (the Gomez-Romero grouping). For other members, this strengthening of ties within the village is not so much a priority since they have grown up and married within Ayuquila and therefore form parts of established family networks linked into local genealogies. Such members often face the opposite problem of extricating themselves from the pressures of belonging to such networks where "traditional" gender norms and attitudes are much more fixed.

Rosa is also married in but her situation is very different. She in fact spends relatively little time in the village. Many of her days are devoted to working outside Ayuquila for the tomato companies, during which time she interacts with other tomato workers and company personnel who come from a number of localities in the region. During working hours, therefore, she hears about what is going on in other villages and in the tomato companies, and it is with a group of women workers that she shares her own observations and problems. Working in the same cuadrilla over an extended period has led to lasting friendships with some co-workers, especially two who also live in Ayuquila. As we explained earlier, this commitment to working outside makes it difficult for her to fulfil her obligations to the women's group 7 . It also tends to marginalize her from the informal discussions and everyday flow of information that take place between members in the course of their daily activities in the village. However to reduce or to give up working for the tomato companies in order to devote time to beekeeping, as she herself once proposed, seems impossible given her household situation. To drop this work would bring about a major 
confrontation with her husband who insists that she earn regular money to supplement his earnings. Rosa's present situation then limits her commitment to the women's group, although, as she herself explicitly acknowledges, being a member helps her to carve out a little bit more room for herself $v$ is-a-vis her macho husband. However, somewhat paradoxically, the segregated nature of her and her husband's fields of activity gives her an advantage over women who are more housebound, since she can develop an external network of friends and acquaintances, and devise ways of pursuing livelihood strategies that lie outside the direct control of her husband. Membership of the women's group has increased her livelihood options but is unlikely to make it possible for her to renegotiate the terms of her "conjugal contract" (Whitehead, 1981) 8 .

\section{A development project}

We now trace out the history of the project, focussing on a series of situations that evolve around the need for a locale for the activities of the group. This issue involves the interaction of the women with people from "the outside", in this case with employees of the Ministry of Agriculture and water Resources (SARH). The process of intervention that is generated provides insight into the way a project slowly gets started, acquires its own momentum, but then undergoes a series of shifts and ambiguities in objectives that result from the differential perceptions and interests of the participants. In describing the events that took place during a period of 14 months, we hope to highlight how plans from outside are modified, as well as the decisions taken by the group, when new information is received and new knowledge generated. These changes involve alterations also in the life-worlds of the different actors, in the projects they conceive for themselves, and in the way they see themselves vis-á-vis to the outside world. 
A store is constructed: October 1986

In October 1986 the group was extracting their honey. The yields were very good. Petra - then Vice-President - comments that it was like a dream to see so much honey. They gave away pieces of honeycomb and jars of honey to friends, neighbours, relatives, and to public offices. After that it was even better. As soon as they had finished extracting the first yield, the combs were full again. They harvested again in November, then in December, and once again in January.

For many people of the village this was a surprise. Many say they had not believed that the women could really do it. There had also been conflicts because some of the ejidatarios did not agree to their being given land, arguing that they were women who did not do the things they should, they neglected their duties ("desquehaceradas") and would not know how to manage the enterprise.

There is a shortage of land in Ayuquila, with a number of ejidatarios having less than one hectare of arable land. These are given plots on the nearby hillside, which they use either for grazing cattle, if they have some, or for producing pasture for sale. The women's group who had been donated hillside land by the ejido adopted the same strategy of selling pasture. With the money they earned and from that received from the sale of their honey, they decided to build a small store. It was a big sacrifice for them not to share out the earnings, since each had many ideas on what she would do with her share. But it was a real problem to store all their tools, the bulky extractor, the big 200-litre can, and the growing number of wooden boxes and frames for the wax in their houses. When they were extracting, it was an even greater inconvenience, not only because the sticky honey and wax got all over the place, but because the house immediately filled up with hungry bees.

The decision to construct a store was unanimous, given the need for a physical space in which to work, to store their things and to hold meetings. An ejidatario sold them a small piece of his urban plot for 40,000 pesos, which was very cheap, and they contracted a local bricklayer. Although the store was small, it satisfied the requirements of their enterprise. They only needed sufficient space for the extractor and the decanter, a space for capping the combs, and a place to keep 
the boxes and frames. The space was also big enough for the sixteen members to meet.

Another store! Circa January-February 1987

However their store was not yet finished when an extension officer from the local district SARH office came to offer them a bigger one. In a later interview, he explained to us that he had been commissioned to:

"offer them the possibility of applying for a building that the Federal Government would donate to them as a honey-producing group. I took the documents and called an assembly."

This initiative was the result of information on all production groups in the zone sent to Mexico City by his predecessor. The Mexico City office obviously liked what they were doing and offered support. The extension officer commented that it is often difficult to get people to form into groups, that peasants have little faith in the government, are tired of promises and prefer individualism. He takes himself as an example: He runs a stall at the local market with his father. He says he owes much to his father, who gave him an education, but he says it does not work, and he is constantly asking his father to sell him his share. In his opinion, he thought that the group was being offered support because they were women, which he affirmed was not at all common. But the funds had to be applied for and so the extensionist took along with hin the application form which he hoped he would persuade them to sign. He adrits that he knows nothing about beekeeping since $h$ is work is centred around agriculture and irrigation, but claims that this is an opportunity that only presents itself once in a century. He told the women that the offer was conditional upon then supplying the labour for construction:

Initially they said yes, but then backed down when they thought that they themselves were going to have to construct it. The problem is not that they are afraid of work, but of what people will say about them. They will say they are "gallos machetes" (i.e. what we call "butch women" or "masculine types"). I told them that if they wanted, they themselves could of course do the work, they could take the shovel, but it would be better to pay a labourer. We insisted they accept the new store because, in the first place, they had overcome the difficulty of working as a group and they were willing to work together. They thernselves say that they can stand up to 100 bee stings, and that they do it to help their families, because they can't live on 
what their old man makes. We have to help them because it is our responsibility to contribute to their development!"

It was important for the women to accept immediately, because if not that part of the budget would have to be returned to the central office and allocated to another zone. There is a certain amount of prestige for the field worker and for the departments involved with this type of work, especially if it is a women's group, because present government discourse or rhetoric emphasizes the importance of the development of "peasant women" (mjeres campesinas). On the other hand, there is the possibility for government personnel to inflate the figures a bit, or to contract construction companies through personal connections, which allows some financial gain, a not uncommon practice in Mexico.

Do we want another store?

This posed a problem for the group for the convenience of having a new store was not clear to them. Having to spend their earnings on labour was only part of the problem, though it was an important part. As one of the oldest of the group, Eugenia (B16), put it:

"I would rather have my share, even if it is only enough to buy myself some tennis shoes, for it will not be long before $I$ die, and I want to see the profits of my work. If I die, my daughter will. not take over and risk being stung by the bees!"

Eugenia is 67 and often jokes symbolically about her desire for a pair of 'tennis shoes'. She loves to watch TV soap operas. She is said to have enjoyed "la vida allegre" (i.e. "the good life", implying having had many lovers) before she married. She has a sympathetic husband who helps with the bees and has an adopted adult daughter.

Another part of the problem was that they feared they would run out of money half way through the project and not be able to fulfil their commitments. Some, especially Sara (C5), a peasant woman who has spent all her life helping raise cattle and cultivate the family plots, and is said to be "finely in tune with nature", felt that the present store was enough for their needs, that it was near and convenient for everyone. Dora ( $\mathrm{Cl} 3$ ), for example, could leave her new born baby with her mother who lived close, and could then easily go to meetings and still be within calling distance. Another, Benita (B18), has quite 
severe problems with varicose veins, and when she cannot work because of this, she can at least get to the meetings. The idea of the new store implied looking for a new plot, which was unlikely to be sited close, and it would probably mean taking a new loan from the bank to cover the labour costs. They were relieved that they had almost. finished paying the original loan, and thus were reluctant to take out a new one.

On the other hand, Petra, the President, was quite enthusiastic about the idea of a new, big store. For her, it meant the possibility of expanoing, even if they had to sacrifice a little for the moment. Another pressure on the group was the feeling, held by several of the women, that the comisariado ejidal (local ejido leader), who was also a brother-in-law of Pastora (B20), had put a lot of effort into getting the funding through. He had told thern that they had to accept, if not, he would get it for himself and they would lose their opportunity. since he is a respected person in the village, and has helped them on many occasions, it was difficult to refuse. Petra is particularly susceptible to such pressure, usually agreeing with any authority. Most of the members agreed that it was an opportunity that could not be easily turned down, but they did not conceive of their project as a large enterprise that required such a big and costly building. The thought of expanding had not been one of their dreams, and it implied more time away from their household tasks and their families, as well as the fear of not being able in the long run to fulfil the commitment. so finally the group decided to tell the extension worker that they did not want the store.

You cannot give up the opportunity! March 1987

The extension worker, however, did not give up. He asked for help at a Municipal Cormittee meeting where representatives of all the local government agencies and the towns and communities of the municipality were gathered. He asked what he should do if the women continued to refuse the store. The Mayor of Ayuquila offered to meet with them and to try and convince them.

This was done, and the women comment enthusiastically about the meeting. They were told that they had won a lottery, and that opportu- 
nities like this should not be wasted. During a role play session, in a workshop organized by us, they chose to re-enact this meeting. They selected this meeting as one of more important ones they had had with "outside institutions". Through the play we learned that the Mayor had agreed that their own store was alright, but that in time they would need a larger one. He was pleased to know that they were well organized, and to hear everywhere that there was a peasant women's group in Ayuquila. It was a credit to the village. For that reason, he had come to see if he could help them and to tell them not to get discouraged, for it was a very good opportunity for them. He offered to lend them money if they could not pay, and also to donate some truckloads of sand and gravel.

Faced with this kind of pressure - an imposing visit from an important local authority - the women accepted the store, deciding not to share out the profits from that year's harvest and thus to save as much as possible until they knew how much the labour was going to cost. They also decided that if they had no other alternative, they would sell their own small store, but only as a last resort because they had become fond of this small building. After all, it was the product of their own work and adequate to their current needs. Nevertheless, they did not want to let down the authorities by not agreeing, and they preferred to have some cash in hand, since they constantly said to us, "What if the people from the Ministry come and we have nothing?"

Neither one thing nor the other. October 1987

But time passed and the people from the Ministry did not come, and the wornen heard nothing more about the new store. As November was approaching, and with it, the time to begin harvesting the honey, the issue of sharing out the profits was beginning to reappear in the everyday talk of the women. One of the members who had been most in favour of the store, Juana (C9), the Ex-President, even made calculations as to how much money each of them would get. She concluded that each one would receive around 100,000 pesos (about 100 us dollars at that time). Petra (B7) began to accept that they would have to divide up their gains, as the store issue was "too cold". Luisa (C3) also thought they should divide up the profits: she had never been entirely 
in favour of the idea of a bigger store and anyway is generally sceptical of government offers. Luisa is well-connected politically, her husband having held several village offices, including that of comisariado twice, and maybe it is her insider view that accounts for some of the scepticism she expresses regarding government efficiency and its ability to keep promises.

However, circumstances changed and they started noticing with some concern that they might be able to do neither one thing nor the other, because each time they went to check the hives, they found them very low in honey. They started going twice a week to feed the bees, carrying the heavy 20-1itre can of sugared water with them. Petra became even stricter over the workdays, and when it was no longer necessary to feed the bees, she would make them repeatedly go to see how much honey there was. This created some resentment for it was extra work, but it also made some of the women laugh, saying that the bees "would catch a cold from so much uncovering". It was soledad the dressmaker (B13), who made this light-hearted comment, but behind it lay a growing irritation with Petra, the president. Sara (C5), with a life-long experience of the land and its creatures, felt that petra was interfering with the bees' work. Petra herself, of course, has no intimate knowledge of farming and tends to rely heavily on books for her knowledge. They felt it was time to harvest and were waiting for the green light to go ahead, even if there was little honey, for they feared the bees would eat it all if they did not remove it. Petra, however, wanted to wait a while longer to see if they would produce more. Finally one of them convinced her that they ought to start, stressing that they would not have to hire a truck, but could bring back the honeycombs by wheelbarrow. The bank bill had arrived, and they needed the money badly. Under no circumstances would they consider refusing or delaying payment. They would make tamales (a special Mexican dish) to sell if they had no other alternative, but they would certainly pay.

A shared store would be better! November-December 1987

Then a new idea for the store arose. This came about in the following way. The organization department of the SARH had created an association of bee-keepers for the whole region, as part of a special government 
programme geared to counteract the possible devastation that would follow the arrival of the African bee, an aggressive variety that attacks other bees and produces little honey. The women (normally represented by Petra, the President, and Ana, the Treasurer) had attended all the meetings discussing this problem and took advantage of the opportunity to ask other bee-keepers about their knowledge and experience.

The head of the local SARH office, Engineer Lopez, was planning to establish an agro-industry for this Association, for which the Ministry would supply the materials for constructing the necessary building, the Association the labour, and BANRURAL the credit to equip it. The credit had to be approved before the end of the financial year. Engineer Lopez attended a meeting of the Association where he explained to the members this possibility. There were two problems, however, to concluding any agreement. One was the lack of a quorum: participation at the meetings had been flagging. The other, more serious, was the lack of land upon which to build. Since all the bee-keepers, except the women, were individual producers with private plots and no access to ejido land, no-one could offer a plot.

At the beginning, the women were not too enthusiastic about getting involved in this venture which was being pressed on the Association. They thought the processing plant would be located too far away for them to take their honeycombs and wax to be stamped. Then someone suggested that the industry be installed in Ayuquila, since all the rest had transport, and it was a central place. Besides, and most important, the women were a formally-recognized Industrial and Agrarian Unit for women that had the right to ask the ejido for land, which none of the other members of the Association could do in their villages. Petra considered this a good opportunity to share the responsibility which they had been reluctant to shoulder on their own. In this way, they could benefit from the wax-stamper, the electric extractors and knives etc, without being burdened with the whole debt themselves. Also they would have more resources at hand without having to expand so much. Hence they could remain a small industry, but benefit from the use of modern implements. petra talked it over with the rest of the group, who saw the advantages and promised to think it over. They then started to look for a suitable plot in the ejido, consulting their husbands and other members. This search was not, however, without 
problems for it opened up old conflicts concerning whether women should get land, and reactivated some old quarrels between families, including the two big families to which a number of members are directly or indirectly linked. And these difficulties and tensions, in turn, became reflected with in the group.

Here it must be said that the above course of events was not at all clear to the women. There was considerable confusion and they did not at first see that the two initiatives were separate, the store being introduced by a local extension officer as part of a special programme launched from Mexico City, and the idea of an agro-industry being proposed by the local office of the Department of Organization (SARH). The field researcher, who at the time was interviewing and interacting with all parties, in fact had a clearer view of these processes than the women thernselves, who often turned to her for clarification. The women had to grapple simultaneously with the idea of a bigger store for their future possible expansion, and the notion of an agro-industry that would serve the district. The suggestion to locate the Association store in Ayuquila was seen by the women as a way of sharing the processing expenses. They had little understanding of what large-scale processing in terms of labour and equipment might entail.

It is difficult to say exactly when some of the women actually started wanting "this store" and its benefits, and when some started reacting against it. Reservations arose not only because the store was likely to bring more work, interfere with domestic tasks and mean, for some, entering the unknown and probably masculine world of the enterprise, but also because it had, in a way, become Petra's project, and some had personal things to resent. For instance, the old and inactive member, Mercedes (A3), had finally been excluded from the group, and her niece, Magda (B5), still a member, had not liked this. Then there was the question of finding land for the proposed store. It was rumoured that the comisariado ejidal suggested that the most suitable plot was close to the present canal. This site had once belonged to Juana's father-in-law before the canal went through, but had somehow been taken over by a government employee who now grew crops on it. Although it seems unlikely that this was actually proposed by the comisariado, it set off a series of accusations between the two big family groupings, with the Martinez accusing the Gomez-Romero of being "too soft" in their dealings with outside authorities. Because of this, 
it was suggested by some members that they should simply build on the hillside plot they already had, and not get involved in the search for a new site.

All this had negative repercussions on the group, leading gradually to a quiet but significant opposition to the project as a whole. This was especially noticeable in the "go-slow" attitude (called "tortugismo" in Mexico) shown towards the work and meetings of the group. In spite of Petra's strictness in taking roll calls on workdays and at meetings, and compelling absentees to complete their work tasks later on their own, several members found excuses to absent themselves: they had a headache, needed to make a trip to the Municipal capital of El Grullo to do some urgent job, or they had children they said they could not leave. One member, Luisa (C3), who often spoke openly against the government and its broken promises, was always late for the meetings and work. She argued that she had more important things to do. And, even though she showed herself to be intelligent and knowledgeable about bee-keeping, she adopted a slow working pace in all the chores which involved the group. At least three of the members (Benita, B18; Dora, $\mathrm{Cl} 3$; and Elsa, Cl4) showed no real interest in learning anything further about bees, the older ones claiming that they could not see the tiny eggs in the cells well enough, or that they were too old to learn. These three normally picked jobs, Iike holding the fumigators, which do not entail much responsibility. Eugenia (B16) would constantly interrupt the meetings to tell them to hurry on to the next point, since it was almost time for her T.V. programe. Rosa (C15) manifested her disagreement with silence. She simply did not talk when Petra was present, even if she did work efficiently.

Petra, on the other hand, saw her dreams of a productive and efficient enterprise reflected in this project. It was no problem for her to put her household chores to one side. On several occasions she commented that all her time was at the disposal of the project. A further five members showed a real interest in this joint venture: four were Petra's affines and members of the Gomez-Romero family - the two sisters Socorro (B11) and Soledad (B13), Socorro's daughter Ana (Cl1), and Juana (C9), the Treasurer; and the fifth protagonist was Gloria (Cl), the secretary, who is a menber of the Martinez family but ahijada (godchild) of socorro (B1I) and comadre of Ana (C11), both of whom belong to the Gomez-Romero family. In other words, Petra was supported 
by a network of close ties centred around the current office-holders and women in the Gomez-Romero grouping.

Now its an Agroindustry! December 1987

On the fifth of December, Engineer Lopez, from the District Organization Department of the SARH came to the Treasurer's house to inform her of a meeting of the Association and to ask them to accept the agroindustrial plant for processing honey for the women's group, since the other bee-keepers showed no enthusiasm, and the SARH needed a quick answer.

The Treasurer told us that she was not used to men coming to visit her at her house, so she was nervous and did not know what to answer, but that she finally explained to him that for the moment it would be difficult to accept, since they were not doing too well with their honey production, and therefore were not solvent economically. (She later explained to us that she wanted to see whether there was a chance of them paying for the labour). His answer had not been very clear, but she was under the impression that things might be arranged so that SARH covered these expenses. They agreed to organize a meeting for the next week, when the women's group would give them an answer.

This officer was relatively new in the region, and had met the women at the bee-keepers Association. The Association, like all other organized groups of producers in the district, falls within his competence as head of organization and Training. He subsequently discovered that, under another department, SARH had already offered the women a store, and that the application was being processed. However, he continued his interest in the women's group, explaining that he hoped the group would

"... develop and integrate itself, so that they do not see their actions as merely subsistence and hobby, but with a managerial mentality; it is important that they understand that they can grow with the products that they have."

He considers that they can even export their products, and can become

".. a source of development for all the bee-keepers of the region. of course, they would first need an intensive technical training, in order that they are more prepared." 
Should we accept, or not?

The Treasurer and her aunt (her mother's brother's wife), the President, were worried at having to give an answer to this officer at the meeting, for apart from feeling that they still needed more information, they were afraid of the reaction of some members of the group. Events had moved so rapidly. So they decided to invite them without telling them what the meeting was going to be about, knowing, that if they told them, they would give their opinion - probably a negative one - before the meeting, and then would probably not attend, thus closing themselves off from the opportunity of learning the details. It would be better if they heard about it directly from the officers. Petra believes that some women close themselves off because they are ignorant of the possibilities they have and, as they hardly ever go to meetings with other people, they do not hear things, and have little information about how things are, that is why they think the way they do. She explains that the ones that are interested in "growing and progressing" are those that attend meetings and talks.

other members, however, argue that Petra is too inclined to think that everything is possible, that she doesn't take into consideration that they have families to look after, that it is a waste of time to go to meetings where government people just promise things and never comply, and so on. Interpersonal family quarrels were, as we indicated earlier, also involved in the positions individuals took towards the idea of the new project: for example, Socorro (Bll) was having difficulties in relating to Eugenia (B16) as her son had made Eugenia's daughter pregnant! In rural Mexico there still are heavy social and religious sanctions on such conduct.

Thus it was that the president and the Treasurer decided not to inform everyone of the purpose of the meeting. They decided that the other four who were positively for it could be told, but the remaining ten members, though not overtly against the SARH store, might still present some opposition. In the event, only two others knew of the reason for the meeting, and one of them could not attend, because she had another appointment outside the village. 
The chief of the Organization Department could not come to the meeting as he had promised, but sent in his place an extension officer of $h$ is department. He had not been told that the women had already been offered a store by the same Ministry, and as most of the women thought he had come to talk about that, there was considerable confusion.

As was their custom, all the women stood up when the government official arrived. He immediately began to talk about the proposal for an agro-industry:

"What will be proviaed to you has been offered before to the people of the Association. I believe you are also members. We saw that they were not interested in this honey-processing plant, so then it was proposed that, as the budget for this had already been accepted, it should not go out of this district, and if they don' $t$ want it, we would like to offer it to you. We hope you will accept it. We know this will not commit you to anything. SARH promises to do all the construction, and the bank will lend you the money for the machinery, implements, or whatever else you need. That you will have to pay back to the bank."

The women asked questions. They asked about the future loan, if it would be a fixed amount or they could ask for only what they wanted, keeping in mind that none of them wanted to owe anything. Then they asked about the labour, at which point, the extensionist, detecting their fears, reassured them that the Ministry could inflate some costs in the budget and pay the labour with those extras. He insisted that:

"...this can be managed by yourselves, so that you feel its yours. That way, when you feel you own it, you will be able to manage it, you will have a greater interest, and will feel affection for it. If you say "no, it's the government's", you won't feel it's yours."

It was then that the Treasurer asked $\mathrm{h}$ im if he knew about the other store. He was surprised, as were the other women who had assumed that that was what he was talking about. After asking questions, he seemed pleased and said that the other project could probably be integrated into the new one, which was to have covered more things. The women now realized that he was talking of the agro-industry, which they now understood was to be for them alone. Their store would then be part of the project, which would also include space for processing and a bathroom, and an office, etc. "In this way", he said, "they might even have money left over for other things".

The conversation then started to get more animated: the women asked more practical things (which showed they had accepted it more as a 
possibility), such as where could they get a plot of land for building it; would it be possible for the Ministry to bring machinery to level out a plot that was on the hill, and so. The extensionist thought all this would be easy, as the Ministry had its machines nearby. Petra then explained how little money they had at the moment, the problem of the low yields of honey they were getting, and the payments they had to make to the bank. This last statement pleased the extensionist, who had been worried that the group might not be eligible for government credit. That they still owed money to the bank was no problem at all. He then insisted several times that the project was urgent, and that they had to send the papers to Guadalajara before the Christmas vacation, although he wanted to make clear that he did not wish to precipitate decisions that they would later regret.

The decision to accept was unanimous. The extensionist even offered to wait, if they wanted, so that he could talk to the two absent members, but the women argued that they had an agreement that when a member was absent, she was bound to accept the decisions of the others.

Later, several of the women commented to us that it was possible to have easy dialogue with this extensionist, because he talked at their level, explaining everything patiently, not like the other ones that had come, whom they often did not understand. True, but it was also true that these wornen from Ayuqyila were becoming more confident at dialogue.

\section{Conclusion}

This chapter has consisted of an ethnography dealing with the formation and social dynamics of a small-scale development project for women in western Mexico. It was organized in two parts. The first examined the ways in which the women's group provided the stimulus for individual members to reflect upon and begin to reorder their life-worlds, especially in relation to their households and the village domain. The second focused on the history of the project from the point of view of the group as a whole, showing how its social meaning shifted over time as new circumstances arose. Although some attention was given to describing the interests and strategies of government institutions and personnel, the main emphasis of the chapter was on documenting how the 
women's group struggled to define, and then to reassess, their own objectives and to orientate themselves towards new contingencies that were opening up to them.

The case raises a number of interesting issues for further exploration. In the first place, it highlights the complex process by which local groups and individuals internalize outside interventions. These externally-originating ideas and resources are reworked by the receiving parties on the basis of existing interests, organizational capacities and knowledge frameworks. They are also shaped by the ongoing exchanges and negotiations, both material and symbolic, that take place between local and extra-local actors. This internalization process, as the Ayuquila case brings out, however, is seldom smooth and linear. It is full of "ups and down", ambiguity and potentially new directions and rationalizations.

Secondly, the case itself may seem small and insignificant but, set within the context of enterprises undertaken by groups of women at village level, it assumes greater importance. There are relatively few such groups in Mexico and even in the Autlán-El Grullo region, one of the more prosperous and go-ahead areas of Jalisco, we have come across only three. One of these ran into major difficulties and disbanded, but whether or not they fail, they are the beginnings of something that is likely to grow as the experience of women makes them more aware of the possibilities for developing their own projects. Government has played, and continues to play, some role in this: credit for groups of peasant women is relatively recent, but almost as important is the rhetoric of "women's initiatives", which has entered village discourse and is therefore unlikely to fade away completely. Such random small beginnings, often with unintended consequences, can constitute the seeds of more enduring change.

In the third place, the case shows implicitly that the notion of interface is an important structuring principle of social life since the identities of individuals and social groups are generated and reproduced, among other things, through their many encounters with like and unlike - encounters at the boundaries. Self reflection can only take place in relation to contrasts and oppositions to self; and the definition and transformation of life-worlds can only occur through reference to their boundaries. This case elucidates how these processes begin to take place for a small group in one small Mexican village. It 
also has much greater relevance, touching as it does upon the central issues of understanding how life-worlds are reshaped at the point where structural discontinuities manifest themselves.

\section{Notes}

1. Part of the field data included in this analysis was collected by Gabriel. Torres, who also contributed to an earlier unpublished paper which deals with the theraes of the first part of the present chapter. We would like to thank him for his contribution and for his interest in the analytical issues we exploxe. Also we wish to acknowledge the detailed editorial work, critical comments and significant suggestions made by Ann Long in the writing of the final version.

2. The ejido is a socio-legal entity concerned with the administration of land and other collective properties. Ejidos were established under the 1920's land reform law that followed the Mexican Revolution. The ejido of Ayuquila consists of inaividual household plots divided anong ejidatarios and a communal grazing area. The term ejidatario is used for those who possess land rights to specific plots and who axe listed formally as members of the ejido. The utilization of ejido land is, however, complicated by the existence of different kinds of renting and lending arrangements both among ejidatarios and between them and non-ejidatarios.

3. The names of families and of individuals are pseudonyms. Individuals are identified in the text by generation and number in the genealogy (e.g. Petra is generation $B$, number 7 ).

4. A total of 17 women in Ayuquila combine household work with other familybased economic activities, such as the running of small shops, selling of milk, making and selling of tortillas (a Mexican substitute for bread), etc. A further seven regularly assist their husbands with agricultural tasks, six sell clothes, shoes, perfumery, and prepared foods and six are dress-makers. Eight work as teachers or secretaries and at least eight others work as day labourers for the tomato companies. Of all these women, a majority are members of the women's group, which suggests they are economically the most active women in the village. For details see Table I.

5. Vincent (1977) introduces the notion of "activity fields" to deal with this methodological problem. Habermas" "Theory of Communicative Action" (1981) provides an interesting and ambitious analysis of the relations between "lifeworlds" and economic and political "systems", arguing that in the modern era life-worlds are "constantly subjugated to mediatized colonization by the economy and the state (money and market, power and bureaucracy, respectively)" (Pusey, 1987: 107). However his analysis falls short, it seems, in that it rests too heavily upon Webex's view of the rationalization/modernization of so-called "traditional" social orders, maintaining for example that "communicative action", characteristic of life-world phenomena, is incompatible with "systems of action organized around media like money and power" (Thompson, 1984: 299). This issue requires much more careful research into the restructuring of life-worlds (see Long, et.al. 1986, 1988, and Long and van der Ploeg, 1988, who argue for an actor-oriented analysis of processes such as commoditization, the externalization of labour process, and state inter- 
vention)

6. Coanil is a type of slash-and-burn agriculture practised on the rocky hillsides where maize is grown.

7. After writing this account of Rosa and her problems with the group, her difficulties increased, despite her attempts to comply with the rules enforced by Petra. This led eventually to her being eased out of the group altogether.

8. Whitehead (1981) describes how conjugal contracts structure the ways in which products and income produced by the labour of husband and wife are divided up to meet their personal and collective needs. Her argument is based on a comparison of domestic budgeting in West Africa and Britain. The precise nature of conjugal contracts, how explicit they are, and how they are negotiated willl, of course, vary both between and within cultures. 


\section{KNOWIEDGE SYSTEMS, METAPEOR AND INTERFACE: THE CASE OF POTATOES IN THE PERUVIAN highLANDS}

Jan Douwe van der Ploeg

\section{Introduction}

In so far as the concept of "interface" refers to typical encounters between representatives of development agencies and farmers, an element of negotiation and re-negotiation will, nearly always, be implied. This leads me to the observation that the rules and procedures of these negotiations, the resources involved, as well as the contents and limits of such negotiations, are only very rarely defined in these typical interface encounters. More often than not, they are developed, defined and sanctioned at other social and institutional levels.

This chapter, then, focusses on the confrontation of two knowledge systems in Peruvian potato cultivation and on the subsequent marginalization of local knowledge by a scientific knowledge system 1 . Through this (still incomplete and highly diversified) process farmers are deprived of one of their major resources: local knowledge becomes superfluous. This of course has profound consequences for the dynamics of interface between, what I call, the "experts" on the one hand, and the "invisible men" on the other, and where "development" becomes the merchandise of the former. Anyway, if there is a methodological conclusion to be drawn regarding the issue of interface, then it is that to understand what is happening in interface situations, and especially to understand why things happen the way they do, one has to go beyond interface, and try to decipher how the rules of the game are defined and reinforced elsewhere.

An indispensable link in the reproduction of potato farming over time is the continuous selection and multiplication of seed potatoes. 
In the Andean highlands these tasks still are, to a certain degree, integral parts of farm labour as praxis. They imply a specific structuration of time and space, as well as the management of a specific knowledge system, which can be described as art de la localité (Mendras, 1970). In this paper I first briefly discuss some general features of art de la localité as it manifests itself in agriculture. Then I highlight several aspects of a particular local knowledge system found among potato growers in the Andean highlands, paying special attention to those aspects relating to the management of potato reproduction. Finally, the now rapidly spreading scientific knowledge system, which entails new methods of potato selection and which tends towards a rapid marginalization of local knowledge, is discussed.

\section{"Art de la localité"}

A crucial feature of local knowledge in craft-based agriculture is the way it is interwoven with the labour process. Knowledge, the labour process and those involved in it compose a unity that is hard to unravel into separate elements. The labour process is essentially a craft. In the first place, it entails a permanent interaction between "mental" and "manual" labour and, secondly, it presupposes a continuous interpretation and evaluation of the ongoing process of production so that one can intervene at any required moment and in any desired way. Through such interventions (which for evident reasons are hard to predict exactly) the magnitude of the harvest and the quality of the final product are greatly determined. Thus the labour process does not lend itself easily to any standardization or exact planning. Diversity emerges during the process itself. Decisions taken during the labour process determine the results and, when evaluated in relation to the results, lead to the generation of new or more detailed knowledge as well.

Art de la localité, then, is potentially a dynamic, high complicated and detailed knowledge system. This last characteristic predominates when the labour process involves a broad and complex range of ecological, economic, social and cultural conditions. Then a very detailed and multidimensional knowledge is generated, a "savoir-faire paysan" as Lacroix (1981:95) describes it. "'Savoir-faire paysan' is 
understood as the management of the labour process, within the context of the local eco-system, in order to improve the valorization of elements provided by this local eco-system" (my translation). On the other hand, it could be argued that this same focus on local conditions and on the localized interaction between labour and local eco-system acts temporarily as a boundary and as a potential limit to these particular knowledge systems.

Art de la localité has also been characterized as a kind of knowledge that goes directly "from practice to practice" (Bourdieu, 1980). It does not pass through a theoretical stage in which "discourse" is developed; there are, so the argument goes, "no theoretical expressions". "Experience is not expressed in a univocal, clear language" (Koningsveld, 1986), so the space for further elaboration of this kind of practical knowledge is seen as minimal. There are only a father and his son working in a field, the former every now and then transmitting a rule of thumb to the latter, or punishing $h i m$, as a "padre padrone", when the work is not done properly. This image (presented in a fair number of rural sociological studies as well) is, in my opinion, fundamentally wrong.

There is, of course, "theory" in art de la localite, but this type of theory is organized in a way that differs markedly from scientific discourse. The syntax for instance is not nomological like that of science; the scope is not a presupposed universe but their own and therefore localized labour process; and legitimation is not sought in the construction of laws, but in the coincidence of perspectives and interests, which again are perceived as part of the locality. As Darré, who carried out a beautiful study of the concepts used by French dairy farmers in the conscious and goal-oriented practice of feeding their cattle, concludes: "Elle (i.e. l'art de la localité) n'est pas non plus mesurée à la verité du discours scientifique: nous chercherons sa pertinence en la rapportant au group pour lequel elle est associée à un ensemble d'activités techniques" (1985:43). Perceived through the matrix of scientific criteria art de la localité thus becomes nearly invisible, ignorance of the people involved being one of the most conmon assessments. In addition to this, Darré makes it clear that if need arises even the typical theoretical expressions of art de la localité (often of a metaphorical kind, as I will demonstrate later) can be transformed. Such a transformation occurs when, for instance, 
farmers have to confront newly emerging technical elites such as agronomists, technicians, and so forth.

Local knowledge concerning the soil that is tilled: the importance of metaphor

Andean farmers are confronted with a huge variety of different ecological conditions. Moreover, they consciously aim to increase this variety a) by trying to locate their plots on different ecological "floors" (Mayer, 1981) and b) by trying to improve each plot, not along standardized lines, but by responding to the specific set of conditions that each plot presents to them. The plots are observed, interpreted, evaluated, cultivated and improved by means of an impressive cluster of bipolar and metaphorical concepts. The distinction fria/caliente (cold/hot), for instance, is used to characterize certain aspects of what we would call soil fertility. It relates - but not in an exact or unilinear way - to the amount of nutrients and humus in the subsoil. Dura/suavecita (hard/soft) is another conceptual pair: it refers to the degree to which the soil has been tilled in previous years. It also communicates another important meaning, i.e. the degree to which the particular plot has been "cared for" and therefore the degree to which the plot may be considered as "grateful". The soil is not simply equal to "land" in its physical or geographical sense. It is pachanama (mother earth), and when she is suavecita, then "mother earth is generous". She is "grateful for the respect paid earlier to her". Pachamama, and associated categories such as "hard" or "soft", refer to the specific localized interaction between man and nature. Alta/bajita (high/low) again express notions that at first sight seem quite imprecise, especially if one walks with farmers through their fields and one hears them describing lower lying fields as being "higher". But then, it is not only altitude (taken as a mathematical notion) but also the winds, the way topography shelters the plot from the cold, and even the degree of calor, of fria or caliente, that are taken into account when describing a plot as alta or baja. So in certain respects the different concepts are interrelated; the concepts overlap, not in accidental but in strategic ways. Taken together they form a "network of meaning" as Hesse (1983:27) would express it. These and other concepts are not unequivocal, nor do they lend themselves to precise 
quantification. They cannot be built into nomological models of the kind used in applied science, and technology development. Moreover if one separates these concepts from the people who use them and/or from their context they indeed become "inaccurate". Yet their inaccurate character does not prevent farmers from establishing fairly exactly the overall condition of specific plots. They are also quite able to communicate with each other about this. Indeed the inaccurate nature of these concepts seems to facilitate such an exact interpretation of a plot's condition and the ensuing dialogue. Interpretation and communication are active processes: concepts must be weighed against each other every time a specific plot is being considered. Hence the conceptual overlap becomes strategic. In synthesis: it is precisely the vagueness or "imprecise" character that allows for interpretation and change. "The farmer", to quote Mendras (1970:47), "felt as if he had "made" his field and knew it as the creator knows his creation, since the soil was the product of his constant care: plowing, fertilizing, rotating crops, maintenance of fallow ground, and so on".

\section{Local knowledge concerning crops and varieties: a folk taxonomy}

Most farmers cultivate between 12 and 15 plots continuously and, in addition, a number of plots which are cultivated in rotation. Farmers also interchange plots, sometimes following quite complex schemes that embrace whole communities. Each plot is thoroughly known by its cultivator. A specific combination of concepts, which in themselves are rather vague, allows $\mathrm{him}$ to establish the best way to cultivate it (and in the long run, to improve $i t$ ). "This personal knowledge of the field" (Mendras) is one of the basic elements of the art de la localite. It is local knowledge, which is hard or even impossible to generalize. It is local knowledge because it presupposes an active, knowledgeable actor, who is the "agent" of the unity and constant interaction of mental and manual work. It can also be defined as local knowledge because it allows these actors to obtain a high degree of control and mastership over the highly diversified local situation. In this art de la localité, knowledge of the fields is permanently coordinated with knowledge of the genetic stock that each farmer has at his disposal. Most farmers maintain up to 30 or 40 different cultivars in their fields as well as 
in their chacrita (garden). And through socially regulated exchange they can easily obtain up to a hundred different cultivars, each of which is known to them, or their neighbour and friends in other villages.

The distribution of cultivars over the plots makes for an extreme heterogeneity. Some fields contain only one cultivar, others between 2 and 10, sometimes interplanted in the same row, then again each cultivar in its own row. Mostly one finds a chacrita as well: small plots of 20 or 25 square metres, which contain up to 30 or 40 cultivars. This heterogeneity not only leads to continuous experimentation (which genotype fits best with the specific phenotypical conditions of each plot) 2 and risk aversion, but it also results in the production of new genotypes 3: "The crop evolution of the cultivated potato is closely linked to the mixture of species and genotypes which promotes hybridization and crossing between ploidy levels and among clones" (Brush et al. 1981:80). At a more general, level Brush et al. go on to state that this consciously produced heterogeneity has three consequences: "a) the maintenance of numerous genotypes over space and time, b) the wide distribution of particular genotypes, and c) the generation of amplification of new genotypes" (ibid).

Crucial to the maintenance and correct handling of this genetic diversity is the availability of a "folk taxonomy", another interrelated set of concepts used for the identification and naming of varieties, for the selection and definition of planting patterns as well as for the exchange of cultivars between farmers (an exchange that sometimes covers distances of up to 30 or 40 kilometres). In several ethnobotanical studies the impressive range as well as the taxonomic structure of this nomenclature has been highlighted. What is important here is that this taxonomy must be seen as an integral part of the art de la localité. Not only does it follow some of the features already noted (such as the "vagueness", the "overlap" of criteria, the need for an active interpretation), but in some respects it is even directly linked with the typical knowledge of the different phenotypical conditions represented by the variety of plots. I often noted farmers stating that such and such a tuber could not be a calhuay (for instance) since it could not be grown under certain conditions (considered to be ideal for the calhuay cultivar). Or would state bluntly that a compi is a calhuay, even though they know quite well 
that the particular cultivar is indeed a ccompi and not a calhuay. But that is exactly what metaphor is: "an attempt to understand one element of experience in terms of another" (Morgan, 1986:13). Thus the wellknown ccompi (interpreted here as a cultivar) is related to and temporarily interpreted in terms of the soil conditions required by calhuay. Andean farmers are often labelled as being ignorant. It was indeed the first conclusion that passed through my mind when hearing the expression that a "ccompi was equal to a calhuay". But then, such an argument differs in no way from our everyday manner of speech in that we talk about "god as a shepherd", or "a man like a lion" (or, as sometimes occurs, "as a mouse"). Metaphor is strategic. It is the theoretical expression through which the communication of multiple meaning is organized, its rather "loose" framework (including the overlaps) being an essential prerequisite as well as an important vehicle for the very dynamism entailed in these particular knowledge systems. Through metaphor, coordination of different domains of knowledge is realized; and through metaphor, the proper dynamics created by this coordination can be understood and oriented. Let me illustrate this by means of the practice of potato selection as elaborated by Andean farmers.

\section{Selection: the coordination of knowledge segments}

Now, how is selection organized? At first sight it seems quite simple: the "best" tubers (these are normally the smaller ones) from the "best plants" are laid apart and will be next year's seed potatoes. In reality the process is far more complex, as illustrated in the following diagram: 


\section{Figure 1}

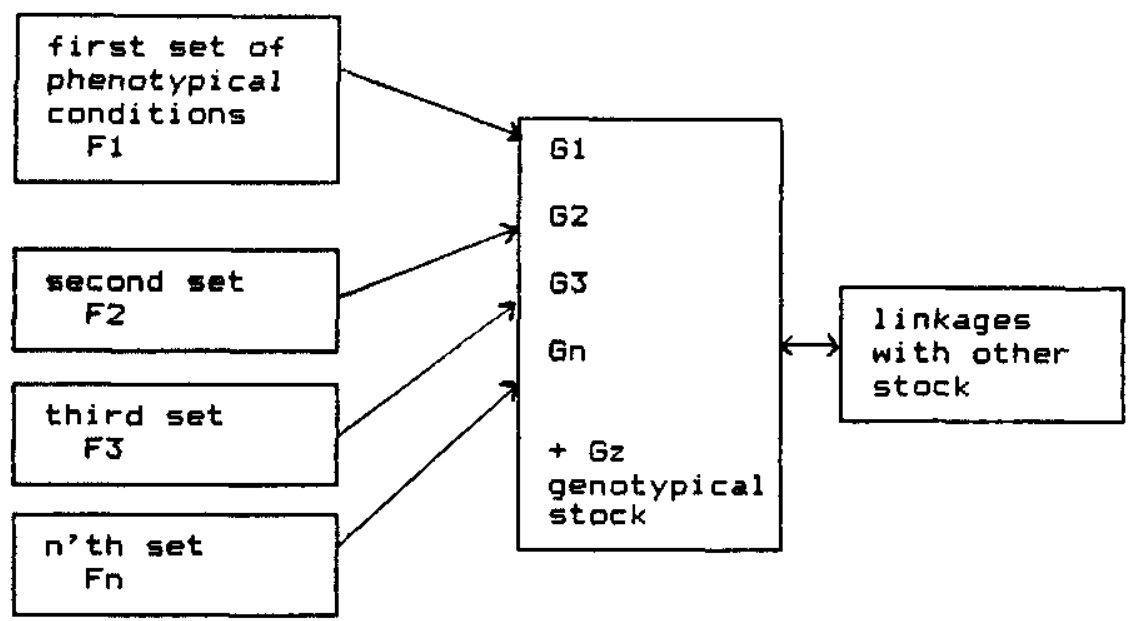

Each plot is known as a typical set of phenotypical conditions. Then the most suitable genotype is selected for each plot. It should be noted that this selection is in no way to be considered as trial and error. It is a clearly goal-airected process, which takes shape within (and can only take shape within) the global framework of the art de la localité, the internally-coordinated and finely-tuned knowledge on plots, cultivars, labour processes and earlier experiences (one's own and others'). To complicate matters even further, one must emphasize that the above-mentioned expression "the most suitable genotype" does not refer to a static state of affairs. The problem is that "the most suitable" genotype changes all the time, sometimes slowly, sometimes abruptly. This is because its definition is dependent on different criteria, such as yields, prices, response to changed plot conditions and so on, criteria which in their turn are variable as well. Through the process indicated, in which the plot (and the labour invested in it) form the starting point, a finely-tuned adaptation is reached. But this is not the point at which the dynamics of local selection stop. The process always goes beyond the limits reached in previous cycles. The dynamics of the selection process are based on two things. The first one has already been indicated: this is the creation of new genotypes. Second, one should keep clearly in mind that no plot, understood as a specific set of phenotypical conditions, can be interpreted as a static unity. In the medium and long run they can be 
improved, precisely because they are the subjects of the farm labour process itself. So progress can be made and new experiences can be gained. Through the cycle of observation, interpretation, evaluation and manipulation, the scope of the art de la localité is enlarged, which enables the farmer to obtain new insights, and so on and so forth.

\section{Local knowledge and the organization of time}

The mechanisms of change and development that are inherent in the dynamics of this local knowledge system do not usually lead to an unstable state of affairs. Changes are more likely to be an accurnulation of all kinds of minor adaptations (which are "invisible" for the normally trained agricultural scientist). Besides, even these minor changes often take place according to a "calendar" which spans great lengths of time. From the "discovery" (or acquisition through exchange) of a slightly different cultivar, via the first tests in different plots, and through its multiplication to a substantial harvest will take at least five to six years. Moreover, every successive step carries certain risks. Risks that are to be evaluated among other things against the particular situation the farming family finds itself in. Indeed, there is a lot of magical belief that prevents farmers from risking too much at once. But, contrary to those who associate such attitudes with stagnation or circularity, I think they are crucial for exactly the opposite reasons: magic - at least in the Andes - is essential for achieving progress within the framework of the art de la localité. The experiments and "the dreams" (as farmers say) are made possible (c.f. Herrera, 1980) precisely because the magico-religious interpretation of the world reduces the risk to acceptable proportions. Tradition and transformation are not at odds - at least not on this level. It is "traditional" magic, with its built-in explanation and fear of the natural world, which makes renewal and transformation possible. Magic delineates, it reduces the space for experiments to socially acceptable proportions. So tradition is converted into the protection needed against the potential turbulence and destruction implied by every experiment. And magic becomes converted into the 
required set of symbols that guides the experimenter into an unknown world 4.

\section{Scientific potato breeding}

According to a now widely accepted scheme in which rural development is seen as being mainly dependent on technological change, the introduction of new, so-called "improved varieties" 5 in Andean farming systems is being promoted in several programmes (state-controlled or run by international experts) as a crucial lever for "development". These improved varieties are the result of scientific plant breeding, partly done in the Lima-based International potato Centre (CIP), one of the institutions belonging to the international CGIAR network. The scientific knowledge system on which this plant breeding is based as well as the subsequent diffusion of its results, is, in many respects (its inner logic, its scope, its dynamics as well as the role allocated to the farmer), quite different from the art de la localite - the local knowledge system discussed earlier.

The process of scientific plant breeding typically starts with the formulation of an "ideal plant type" (see Oasa, 1981). One of the frequent specifications of such "ideal types" is that they must be "superior" (mainly, but not only, in yields) to the "traditional" varieties. This is deemed necessary in the first place to create a "breakthrough", as "traditional" agriculture is seen as having reached its linits and cannot be extended through internal processes. Second$1 y$, such a "superiority" is seen as being one of the main factors to induce farmers towards acceptance of the improved varieties. After the definition of an "ideal plant type", the second step is the creation of a new genotype that contains as many of the desired characteristics as possible. In potato breeding this is known as "building in new characteristics" (which, as far as potatoes are concerned, is a relatively easy procedure though the selection which then follows is extremely difficult). Thirdly, and this is again typical, the phenotypical conditions which will render the newly-formed genotype effective, are derived, specified and tested in experimental stations. In synthesis, the construction of a new genotype essentially follows a course that differs basically from the one entailed in local farm practices. In the 
Andean highlands the given phenotypical conditions are - within the framework of the art de la localite - interpreted as starting points for the selection and adaptation of genotypes, whereas in the scientific knowledge system the genotype is the point of departure for the specification of the required phenotypical conditions.

One of the consequences of this drastic change is that the new genotype will only prove to be an effective and rational innovation in so far as these required conditions can be effectively repeated in the fields. This complication is presented in Figure 2, which indicates at the same time that to "innovate" is not just the simple adoption of a recommended object ("a miracle seed"), but - as far as the farmer is concerned - a highly complex reorganization of several farming routines.

\section{Figure 2}

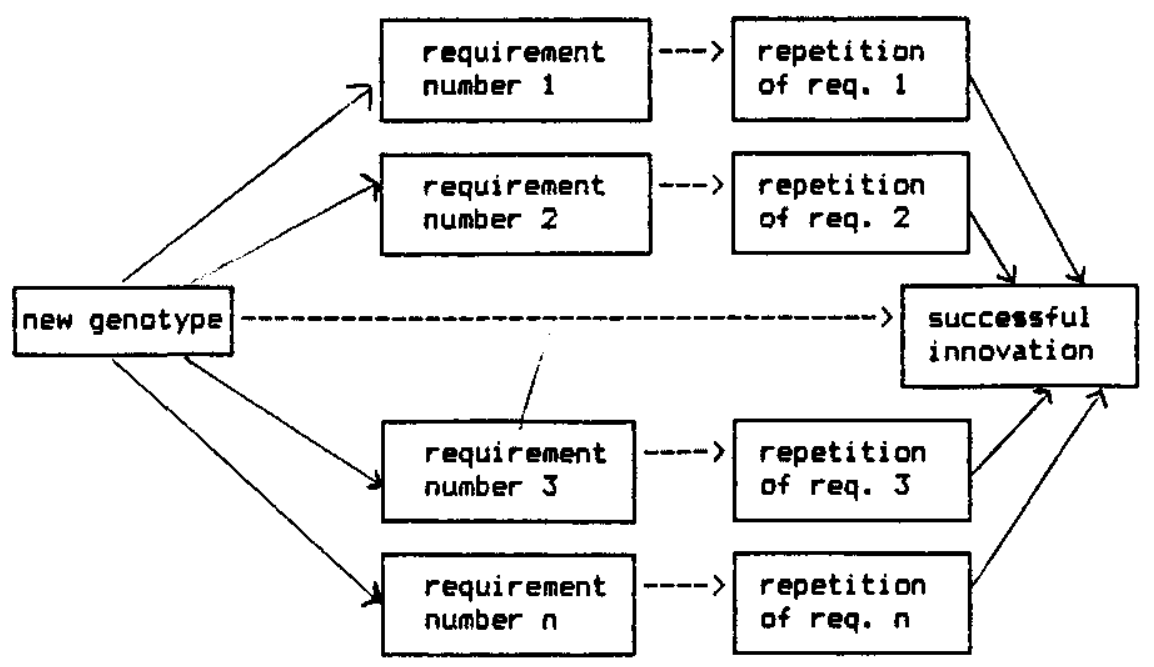

\section{Scientific knowledge and the restructuration of time}

Another important consequence of this (mostly invisible) reorganization is the implied redefinition of the "calendar". Whereas the local practice of potato selection and amelioration allows for a step-by-step improvement of different phenotypical conditions (steps that in their turn can follow, for instance, the demographic cycle within the farming 
family and/or the logic of patterns of cooperation within the community), scientific plant breeding demands a sudden and complete repetition of specified requirements in farmers' plots. Let us take, to illustrate this briefly, an "ideal plant" definition that is based on the possibility of converting available sunlight into a daily caloric growth of the tubers three times higher than is the case in "traditional" cultivars. This demands a highly nitrogen-responsive genotype, from which in turn the phenotypical requirements are derived: the amount of nitrogen in the subsoil is to be such and such a quantity. To avoid burning, this amount of nitrogen must be distributed according to a precise time schedule, derived in turn from the specific genotypical cycle. From this, water-regulation requirements can be derived, and so it continues. However, the point to note is that these specified requirements must be repeated in the fields, as an integral whole. Even if all the specified conditions are followed, but their exact distribution over time is not, then the "innovation" fails. Thus, time is converted from a basically indiscrete into a discrete category. And the labour process changes from the skill of confronting and exploiting specific circumstances, to the skill of applying general and standardized procedures to circumstances that are to be seen as more adverse the more they are specific.

\section{Scientific knowledge, control and power}

The different requirements are specified in scientific language. Taken together they compose a nomological model: if requirements 1 to $n$ are all fulfilled, then (and only then) will genotype $x$ function. This model is formulated at a general level, i.e. within the abstract "synthetic nature" constructed by science. And the terms on which it is built are, in theory anyway, highly standardized, quantifiable and not subject to subjective interpretations. It is through such a model, its language and its terms that the necessary control, manipulation and supervision of the experimental situation is established. Once tested the model can be converted into a means for the external prescription and sanctioning of farm labour. This is exactly what happens in the context of "planned" or "induced" rural development. 
Artifacts produced by agribusiness (such as fertilizers, pesticides, herbicides, irrigation equipment, tractors and implements, storage facilities and the like) conform pretty closely to the crucial condition of standardization. So it is logical and - within the world of carefully controlled experiments - also quite efficient to develop a model (or "scientific design") along the lines of these available and standardized elements. The requirement of a certain amount of nitrogen in the subsoil is then expressed as a certain dosage of a specified chemical fertilizer. In theory, however, such requirements are in no way "logical" on local farm plots managed with the corresponding art de la localité. The amount of nutrients can be augmented, and the subsoil composition changed by using dung, or through applying natural fertilizer (such as clover, alfalfa, etc), or by techniques such as intercropping, or by changing cropping and rotation schemes, and so on. However, the outcome of such methods cannot be exactly predicted. Nor can the methods needed for reaching pre-established levels be prescribed in detail. For farmers this is no problem whatsoever (indeed these were the methods that made large parts of The Netherlands fertile, especially the poor sandy soils of the eastern part ${ }^{6}$ ). But, regardless of the advantages such methods offer in a situation managed through local knowledge, they cannot be integrated into scientific design, since they are not sufficiently open to the necessary standardization. Local methods (and therefore the art de la localité) fall outside the scope of scientific design. And so consequently, farmers as active and knowledgeable actors, capable of improving their own conditions, also fall outside the scope of scientifically-managed rural development. 


\section{Figure 3}

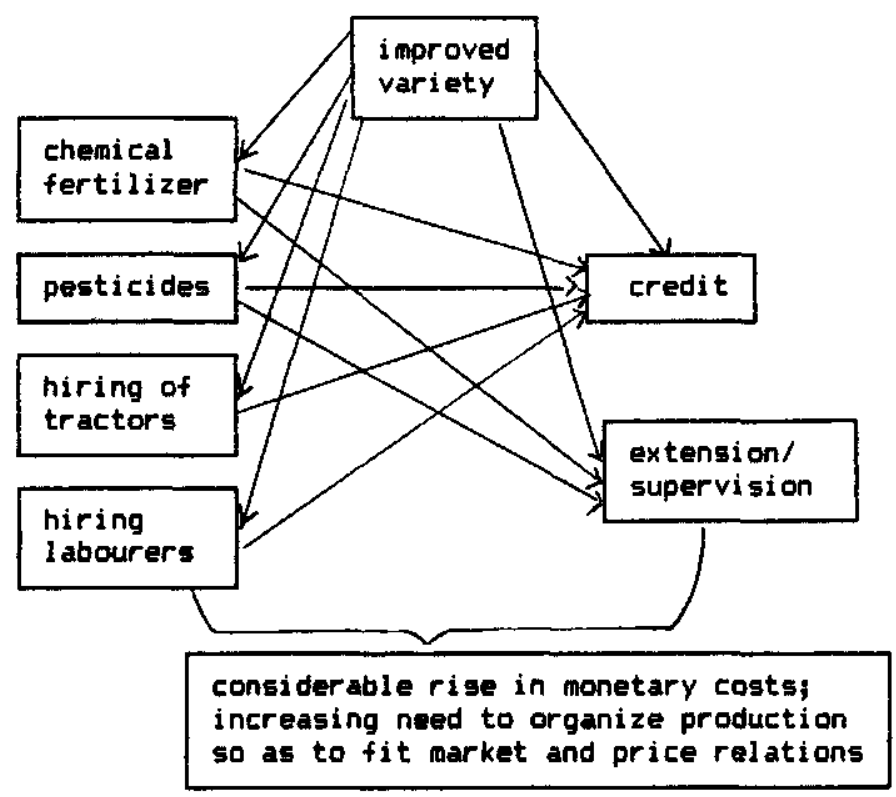

The foregoing inplies that the introduction of "improved varieties" initiates the creation of several chains of new dependency patterns. New artifacts (namely those specified in the scientific design) must be bought, new procedures must be followed, new circuits (several markets and the banking system) must be entered and new expertise (the ability to decipher scientific and bureaucratic language) must be mobilized 7 . In Figure 3 some of these chains and their mutual interdependencies are indicated. One of the consequences is that the farm enterprise must now be managed according to a relatively new logic: the newly emerging elements of monetary cost are to be coordinated with monetary benefits. In itself, such a $\operatorname{logic}$ - although differing radically from the logic used normally by Andean farmers in running their enterprises ${ }^{8}$ - is not hard to understand. It is, however, incomprehensible and hardly applicable where markets (and therefore price/cost relations) are highly unstable and often show completely "irrational" tendencies; the more so where these markets are considered as "arenas" where "others" (brokers or "intermediarios") are the first to benefit, and where, finally, the effects of market tendencies are, to quote cole and Wolf, (1974) "anti-ecological" 9. 
Local knowledge - art de la localité - is, under these conditions, rapidly becoming not just a marginal, but above all, a superfluous or even a counter-productive element: "a hindrance to change". Without being able to prove this in a scientific way, I am convinced that the many stories I was told in the Andes, stories that often centre on a phenomenon which at first sight is seen to be only "magic", viz. the "invisibility" of man 10, are strongly rooted in and confirmed by farmers' experience with the diffusion of "improved varieties". "Invisibility" means in these popular stories that, although you exist in a physical sense, you are not seen by anybody. People go around as if you yourself did not exist: as if you, as a social being, were indeed invisible. They address themselves to you in such a way that anybody or nobody could be in your place. You only exist if others (technical advisors, bank bureaucrats, etc.) are kind enough to remember that you are there - which they most often do not do. That is how invisibility as daily experience is reproduced. Invisibility seems to become especially reinforced when all the careful attention and love for the land are at once declared insignificant by the introduction of general schemes to be followed in production and by the introduction of "miracle seeds". Maybe that is why farmers, in their turn, mystify their own past: they talked to me on many occasions about "those times" (i.e. the Inca-period) "when we grew gold, pure gold on these grounds". This popular image of "invisibility" is then, in my opinion, a perfect metaphor for the relation between scientific and local knowledge.

Right from the beginning the scientific design of "improved varieties" is inspired and structured by a claim of "superiority", a claim omnipresent in all science as far as its relation with local knowledge is concerned (Hesse, 1978). Outside the immediate scope of scientific circles and especially in the fields improved varieties appear as something quite magical: they seem to hold promises outside the scope of reality. What happens, however, must be interpreted, in the end, as a particular combination of failure and reification. Farmers are, as other studies (Hardeman, 1984; Dewalt, 1975) also show, obviously unable to cope with all the supposed requirements. And even if they are, then the very technico-administrative environment energing 
around them (as schematically indicated in Figure 3) 11 excludes by means of its own contradictions and turbulence, a proper "repetition" of the required phenotypical conditions. Consequently, the new or "improved" varieties quickly degenerate. Within three or four years, this material is incapable of generating even low levels of production. It is finished or, as farmers in the highlands state, "ya no tiene fuerza" (it no longer has power). That is to say, the claim of "superiority" provokes a reaction that is equally formulated as a magicoreligious statement: the power which was once claimed turns out to be rather ineffective (to be lost).

In more general terms this implies that the increasing influence of science in the world produces just the opposite effect, at least under the circumstances described: myths, vagueness, poly-interpretability and a certain subjectivity vis-á-vis nature are not superseded through heavy inputs of applied science, but are instead reinforced and extended to the farmers' relations with science itself!

\section{Back to the potato fields}

Let us then finally return to the simple business of counting potatoes and measuring plots (which is, after all, my job). In the farming systems I studied in the Andes, farmers reached yields of up to 25 tons per hectare, "simply" through their art de la localité. The mean production was, of course, much lower: around 10 tons per hectare. An intriguing aspect of the programmes for rural development is that, in their ex-ante assessments, the mean productivity was stated as being just 5 or 6 tons/ha (Haudry 1984). Thus parallel to the scientific design of a "new" superiority, a systematic (and quite functional) component of ignorance is created 12. Or, to put it more bluntly, it appears that ignorance of local knowledge systems, their dynamics and their scope, is actually a crucial precondition for the diffusion of the scientific knowledge system.

Finally two questions remain to be answered. Why, in the first place, are farmers in the Andean highlands increasingly exchanging their own seed potato for these "improved varieties"? And second, what is happening at the interface between these two knowledge systems and their main agents, the farmers and technicians? 
"Magic" and "misery": those are the clues that explain the increasing adoption of improved varieties by Andean farmers. "Magic": because a cultivar intentionally constructed to be "superior" effectively functions as a spell. It is introduced and perceived as an emanation from another, more "powerful" world; even as a "gift" - an association frequently made in the lower level contacts between farmers and technicians and promotores. The problem is that after some time the "gift" seems to lose its "power". But then, in the mean time, other things have changed too. Through the adoption of the "gift", the genetic stock, normally conserved so carefully by these farmers, may have been eroded. And then the "misery". It is worth noting that - at least in the cormunities where I did my fieldwork - it is not the richer farmers who change completely to the "improved" varieties. It is mainly the so-called medios, farmers having sufficient land but lacking (for whatever reason) the means to cultivate it. They need credit, but credit forms part of the formula of "integrated rural development". It is handed out in kind, in the form of improved varieties, fertilizer etc. All this of course does not imply that farmers do not now and again withdraw from such "schemes" and "formulas". The point, however, is that after such a withdrawal their material position makes it even more difficult to structure their farm labour process along the lines they consider to be the correct ones.

The above-mentioned contradictions are reflected in the interface between the agents of scientific knowledge systems on the one hand, and farmers, on the other. Distrust, combined with dependency versus the "other", characterize the uneasy position in which both groups are placed. A systematic creation of a sphere of ignorance is indeed one of the answers that lower level technicians come up with as time and again they are confronted with farmers who try to convince them that their particular situation requires a particular solution (a deviation from the standard scheme, as illustrated in Figure 3). The technicians are unable to react adequately to these requests, let alone to respond to the rationality such requests might contain. So, whilst at a higher level such programmes need and therefore create a great deal of ignorance (cf. the already-mentioned systematic underestimation of the productivity of local farming systems), in the fields too, this ignorance is systematically reproduced. At the same time, farmers, unable 
to continue with their local cultivars and therefore in a worse or even impossible position for reproducing their local knowledge, are indeed becoming (to a certain degree) "black boxes". That is to say: finally they tend to become identical to the image ascribed to them in modern agricultural science: "invisible men".

Notes

1. This chapter was originally written for a workshop on "Systems of Knowledge and Systems of Ignorance" held at the School of oriental and African Studies, London University. I am grateful to Mark Hobart for his detailed comments on an earlier draft of this paper. I also want to thank the Dutch potato experts D.E. van der Zaag, J. Parlevliet and Th. Laudy for their detailed comments and criticism.

2. Throughout this text I use the terms "genotype" and "phenotype" in a rather loose way. Strictly speaking, that is from an agronomist's point of view, it is even incorrect. The phenotype is the result of the interaction between a particular environment and a particular genotype. So a genotype can only be known through its diffexent phenotypical expressions. However, once the reader realizes that "phenotypical conditions" can be read as "environmental aspects", then there should be no danger of confusion.

3. The production of new genotypes evidently follows the lines of sexual reproduction. Contrary to north-western European conditions, both the Andean eco-systems and the way potato growing is organized by Andean farmers lead to a rather high chance of success in the production and survival of seedlings (or "true seed" as it is nowadays called). Plots are small (which implies that there are a lot of "surroundings") and highly diversified as far as the number and distribution of cultivars is concerned. Insect life is abundant and insecticides and pesticides are hardly used. Apart from all these favourable conditions leading to a spontaneous production of new genotypes, some farmers collect seedlings in a goal-oriented way to develop them further. This is especially done in the so-called chacritas. In the Netherlands this practice was realized by farmers at the beginning of this century. Since then, however, the necessary knowledge has been lost. Now most farmers and scientists believe that the production and utilization of "true seed" is only possible under laboratory conditions.

4. Of course the foregoing discussion does not imply that art de la localite is to be equated with "the best ever possible knowledge". The dynamic character of local knowledge - as outlined above - excludes such pretentions from the beginning: what is considered as "good" today, can turn out to be a "mistake" tomorrow. The point is that the criteria for such an assessment are also continuously evolving, as I pointed out earlier. "Each error indeed is the beginning of new knowledge, because every frustration forcefully led to reflection, to a new mediation on the very conditions of practice" (Herrera, introduction, 1980:10). In more general terms, this dialectical interrelation between practice and theory in craft-based agriculture (as opposed to the science-based agriculture now emerging in Europe and America) is discussed by Boserup (1965) who relates demographic growth to the creation of new insights resulting in an ongoing intensification, by slicher van Bath (1960) who 
studied the same interrelationship in north-western European history (focussing more than Boserup on the development of local knowledge systems) and by Hayami and Ruttan (1985) when discussing the agricultural history of Japan.

5. It certainly reflects a good deal of arrogance towards farmers to denominate new varieties as "improved" varieties. Such a qualification should be the result of farmers' evaluation and not an ex-ante assessment by international research stations themselves, as $\mathrm{d} x$. D.E. van der Zaag made clear to me (January 1987).

6. As described recently by Hofstee (1985) and Van Zanden (1985).

7. This role is usually ascribed to the local-level technicians or promotores.

8. For a full description of these "logics", see Van der Ploeg, 1985 and Van der Ploeg, forthconing.

9. Here Cole and Wolf seem to follow Polanyi who stated - much earlier - that "all along the line human society had become an accessory of the economic system (..). But while production could theoretically be organized in this way, the commodity fiction disregarded the fact that leaving the fate of soil and people to the market would be tantamount to annihilating them" (1957). Indeed I found that those Andean potato farmers who were more than others obliged to follow the "commodity fiction" increased the share of potato culture in their cropping scheme up to 508, which is, in an agronomic sense, disastrous within a few years. Soil fertility and pest resistance are completely destroyed (see Bolhuis and Van der Ploeg, 1985:308).

10. The image of invisibility is omnipresent in the prose written by Manuel Scorza, once a lawyer working with farmers' unions in the Andean region (see especially Scorza, 1977). The origins of this particular image, however, can be traced back to the Spanish conquest of the Inca Empire. In this respect, Wachtel's study (1976) stands as a masterpiece.

11. For a further elaboration of this theme see Benvenuti's work on the Technological-Administrative Task Environment (1982).

12. Hibon (1981) proved that indeed such an under-estimation of the productivity of local farming systems is a structural (not to say, a chronic) feature in Peruvian agricultural policies. As can be derived from other, recent agronomic studies (see Fresco 1986), the same applies to typical peasant crops such as cassava in Africa. 



\section{KNOWLEDEE, NETWORKS AND CULTIVATORS: CASSAVA IN THB DOMINICAN REPUBLIC}

Louk Box

The social structure of agricultural knowledge can be studied in a variety of ways. In this chapter I look at agricultural knowledge from the point of view that it is, to a large extent, generated by farmers or clitivators (and not by researchers), and that it is transferred through cultivator and trader networks (and not only through extension systems). I also argue that formal interfaces between parties, instead of permitting, often inhibit the flow of knowledge. This is the reason for structural ignorance among the different parties engaged in agricultural knowledge creation and distribution. These ideas are tested against a case study of cassava production in the Dominican Republic.

High in the sierra region of the Dominican Republic, cassava has been cultivated for hundreds of years: first by occasional Taino indians, then by adventurers leaving the rich Cibao valley; then at the beginning of this century by forest workers and occasional settlers practising "subsistence" farming; and now by smaltholders who scarcely make a living out of cultivating the steep hills with this poor man's crop.

When I first came to the sierra in 1979, there was only one main road through the area. Transport was mainly by mule. In the thirties, communication had been easier; forest exploitation was in full swing then. But, by 1979, there were no roads to speak of in the higher areas, few shops, no facilities. Consequently, the State was almost absent: no police, no health officials and no extensionists. By 1985 this had all changed. A minor army of officials had descended upon the region; clinics had been established, regional extension offices 
furnished, researchers doing their inevitable surveys and governmentassisted farmers' organizations struggling on.

Cassava continued to be cultivated as it had always been, or so it seemed to the occasional observer. Shifting cultivation seemed to be the main cropping system; according to researchers and extensionists, varieties were all "traditional". processing was basically done as the Tainos did it; cassava was rasped and pressed to eliminate the toxic prussic acid. It was then baked into casabe or cassava flatcakes.

officials had done quite a lot to improve cropping, processing and marketing. They had furnished advice through extensionists, had established a processing centre and the state Marketing Board made a contract to buy casabe. But by 1988 the cultivators had not followed the advice of the extensionists; they had not constructed the recommended infrastructure in their fields to reduce erosion, had not adopted the new varieties coming from an international research centre, and could not sell their cassava to the processing centre established by the state. In one word, stagnation.

Between 1979 and 1985, fieldwork was carried out in the sierra by a team of sociologists and agronomists. They observed cultivation practices and discussed these with cultivators, extensionists, researchers, traders and agrobureaucrats. Various case studies and surveys were executed involving these four parties.

In this chapter an analysis is made allowing a greater understanding of what went wrong at the interface between these parties. The analysis focuses on the notion that guided change in cultural practices depends on knowledge network articulation. Three points are stressed:

1. the complexity of knowledge networks, so easily disregarded when using the term "knowledge system" (Röling 1985);

2. the diversity of world views among those engaged in transforming cassava cultivation patterns, resulting in the saddening experiences described above;

3. the role of the sociologist in creating interfaces between these worlds of cultivators, traders, extensionists, researchers and bureaucrats. 
Knowledge, networks and systems

The term "knowledge system" is used in variety of ways in the literature. Röling (1985, 1987), following Nagel (1980), assumes that an overall structure exists by referring to research, extension and education as "subsystems". The users, in this view, form a subsystem as well. But do they really? Users may only be called a subsystem if stable relations exist among individual users, and among them and the other "subsysterns". Given the fact that one of the key problems in extension science is exactly the lack of communication between different parties, such relations may not be assumed.

When I use the term knowledge system, I will use it in a limited sense to refer exclusively to a model we have in our heads regarding knowledge exchanges through social networks in a particular realm of human activity. I stress the element of "model" to prevent confusion with other system definitions which refer to actual reality as such, as in "a computer system". Rather the notion of social networks (Mitchell, 1969) is stressed, or the chains of interactions and communications linking actors in a realm of human activity. The term "interface" was suggested by Norman Long (1984:10), who points out that it "suggests some kind of face-to-face encounter between individuals or units representing different interests and backed by different resources." In this chapter, I take it to refer to the sets of interactions and communications between actors involved in different knowledge networks. The linkage (or lack of it) of such networks is a profitable field of study, as other studies in this book show.

My conclusion is simple: the case of Dominican cassava cultivation shows that knowledge networks are highly segmented. They are, like the sierra landscape with its cleavages, holding communities apart. Instead of one knowledge system there are many complex networks, which lack articulation among each other. The life-worlds of the participants, or their values, norms and interests, differ so greatly that they do not allow for communication and interaction between parties. Sociologists may play a part in the articulation of the networks; thus sociological research can in fact be seen as part of such "networking".

This perspective is in line with authors who stress the important role of farmers or cultivators in the generation of technology (De Schlippe, 1957; Hill, 1970, Johnson, 1972; for recent studies see 
Brammer, 1980, Brokensha, 1980, Chambers, 1983, Hildebrand, 1984, Kurin, 1983, and Richards, 1984, 1987). Cultivators are not viewed merely as "users" or consumers of technology generated by others, but rather as essential contributors to technological change, not as the reproducers of traditional lore, but as partners in agricultural experimentation. When I started my research in 1979, however, these notions were so uncommon that I found it hard to get acceptance among fellow agricultural scientists ("peasants do not experiment") and among fellow researchers in the Dominican Republic ("peasants are traditional"). Nevertheless, I designed the research with the following ideas in mind:

- cultivators experiment

- these experiments are indicative of agrarian change

- the direction of change indicates farmer problens

- problem definitions can be used to define researchable questions

- research questions and results can thus be translated back again to interested cultivators through the elaborate formal networks of research, extension and planning agencies.

\section{The method: adaptive networking}

Before showing the differences between the worlds of cultivators and others, a brief description of the method is necessary. In essence, the method is based on the premise that the respective world views (with regard to cassava production) need to be defined before the differences can be demonstrated to parties, and subsequently overcome. Researchers and extensionists are hardly aware of the differences in problem perception existing among them. Cultivators may be aware of the differences between themselves and the "technicians" but most of the time are not aware of different problem perceptions among themselves. One of the first tasks of the sociologist, therefore, is to establish these differences, so that the parties become aware of them.

The approach adopted was to follow step-by-step the different networks existing among cassava cultivators and the other parties involved. The team started in 1979 with the researchers, who in turn indicated national and local agricultural officials with whom they worked. Through them, the leaders of two farmers' federations were 
contacted; one federation in the mountain region and the other in the valley. In this way, comparisons could be made between a marginal hill area with petty commodity production and a fairly rich valley area, in which capitalist agriculture dominated. The two federations formed the base for the research: everything was done with and through them. It was felt that they were the prime information base and would profit most from the research. In other words, they provided the network, and the team wished to contribute its knowledge through it to cassava cultivators.

"Networking" might therefore be considered as the central concept around which I designed the research. The team profited from the existing networks; ultimately it hoped that local networks would be strengthened through the research results.

The phases of the research can be summarized as follows:

- reconnaissance to identify the main parties in existing cassava knowledge networks, through unstructured interviews, establishing contact with the main networks among cultivators, extensionists, researchers, officials and traders or processors;

- informant inventory, through semi-structured interviews with key informants in different communities, providing insight into the structure of the network through which new knowledge on cassava was exchanged;

- informant selection, through a simple test of their knowledge (of cassava varieties), their history with experimentation, their capacity to verbalize, and their availability for further interviews and adaptive trials;

- identification of ongoing cultivator experiments, through case studies on informants. This led to identification of problem areas faced by cultivators and to suggestions for further agronomic research (adaptive field and station trials) as well as quantitative socio-economic research (surveys);

- adaptive trials on intercropping, erosion control, root rot and stake planting position in both research areas in order to test particular cultivator or researcher strategies;

- surveys among the cassava cultivators in the two areas studied to test the preliminary conclusions we had drawn from the case studies: 
- interviews with the other parties: researchers, extensionists, officials, traders and processors, and bank officials. This allows for comparisons of cultivator and other networks, and for discovering to what extent one "cassava knowledge system" exists;

- group meetings with informants, groups of cultivators, associations, federations, extensionists, researchers to test individual conclusions. The research was concluded with a seminar bringing together, for the first time, experimenting farmers with the other parties.

Adaptive networking, then, shifted its emphasis during the course of the research. At the outset it entailed tracking interaction and communication chains. Later it came to mean: testing preliminary conclusions with the individual, his or her peer group, farmers' association or federation, and ultimately the other parties. And towards the end of the research it meant: feeding information back into the networks, showing the parties the differences in world views existing between them and attempting to generate further integration between networks.

\section{The parties and the networks}

The 360 people who cooperated with this study had only one thing in common: their interest in cassava. They belonged to different social classes, manifested contrasting life styles and came from different generations and different geographical areas. They had different interests, or belonged to different "parties" in the game of agrarian change; accordingly they interacted and communicated with different actors, or shared in different networks of agricultural knowledge. Most of them never met, al though a number did as a result of our research. Yet evidence emerged that the chains of interaction and communication did intersect. Those actors involved in the formal institutions of research, extension and banking were at least aware of each others' presence: but even here their relations proved to be limited. 


\section{Cassava cultivators: adaptive craftsmen}

Cassava is a poor man's crop: cultivated by poor people, on poor lands, for poor consumers. This is true for the Dominican Republic, as it is true for the other main producer countries, such as Brazil, zaire or Indones ia (Cock, 1985).

Who are these cultivators? For the purpose of the present study, they are cultivators growing at least a quarter of an acre of cassava in 1981 in the main production areas of Moca and Monción. Moca, the centre of sweet cassava production for national markets and for some export, is located in the rich cibao valley characterized by capitalist relations of production. In Monción, bitter cassava is primarily grown for national processing and subsequent marketing and also for export of casabe to the Dominican community in New York. It is located in the poor sierra hill region (see Crouch, 1981).

The cultivators are generally old and poor. In the valley area of Moca more than half of our respondents were over 55 years old. In the sierra region of Monción cultivators tended to be younger, with a little less than half between 35 and 55 . Average farm size was about 3 hectares in the valley, compared with 2 hectares in the hills, less than half of which was under cassava. One out of five respondents did not own any land at all.

For most of these cultivators cassava was the most important income generating crop. Most cultivators in the valley area used to grow the crop for both sale and subsistence, and still do so. In the hills, it was and still is a subsistence crop to most, although about one third of our respondents indicated that they grow it for sale to traders. Bitter cassava is almost exclusively for sale, the sweet variety for subsistence.

If these cultivators have a problem they cannot solve, they generally do not go to an official agency such as the extension service. As Brammer (1980:25) puts it, the "unofficial research network is overlooked by all except small farmers themselves." In fact less than 3 percent in the valley area, and only 6 percent in the hill area indicated they would consult extension personnel. Most resort to farmers' associations and traders. Does this mean then that they do not change their practices or varieties? No, they do so all the time. Moreover, our case studies indicated that experimenting cultivators 
maintained collections of up to 25 varieties, some old and some new, so as to test them under varying conditions. Our sample survey confirmed this experimentation. About half of our respondents had tested a new variety over the past five years. This indicated that experimentation occurred on a much wider scale than was hitherto supposed.

From the case studies we carried out (Box, 1984a) we learned that four concerns dominated this search for new varieties or cropping systems: the changing demand for cassava (from subsistence to market, and within the market to varieties which could be processed for export); the concern for a shorter maturation period, or the need for varieties with short production cycles; soil degradation, or varieties which tolerate poor soils; and lastly root deterioration through preharvest rot or other causes.

Cultivators carefully scanned new varieties in terms of these criteria. The corresponding changes were impressive. In the hill region, for example, a so-called "black" bitter variety, little known 10 years before, had taken over the area through intervention of traders who proved its value as a short-cycle, easily-marketable crop. This suggested that new varieties are transmitted through a network of local experimenting cultivators who are linked to small traders who, in turn, are linked to particular markets. It is significant to note that the dominant varieties in both regions are named after the small traders who also engaged in testing them (e.g. Facundo, a trader in the sierra and Zenon, a colleague working in the Cibao Valley).

The network could therefore be characterized as dynamic (50\% of the respondents testing new varieties in the past five years), market oriented (most cassava being grown for markets), and without clear linkage to the formal institutional networks of research and extension (most cultivators did not communicate with extensionists). Cassava cultivators depend on themselves or on traders for new knowledge on what the market wants. They make changes continually; they are adaptive craftsmen at heart.

\section{The world of researchers: risk avoidance}

The researcher's world stands far apart from the cultivator's. Cassava researchers in the Dominican Republic are typically young (between 25 
and 35 years of age), stem from urban backgrounds, and work within the state bureaucracy or affiliated research branches. Despite their corparative youth, they average about seven and a half years of research experience in the crop. They work in two research institutes, one in the south (Centro Sur de Desarrollo Agropecuario or CESDA) and the other in the rich agricultural area of the north (Centro Norte de Desarrollo Agropecuario, or CENDA). Cassava research has been going on for half a century in the country, ever since it was started by a private firm in the 1930's. It is notable that present-day cassava researchers do not refer in their articles to this research, even though quite interesting observations were made at the time. A study made of cassava research (Castellanos and Box, 1981) suggests in fact that there is little continuity in Dominican cassava research. Interviews in both institutes indicated that even within institutions research findings do not accumulate over time. Old information is not used and new information tends to get lost in archives. Publication of results hardly occurs and if this happens it is through non-national agencies like CIAT (International Centre for Tropical Agriculture in Cali, Colombia).

This leads to the interesting question of how researchers' networks are composed. Given the small number of informants, it is risky to make any generalizations. The differences are great: some researchers have intricate networks, articulated with cultivators, whilst others are mainly oriented to survival in a heavily politicized agrobureaucracy. Nevertheless, three generalizations might be made, regarding the researchers' networks: they are bureaucratic in character, have a very weak linkage with field extension and almost no linkage with cultivator networks.

Part of the reason for this may stem from the exclusive dependence on the huge state bureaucracy for funding. Centre directors spend a good deal of their working time visiting ministerial offices to try to obtain the money promised in their budgets. Networks develop around these contacts, and loyalties emerge. This type of funding leads to inflated personnel budgets, and leaves other items (operating funds, transport, publication) quite vulnerable to cuts. Researchers feel, therefore, that the publication of their findings is hampered and their results do not reach extensionists or farmers. Among those interviewed, the most frequent contacts mentioned were those with officials in the 
regional offices of the agrobureaucracy. If one clear strategy emerges from our interviews it is the linkage with state and local agrobureaucrats. Sometimes powerful farmers form part of these networks, and to this extent the networks are articulated with cultivators.

On the whole, researchers have little contact with farmers or their organizations. Various of them could not even indicate when they had last met with farmers' organizations or interest groups. of five researchers interviewed, only one had been in contact with such groups over the past year. Part of the problem lies with low transportation budgets, prohibiting frequent field visits. But, whatever the cause, this suggests that researchers' problem definitions are not influenced by contacts with those who represent cultivators' interests.

There is also limited contact with other networks, like those of traders and of extensionists. On the national level, this communication gap has been the subject of many studies and critiques (ISNAR 1983; Marte, 1984:31-33). Three of our five cassava researchers had not had contact with any field extensionists at all over a three-month period. They did not 1 isten to agricultural radio programmes either, which could have made them more aware of what types of messages were sent out by the extension service. Only one of them occasionally listened to these programmes to inform himself on topics of current interest among farmers.

It is perhaps due to this lack of contact that the priorities of researchers are different from those of the cultivators. We found that researchers considered the prime problems to be: the great diversity of existing varieties and their uncontrolled distribution (the exact condition for cultivator experimentationl); low market prices; lack of credit and lack of crop rotation. To tackle these problems, researchers primarily orient themselves to the testing of promising new varieties, brought from international centres such as CIAT. The researchers were quite satisfied with their contribution to crop development through these promising new varieties, four out of five indicating that such research had contributed to such technological changes. However, over the past decade, not a single foreign variety has in fact been adopted on any scale in the country. The only variety which seemed to have promise and was widely acclaimed by the researchers later turned out to be a complete failure (Box, 1982:42). Researchers tend to define the crop's problems in terms of the lack of new varieties and 
the absence of disease control measures. This is the reason why we found that most of the ongoing studies were variety-oriented (Castellanos and Box, 1981). When we presented the researchers with problem areas as defined by cultivators, these were either redefined in terms of "modern versus traditional varieties" (i.e. foreign versus local germ-plasm) or were discarded as irrelevant. "Modern varieties" (implying high-yielding material, imported from abroad, generally requiring particular treatments) had no priority among the cultivators we interviewed; only 1 respondent out of 247 indicated a need for them.

A good example of alleged "irrelevant problems" was root deterioration, and the different forms under which this presented itself. Researchers were not aware of high cultivator losses due to root rot, and of a particular type of deterioration called sancocho or "cooking". Dominican farmers refer to sancocho when mature cassava roots are deteriorating after a mid-day rain on a heated soil. The roots then "stew" in the hot soil, and the root consistency changes. Researchers, however, disqualified sancocho as a legitimate cause for root deterioration and reference was made to cultivator ignorance (Naut and Box, 1984:26). It took three years of convincing, graphic examples of different forms of root deterioration and a reference in a CIAT manual, before the researchers would admit that the cultivators were right after all.

The world of the researchers may therefore be characterized by a focus on new varieties. Researchers define problems in terms of the solution they can provide, by acquiring foreign material through germplasm collections such as the one at CIAT. They do not have adequate communication with farmers or their interest groups so as to define research questions in terms of cultivators' problems. Moreover we noted that research has contributed very little to technological change in cassava cultivation. Due to a focus on modern (and foreign) technology, researchers seem to be excessively preoccupied with problems as defined abroad and far too little concerned with the results of experiments carried out locally (by peers or by cultivators).

Researchers' networks, therefore, lack dynamism and are state bureaucracy-oriented and not articulated with cultivator, field extensionist or trader networks. This results from a "professional" strategy characterized by risk avoidance, dependence on developments from abroad as far as technologies are concerned, and on developments 
in the agrobureaucracy for priority setting and funding. Accumulation of research findings hardly takes place in this context; and articulation with cultivator knowledge networks is unlikely to occur.

\section{Extension: the broken bridge}

Extensionists stand somewhere in between researchers and cultivators. This is an organizational cliché and a sociological problem. The problem is that these actors form an undefined social category and do not produce the "interface" that is often wished, assumed or simply posited in agrobureaucratic ideologies covering "rural development".

The 28 extensionists we interviewed were young (in their twenties), with a moderate (3-4 year) training in agronomy, poor wages (our "main problem", according to every single one of the respondents), and an almost exclusive dedication to cassava production. Although having quite varied backgrounds, two categories dominated:

- the recent college or university graduate with almost no experience, a minimal salary and a fair amount of ambition to move into the ("urban") bureaucratic hierarchy;

- the experienced extensionist, with a number of years in a number of assignments, a continuing minimal salary, and less hope that he can ever make it in the bureaucracy under the present domination of the political party.

Both categories would agree, however, that field extensionists working in cassava are poorly paid, work on a poor crop, and face poor prospects for a career. Better to work in rice, tomato or some other crop which shows rapid advance (in terms of financial gain for the cultivator and in status for the extensionist). The corresponding interests (and occupational strategies) result in networks which can be considered a mix of the ones we described for cultivators and researchers. They are partially bureaucratic and political, partially linked to private or farmer interests (traders, input-firms, farmer or tenant associations). They have a weak linkage with other state agencies and particular rural interest groups (such as wage labourers) and little articulation with researchers and their world of knowledge. 
The views of extensionists form a curious mixture of the worlds they belong to. On the one hand, they ascribe to the view that cultivator ignorance and traditionalism are among the prime causes of the backwardness that Dominican agriculture finds itself in. Other factors mentioned are lack of mechanization and inadequate production conditions (Naut and Box, 1984:33). On the other hand, they depend on those same cultivators (and on input-firms) for their knowledge of the crop. When we asked for their most important source of information on cassava, 9 out of 28 referred to a fertilizer firm and 6 to the cultivators themselves. The local cassava programme coordinator came third with only 3 mentions. It is with this coordinator that researchers have their most important contacts.

The networks they maintain reflect these evaluations. Extensionists interact and communicate most with cultivators, their peers in the extension office and representatives of input-firms. They do not interact with land reform officials (71\% never did), local agricultural credit officials (57\% never did), local cassava programme coordinators (438 never did!), nor with researchers (438 had not had contact with them in the past 3 years). Most of them (638) found the agrobureaucracy to be poorly coordinated and almost three-quarters (718) did not know about national research results on cassava.

Those extensionists who did know about research results, referred to the positive effect of vertical planting of cassava stakes (hardly ever practised by farmers and not generally recomended by extensionists) and of obtaining new high yielding varieties (which do not exist in the country). This shows fairly well the ambivalent position of the extensionist. Formally he has to bridge the worlds of researcher and cultivator; in fact he finds himself facing a rift.

He cannot depend on the cultivators who are "traditional and ignorant". He does not depend upon the researchers who are inaccessible and provide no useful results. He does not want his sons to becone farmers (the view of 858 of our respondents), wishing them instead to achieve a "better" position through higher education. Yet those who have such positions (such as those researchers whom he knows) do not automatically impress $\mathrm{him}$ by their knowledge. This is the fundamental ambivalence of the extensionist; and why he stands between the two worlds of cultivators and researchers, without being part of either, or being capable of bridging the gap between them. 
This position manifests itself when one asks what the main problems are that cultivators face. Extensionists stress pest and disease control ( 37.58 found this the main cultivator problem), exosion control or soil-fertility management (258) and marketing (12.5\%). Here there is no mention of a need for new high yielding varieties or anything of the kind researchers saw as the main cultivator problem, though there exists one correspondence with researchers: they define problems in terms of the solutions they can offer. Extensionists see as their prime task the diagnosis and therapy of diseases; for this they can use quite well the propaganda offered by input firms. They cannot, however, do very much about new varieties (known to have failed) or root rot or root "boiling" (sancocho, acknowledged as a problem, but not easily solved by them under present circumstances). On the one hand, they correspond with cultivators in their emphasis on soil degradation and inadequate marketing; and on the other, with researchers by stressing phytosanitary control.

Extensionists, then, cannot bridge the gap existing between these two worlds: either on the level of knowledge, due to the inherent contradictions between the worlds of the cultivators and the scientists; or on the level of interaction, since they are precluded from having contacts with scientists. What remains is not the assumed "interface" role these actors might be expected to play. There is no interface, at best a broken briage.

\section{Traders and programme coordinators: factual and fictional brokers}

Before drawing some conclusions, two other types of actors need analysis: the traders and agrobureaucrats coordinating programmes.

The traders form a fairly close-knit network characterized by frequent interaction with cultivators and other traders, but little or no interaction with researchers, extensionists or agrobureaucrats. Those interviewed (4) corresponded in their problem analysis fairly closely with the views of cultivators. The traders varied in age and in wealth but could be characterized as persons who maintained close ties with producers through family ties, informal relations and by providing incidental credit or other services. 
They have been, or still are, cassava cultivators. By luck, endowment, good contacts or hard work they have made enough money to buy a secondhand pick-up truck which makes the single largest difference between them and the cultivators. Owning a truck is seen as a necessary and sufficient condition for leaving the misery of being a farmer. I shall not expand on the traders here, because only four of them could be interviewed. It is clear, however, that they play a central role in the spread of new varieties (as noted before) and new technology in general. They are traders, but knowledge brokers as well.

Agrobureaucrats also have a tight network, based on professional and political (party) linkages. Our respondents differed from researchers and extensionists in giving first priority to marketing as the principal problem faced by cultivators (mentioned by one quarter of those responding), followed by phytosanitary control (mentioned by one in five), and lack of infrastructure (one in seven)(Naut and Box, 1984:35ff). They find that cassava has a rather high priority in government programmes. They attach importance to contacts with cultivators through visits, which about half of the respondents indicated as being the best way to get to know farmers' problems. Development plans therefore should primarily be based on views expressed by cultivators (418 suggested this). Twenty-nine percent mentioned the importance of extensionists and only six percent researchers.

However, few of them regularly visit farmers or their interest groups. They do acknowledge the importance of research findings when formulating priorities for extension and stressed the use of international publications (29\% of the respondents) or national findings (248). For these recommendations only a fraction (10\%) said they would depend on cultivators. Their brokerage in this respect is fictional.

Both traders and agrobureaucrats might nevertheless fulfill a particular role in the linking of various networks. Traders do not really see a task for themselves in this respect, but they do play a part; the agrobureaucrats do see a role, but their role in linking with cultivator interests may be marginal. Both groups are generally not included in knowledge system analysis. Nor is a third group - the social scientists studying network articulation. My closing remarks therefore deal with the role of social science in "interfacing" or network articulation. 


\section{Conclusion: sociology and interfacing}

Not one cassava knowledge system emerges from this analysis, but rather a number of networks which are more or less articulated. Indeed the ruptures or disjunctions are more striking than the linkages or articulations. When discussing these findings with all parties involved, we were struck time and again by the surprise and incredulity of our informants. They were aware of course that they were different parties to the process of technology generation, transfer and utilization. But they had no idea that their priorities could be so different and that the networks could operate so far apart from each other.

At the end of our research we organized a workshop bringing together all parties to the research: the rich and the poor cultivator, the humble extensionist and the powerful political appointee, the researcher and the programme coordinator. For many of them it was the first time they had met. Some did not wish to speak to one another and found our invitation to be less than courteous. The communist labour union leader was upset to be seen in the company of the leading antiland reform politician. The latter, a politician and large landowner, found it embarrassing to exchange opinions with simple campesinos. The national programme director wondered what made the man he knew as a wage labourer, so respected as an "experimenting farmer". Nevertheless, they were all surprised after two days of meetings, how many different points of view were presented and how much knowledge was exchanged. All wondered how sociologists could have managed this.

social scientists, it seems to me, are in the business of confronting different views on reality. If we accept the view on reality suggested by some researchers, an agricultural knowledge system consists of those generating, transferring and utilizing knowledge (i.e. scientists, extensionists and farmers). A knowledge system is then a conceptual model which depicts the total set of relations linking these three sets of actors. Such relations, however, are rather the exception than the rule in the cassava case just described. Therefore I chose at the outset not to follow the knowledge system model as proposed by Röling (1985, 1987), but rather to study the existing networks involving the participants in cassava knowledge.

The situation in cassava is not much diffexent from the Dominican "top crop": rice. When Doorman and Naut (1986) replicated the study for 
rice, they noticed essentially the same phenomena albeit at different levels of articulation. Cultivators had more need for, and access to, the formal networks incorporating researchers, extensionists and programme coordinators. They also found that researchers and extensionists had more contact than in the cassava case, and that problem priorities coincided to a greater extent anong parties. But problems of network articulation remained and so did the disqualification of other parties in priority setting and problem formulation. I therefore suggest that network articulation is differentiated, both among the parties involved in technology transformation for one crop, as well as among crops.

It is this notion which the sociologist can contribute. Most participants in the networks are only vaguely aware of the values and interests setting them apart from others. Since a number of these values may imply disqualification of other parties, network articulation becomes difficult. When extensionists do not expect researchers to contribute anything to their knowledge, or when researchers do not expect cultivators to do so, knowledge does not flow any more.

One task for the sociologist is to find out where and when communication blockages exist and structural ignorance occurs. Arce and Long (1987) have indicated this in their study of Mexican agrobureaucrats; and recently Botchway (1988) has shown structural ignorance among Ghanaian extensionists and researchers. Once these blockages are defined, the sociologist can indicate how a knowledge flow can be established. The applied sociologist helps to develop the organizational means for interfaces that enable knowledge to flow. Creating such contacts is what could be called "interfacing". From the actor's point of view, an unexpected meeting takes place: researcher meets experimenting farmer, etc. From a structural point of view, network articulation takes place and the flow of knowledge is stimulated. From a methodological perspective this could be called "adaptive networking".

Interfacing and adaptive networking can be done in a number of ways. In the Dominican research it was done through meetings, through the creation of teams, involving researchers and cultivators; through trial adaptation, or the transformation of farmers' experiments into researcher-managed trials, and vice versa. It is exactly this whole gamut of activities, which allows interfacing; each activity by itself would not create network articulation. The dialogue which thus emerges 
allows knowledge to flow. It creates an interface which mends extension's broken bridges. 


\section{IRRIGATION SYSTEMS AS SOCIAL INTERFACES: TOWARDS AN UNDERSTANDING OF IRRIGATION DEVELOPMENT AS AN INTERACTIONAL PROCESS \\ Jan Ubels}

\section{Introduction}

For irrigated agriculture it is necessary to design, construct and manage water-delivery systems. Often these systems consist of a set of canals provided with water by means of a dam or pump. If such a systern is managed adequately, it should assure a relatively $h i g h$ and stable production level in situations where rainfall is deficient or uncertain.

Many important civilizations in the history of mankind have been heavily dependent on irrigation. Famous examples are Mesopotamia, the Aztecs in Mexico and the old Sinhalese civilization of Sri Lanka. The level of development of these complex societies is not only explained by the relatively stable and high production levels, but also by the technical and organizational requirements of the irrigation works to be built, operated and maintained (Wittfogel, 1957; Glick, 1970). From a more recent date are the more humble but no less delicate and wellestablished examples of the irrigation cultures of the Balinese Subaks (Geertz,1967), the East African Sonyo and Taita peoples (Gray,1963; Fleuret, 1985), and the traditional village tanks in Sri Lanka (Leach, 1961). In all these examples, irrigation organization, which developed over a long time, is an important element of the entire fabric of social relations within the community involved.

Irrigation projects are presently popular in the drive towards agricultural or rural development. They are important policy instruments, especially for the governments of many so-called Third world countries. Large differences exist in the scale and technical charac- 
teristics of irrigation systems, from individual wells or pumps, small canal systems managed by local peasant communities consisting of from ten to several hundred hectares) up to very extensive bureaucraticallymanaged systems (for example, of more than 100,000 hectares). In the context of modern irrigation development, however, even the so-called farmer-managed systems cannot usually be understood as stable and integrated parts of local society and farming systems. Government agencies have usually taken an important role in the initiation and construction of modern irrigation systems. Also other interest groups, such as construction companies, regional traders and industrial firms which pack and treat the product, are directly or indirectly involved. Irrigation development is thus part of the complex and dynamic processes of incorporation, social differentiation and state penetration so characteristic of present-day Third world societies.

As compared to accounts of ancient and indigenous irrigation systems, modern irrigation developments often appear to be rather problematic. Since the beginning of the seventies a large body of literature has been produced on "irrigation water management" describing a large variety of problems. Systems meant to be farmer managed continue to need government assistance. Proper management of large-scale systerns often seems an even bigger problem: accounts of technical chaos, corruption, hostile relations between farmers and authorities etc. abound. From an economic point of view the results of irrigation systems are often disappointing. In general irrigation projects seem to give rise to rapid social and economic differentiation. And finally many irrigation systems appear to increase ecological instability (Lampe, 1983; Drijver, et. al., 1985; Murray-Rust and Moore, 1983; Schrijvers, 1985).

More and more scientists, politicians and professionals have been trying to tackle these problems and to develop solutions or alternatives. The following important issues have been dealt with in the irrigation literature: organizational improvement for the bureaucratic management of large-scale systems (Wade and Chambers, 1986; Bottrall, 1981); farmer management and the participation of water-users in the management of large-scale systems (Uphoff, 1984 and 1988); application of organizational principles from indigenous irrigation systems (Coward, 1977 and 1980); and alternative design concepts and procedures aimed at more simple and thus more manageable technical systems (Horst, 
1983). From more socio-economic point of view, attention has been paid to such issues as a better understanding of the social structure and farming system of the receiving population (Barnett, 1977; Diemer, 1988; Merrey, 1986); the ways in which irrigation projects are part of processes of incorporation and differentiation (Barnett, 1977; Krimmel and Massler, 1982); and the functioning of bureaucracies and regional elites in irrigation situations (Barnett, 1977; Wade, 1982; Siriwardena, 1984).

Within this wide body of topics a variety of approaches have been applied. Not wishing to neglect the many differences between them, and after more than 15 years of research and discussion on irrigation water management, one conclusion has become very clear: the problems relate, not so much to the handing of water itself, but to the ways in which people act and interact in response to the issues posed by the particular irrigation system. This conclusion may seem rather simple and self evident. However, my argument is that the translation of this simple conclusion into concrete guidelines and concepts for the management and analysis of irrigation projects is often missing.

As the cases elucidated in this paper will show, in the practice of irrigation development little attention is paid to the ways in which these guidelines and concepts influence and are influenced by the actions and interactions of different parties involved. In my opinion this is not only a question of inadequate policy formulation, implementation methods and project organization; it is also fundamentally a conceptual problem. Concepts from the different approaches and levels of analysis seem difficult to combine. Irrigation engineers and managers often cling to "their" physical system, when they think of technical measures and organizational structures to guarantee the smooth functioning and goals of the system; and in the socio-economic sphere, it is difficult to link and integrate the analysis of different problems or different levels of social order. Moreover, few social scientists seern aware of the concrete technical choices made in irrigation design, construction and management, which makes it difficult to relate their analyses to the concrete measures to be taken within the technical system. One may conclude that both technical and social sciences often seem trapped in their own theoretical concepts and analytical frameworks. In my opinion a way out of these problems lies in a serious appreciation of the dynamic and interactive aspects of 
irrigation development, a process which combines technical and social properties and in which different social entities interact.

In summary the approach I seek has three characteristics:

1) It analyses irrigation development as a vivid interactional process in which people in mutual interaction shape the reality they live in (of course, not neglecting structural and physical aspects).

2) It provides a logical link between different levels of analysis and especially of technical and social aspects of irrigation situations.

3) It provides concepts and insights that are applicable in the practical organization and managenent of irrigation systems and projects.

In the following sections I a im to show that the concept of social interface could serve as a basis from which such an approach could be developed, since it provides a focal point to which existing analytical frameworks can be linked and in which problems at different levels can be related to each other 1 .

\section{Social interfaces: life-worlds, organization and change}

The basic assurmption underlying the application of an interface approach to irrigation situations is that, although from a technical point of view one could speak of one system, from a social perspective it is more realistic to speak of situations of contact or intersection between different social entities (see Long, 1984, and 1988:127-128). Different parties are involved in different econonic, social and cultural spheres and interests. And that is exactly the reason why irrigation development is such a complex process that often appears so difficult to plan and manage. But of course this dynamic and interactional character of irrigation development also makes it an exciting and challenging undertaking. Indeed it is a process in which social relations are changed and shaped. Is that not the essence of societal development?

In analyzing any irrigation situation or problem as made up of social interfaces, three basic questions should be posed: 
- What different life-worlds or parties are involved in the irrigation situation?

- How are these life-worlds related to each other, or in other words, how are the interfaces organized?

- What processes of change are taking place in interface situations?

To define the different parties or relevant actors I deliberately do not use the concept of social group, as this is too rigid and restricted. "Life-world" (see Schutz and Luckmann, 1973; Long, see Appendix to this volume) is used to embrace different dimensions of social life. It refers to material-economic dimensions, in terms of production and reproduction; to social dimensions, in terms of relations, networks, groups and organizations; as well as to the cultural and ideological dimensions of people's lives, in terms of their perceptions, values and ideas.

But how can one distinguish these different life-worlds?

One could distinguish them, for example, on the basis of their formal relation to the irrigation system and describe the life-worlds of water users (possibly further subdivided according to their differential positions or rights within the irrigation system), farmer leaders, ditch-tenders, and higher ranking personnel of the irrigation bureaucracy. There are, however, a number of other possible bases for distinguishing 1 ife-worlds that relate to an irrigation system. On an econom mic and agricultural basis, one might wish to identify those associated with different categories of labourers, peasants, farmers, landowners and traders. And in some situations it might be relevant to distinguish between different ethnic groups, who have their own social networks and perhaps special economic activities, as well as different relations to and ideas about the irrigation system. For the same reason it is often important to differentiate between the life-worlds of women and men, or of those different political factions, or groups depending on different patrons, or for example between producers of different types of crops.

We can conclude then that different parties form themselves around an irrigation situation for a variety of reasons based on different criteria. The life-world concept does not choose one criterion as decisive. Rather it puts forward the question: what are, in any specific situation, the most important interests, relations or ideas that 
help us to identify the relevant parties or life-worlds that occupy differential positions with respect to a particular irrigation issue.

The concept of life-world may also be used to describe the situations of specific individuals whose life circumstances and social networks are in some way distinctive. This is of great importance in interface studies since often a single individual or small number of individuals operates as the principal contact between different levels of social order (for example, between a government agency and a peasant. community). It is often useful to regard these actors as living in specific life-worlds which, as it were, are located at the interface with other life-worlds. Because of their "linking" position, they frequently have quite particular resources, networks, goals and ideas (Long, 1984, and Arce and Long, 1987).

The second question to be answered in an interface analys is is: how do the different 1 ife-worlds relate to each other? In order to tackle this, one might start with a formal analysis of the irrigation organization and the relevant interfaces. Irrigation development poses a range of issues that must be dealt with. These issues can be identified in relation to how, in a specific situation, responsibilities, tasks and power are distributed between the various actors involved. Documenting the ways in which contact between these actors takes place, through the exchange of information and how decision making and the execution of tasks is organized, provides a picture of the pattern of irrigation organization.

If, however, we then confront this organizational picture with an understanding of the different life-worlds of those involved we can reach a deeper and richer account of the situations of irrigation organization and interface. Often quite different pictures of the goals of the irrigation system and its mode of organization emerge from the points of view of different parties. Relations between people or groups are not only a question of tasks, responsibilities and procedures. They are given form, reproduced and reshaped in day-to-day interaction. The personal characteristics of the actors involved, and the specific relations between them that develop over time, can in fact substantially change the formal organization of interfaces. Hence private projects and strategies are also of significance. By analyzing interface organization from a life-worlds perspective one is able to give attention to aspects such as fields of interaction, organizational culture and 
personal relations. And every "frontline worker", be he or she an engineer or an extensionist, knows how important the specificities of people and communities are for the outcomes of implementation. Moreover responses to intervention are often determined by the individuals' previous experiences.

The third basic question entailed in an interface analysis concerns the changes taking place in the character of the different life-worlds and their interrelations. Here one aims to describe trends in the dynamics of interface both at the level of the changing relations of specific life-worlds to the irrigation system, and also at the level of patterns of interaction between the respective parties. From a management perspective, this analysis of processes of change forms an important basis for designing interventions aimed at changing the organization of interface situations. It is not within the scope of the present chapter, however, to deal with this third question in detail, my main emphasis being the elucidation of the basic concepts and issues of an interface analysis as applied to the study of irrigation organization.

In order to make my argument more concrete and to identify the kinds of features and dynamics that an interface approach addresses, I outline the findings of three recent irrigation case studies 2 . This is then followed by a summary account of how to approach irrigation development as an interface process, and the chapter ends with a discussion of the implications of this approach for research, system design and project managenent.

\section{An Ecuadorian case}

The 5,000 hectare irrigation system was build in 1978 by a government agency in cooperation with a foreign contractor, financed by USAID. A USAID mission later concluded that this and other comparable systems in Ecuador were not as productive as they ought to be have been, considering the investment made. Willet and Jeldres (1987) therefore carried out a study to investigate this low productivity. They distinguished three different levels of analysis: the national political context, the functioning of the irrigation system as a whole, and the character of local households and their production systems. In order to 
acquire a better understanding of the concrete reality of this particular form of production, they focus principally on the third level of analysis. The main argument of their report is summarized below.

The day-to-day functioning of the irrigation system occurs without big problems or conflicts. The ma in system is constructed in cement and equipped with simple proportional division structures that guarantee a permanent and almost constant flow of water to the various terminal units. These structures do not need any adjustment over the growing season and it is difficult to influence the ir fixed water division. No large problems occur within the terminal units either, although the water distribution is often rather chaotic. The main reason for this, according to willet and Jeldres, is that many of the water users are frequently absent. Hardly any household sees irrigated agriculture as a major source of income. In fact migrant labour and small-scale trading and crafts are far more important as an economic basis for the households involved. Because of the labour requirements of these other activities, most households do not pay regular and accurate attention to irrigated agriculture. It is seen as a subsidiary source of income and the produce is mainly used for home consumption and exchange within the area.

Although in the official plans the system was designed for a highly-productive and market-oriented type of irrigated agriculture, as usual for most irrigation systems, willet and Jeldres question the relevance of these assumptions either for national policy or for local elites. The major concern of government policy in the period of construction seemed to be to keep the country stable through directing more effort and investment to the rural areas, which were in danger of becoming more and more marginalized and conflictive. Policy was not therefore primarily concerned with high levels of production. Neither were the local elite particularly interested in highly productive systems. Their interests were mainly in extensive cattle breeding and the biggest profits for this group were earned in the construction phase by local contractors and the like.

The main conclusion of willet and Jeldres is that USAID's problem of underproduction only exists from the typically technoeconomic point of view adopted by financiers and engineers. For other "life-worlds" the system has a quite different meaning and importance. Within present socio-economic circumstances, they argue, it is more realistic to see the investment made in the system as a subsidy which creates the possibility for subsidiary income and home-production for local people. The main objective is then to keep the area attractive as a living place for people who would otherwise migrate to the cities or become impoverished.

The case clearly illustrates how various parties involved in irrigation development have quite different goals and quite different perceptions of how the system should be used. The functioning of the system can therefore only be understood from the broader perspective of these different life-worlds. The picture sketched in this example, however, is still one of rather static life-worlds only related in structural 
or functional ways. In the next example more attention will be paid to the actual relations between different parties and the interactions that take place.

\section{A Sri Lankan case}

In irrigation literature, Gal oya is a relatively well known systern. It has been studied quite extensively by Sri Lankan and American researchers 3 . It was also the place where a major experiment in farmer participation in irrigation water management was implemented: the "Institutional Organizer Programme". Herman Fleer was interested in the success story of this programme. From the rich material available he was able to make a detailed reconstruction of water-management in one critical season on the Left Bank of the system. In so doing he tried to obtain a concrete picture of the relations and interactions between the various parties involved 4. The following description of this season is based on Fleer's report on "Irrigation and System Rehabilitation in Gal Oya" (1987).

The Gal Oya irrigation system has a command area of some 50,000 hectares. It was build in the fifties as a colonization scheme. An important part of the right bank area is used for sugar cane production. The left bank, occupying some 25,000 hectares, is cultivated by small farmers, who primarily grow two crops of rice a year. The official command area is only partly served, but there are important illegal extensions in the drainage area of the upper reaches. The system gets its water mainly from the Senanayake Samudra reservoir, and from the smaller Navakiri tank. The Irrigation Department is responsible for the operation of the reservoirs and for distribution of the water until it reaches the field canals, where the farmers divide the water among themselves. Because of the large area covered by the system, responsibility for it is divided between three irrigation engineers, headed by the Range Deputy Director. The area under each irrigation engineer is aga in subdivided between several technical assistants, who are the superiors of the lowest irrigation officials, the Jaja Palakas, who have command over several field canals. The system is located within two different districts. In each district a government agent coordinates the several government departments. At the beginning of an irrigation season this agent will organize several Kanna meetings within his district, where authorities from different departments, technical staff and water users meet to plan the season and take decisions. He is the only one with the authority to change these decisions. In both water distribution and technical adjustments to the system (such as the building of new inlets or weirs) the local representatives of the Agrarian Services Department, often appear to have more power than the Jaja Palakas, for they are responsible for the distribution of some crucial inputs. 
In general the actual tasks and responsibilities of the different officials are more strongly determined by their political contacts and power than they are by their formal position.

The Yala season (the ary season running from April to August) in the year 1981 was a critical one. Never in the history of the system had the Senanayake reservoir been so empty in February, when plans for the coming season are normally made. The Irrigation Department (I.D.) in that year severely restricted the area to be cultivated. Rumours about water shortage spread quickly over the area and water users from different parts of the system sent representatives to the I.D. officials to lobby for their water rights. On the 24th of March the official inauguration of a new Rehabilitation and Water Management Project was to take place, to be attended by a lot of high authorities from Colombo. The potentially conflictive Kanna meetings for that year were delayed until after the inauguration to prevent a politically embarrassing situation. Lobbying by farmers was apparently so strong, however, that on the day of the inauguration, the District Minister felt obliged to promise that in the event of rain there would be enough water for everyone. The Kanna meetings were held shortly afterwards without any rain having fallen.

At these meetings the I.D. officials proposed a severe restriction of the area to be cultivated. The farmers protested, sometimes aggressively, and angry discussions and negotiations took place. In one case tensions between farmers and irrigation officials reached such a peak that they almost started fighting and the meeting ended without any formal decisions being taken. The results of the various meetings were rather different. In some cases the area authorized for cultivation was only slightly restricted, whereas in others hardly any irrigation was permitted. The overall outcome was that the area to be irrigated was three times that proposed by the I.D. The date for starting the season and the duration of the first water-rotation for land preparation was also appointed differently at the various meetings. As Kanna meetings are organized by district and district boundaries intersect with different hydraulic sub-divisions of the irrigation systern, this resulted, in some cases, in different regimes of water-control being agreed upon for one and the same canal. And this despite the fact that at these meetings the same irrigation officials were often present.

When the irrigation season started the actual water quantities used for land preparation from the Senanayake reservoir was much higher than the level agreed upon in the Kanna meetings. From the Navakiri tank, however, where sufficient water was available, the flows were severely restricted. From Senanayake the area cultivated was almost twice the area authorized, while from Navakiri authorized crops of Tamil farmers at the tail end of the canals were lost or damaged. At the beginning of July this resulted in ethnic riots between Tamil and Sinhalese farmers. To prevent a further escalation, the authorities decided to provide large quantities of water to all parts of the system.

All this resulted in a severe depletion of the water reserves. For the preparation of the fields 358 of the contents of the Senanayake reservoir was consumed. Fortunately the situation was saved from being a disaster by two huge rainstorms in the second half of July (very unusual for this time of the year), which increased volume in the reservoirs considerably. Consequently, it 
was possible to harvest 908 of the planted area. However production levels for the season were considerably lower than the average.

This description of an irrigation season in a bureaucratically-managed irrigation system leads us to several conclusions. In the first place irrigation water management is indeed an interface process in which different parties interact and negotiate over the way the system should be operated. This interface has a formal forum in the Kanna meetings where strategic decisions are made concerning the planning of the season, while interactions about the daily distribution of water take place around the Jaja Palaka and the technical assistants. If we look at what is actually going on, however, we see that this formal organization at the interface is considerably modified in day-to-day reality. Several parties take part that formally have nothing to do with irrigation management, such as officials from other departments and higher-level politicians. Moreover, if we consider the large differences between the areas authorized for irrigation in the different sectors of the system, we have to conclude that informal lobbying and personal relations are important determining factors of irrigation organization.

This leads to the second conclusion: that the outcomes of the interactional process cannot be understood solely in terms of the formal organization. The character of the different life-worlds and their specific interrelations have also to be taken into account. For political and economic reasons, agricultural services officials in this case are often stronger and thus manage to acquire a degree of control over irrigation management. The socio-economic strength of different groups of farmers or their patrons, and the quality of their relations with government officials, apparently influences the area that is allowed to be cultivated. And finally even the behaviour of the irrigation officials cannot be understood in terms of the logic of running a system, for they make conflicting technical agreements at different Kanna meetings. Their actions can only be understood by acknowledging that even for them the irrigation system is not a goal in itself but part of a whole complex of activities, relations and ideas, which constitute their life-worlds and in which they seek to guarantee their living and to realize their personal goals. In this context the activity of water management is often an econornic activity which can provide an official with subsidiary incone and a position of power. 
A third conclusion to be drawn from comparing this case with the former one is that the character and sphere of interactions around irrigation issues may be quite different. In the Ecuadorian example we found a situation where contacts between officials and farmers were few and local people showed little interest in irrigation management. In the Sri Lankan case the contacts are intensive and often conflictive. Ethnic distinctions were a factor of importance here. These differences are not only caused by the specific social positions and interrelations of the actors involved, but also by the technical characteristics of the system and by the mode of intervention, as will also be illustrated in the next case.

\section{A Tunisian case}

In many semi-arid regions, especially in the Arab world, one finds spate-irrigation systems which make use of the irregular and sudden water flows through so-called wadi's or oueds. These are river beds that do not carry water for the major part of the year, but have peak flows after rainfall. Rutger van Mazijk and steven Scheer (1988) studied such a system in Southern Tunisia, where, in 1986, the government completed a project to replace three existing "traditional" earthen systems by one new system with concrete canals and a concrete in-take structure. It was hoped thus to improve water availability and to eliminate the arduous work of rebuilding the earthen dams every year. The study was embarked upon because of problems of both water distribution and maintenance in the new system that at the time was in its second year of operation. Their research report has three foci: an identification of the exact nature of the problems; the place of the systern in the life-worlds of the farmers; and the history of the project described from an interface perspective. In the summary of the material below the last aspect is given major attention.

The system is used by three different sub-factions of the tribe living in the area. These three factions have distinct territories, lying from top to tail along the main canal. The irrigated area of each tribe is approximately $100 \mathrm{ha}$. Before the project each of these factions used to build its own dam(s) in the wadi to provide its territory with irrigation water.

The system, based on technical data on topography, climate, soils and peak-flows, was designed in offices in Tunis, without 
thorough reconnaissance of the agricultural situation in the project area. During the construction of the new system no formal contact was established with the local communities. The official way for the local population to communicate with the project was through the normal hierarchy of the administrative district. The construction work was carried out by a contractor from the district capital and supervised by officials of the government design agency. It started at the top end of the planned system. The faction occupying this upper section was relatively well organized and had a strong leader who managed to make good relations with the implementing contractor as well as with the official in charge of the daily work. Consequently this faction managed to influence the project, in the sense that the location of outlets from the main canal were adapted to the location of the already existing secondary canals of the old system. In this period this faction also obtained an assurance that water rights would be established on the basis of priority for the upstream water users (as is usual in Islamic societies).

The construction work then arrived at the territory of the middle faction, which from the beginning was less well organized than the first. Moreover rivalry existed already between the two factions. The project official considered the second faction to be lazy and disinterested. Also he was not very eager to enter into another time-consuming relationsh ip with a local group. Consequent1y no informal relations were established. In practice this meant that the outlets from the main canal through the territory of the second faction were constructed according to the official design and were not connected to existing secondary canals.

The territory of the third faction had always been located downstream of the old intakes of the two other factions, as a consequence of which water availability had always been very low and even more uncertain than for the others. Over the last ten years, therefore, a considerable number of the farmers in this area had constructed wells and had established quite successful vegetable production for the regional market. As the spate-irrigation method is rather rough (a form of controlled inundation) these relatively well-off vegetable growers saw the irrigation project as a threat to their plots and wells, which could be damaged and inundated. Their resistance resulted in sabotaging canals and machinery. Finally project officials were forced to decide not to continue the construction of the main canal.

In the first year that the system was used for cultivation several problems occurred. The distribution of water to the fields of the second faction was problematic as the outlets were located in unfavourable places, either too low or too distant from the existing secondary canals. Between the upper and middle factions severe conflicts developed over rights to water. The first faction established direct control over the water as they were located upstream. The second faction received little compared to the upper faction, and less than they had from their own earthen dam. In the case of high peak-flows a drainage problem arose. As the canal construction was not finished to the end and no good drainage facilities were constructed, the plots of the third fraction were indeed twice inundated. The construction of the concrete dam also appeared to cause some technical problems. During high peak flows enormous quantities of silt were deposited in the main canal. The farmers saw this as a problem caused by the project and thought it 
therefore the project's duty to excavate the silted canals as well as to look after general maintenance. The project authorities, however, argued that the system should be managed by the farmers.

Finally, the height of the crest of the concrete dam appeared to be too low to divert sufficient water into the canal during small or mediun-sized peak flows. It therefore appeared to be necessary to construct an earthen dam on top of the concrete one.

This case illustrates beautifully how the outcomes of the implementation process are determined by the way in which interaction between the various parties evolved. The physical state of the system was a perfect reflection of the interface situation between the different factions. In the upper reaches, where an intensive informal relation between local community and project functionaries was established, the main canal became directly connected to the existing secondary canals of the local population. In the middle section, where less good contact was established, this did not happen. And at the tail end of the system the canal was not even constructed because of conflict between farmers and the project.

On the other hand, however, it is also clear that the technical design of the system contained a number of social organizational assumptions. The first assumption was that the three conmunities, which until that moment had been independent in capturing their irrigation water, could be brought together in one system and be expected to form an integrated organization for managing the system. A second assumption was that all farmers active in the service area would profit from the water delivery and thus would be willing to be involved in the system. Both assumptions appeared to be invalid when the project plans were implemented.

Thirdly, it is important to conclude that, from an interface perspective, significant differences existed between the design phase, the construction and the actual use of the system. Different parties were involved in these phases and their responsibilities, tasks and relations changed fundamentally. The main actors in the formulation and design of the irrigation project were government agencies, experts from different disciplines, financing agencies and consulting firms. When implementation started, the plans they made were confronted with the life-worlds of farmers, contractors and others. After completion of the work, the system had then to be operated by the farmers, or in some cases also by government officials, but usually those from services other than the ones already involved. The lack of communication between 
the different parties and the enormous differences between their Iifeworlds, caused abrupt discontinuities in the transition from one phase to another in the project.

\section{Irrigation development as an interface process}

Many governments try to create particular types of agricultural production by implementing irrigation projects, of which some examples were given in the cases before. The goals usually motivating such projects are: export production, raw materials for national industries, food for national and regional markets, and stabilization of the rural areas. In order to pursue these goals project plans are developed and implemented.

The cases discussed above have demonstrated that the implementation of such plans is not such a clearcut and goal-oriented process as project plans would often suggest. The following appear to be some important characteristics of irrigation development.

* The outcomes of the process are often very different from the plans made and appear to be determined by the interaction between the various parties involved: different government agencies, various categories of farmers and other parties such as building companies, regional leaders and political factions. Each of these parties may have a quite different interest in and perception of the development of irrigation.

* For the various parties involved in an irrigation situation, the system is not a goal in itself, but part of a broader life-world, in which each party seeks to guarantee a living and pursue particular goals. Important elements of each of these life-worlds are: the economic base for production and reproduction, the social network in which people live and their perceptions and values. The attitudes and actions of the various parties with regard to the system can only be understood, therefore, when one considers the meaning of the irrigation system in the context of these varying lifeworlds. 
* In order for irrigation development to take place, some kind of relation between the various life-worlds must be established. The actual organization of this interface is often very different from the formal organizational structures developed for project implementation and system management. Real division of responsibilities, tasks and power often appears to be determined by other factors. Informal networks of lobbying and decision making appear to be influential. Wider socio-economic and political positions and mutual relations of the various 1 ife-worlds are important for the kinds of relations that evolve.

* The technical design of an irrigation system contains a number of social and organizational assumptions. For example it determines the groups that must cooperate, the activities and tasks to be executed and the decisions to be taken. Consequently the technical design is a determining factor in the interface process, since it raises a number of issues (sometimes problems or errors) to be dealt with and identifies certain actors and their formal positions.

* Apart from the organization of the interface and the more structural positions of the actors involved, the personal relations between certain individuals at the interface (such as farmer leaders or representatives, engineers supervising construction works, project chiefs, extensionists and water dividers) appears to be an important factor in the development and outcomes of the process.

* Conventional concepts and methods of project planning and management often ignore the interactive character of irrigation development. By thinking and acting on the basis of such conventional concepts, one in fact creates a situation where the real issues at hand are forced to assume informality, and an interface organization energes which is often characterized by unclear decision making, informal wheeling and dealing, private projects, misuse of power and the like. 
What emerges is a picture of irrigation development as a truly interactional process, in which various parties have to deal with a number of issues raised by the irrigation plans. The parties typically represented in an irrigation situation appear to have distinct life-worlds, belong to different levels of social order, have differential power over resources, and are characterized by distinct cultural settings, ideas and values (Long, 1984, 1988: 127-129). In the process of irrigation development new relations between these life-worlds are established, existing relations are changed, broken or reinforced, and as a consequence the position and character of the various parties transformed. Thus the actual irrigation system developed in such an implementation process, or the irrigation organization established around a certain systen, can thus not simply be considered as a planned phenomenon; rather it is an emergent property characteristic of specific interface proresses.

\section{Implications for desigri, research and management}

For engineers who design and construct irrigation systems, an interface perspective has some far-reaching implications. The technical system cannot be seen nerely as a technical or productive system which is a goal in itself. It is a basis for social interaction. And the outcome of this interacticn determines not only the ways in which it is used but also the concrete technical properties of the system constructed.

For engineers it is therefore necessary to unravel the social dimensions of their design. At a very fundamental level this even questions the nature of the basic design elements that the normal irrigation engineer uses to build an irrigation system. In a recent paper Geert Diemer has made an interesting comparison of the ways in which African farmers design their own indigenous irrigation systems and the ways in which engineers do it for them. His conclusion is that several basic elements of the engineer's design, such as the form and size of plots, the concentration of irrigated fields, the lay-out of canals and the assumed water-distribution system are in fact culturally detemined constructs, reflecting a specific interpretation of what 
irrigated agriculture is supposed to be and how the farming system should be organized (Diemer, 1988).

From an interface perspective yet another issue needs attention: technical design in fact contains a whole gamut of organizational and management assumptions. The lay-out of canals influences quite directiy the size and composition of groups within the various units of the system. Choosing fixed, proportional or adjustable structures determines the operative tasks and power positions at particular places within the hierarchy of the system. The cropping pattern and water-distribution system chosen presuppose crucial decisions about labour input, farming methods, and seasonal planning. It also assumes the necessary maintenance activities and thus the labour and resources needed for them.

Such social assumptions in system design must then be related to present forms, capacities and traditions of farming and organization with in the population, and, in the case of a government-managed system, also to the characteristics of the government bureaucracy. In this way it might be possible to predict what new organizational demands might arise as compared with those existing. One is then in a better position to judge in what ways new organizational activities, procedures and positions will change or reinforce present positions, and thus to understand the implications of the plans for relations between the various actors. This brings us to the necessity of participatory design procedures, of discussing and negotiating the feasibility of new organizational demands with the different parties involved, so as to provide adequate organizational development to parallel the technical construction of the system. In this way the distinction between design and construction becomes less relevant. The design of an irrigation system is often adapted to local wishes, formally or informally, during the construction phase. This usually improves its performance. And in later phases farmers are well known for their capacities to adapt the system to their own needs by constructing new canals, outlets, and changing the functioning of structures. Thus from an interface perspective, it seems necessary to develop participatory forms of design and construction, in order to let the physical system indeed reflect social processes at the interface. 
For managers of irrigation systems or projects, an interface approach has also far-reaching implications. We have described irrigation development not simply as the establishment and management of technical systerns, but as a process in which different parties interact around the issues raised by the irrigation situation and in which, as a consequence, the relations and positions of various parties are changed. Guiding such a process is therefore not possible by simple planning and monitoring. It is a dynamic interactional process in which the outcome can be neither determined nor predicted by one party, since it is by definition also shaped by the other parties involved.

The primary task of a manager, then, is to guide this interactional process. This perspective has much in common with many modern management theories. These argue that organization is not a structure but fundamentally a process (Morgan, 1986). Organizational structures are instruments which, if necessary, have to be adapted to the needs of the organization as a whole and of the different participants. Organization is also recognized as resting on shared systems of meaning, and thus on the shared interpretative schemes that create and recreate that meaning. In a situation with various (sub)cultures, as is the case with many irrigation interfaces, an important role for the manager is also, therefore, translating and relating the ideas and perceptions of the different actors. Such a view does not, however, interpret differences of meaning and conflicts as problematic situations and deviations from an ideal process. They are more a necessary bas is for finding creative solutions and helping to keep the organization flexible and adaptive to new circumstances. An important responsibility of the manager is thus to keep procedures, responsibilities and tasks clear. When necessary, actors may need to be confronted with their responsibilities, but where this is not functional, because relations are basically different or issues have changed, the organizational structure itself should be changed. To be able to perform this type of management role, one must in the first place be open to the realities of the various Iife-worlds involved and willing to perform an assisting and guiding role, that is not primarily aimed at personal objectives.

Possibly a more important limitation, however, is that many government agencies wish to control irrigation development and thus tend to patronize farmers and their organizations. A vicious circle may be created in this way, in which government implements irrigation develop- 
ment primarily for its own reasons and without much participation of local groups or enough attention to the development of adequate local forms of organization. When the system is physically established, government expects farmers to take on certain responsibilities and tasks. Yet the latter may be unable or unwilling if they do not consider the system to be their own responsibility and creation. The government then finds itself in a trap, because it wishes to retain a high degree of control, but at the same time the policy itself prevents the development of adequate water users' organizations. The result is that irrigation bureaucracies of ten get stuck in seemingly endless relations with dependent farmer communities unable to manage and maintain the physical system, and/or unwilling to repay debts or to pay water fees. This situation is often maintained and enforced by local leaders, regional elites and government officials, for whom the situation offers an ideal opportunity to develop their own personal projects, profiting from dependent groups of farmers, as well as from government resources.

A real recognition of the interactive nature of irrigation development would require the government to diminish its wish to control the process, but at the same time it would provide the opportunity to request more responsibility from the other parties involved. In realizing such a policy, managers willing and able to apply such a management perspective would be crucial.

For researchers interested in contributing meaningful insights into irrigation development, the interface perspective has a number of theoretical and methodological implications.

Many social theories appear to be based on some kind of deterministic view in which societal development is explained in terms of basic mechanisms or factors (Long, 1984). In contrast, the interface approach focuses on how people creatively, through their actions and interactions, shape the environment in which they live and thus contribute to the reproduction or transformation of existing structures. Here it is necessary to pay more attention to exploring ways of combining actor with more structural types of analysis. Researchers will also need to pay special attention to people's perceptions, in order to detect how they see themselves and others, and how this shapes their behaviour and ultimately their living situations. 
Paying attention to interactional processes brings many traditional categories and concepts about social groups into question. In interface interaction, depending on the issue at hand, different groups form and re-form. Also "interface actors" must operate at various levels of social order.

Further research is needed on the social assumptions of irrigation design and on the processes of implementation. In order to pay adequate attention to these aspects, concepts and methods must be developed to depict the phases, issues and forms of organization occurring at interfaces. An integration of sociological and management approaches is thus necessary. In analyzing the interaction patterns, communication theory and psychology could provide additional contributions to sociological thinking on social relations.

\section{Conclusion}

The interface approach as developed in this chapter is not a theory in the sense that it describes general relations and mechanisms of causes and effects. Rather it is a way of looking at problems in order to relate different levels of analysis using the concept of interrelated life-worlds. It also affords an understanding of how technical phenomena and processes are shaped by people's actions.

We live in a world which, on the one hand, becomes more and more complex and in which everything seems related to everything else, but, on the other hand, scientific specialization is reaching a point where it is more and more difficult to understand each other. It is my conviction that there is now a great need for concepts that can help us to interrelate and translate the findings of various disciplines and levels of analysis. I hope that the further development of an interface approach might contribute to such forms of integrated analysis that elucidate how people's creative capacities and possibilities influence and shape the world in which they live. 
1. The development of the approach presented in this chapter has not been a private undertaking. It is the result of collaboration and discussion with many people in and around the Department of Irrigation and Civil Engineering of the Agricultural University, Wageningen, I wish to mention especially Jan willem Eggink, with whom I started this intellectual journey, Norman Long who has been an experienced guide through the traps and pitfalls of the social sciences, and Pieter van der zaag, a fellow engineer whose commitment to get to grips with the social dynamics of irrigation in western Mexico has been a great inspiration to me.

2. All case studies were undertaken by M.Sc. students of the Department of Irrigation and Civil Engineering of the Agricultural University, Wageningen. The approach presented in this chapter has, until now, hardly been implemented in the field of irrigation. Only the last case study uses an explicit inter face perspective. A major project to develop and test the analytical framework is presently underway in western Mexico (see Long, 1986).

3. The main institutions involved in these investigations are the Agricultural Research and Training Institute in Colombo, Sri Lanka, and Cornell Univer sity, Ithaca, USA. For some relevant publications see the list at the end of this article.

4. In his research report Fleer also makes a critical evaluation of the basic premises of the Institutional Organizer and Sri Lanka Water Management Programmes implemented in the system. Hexe I will restrict myself to Fleer's reconstruction of the Yala 1981 season, for which the material of Murray-Rust \& Moore (1983) has been an important source of information. 
VIII. INTERFACES AND JANUS-FACES: A CRITICAL APPRAISAL OF THE INTERFACE APPROACH IN DEVELOPMENT SOCIOIOGY FROM A SOCIO-LEGAL STUDIES PERSPECTIVE

Franz von Benda-Beckmann, Ab van Eldijk, Joep Spiertz, and Fietje Huber

\section{Introduction}

In this chapter we offer a critical appraisal of the interface approach as set out in Norman Long's discussion paper (see Introduction, pp. 1-5, of this volume). We do so against the background of ideas developed in our genre of research and analysis, a mix of legal anthropology, legal sociology and legal science. By way of introduction we shall briefly sketch the most important ideas developed in these fields. While our field of study has made significant advances during the past twenty years, we are most certainly not, however, in a position to be content with the state of our analytical and theoretical art. We are faced with similar, and in part identical, problems to those that concern other social scientists, including development sociologists. We share their hunger for more adequate analytical frameworks, and we try to nourish ourselves as far as possible on what is produced in other analytical and theoretical fields.

In our critical assessment of the interface approach we shall go beyond the exposition of Long's paper, which makes no claim to offer a comprehensive framework for the study of rural development. Neither can one expect from such a short discussion paper a systematic analytical treatment of the questions of how, and in which types of interactional settings, social systems which exhibit structural discontinuities are reproduced (i.e. maintained and/or changed), or of how the activities of government and other development agents should be seen within this 
wider methodological context. What one can expect, however, is that the answers given in any selective analytical treatment, such as the interface approach, be consistent with those answers which would make up a more encompassing analytical framework. We shall therefore extrapolate from it to consider more general questions about the reproduction of (rural) social systems in order to evaluate its analytical potential. In other words, we shall ask whether the assumptions which apparently underlie the interface paper are compatible with the assumptions which should guide the answers to the more comprehensive questions.

Summarizing our conclusions, we can say that ultimately we are not convinced that the interface approach, seen as (the core of) a general methodology, is a fruitful one. Although the notion of interface has a stimulating and sensitizing function, we cannot see how it could be developed into a general analytical framework in which the questions arising in the study of rural development could be systematically and consistently studied.

\section{Iaw, legal pluralism, the interaction of folk and state law, and the selective use of legal systems}

Our specific field of interest is law, which may be taken as a cover term for the complex arxays of cognitive and normative conceptions concepts, standards, rules, principles etc. - to be found in any society 1. Our work does not consist of a mere inventorization or recital of such conceptions; we are concerned with law in society, and here at the Agricultural University more specifically with law in rural areas in developing countries. "Law in society" again is a cover term for all those social processes in which law is produced and reproduced, or in which law can be said to be involved in human action. Since we do not believe that law is made by forces other than by human agency, or that it could do anything by itself except through human agency, we must work with the idea of human agency and how it relates to law (cf. F. von Benda-Beckmann, 1983a, and 1983b). Hence our affinity with sociology and anthropology, economics and political science, and hence the obvious overlap of our theoretical concerns. 
At the basis of our study lies the notion of legal or normative pluralism. In most societies and, in a particularly visible form, in developing countries there is usually more than one body of rules and procedures (government law, religious law, local village law, and other forms of self-regulation), which originate from different sources and which are reproduced by different institutions and individuals in different ways and with different consequences. The notion of structural (legal, normative) pluralism therefore is a very common notion, and with this the notion of structural discontinuity in the overall legal system 2. As a consequence, it has become self-evident for us that any relation of law to human agency must be treated in the context of legal pluralism.

Studies of law in action or of the social, economic and political significance of legal pluralism have long been concerned with the relations between structure and action, rule and process, general principles and the details of case-studies. The concern with structures is obvious, for law - as a body of general rules and principles - is a cognitive and normative structure. The reason for our concern with the details of rules and human agency, which finds its expression in an emphasis on case-studies, is equally obvious once it is realized that the abstract general and often very ambiguous conceptions of law only make sense in social life if interpreted and concretized in terms of specific life-situations.

In our field of study there is also quite a longstanding interest in research on the "implementation" and "efficiency" of law, a field of study largely identical with the policy-implementation-outcome problenatic. Not all policy, of course, is law, but in all contemporary societies salient elements of State policy have to be framed and legitimized in terms of law, be this the state budget of the Netherlands, the land reform of Peru, or the tribal grazing land policy of Botswana. And most of law, particularly law originating in government institutions, can be seen as policy. Theories and empirical studies on the problem of intended socio-economic change through the formulation and implementation of law (legal engineering) and "impact of law" studies are quite fashionable in our field, and with it the whole problematic of "external" law coming into contact with law "on the ground", village-level law, and with local social and economic relations 3 . From the critical discussion of the assumptions and motives behind such legal engineering 
policies it was only a short intellectual step to the problematic of "differential response", and Sally F. Moore (1973), a legal anthropologist, can be counted among those who have laid the basis for a further elaboration of what is becoming a special theoretical focus. In fact, socio-legal studies in developing countries have contributed an important share to the destruction of legal and social engineering ideology by showing that the social and economic consequences of government policies are differentially mediated through local normative, socio-economic and political structures and interaction processes (see F. von Benda-Beckmann, 1983a for further references).

Given these concerns, it is not surprising that students of law in developing countries were quickly led to studies of what, in Long's language, would be termed structural discontinuities in the normative system ("conflict of laws") and interface situations ("interaction of folk law and state law"), situations in which different normative systems clash with each other or are mobilized against each other (see, for example, Burman and Harrel1-Bond, 1979; Allott and Woodman, 1985; Chiba, 1986).

The metaphor "interface" has been used in legal sociological writings (Galanter, 1981: 31) but has never acquired any significant conceptual importance. There are a number of ethnographically rich case-studies of, what Long would call, interface situations, in which we can see the clash of government legal concepts and principles with customary, village or tribal legal principles (see, for example, Snyder, 1981a; Werbner, 1982; K. von Benda-Beckmann, 1984). In these studies we can see the western hegemonic legal ideology at work in the processes of adjudication by government judges, and we can also see how this affects traditional indigenous legal notions. We can see how traditional notions are transformed, misinterpreted, created, or perverted when handled in the organisational context of bureaucratic government courts 4. And we can also see how government law itself is interpreted, transformed, applied in the context of adjudication, and what the results of these processes are. In other words, we can see how those parts of government policy (aimed at maintaining the status quo or at change) which are expressed in law are transformed in the interaction of judges (seen as street-level bureaucrats, see Lipsky, 1980) and their clients (disputing parties). 
Such studies were, originally and for much too long, confined to a 1 imited number of interaction settings: mainly to the settings of law making and law application in courts or court-like institutions. But legal anthropologists finally also gave attention to the fact that one decision-making actor (such as a judge) can be guided by, and may employ, elements of different normative sub-systems in the same action (see F. von Benda-Beckmann, 1983b, and K. von Benda-Beckmann, 1984). More recently, socio-legal studies have given more attention to these phenomena also in other contexts: for example in the context of administrative action, as well as in varying contexts of the everyday life of citizens.

From these studies we have learnt several lessons.

1. If we wish to study the social significance of law (policy) we may not confine our study to the context of "implementation" in the limited sense of that interaction setting in which law is said to be implemented according to the normative assertions of lawyers, politicians and the like, viz. the courts. We also have to take into account the fact that law is also reproduced "out of context" (F. von Benda-Beckmann, 1984), in other interaction settings. We have become used to the idea that State law can be reproduced by interactions between peasants, that customary law may be reproduced by government officials, and that transformations occur in both types of settings. Implementation of law (policy) therefore must also be conceivable as "implementation by citizens", a difficult notion for those firmly thinking in terms of legal and state ideology, but inevitable from a social science perspective.

2. We have also drawn the conclusion that we cannot go on treading the analytical path of the "external/internal" problematic in the traditional way; in any case not when we are concerned with the analys is of actions through which the plural normative system is reproduced (see Moore, 1973; Kidder, 1979; Spiertz, 1984; F. von Benda-Becknann, 1987). We have learnt to live with the idea that, although government law can be regarded as an external phenomenon in one sense, it can also be a phenomenon internal to a village, to peasant life, etc., if it is reproduced inside the village, in interaction between villagers. Where law is reproduced is not a theoretical question but an empirical one. 
3. These experiences have also coloured our conception of actors in systems which are characterized by plural normative structures and institutions. Actors cannot analytically be identified as representatives of one system. They turn out to be janus-faced. They have choices, make choices and selectively draw upon what they perceive as the total legal repertoire of concepts, norms, rules etc., and also of judicial and other administrative procedures and agencies which are supposed to rationalize and justify their decisions in terms of law (see, for example, the contributions in Nader and Todd, 1978; K. von Benda-Beckmann, 1984). These agents may also bake their own legal cake using the legal conceptions which have been, and continue to be, reproduced around them as a cooking book (Galanter, 1981), compound elements of different structures (F. von Benda-Beckmann, 1983b), or they establish their own normative ordering "between folk law and government law" (Van Eldijk, 1986). of course, not everybody can cook so easily nor so well, as several studies of differential access to, or use of, law/institutions in dispute settlement have demonstrated 5 .

4. Finally, we have learnt that it is essential to the understanding of law in society to realize that the normative repertoire, as one aspect of the institutional environment in which people act, is constituted and reproduced through time (i.e. historically). At any given moment in time agents are confronted, constrained and enabled (Giddens, 1979) by historically-reproduced structures, and maintain and change these structures through their actions. In research and analysis, therefore, the combination of historical with interaction studies has also become more prominent (see, for example, F. von Benda-Beckmann, 1979; Snyder, 1981a; and Moore, 1986).

\section{Structural interface, interactional interface and interface actors in the study of rural change: a critique}

The interface problematic thus is a problem known to us, and through the studies in our field we have been sensitized to most of the problems addressed in Long's paper. Read as a critique upon traditional development studies, his discussion appeals to us. In our field, too, research on interface situations has yielded rich material and in- 
sights. However, the question remains whether a general methodology can be built upon it.

One of the minor difficulties we have with the paper is its ambiguity. Its goals and ambitions are not really made clear. Does it intend to offer more than a refined analytical framework for the traditional policy-implementation-outcome problem? Is an interface situation in this sense actually no more than interaction between persons representing policy making, implemention and target groups? Does it delineate a unit of analysis, or just a field of observation? or does it aim at providing an analytical framework in which the reproduction of structural continuity and change in structurally discontinuous social systems can be analysed? And does it intend, in general or in the context of policy-implementation, to provide a systematic way of integrating structural and actor-oriented analysis?

As we shall try to make clear, these ambiguities do not matter in the end since our major reasons for questioning the interface approach are more fundamental in nature. They relate to (1) the relation between structural interface (discontinuity) and interface interaction settings, (2) the approach to the policy-implementation problem in this wider context, and (3) the conceptualization of the interface actor.

\section{Structural interface and interface situations}

Structurally discontinuous systems (like all social systems) are reprom duced in a multitude of time-space contexts, "locales" in Giddens" sense (1979). Interface situations, like policy-implementation contexts described in Long's paper, can be regarded as one typified locale, or interaction setting, in which structurally discontinuous systems are reproduced. There is no reason, however, to assume that such interaction situations, however fascinating and revealing their study may be, are the only or the most significant ones in the overall process of system reproduction. Otherwise one would have to maintain that the social system, and its critical points of discontinuity, constitute the interface-interaction situation writ large. Such a notion is clearly untenable. Whatever significance interface situations have for the overall reproduction of the social system (or the relationship between 
sub-systems) is an empirical question which cannot be answered by a theoretical or methodological a priori.

A similar objection can be raised against the attribution of a special and particularly dynamic character to structural reproduction resulting from interaction at specific linkage points, i.e. linkage points in which actors representing different structures interact. Long suggests that interactions at these linkage points are particularly important for the processes of structural change in complex social systems. This may, of course, be the case; but we can also assume that interaction at linkage points is particularly suited to upholding the status quo. More importantly, we can as easily assume that the reproduction of structural discontinuities and of more important and dynamic relations of interdependence between subsystems run through a series of time-space contexts other than the typified linkage/interface-situation.

\section{Social security on Ambon}

Let us try to illustrate these points with an example drawn from recent research on social security on Ambon, Indonesia, carried out by F. and K. von Benda-Beckmann.

Considering the field of social security as a nation-wide system, we can see that some small parts of the population, mainly civil servants, the military, and employees in large-scale economic enterprises, receive social security provisions from government or semi-government organizations, or from some other organization which is obliged to do so under government law. Yet the larger part of the population, particularly in rural areas, receives no such provision. In this case social security is largely based upon local normative systems, traditional normative systems and institutions of mutual help and of help to the poor and needy, usually based upon kinship, friendship. neighbourhood and self-help organization (see F. von Benda-Beckmann, 1988). It can thus be said that there is structural discontinuity in the normative basis upon which social security provisions rest and in the processes by which social security resources are allocated.

But where are these structural discontinuities reproduced? The interface approach would lead us to $100 \mathrm{k}$ at those interaction settings 
in which agents of the state social security system interact with their village clients. Indeed, there are government programmes based upon state social policy (dealing with socio-economic security for the rural population), which are specifically directed towards intervening in the local system in order to channel state resources for the provision of village social security. These make for interesting case-studies (see K. von Benda-Beckmann 1987, and 1988), showing how state policy is transformed at village level. They also offer an interesting opportunity for studying differential response to differential impact for village-specific transformations of district-specific variations of the general policy). From this we can learn much about state-peasant relationships in the field of social security, and can also draw some "development-relevant" lessons for future social policy directed at the village population. This social security interface situation can also be seen as a dynamic linkage; it leads to changes.

So nothing against the study of interface situations. But how relevant are they? Are the critical points of intersection or linkage between the (for simplification) two systems of social security in which the structure of the encompassing social security system is maintained or changed, to be found in such situations?

If we focus upon the provisioning of socio-economic resources, then the maintenance and change of these discontinuities on Ambon will not be found, to any significant extent, in the interaction of social security officials with peasants. For the simple reason that there is very little interaction and that only a small amount of economic resources is involved. Structural discontinuities in the field of social security are reproduced in other contexts: the government bureaucratic system, the military system, in a few large enterprises, and in the villages. There is little direct linkage/interaction between representatives of these systems in the context of social security. In the interaction fields typified as interface situations there is "emptiness", more disjunction than linkage.

The really dynamic "linkages" - here understood as interdependences between time-space contexts, not as interface-interaction situationsin the policy field of socio-economic security are elsewhere. For instance, they form part of the system of direct and indirect taxation, when government increases social security provisions in the civil service sector and draws part of the required funds out of an increase 
in indirect taxes, which, in turn, decreases the economic position of rural villagers and therefore the resources which villagers might invest in village-based social security relations and provisions (cf. Midgley, 1984).

One of the most dynamic linkages between the two social security systems is probably the sending of village children to secondary schools and universities (F. and K. von Benda-Beckmann, 1986; F. von Benda-Beckmann, 1988). Sending your children to school is one of the main social security strategies of villagers, who reason that by putting their children into administrative/government jobs, in which they will earn a regular salary and receive government social security services, they - as parents - will also be able to profit. Since schooling is expensive, there is nowadays a definite trend towards converting economic resources, such as land, trees and labour that are important for traditional social security, into school fees. Also people tend to take labour obligations in relation to the school more seriously than those towards their fellow villagers. They try to reduce their obligations towards the wider set of $k$ in and neighbours - from whom they might expect help in terms of the traditional social security system - in order to be able to better fulfill the self-imposed obligations towards their new social security hopes. They weaken the traditional system in the hope of gaining through the state system. And they do so largely in their interaction with their fellow villagers.

Here then is a dynamic linkage in which villagers, in interaction with other villagers and agents of the state educational system, are the dynamic forces in a process which may lead to structural change, and in which peasants in interaction with peasants change both the State and village systems of social security and their interrelation, both on the level of normative values and through a change in the allocation of resources.

\section{Inplementation and interface}

This, of course, has consequences for our attempts to analyse the "implementation of state policy", a point which can be illustrated through the example of recent research on Bali (see Spiertz, 1986). 


\section{The transition to high yielding varieties on Bali}

In the early $1970^{\prime} \mathrm{s}$, efforts were made by the local government to convince the Balinese to switch to new high-yielding rice varieties (HYV). In the irrigation associations, at which the implementation of the policy was primarily directed, an analysis starting from the concept of a state-target group interface would certainly have revealed much of the complex array of linkages mobilized by the actors in regard to the issue. In many instances, however, the HYVs were adopted (and thus the policy "implemented") in quite different interaction settings.

Take the developments which occurred in a small irrigation hamlet in centra1 Bali. The peasant population were sharecroppers on the lands of a precolonial elite whose residential centre was at a distant village. After Bali had been incorporated into the colonial state, this elite did not need the territory and population of the hamlet any longer as a buffer and early warning system against possible attacks of rival baronets. On the other hand, the land tenure system had become the elite's basic means for assuring their elite status. They had lost much of their political power to the colonial government and therefore were the more attentive to protecting what was left of it. One way of preserving some of their former prestige was by promoting the production of traditional rice varieties through the system of sharecropping. Hence the growing of traditional varieties became an important element in political ideology, expressing the love and respect of sharecroppers for their landlords, and perpetuating patron-client relations.

With the elite's increasing orientation towards acquiring administrative positions in post-independent Indonesia in order to maintain their status, education at prestigious centres outside Bali became increasingly important as well. Because of this, and other reasons, the need for cash began to infiltrate the other prestige and social security contexts in which non-market rice production and non-businesslike relations between landlords and tenants were important. In the late 1960 's, the representatives of the elite and the sharecroppers, both influenced by these new interdependences between prestige, power and money, rearranged their relations by converting them into what they called "private contracts". Private contracts meant that tenancy fees were set at a fixed price in cash, thus differentiating the tenancy relation from the traditional multiplex patronage relationship with its 
concomitant obligation to produce traditional rice varieties. The tenants, it seems, enjoyed paying the fixed tenancy fee, perceiving the new relationship as being advantageous to them; and few years later, they proved to be the most obedient citizens in the implementation of the HYV policy. Yet a policy implementation interface, in the sense of an interaction setting between government officials and tenants, never came into being.

\section{The interface actor: a normative construction}

This leads us to the relation of actors to structures and to our critique of how human agents are conceptualized in the interface approach. It follows, from what we have said above, that we cannot accept the notion of actors (engaged in the reproduction of the social system/the structural discontinuities or in linkage interaction settings) being "representatives", either by virtue of "their" role as such, or by their "belonging" to one particular sub-system. Such a conceptualization is structuralist in nature. It derives either from a normative (legal) definition, from sociological dogma, or from the summary generalization which is expressed by the notion of system or sub-system. It defines the actor from the outset as a member of a category (i.e. as villager, peasant, bureaucrat) with which normatively, or summarily, certain normative values and/or social interests are associated. From such a starting point, it is difficult to question systematically the relationship between the individual actor and different roles, pluralistic rule and value sets, individual or group interests, and social and economic networks in which one is, or intends, to get involved. It consequently does not permit a systematic analysis of choice making, the selective use of plural normative systems, or the innovative combination of normative values and social interests attributed to different sub-systems (normative, economic, social, cultural, political, or what have you).

We would certainly not dispute that there are probabilities inherent in such normative or categorical attributions which would justify the assumption that a villager, for example, would primarily act as a peasant, representing and reproducing the peasant role and value set, and that he/she in his/her choice between behavioural and normative 
options might be more strongly constrained by "his" or "her" background system; and the same holds true for the bureaucrat. But, in the analysis of interactions, what we are interested in is the question of whether and to which degree an option is chosen and whether this choice will vary with different contexts and according to the degree of involvement in different interaction networks, and what all this means for the reproduction of structurally discontinuous social systems (for an illustration, see F. von Benda-Beckmann, 1987b).

\section{Some conclusions}

Although the research orientation we have indicated above is a prominent part of the interface approach, we are not convinced that it can be consistently treated in a general methodology based upon this approach. Ultimately we believe that the concept of interface starts with notions of structure, groups and organizations; and that via the notion of representatives it tends to collapse interface-interactions, individual interaction, and inter-group interaction. The civil servant becomes the state, and the villager, the peasant. It thus tends to transform normative group categories into analytical categories, and runs the risk of reifying those categories. This would seem to be the logical consequence of such an approach.

Aga in we would not dispute the reality of such groups or of the normative definition of groups, group boundaries, ranges of discretion etc. We would also not dispute that their existence would influence the behaviour of actors, in the sense of constraining behaviour, or, on some occasions, even motivating it - on the contrary, the analysis of such influences is our daily bread. But we would argue that "pure" role categories are the products of processes in which norms are reproduced in specific time-space contexts, whose social significance has to be researched, not assumed.

All this has consequences for our treatment of the external/internal problematic. Obviously neither we, nor Long, wish to use these concepts in a purely spatial sense but rather as a spatial metaphor for determining points of inclusion/exclusion in social organisations. Such points are, on the level of structure, normatively or sumarily de- 
fined. But we must assume (and can point to many instances, see, for example, Spiertz, 1986; Van Eldijk, 1987; K. von Benda-Beckmann, 1987; F. von Benda-Beckmann, 1987) that actors can and do redefine these normative boundaries differently in specific interaction processes, and that their actual relationship towards persons who are normatively categorized as "external" or "internal" cannot be adequately expressed in terms of normative categories. Here, one can better think in terms of "interactional closeness/distance" (interactionele nabijheid, F. von Benda-Beckmann, 1987:78), or in terms of space and presence (Giddens, 1979). A government official or a government institution, such as a cooperative, thus can be much closer or, to strain the word, more "internal" to a village actor than his father or the institution of kinship (see K. von Benda-Beckmann, 1987; F. von Benda-Beckmann, 1987a).

Turning to the conceptualization of "development agents" as actors, we see that the concepts of "implementation" and "intervention" by "external" actors do not fit well into our approach. They are too closely connected with or interwoven in the image of the external state and the internal target group. They are conceptual tools in the ideological language of individuals or interest groups who intend to, or actually do, exercise power through the normative and institutional state structure. But the state is an abstraction which encompasses all citizens, government officials and villagers, and which, in principle, can constrain and be used by all citizens, peasants and bureaucrats, in the pursuance of their social and economic and political interests.

obviously, the intensity of constraints and the probability of effective mobilization of resources will vary with the political and economic resource potential of the actors and with their skill in deploying them. We can generally assume a certain probablity that actors normatively representing political and economic macro-structures ("the state") will find it easier to mobilize political and economic resources than those who are normatively excluded from such structures, as is often the case with poor peasants. It is less certain, however, when we are talking about agri-business. Thus it would seem better, if we are interested in "State policies", not to start from the assumption that government agencies, which are part of a highly complex institutional setting, have sufficient "externality" to justify our labelling their policy-implementing activity as an external influence in civil 
society. How far the activities of government agencies are to be regarded as being external or internal to specific social processes is not something to be assumed but should be one of the major questions on which research focuses.

Thus we come to the crucial methodological problem. The interface approach defines an interesting and important domain of social interaction in agrarian change. Its value (like that of case-study methods in social and legal anthropology in general) has been demonstrated by Long, and is also illustrated by other chapters in this volume. But rural development, agrarian change, or some aspects of these, such as social security or the use of crop varieties in our examples, cannot be reduced to such a domain. Our examples have shown that the maintenance and change of structural discontinuities (in the spheres of normative structures and the allocation of economic and political resources) will not be found in any one "domain", "part" of social action, or system, but in many. It therefore should not be conceived of as a domain, but rather as an aspect of action/interaction in many domains. In choosing one's focus for comparative research and analysis, it would be better therefore to start from an analytically defined field of problems (or "social functions" in the sense of Goldschmidt, 1966) which is freed from normative and ideological biases (see also F. von Benda-Beckmann, 1979; F. von Benda-Beckmann, et al. 1988).

This holds true also when the influence of government policies is the main research focus. The brief illustrations from Ambon and Ba1i show the importance of dissolving the rigid, and implicitly normative and ideological, association of implementation and intervention with those categories of persons who are supposed or obliged to implement or intervene. A better approach to the problern of "implementation" and "intervention" is to examine more broadly the social significance of programmatic policy statements directed at behavioural change. Social significance here refers to a normative reorientation and to the reallocation of economic and political resources. This entails studying the life cycle of a programmatic policy statement which has become a "public issue"; looking at the different meanings these issues acquire in different contexts in which they are interpreted, transformed, linked to other issues, accepted or rejected; at the subsequent behaviour which is oriented to these interpretations; and at the intended and unintended consequences of this behaviour (see Van Eldijk, 1987). 
Thus, even when studying the "impact of government policies", we should not confine our attention to the interactive interface between representatives of the government and their target groups. One danger of the interface approach is that it may conflate the domain of government-peasant interaction with those aspects of rural development in which government policies and activities of state bureaucrats are of influence. We hope to have shown that such fusion is not tenable. We realize and certainly appreciate that the interface approach wishes to avoid the anachronistic opposition between "the State" and "the peasantry" by extending it to NGO's and other interest groups. But we think that it is still somewhat bound by the assumptions of the model of policy-implementation-outcome and of those sociological theories that put state-peasant relations at the centre of their theoretical and methodological concerns.

As Fitzpatrick (1984:20) has stated, "representations of knowledge give life to that knowledge. This life shapes the object of knowledge". It would seem to us that the interface approach, by its emphasis on interface situations and its explicit critique of anachronistic concepts and theories, tries to change our knowledge about policy implementation processes and about agrarian change; yet without, however, seriously questioning the representations which originally gave life to that knowledge.

\section{Notes}

1. We shall not be concerned here with more elaborate definitional exercises. Feeley, 1978, discusses some definitional approaches in legal sociology; for our own conceptual approach see F. von Benda-Beckmann, 1979, 1986.

2. For conceptual approaches to legal pluralism, see vanderlinden, 1971, Hooker, 1975, Galanter, 1981, Griffiths, 1986, F. von Benda-Beckmann, 1983a.

3. See Merxyman 1977, Kidder 1979, F. von Benda-Beckmann 1983a for a critical review of law and development studies and for further references.

4. See Chanock, 1978; Snyder, 1981b; F. and K. von Benda-Beckmann, 1985; K. von Benda-Beckmann, 1982, 1984; Fitzpatrick, 1984; Woodman, 1985.

5. See Nader and Todd, 1978, and F. von Benda-Beckmann, 1985, who work with more or less the same assumptions as other access theories. 


\section{CONCLUSION: THEORETICAL REFLECTIONS ON ACTOR, STRUCTURE AND INTER- FACE}

Norman Long

In concluding this volume I wish to underline its explorative nature. Though much of the discussion touches upon perennial debates in the sociology of development - such as the relative merits of actor versus structural analysis or micro versus macro approaches - we have tried to avoid becoming involved in theoretical generalities or in the search for yet another abstract theoretical "solution". Instead we have focused our attention upon a critical area of research and analysis which, I believe, strikes at the very heart of the sociology of development. This concerns, as the title of the book conveys, the study of interface encounters involving social actors with conflicting or divergent interests and values. In the field of rural development, these interfaces often occur where government or other outside bodies intervene in order to implement a particular development policy or to assert politico-administrative control over an agrarian population and its resources.

This interest in interface, however, goes beyond the simple wish to document the types of struggles, negotiations and accommodations that take place between intervening agents and local actors. The concept functions as a metaphor for depicting areas of structural discontinuity inherent in social life generally but especially salient in "intervention" situations 1. In other words, it sensitizes the researcher to the importance of exploring how discrepancies of social interest, cultural interpretation, knowledge and power are mediated and perpetuated or transformed at critical points of linkage or confrontation. Such discrepancies arise in all kinds of social context. For example, in a village they may entail struggles between peasant and non-peasant 
interests and life-worlds; in a bureaucracy, the intersection of political groupings, differing ideologies or authority levels; or in a broader arena, they may involve the interplay of different "worlas of knowledge" (or what Knorr-Cetina, 1981, calls "epistemic communities"), such as those of the farmer, extensionist and agricultural scientist.

It is my view that we can develop this simple idea - already implicit in a lot of previous research - to achieve a more dynamic actor-oriented analysis of planned intervention processes. But, in order to do so, we need to situate the idea of interface within a conceptual framework that maps out, more systematically than is attempted in the main body of this book, other essential theoretical notions. Otherwise there is a danger that the word may quickly become empty or obscure of meaning. This chapter sketches out the essentials for developing such a framework.

over the past ten years I have been concerned to promote actororiented analysis of agrarian change (see especially Long, 1977, 1984; Long et.al., 1986; Long and van der Ploeg, 1988; and Arce and Long, 1987). Such an approach starts from an interest in explaining differential adaptations or responses to the same or similar circumstances (see Long, 1988: 120-121, for a discussion of the theoretical importance of analyzing structural variance within agrarian populations). It assumes that variations in organizational forms and cultural patterns are in large measure the outcome of the different ways in which actors deal, organizationally and cognitively, with problematic situations and accommodate themselves to others" interests and "designs for living". In the field of rural development, the actors include not only farmers and their households but also many other persons and institutions such as traders, government bureaucrats, banks, agri-businesses, and politicians.

This type of theoretical approach "posits a knowing, active subject" (Knorr-Cetina, 1981:4) who problematizes situations, processes information and strategizes in dealings with others. This holds whether the subject is an individual, group or institutional body; and whether the particular actor is deened "powerful" or "powerless". Hence specific patterns and paths of agrarian social change cannot simply be explained by the intervention of public authorities or powerful outsiders, nor by the uncovering of some inexorable structural logic. In a fundamental sense, they can only result from the interactions, negotia- 
tions, and social and cognitive struggles that take place between specific social actors. These latter include not only those present in given face-to-face situations but also those who are absent but who nevertheless impinge upon such situations, thus affecting both actions and outcomes.

\section{Agency and the social actor}

Lying at the heart of the concept of social actor, then, is the notion of "agency", which attributes to the individual actor the capacity to process social experience and to devise ways of coping with life, even: under the most extreme forms of coercion. Within the limits of existing information, uncertainty and other constraints (e.g. physical, normative and politico-economic), social actors are "knowledgeable" and "capable". They attempt to solve problems, learn how to intervene in the flow of social events around them, and monitor continuously their own actions, observing how others react to their behaviour and taking note of various contingent circumstances (Giddens, 1984:1-16).

Anthony Giddens (1984:9, 14) points out that agency "refers not to the intentions people have in doing things" - social life is full of different kinds of unintended consequences with varying ramifications"but to their capability of doing those things in the first place". - ...."Action depends upon the capability of the individual to "make a difference" to a pre-existing state of affairs or course of events". This implies that all actors (agents) exercise some kind of "power". even those in highly subordinated positions; as Giddens (1984:16) puts it, "All forms of dependence offer some resources whereby those who are subordinate can influence the activities of their superiors." And in these ways they actively engage (though not always at the level of "discursive" consciousness) in the construction of their own social worlds, although, as Marx (1852, 1962:252) cautions us, the circumstances they encounter are not merely of their own choosing.

Considering the relation between actor and structure, Giddens argues persuasively that the constitution of social structures, which have both a constraining and enabling affect on social behaviour, cannot be comprehended without allowing for human agency. He writes:

"In following the routines of my day-to-day life I help reproduce social institutions that I played no part in bringing into being. 
They are more than merely the environment of my action since...they enter constitutively into what it is $I$ do as an agent. Similarly. my actions constitute and reconstitute the institutional conditions of actions of others, just as their actions do mine.....My activities are thus embedded within, and are constitutive elements of, structured properties of institutions stretching well beyond myself in time and space" (Giddens, 1987:11).

This embeddedness of action within institutional structures and processes does not of course imply that behavioural choice is replaced by an unchanging daily routine and repertoire. Indeed actor-oriented analys is assumes that actors, are capable leven when their social space is severely restricted) of formulating decisions, acting upon them, and innovating or experimenting. Thus, although one may criticize the premises of decision-making and transactional models (see Alavi, 1973; van Velzen, 1973; Kapferer, 1976), social action undeniably entails the notion of choice, however limited, between different courses of action, as well as some way of judging the appropriateness or otherwise of these. Indeed, as Giddens points out, "it is a necessary feature of action that, at any point in time, the agent "could have acted otherwise": either positively in terms of attempted intervention in the process of "events in the world", or negatively in terms of forebearance" (Giddens, 1979: 56; for a similar point see Hindess, 1986: 115).

Hindess (Hindess, 1986: 117-119) takes the argument one step further by pointing out that the reaching of decisions entails the explicit or implicit use of "discursive means" in the formulation of objectives and in presenting arguments for the decisions taken. These discursive means or types of discourse 2 vary and are not simply inherent features of the actors themselves: they form part of the differentiated stock of knowledge and resources available to actors of different types. Since social life is never so unitary as to be built upon one single type of discourse, it follows that, however restricted their choices, actors always face some alternative ways of formulating their objectives and deploying specific modes of action.

It is important here to point out that the acknowledgement of alternative discourses used or available to actors challenges, on the one hand, the notion that rationality is an intrinsic property of the individual actor, and on the other, that it simply reflects the actor's structural location in society. All societies contain within them a repertoire of different life styles, cultural forms and rationalities which members utilize in their search for order and meaning, and which 


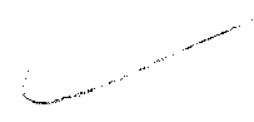

they themselves play (wittingly or unwittingly) a part in affirming or transforming. Hence the strategies and cultural constructions employed by individuals do not arise out of the blue but are arawn from a stock of available discourses (verbal and non-verbal) that are to some degree shared with other individuals, contemporaries and even predecessors. It is at this point that the individual is, as it were, transmuted metaphorically into the social actor, thus signifying that "actor" (like the person in a play) is a social construction rather than simply a synonym for the individual person or human being.

One needs also to distinguish between two different kinds of social construction associated with this concept of social actor: first, that which is culturally endogenous in that it is based upon the kinds of representations characteristic of the culture in which particular individuals and social groups are embedded; and second, that which arises from, the researcher's or analyst's own categories and theoretical dispositions (also of course essentially cultural in that they are usually associated with a particular "school of thought" or "community of scholars"). Actor-oriented analysis necessarily implies the difficult task of interrelating these different levels of understanding and subjectivity. 3

The social construction of actors touches crucially upon the issue of agency. Although we might think that we know perfectly well what we mean by "knowledgeability" and "capability" - the two principal elements of agency identified by Giddens - these notions must be translated culturally if they are to be fully meaningful. One should not, therefore, presume (even if there is considerable evidence of increasing commoditization and westernization) the existence of a "universal" interpretation of agency across all societies. Cultural expressions of agency vary and reflect different philosophies regarding the capacity of the individual to influence actions and outcomes.

A related point concerns the need to recognize that, while the quintessence of human agency may be embodied in the actions of individuals, single persons "are not the only entities that reach decisions and act accordingly. Capitalist enterprises, state agencies, political parties and church organizations are examples of social actors: they all have means of reaching and formulating decisions and of acting on at least some of them " (Hindess, 1986:115). But, as Hindess goes on to argue, the concept of actor should not be used to 
cover collectivities, agglomerates or social categories that have no discernible way of formulating or carrying out decisions. To suggest for example that "society" in the global sense of the term, or classes or gender categories, make decisions and attempt to implement them is to attribute mistakenly to them the quality of agency. It also tends towards reification of classificatory schema that form part of an individual's or organization's conceptual apparatus for processing the surrounding social world and upon which action is premised. We should be careful therefore to restrict our use of the term social actormly to those social entities that can meaningfully be attributed with the power of agency:

Small-scale interactional settings and their significance for understanding macro phenomena

Actor-oriented analysis has often been criticized for concentrating upon the minutiae of social life at the expense of understanding the nature and impact of large-scale social structures and processes. It has also been criticized for being methodologically individualist in its explanations, thereby reducing the understanding of social phenomena to statements about the dispositions and interests of individuals.

Both arguments are founded upon erroneous assumptions. The accusation of methodological individualism rests upon the misunderstanding that actor-oriented analysis works with the individual as the basic unit of analysis. In fact, as Knorr-Cetina (1981: 7-15; see also Long, 1984: 181, fn.12)) stresses, it is interaction in social situations wherein social conduct is contingent upon the social conduct of others that counts, not the individual per se. Thus, even if we focus on decision-making at the level of the individual farmer, this does not commit us to explaining his actions simply by reference to his own imputed dispositions and beliefs. On the contrary, we would have to take account of the influence of the various sets of social relationships in which he is embedded, both within and beyond the farm/household. This leads to the consideration of what we may call "intermediate structures", such as social networks based upon criteria such as kinship or patron-client ties, household confederations consisting of - 
groupings of households tied together by mutual commitments and interlocking rationalities (Smith, 1984:224), farmers' organizations and cooperatives (see Esman and Uphoff, 1984: 61-68, for a typology), systems of production relations tying the farmer into the wider economic environment, and informal or formally-organized "interface" structures that constitute the modes of interaction between farmers and public authorities (Benvenuti, 1975, and Long, 1984, 1988). The significance of these and other interactional networks for farm decisionmaking will, of course, depend upon the particular social context and farmer in question.

In addition, we would need to consider other more diffuse "external" institutional and cultural factors that may shape farmer behaviour and reasoning. Here I have in mind elements that derive from space and time contexts that transcend the social situations directly experienced by the farmer himself or his immediate associates: for instance, mass media sources of information on market prices for agricultural products and personal contacts maintained through correspondence or by telephone. Although such influences are at a spatial and/or temporal remove from the farmer's interactional field, they become, like Bourdieu's notion of cultural habitus, embodied in, and therefore constitute an integral part of, the farmer's resources, stock of knowledge and behaviour. In this sense they are not strictly speaking "external" to the social situation or to the decisions that are made (see Giddens, 1984: 132-144, for a fuller exposition of this argument). And, of course, the same point holds for interface encounters.

Let us now consider more explicitly the issue of how to integrate theoretically the analysis of small-scale interactional settings with that of larger institutional or social structures. This remains a thorny problem in research and a number of solutions have been proposed (for an excellent recent overview of micro and macro theory and methodology, see Knorr-Cetina and Cicourel, 1981). A radical solution is proposed by Collins (1981), who argues for the reconstitution of macro-sociology on the basis of its necessaxy micro-foundations. According to him, what is needed is a systematic programme of "microtranslation" of the principal concepts of macro-sociology. This entails the "unpacking" of macro-sociological metaphors: for instance, the notion of "centralization of authority" can be reduced to (a) a series of statements about micro-situations in which certain actors exert 
authority over others, and to (b) a description of "the links in the chain of command", i.e. an account of who passes orders to whom. In Collins' view, the only genuine macro-variables in any such unpacking of concepts are those concerning time, number and space. "All social reality, then, is micro-experience; but there are temporal, numerical, and spatial aggregations of these experiences which constitute a macrolevel of analysis" (Collins, 1981: 99).

It follows therefore that sociology should focus its attention on the systematic analysis of micro-situations and thus avoid working with macro-concepts that are not properly grounded in everyday social life. Hence, for example, concepts of class and class relations only become meaningful once they are shown to characterize particular lifeworlds made up of certain shared experiences involving struggles over differential livelihood chances (often but not exclusively centering around the workplace and access to the basic means of production). A similar point of view is taken by Foucault (1980:102) when he outlines his approach to the study of power relations. Foucault argues that, although power may seen remote and tied up with "juridical sovereignty and state institutions" and thus beyond the arena of everyday social interaction, it actually manifests and reproduces or transforms itself in the workplaces, families and other organizational settings of everyday life (see also Foucault, 1981: 94).

\section{The importance of "emergent structures"}

These arguments suggest that, in order to avoid reification of macro-concepts, we should build our understanding of society "from below", that is, by documenting everyday micro-situations. However this cannot succeed unless we challenge collins' reasoning in one important respect. Macro-structures should not simply be conceptualized as aggregations of micro-episodes or situations, since many of them come into existence as the result of the unintended consequences of social action. Thus, as Giddens has insisted throughout his writings, the properties of social institutions 4 and of certain global structures (such as Wallerstein's notion of "the world system") are emergent

forms that are not explicable (nor fully describable) in terms of micro-events. Whilst it is true that institutional forms do not strict- 
ly speaking have a "life of their own" - somehow beyond the reach of human agency - and are deeply engrained in everyday social practice, they do nevertheless possess characteristics that cannot be fully comprehended by merely dissecting the minutiae of social encounters.

It would, for example, be nonsensical to argue that the operation of commodity markets and capitalist economic institutions can be meaningfully described or accounted for solely by observing the behaviour of individual capitalists, international financiers, stockbrokers, etc; or through studying in depth the social encounters and struggles that take place between the owners or managers of capital and workers. Marx was right to emphasize the existence of certain structural conditions (such as those facilitating the formation of a "free" labour force or the realization of exchange-value and profit) that make possible the processes of capitalist production and exchange. He also argued that the various actors involved in capitalist production have a $l \mathrm{imited}$ and distorted comprehension of the nature of the system as a whole. 5

Macro-structures are in part the result of the unintended consequences of numerous social acts and interactions which, as Giddens (1984:8-14) explains, become the enabling and constraining conditions of social action itself. A run on a bank resulting from heavy withdrawal by creditors (set off by rumours that the bank is unable to meet its financial obligations) generates further withdrawals due to increasing lack of public confidence, perhaps in the end leading to its eventual collapse. The actions taken by the individual customexs and by the bank officials would have, of course, contributed to this deteriorating situation, but they were hardly likely to have intended the outcome. A pertinent agrarian example is a land settlement programme aimed at promoting the economic independence of peasant family farmers which, after a number of years, resulted in these farmers becoming indebted to moneylenders to the extent that they could no longer make their own decisions as to which crops they would grow (Siriwardena, 1983). In this case, neither the government planners nor the peasants themselves intended or really foresaw this eventuality. It resulted principally from the types of relationships that gradually evolved between the key actors involved (peasants, moneylenders, traders and government officials). 
These examples are relatively simple to understand and to trace out the chain of effects. Most sociological cases are much more complex and it is often difficult to disentangle the numerous consequences of particular social actions as well as their feedback effects. Nevertheless, carefully focused research can document the ways in which particular social interactions and decisions may have a ripple effect on more distant social arenas, or which over time create emergent sets of relations that form larger scale systems. It is therefore important that we have ways of characterizing and analyzing these more "global systems". Collins' insistence, then, on the study of micro-situations and micro-translation should not be interpreted to mean that we can do away with concepts for dealing with more macro phenomena. We should also not conceptualize the macro level as solely made up of the aggregation of micro-situations or micro-processes, since we must give attention too to emergent properties which manifest themselves in qualitatively distinctive modes of organization 6 .

I cannot here expand much upon this important issue of emergent structures and their feedback effects on choice and social behaviour. Suffice it to point out that emergent forms range from relatively small-scale interpersonal networks, to institutional arrangements for organizing people and territory (e.g. as shown by the pattern of activities and interrelations of state agencies in particular local settings), to large scale political and economic systems. These different scales of emergent phenomena are of course often intricately interrelated, as the following example from the central highlands of Peru shows.

During the 1970's, Bryan Roberts and I carried out detailed field research on regional development in central Peru (Long and Roberts, 1978 and 1984). One important theoretical conclusion we reached was to challenge the prevailing "enclave" model of development that suggested that integration into the international economy, through the establishment of a modern mining sector, entailed relative stagnation and dependency for the hinterland. On the contrary, we were able document significant growth and diversification for the non-enclave sector, leading to an elaborate and dynamic network of interrelations between mine production, trade, transport, peasant agriculture and urban economic activities. This emergent set of linkages we called "the regional system of production", a shorthand for the complex system of 
capital, labour, and socio-political linkages that had developed historically between the various economic activities and sectors, and between the social groups that were spawned by them. The system of linkages looked different from different parts of the social landscape and at different historical junctures. It was also continually being remoulded by a series of ongoing social struggles involving peasants, miners, entrepreneurs, mining companies and state agencies; and retroactively the regional system came to shape the life-chances, social networks, livelihood strategies and cultural ideologies of the different social groups of the region. It also enabled individuals and groups from the region to enter and occupy particular economic niches within the metropolitan capital of Lima (Long and Roberts, 1978 and 1984).

We could only arrive at these general findings through detailed ethnographic work on the micro-histories and micro-situations of individual peasants, miners and entrepreneurs. Entering the life-worlds of particular actors allowed us to build slowly a picture of the main participants and emergent social forms implicated in this ongoing regional scenario. Only in this way could we cone to a full appreciation of the dynamics of small-scale, local initiative and its ramifications in the wider social and political arena.

\section{The interface problematic}

We are now in a position, having clarified in broad terms certain conceptual issues relating to actor-oriented analysis, to consider the rationale and characteristics of interface studies.

In the opening chapter to this book I suggested that they are significant for three basic reasons: they can help to develop a more adequate analysis of policy transformation processes; they enable us to understand more fully the differential responses by local groups (including both "target" and "non-target" populations) to planned intervention; and they may assist us in forging a theoretical middleground between so-called "micro" and "macro" theories of agrarian change by showing how the interactions between "intervening" parties and "local" actors shape the outcomes of particular intervention 
policies, often with repercussions on the patterns of change at regional and national levels.

In the present chapter (as well as in the Appendix) I argue that interface - given the way I define it - is married to an actor-oriented perspective. If we fail to make this connection, then it loses its analytical power, since it simply becomes another way of talking about the articulation of normative or institutional orders, as von BendaBeckmann et.al. (p. 216) assune.

Interface studies are essentially concerned with the analysis of discontinuities in social life. Such discontinuities are characterized by discrepancies in values, interests, knowledge and power. Interfaces typically occur at points where different, and often conflicting, "life-worlds" or social fields intersect 7. More concretely, they characterize social situations (what Giddens calls "locales") wherein the interactions between actors become oriented around the problem of devising ways of "bridging", accommodating to, or struggling against each others' different social and cognitive worlds. Interface analysis aims to elucidate the types and sources of social discontinuity present in such situations and to characterize the organizational and cultural means of reproducing or transforming them. Although the word "interface" tends to convey the image of some kind of two-sided articulation or confrontation, interface situations are generally much more complex and multiple in nature, containing within them many diferent interests, relationships and modes of rationality and power.

An early attempt to analyse the problems associated with the intersection of different normative and politico-administrative orders is that by Gluckman, Mitchell and Barnes (1949) who describe, what they cal1, "the intercalary position" of the African village headman created by the establishment of British colonial rule. They argue that the role of the headman was potentially fraught with conflict and ambivalence since he was pulled in two opposite directions at once: loyalty to his kinsmen and village, or loyalty to the chief and colonial administration.

Although at the time this offered a useful insight into some of the inherent problems of the British colonial policy of "indirect rule", their formulation differs from my own in that it leans heavily upon a role model that gives a somewhat static and dichotomized picture, implying that, despite conflict, the structural relations 
between the two social orders remained more or less well equilibrated and unchanged. There is also no attention given to documenting the precise strategies adopted by village headmen for steering a middle course between these conflicting demands, nor any account of how colonial officers accommodated themselves to the situation. These shortcomings, of course, are consistent with Gluckman's commitment to an institutional and equilibrium model of social change (Gluckman, 1958, 1968; Long, 1968: 6-9).

A completely different and much more recent attempt to deal theoretically with issues of social discontinuity in local settings is Cohen's (1985) The Symbolic construction of camminity. Cohen links the problem to the need for a new perspective on "community", which he applies to both local residential and ethnic groups. The approach he suggests focuses upon the exploration of how such groups construct boundaries around themselves in order to mark themselves off from others. This process simultaneously involves shared symbolic elements that broadly define community boundaries (i.e. marking out the distinctions between "us" and "them"), thus creating a "sense of belongingness", as well as forms of strategic interaction between particular individuals who, as it were, establish the parameters and conceptions of "self" and "other" relevant to particular interactional contexts and to confrontations with "outsiders".

Cohen develops his standpoint through critically reviewing existing approaches to the study of "community" and through presenting a series of ethnographic vignettes selected to make the case for a symbolic anthropology of community. By concentrating upon the processes by which "people become aware of their culture when they stand at its boundaries", Cohen's (1985: 69) discussion comes close to some of the conceptual and theoretical issues raised in the present book under the rubric "interface". A major difference lies, however, in its heavy emphasis on cultural constructions and symbolic defence of "comunity", at the expense of considering in more depth the strategic deployment of organizational and political resources. A further limitation is that the study concentrates upon the "communities" of local groups, giving scant attention to the strategies and "symbolic communities" of the intervening parties, such as government officials, missionaries or traders 8 . 
These shortcomings are in fact largely overcome in an earlier symbolic interactionist study by Handelman (1978), who argues that

"insufficient attention has been given to the clash between the ways in which supralocal institutions conceive of administrative territories and the ways in which territorially based populations conceive of themselves as communities".

He then goes on to identify

"the official/client interface as the crucial point of articulation wherein such discrepancies of connection and communication are most likely to be evident, and hence as a likely node through which to expose the coercion and fragility of structures of power" (Handelman, 1978: 5-6, my italics).

This methodological point, of course, coincides completely with the case for interface analysis made in this book.

Handelman develops his theoretical point of view through detailed studies of social security in Israel (1976) and child care in Newfoundland (1978). He demonstrates that government officials dealing directly with the public do not simply allocate benefits to individuals in a mechanical, "according to the book" fashion. Instead they are active contributors to the production of decisions, using their own discretion and evolving their own modus operandi. Underlying and providing a rationale for the adrninistrative and allocative practices they adopt, are certain "world views" that have crystallized out of the many interactions and decision-making processes in which they have been involved previously, both with clients and colleagues (see Rees, 1978, for a similar account of differential "world views" among social workers in Britain). He also shows how "client cases" are constructed by officials on the basis of ways of typifying persons and behaviour that are consistent with the stock of knowledge and ideology of the "life-world" of the organization in which they work. Hence official/client interfaces are simultaneously shaped by organizational "imperatives" and by the particular organizational experiences of the official in question. As Arce points out in Chapter II (p.48-49), one important lacunae in Handelman's approach (see Handelman, 1976, as well) is his lack of attention to the ways in which an official's "world view" and strategies are affected by past and present experiences outside the bureaucratic context.

A different approach to this question of the allocation of public services or benefits (or even penalties) is illustrated by the work of the late Bernard schaffer and $h$ is colleagues at the Institute of 
Development Studies, Sussex (Schaffer and Lamb, 1976), who write about "access theory". Their main aim has been to develop an analytical framework for the analysis of bureaucratic transactions with clients involving the administrative allocation of goods and services in nonmarket distributed systems, where factors other than income determine allocation. Their empirical work has concentrated upon documenting the factors affecting access to particular public goods and services, such as housing, social security, and agricultural credit, by different categories of client.

Their approach to the problem can be illustrated by an agricultural example. A given cultivator - placed at the base of the access pyramid - may be eager and defined as eligible for one or more services such as agricultural extension, credit and technical inputs, but he may still not get what he wants or is legally entitled to. The reason for this is that there operate a number of informal, spoken or unspoken, rules governing his exclusion. Such a cultivator usually finds himself at some point, either actually or metaphysically, standing in a queue before an administrative counter across which the service he seeks could be delivered. Yet the counter is more than a physical barrier or location where official transactions take place. It functions as a medium for reconciling the interests of applicants and allocators and for defining precisely who will and will not receive access to the goods or services "on offer". Behind the counter is an administrator who is, at one and the same time, maintaining the service, serving $h$ is own private or group interests, and waiting in a queue himself for the service to be approved by $h$ is administrative superior. He is therefore part of an administrative hierarchy or bureaucracy. The passing down of goods and services depends not only on simple allocative efficiency or upon the individual behavioural characteristics of the farmers or allocators but also on regulations governing the eligibility of recipients, queue discipline, and the characteristics of superior and inferior administrative levels in the allocative hierarchy. It will also depend upon the existence of alternative channels for the service (what Schaffer calls exit) and on the susceptibility of the different systems of access to client manipulation (what is called voice).

This image provides Schaffer et. al. with the basis for developing a descriptive model for depicting the various factors and processes affecting allocative decisions and for defining the type and level of 
access accorded to different clientele. The approach has been applied to a number of Third World situations. For example, Barbara Harris (1978) uses access language to analyse the organization of multipurpose cooperatives in Sri Lanka. She concludes that access concepts are indeed a fruitful way of identifying the factors that account for variations in the organization and provision of services between cooperative unions, between them and their branches, between branches, and within the cooperative hierarchy. She shows in fact how the organizational structure encourages the use of both exit and voice strategies, which militate against the achievement of equity among members or between branches, and how this is affected also by the outside entrepreneurial interests of managers.

A major difficulty, however, with this type of analysis is that one cannot always easily identify counters and queues, etc. The analogy of obtaining goods and services across the counter goes too far and can operate only when there exist clearly defined tangible items for allocation. In contrast, many interface situations involve a series of encounters between implementors and clients which cannot be bundled up into discrete packages of goods and services. Extension officers may regularly visit farmers in their areas but it would be difficult to regard each visit as entailing some clearly defined benefit for the farmer. The interaction between extensionist and farmer is composed of a number of different, and often diffuse, elements, of which only some could be seen as entailing questions of access. Furthermore client interfaces are not one-off affairs: they imply interactions over time during which the actors' perceptions may change and their goals may be deflected or redefined. Also the client may become interested in acquiring new sorts of services, pieces of information, or social contacts (even to the extent of breaking off the initial relationship all together). Or farmers may decide to focus their efforts on obtaining political favours for the future - accumulating "goodwill"rather than seeking access to new forms of agricultural knowledge and technology. And this is further compounded when dealing with large and complex forms of State intervention (for example, land reform programmes), since one is faced by such a plethora of types of counters and interfaces (formal and informal) relating to allocation processes that it becomes almost impossible to know which ones to study in depth. Add to this the existence of so many interface workers and so many 
potential sources of interpretation and manipulation - with the high probability that actors will misread information or play games of bluff with each other and so forth - then it becomes doubly difficult to apply access concepts.

In order to come to grips with these complexities, one would need to specify the types of interactional fields and situations one wished to deal with and, like Handelman and several contributors to the present volume, collect detailed extended case-studies documenting how social meanings, as well as material "goods", are transacted and negotiated at particular interfaces by the actors involved 9 . Access theory, whose conceptual framework derives from the image of making deals across the counter, seems ill suited to exploring these important social and cognitive dimensions.

\section{Key dimensions of interface analysis}

The above discussion serves to acquaint the reader with some relevant work on issues of social discontinuity and interface. It also points to the need for an actor-oriented approach to the problem, whose conceptual basis I described earlier in the chapter. Let me now, in conclusion, sumarize what I see as the key dimensions of interface analysis 10 .

1). It focuses upon the linkages that develop between the interacting individuals or parties concerned rather than simply on their individual strategies. In this respect, it addresses itself to the same kind of problem as the Theory of Games, namely the issue of "interlocking intentionalities". Continued interaction, of course, encourages the development of boundaries and shared expectations that regulate the interaction of the participants so that over time the interface itself becomes an organized entity. For example, the interface between management and workers in a factory or between a hacienda landlord and his tenants persists in an organized way over time with rules, expectations and sanctions; the former being structured through the appointment of worker representatives and unionization; and the latter often through a series of personal ties based upon patron-client relations, compadrazgo ( $r$ itual kinship), and 
membership of the same religious congregation. The same is true of interfaces involving government officials and local peasant or farmer leaders, or those occurring between less formally constituted groups or individuals who are opposed to each other on religious, ethnic, or other grounds. As small group studies have shown, even the most informal networks of individuals and families will tend to evolve standardized modes of dealing with non-members or outsiders. The establishment of such normative middleground for interacting and negotiating with outsiders can, of course, be endogenously or exogenously generated, the latter usually involving intervention by some public authority that aims to set "the rules of the game".

2) It draws attention to the forces making for conflict or incompatibility between the individuals or parties concerned. Although interface interactions presuppose some degree of common interest, they are also likely to generate conflict arising from contradictory interests and objectives or due to differential power. As mentioned above, negotiations at the interface are sometimes carried out by individuals who represent particular constituencies, groups or organizations. The social positions of such representatives inevitably creates ambivalence since the individuals concerned must respond to the demands of their own groups as well as to the expectations of those with whom they must negotiate. This of course, as Gluckmann originally emphasized, is the dilemma of the village headman, workshop foreman or the student representative on university departmental boards. Yet those who become skilled in their job manage, whenever possible, to exploit such ambiguities, turning them to their own personal or political advantage.

In analyzing the sources and dymamics of contradiction and ambiguity in interface situations, it is important not to prejudge the case by assuming that certain divisions (such as those based on class, ethnicity or gender) are more fundamental than others. One should also not assume that because a particular person "represents" a specific group or institution, or belongs to a particular social category, that he or she necessarily acts in the interests or on behalf of these others. The link between representatives and constituencies (with their differentiated memberships) must be empirically established, not taken for granted. 
3) It highlights differences in world views or cultural interpretations between the individuals or parties concerned. In fact interfaces often provide the means by which individuals or groups come to define their own cultural or ideological positions in opposition or contrast to those whom they see as espousing or typifying other views. For example, the cultural assumptions and views on development expressed by agricultural extension workers and farmers often do not coincide. And the same is true for individuals working in different capacities within a single government agency or for those who work in different agencies of the same overall bureaucracy: extensionists, credit officers, irrigation engineers, and the like, may all work for the Ministry of Agriculture, but they seldom agree on the problems and priorities of agricultural development. Such differences are not merely individual idiosyncracies but reflect differences in patterns of socialization and professionalization that often result in miscommunication or the clash of rationalities (see Chambers, 1983; Box, 1984c). And the process is further complicated by the coexistence of several different cultural models adhered to by persons of differing age, sex or status within a given population or administrative organization.

This means that interface encounters involve an explicit or implicit contest over the dominance and legitimacy of particular cultural paradigms, development intervention itself representing an attempt to promote or impose particular normative notions concerning planned change. At the same time, it is important to recognize that commitment to given normative or ideological frames of reference, and to certain types of discourse or rhetoric, are situational. They do not remain constant across all social contexts for the actors involved. An actor-oriented approach therefore must try to identify the conditions under which particular "definitions of reality" are upheld and to analyse the interplay of cultural and ideological oppositions. It should also map out the ways in which "bridging" or "distancing" actions and ideologies make it possible for certain types of interface to reproduce or transform themselves.

4) It stresses the need to $100 \mathrm{k}$ at interface situations diachronically. Interfaces change their character over time due to, among other things, changing internal and external relationships, perceptions, resources and social investments. Diachronic processes are short-term 
in that changes in the constitution of the interface have irmediate effects on the actors, but also longer-term in that interface encounters develop their own ground rules and styles of interaction and organization which over time can generate cumulative effects, leading to the restructuring of the interface itself or to the creation of new ones.

In order to understand these processes, one must locate the detailed analysis of interface situations within a broader appreciation of institutional frameworks and power fields. Earlier in the chapter I sketched out the theoretical requirements for doing so. This was based on two crucial methodological considerations: first, that the detailed study of micro-situations and micro-processes can in fact reveal a great deal about more general cultural constructions and social patterns; and second, that one needs to develop a more thorough understanding of both the "structuring" process and the emergent properties of micro and intermediate-level social forms (Barth, 1981, is a fertile source of ideas on these processes).

5) Interface analysis should not focus exclusively on the detailed study of patterns of social interaction that take place between the actors directly involved in interface situations. It should also provide the means of identifying those groups, individuals and social categories excluded from particular interface negotiations, thus highlighting the existence of systematic forms of non-involvement characteristic of marginalized groups such as poorer peasants, certain ethnic groups or categories of women. On the other hand, the question of non-involvement should not be interpreted to imply that nonparticipants have no influence on the constitution and outcomes of interface encounters. On the contrary, they can, as "backstage" actors, have a decisive influence on strategies and scenarios.

6) It contributes to an understanding of the processes by which planned interventions enter the life-worlds of the individuals and groups affected and come to form part of the resources and constraints of the social strategies they develop. Thus so-called "external" factors become "internalized" and come to mean quite different things to different interest groups or to the different individual actors, whether they be "implementors", "clients", or "bystanders". In this way 
interface analysis helps to deconstruct the concept of planned intervention 11 so that it is seen for what it is - namely, an on-going, socially-constructed and negotiated process, not simply the execution of an already-specified plan of action with expected outcomes. It also shows that policy implementation is not simply a top-down process, as is usually implied, since initiatives may come as much from "below" as from "above".

It stresses that it is important to focus upon intervention practices as shaped by the interactions among the various participants, rather than simply on intervention models, by which is meant the idealtypical constructions that planners, implementors or their clients have about the process. The idea of intervention practices allows one to focus on the emergent forms of interaction, procedures, practical strategies, and types of discourse and cultural categories present in specific contexts. It also enables one to take full account of the "multiple realities" of development projects (by which we mean the different meanings and interpretations of means and ends attributed by the different actors), as well as the struggles that arise out of these differential perceptions and expectations.

From this point of view, then, planned intervention is an on-going transformational process that is constantly re-shaped by its own internal organizational and political dynamic and by the specific conditions it encounters or itself creates, including the responses and strategies of local and regional groups who may struggle to define and defend their own social spaces, cultural boundaries and positions within the wider power field.

7) On yet another level, interface analysis can contribute to the general discussion of state-peasant relations. Interface studies reveal concretely the nature of state-peasant relations in particular localities or regions. They also help to identify how much political space exists for local initiatives ajmed at changing the pattern of resource distribution or at improving the benefits received by local groups, and in this way they facilitate an understanding of the character and significance of specific types of state structure, policy and intervention. In contrast, as Skocpol (1979; 31-32) points out, general theoretical interpretations of the state operate at a high level of abstraction and tend towards the reification of state 
institutions and actions. Hece it becomes essential to explore how forms of state and non-state power manifest and constitute themselves in the settings and institutions of everyday 1 ife. Interface analysis, I believe, contributes to such an understanding. It also highlights the processes of incorporation, manipulation and subversion of power practised by the relatively "powerless" in their struggle to defend and promote their own interests and "projects".

\section{Notes}

1. I leave aside the issue of how far the concept of interface lalong with other notions that stress the processual, emergent and self-organizing nature of social structure) forms part of a "root" metaphor" or "conceptual archetype" presenting a "systematic repertoire of ideas by means of which a given thinker describes, by analogical extension, some domain to which those ideas do not immediately and literally apply" (Black, 1962: 241). See Turner (1974: 25-33) for a discussion of the significance and use of root metaphors in social science. Morgan (1986) shows how various contrasting theoretical approaches to the study of organizations are founded upon different metaphorical images, ranging from machine, organic, communicational, cultural, power, and autopoietic ("self-production") models.

2. That is, the cultural constructions involved in expressing certain points of view or ideologies through the making of "statements" verbally or through carrying out certain social practices. The terms are taken from Foucault's work, see especially his "Archaeology of knowledge" (1972), where he also writes of "discursive formations" and "discursive objects". For a discussion of the types of discourse characteristic of different development policies, see Apthorpe, 1984.

3. This raises an extremely difficult epistemological problem, namely the imposition of our own analytical constructions on those of the subjects themselves. In explaining or translating social action we may thus displace the agency or intentionalities of those we study by our own "folk" notions or theoretical concepts. For an interesting discussion of this problem, see Fardon (1985: 129-130, 184).

4. That is, "structured social practices that have a broad spatial and temporal extension: that are structured in what the historian Braudel calls the longue durke of time, and which are followed or acknowledged by the majority of the members of society" (Giddens, 1981:164).

5. Marx puts the point strongly by arguing that there exists a "fetishism of commodities" whereby the "true" nature and value of commodity exchange is concealed through "mystification".

6. See Blau (1967, especially pp.1-32 and 46-50) for a discussion of the significance of emergent forms and properties in interactional settings; and Kapferer, 1972, for a systematic empirical exploration of Blau's ideas using social network and extended case methods. Prigogine (1976: 112-114) illustrates the significance of emergent structures by analyzing how termites construct 
theix mounds, a process that begins with uncoordinated and random behaviour but ends up coordinated and structured.

7. Depending upon the theoretical issues one wishes to explore, one or both of these terms might be used to characterize interface situations. Life-world is the term used by Schutz (1962) to depict the "lived-in" and "taken-for-granted" world of the social actor. It entails practical action shaped by a background of intentionality and rationality, and is therefore essentially actor-defined (see Schutz and Luckmann, 1973, for a fuller explication). social field is used to depict "sets of relations between actors oriented to the same goals or prizes" (Turner, 1974:130, 128; see also Long, 1968:9-10). It includes all those activities, relationships, resources and values utilized in attempting to achieve particular goals. It also implies a degree of common comitment to rules or values that define appropriate and inappropriate modes of social action. Turner (1974:17) calls this normative element "cultural paradigms" and Moore (1973) "the capacity for making rules and enforcing compliance" characteristic of "semi-autonomous social fields". Social fields can be relatively small or large in scale (e.g. in terms of their geographical, demographic or resource make-up) and nore or less unified or fragmented. An advantage in using the notion of social field instead of institutional or normative order is that the former covers both formal institutional arrangements as well as less formal "organizational" components (Long, 1968: 9). Social field differs from social arena in that the latter signifies some concrete setting in which paradigms and/or resources are contested. Although arenas vary in their degree and idiom of "publicness" and their formality, they always exhibit elements of antagonism (actual or symbolic) and incompatibility. Certain interface situations may thus be considered arenas.

8. There exist a number of interesting anthropological studies on "frontline" government actors. See, for example, Worsley (1965) on government officers in Saskatchewan; and Raby (1978) on Sri Lankan district administrators.

9. For an interesting example of this see Gonzalez's (1969) study of the interactions between AID officials and members of the industrial elite in the Dominican Republic.

10. For an analysis of organizational interfaces written from a "management" perspective, see Brown (1983:19-46 especially). Long (1984) discusses its relevance for policy analysis, and Arce and Long (1987) deal with interfaces between knowledge systems.

11. I have in mind here, and throughout the text, institutional forms of intervention involving the direct interaction of government representatives with a local clientele. This often occurs through the setting up of development projects or coordinated programmes of development, such as the currently popular Integrated Rural Development Programmes. I do not consider other less direct forms of intervention, such as the use of price and taxation mechanisms or other fiscal means. 


\section{APPENDIX: NOTES ON RESEARCH METHODOLOGY: MEXICAN PROJECT 1}

Norman Long

These notes are intended to clarify our research foci and to indicate how analytical concepts and theoretical questions relate to methods of data collection and analysis. The particular methods suggested are not described in detail, but I refer to the key literature dealing with them.

\section{An overview of the main research themes}

Our methodological approach must be developed on the basis of the research problems and theoretical interests of the project proposal. The main title of the project provides a shorthand depiction of the major themes: "Irrigation Organization, Peasant strategies and Planned Intervention".

The first element in our research, then, is irrigation organization, not irrigation systems. This implies a concern for how various actors or parties organize themselves around problems of water management and distribution. Thus we must go beyond the analysis of the physical and technical properties of the different systems of irrigation to consider how different interests, often in conflict, attempt to control water distribution and to secure access to other necessary inputs for irrigated agriculture. Irrigation organization therefore is an emergent property: it emerges out of the struggles that take place between the actors involved.

The second dimension is the question of strategies. Here we need to interpret the word "peasant" to include also larger scale farmers and other rural producers, since the region, which includes El GrulloAutlán and El Limón and their hinterlands, is more complex agricul- 
Autlán and El Limón and their hinterlands, is more complex agriculturally than suggested in the original proposal. The issue of strategies is central to our research because we aim to interpret agricultural and social change as an outcome of the struggles and negotiations that take place between groups of different and often conflicting social interests. Strategy is also important at the level of how producers and other rural inhabitants resolve their livelihood problems and organize their resources. In this way producers and householders actively construct their own patterns of farm and household organization, and pursue their own social "projects".

The third issue concerns planned intervention. This covers formally-organized state agency intervention and also the impact of other intervening parties, such as the companies and enterprises that attempt to organize and control production and commercialization of key products. Our proposal stresses the importance of looking at this problem in terms of the interactions that evolve between local groups and the intervening entities and actors. Intervention therefore is an ongoing transformation process that is constantly re-shaped by its own internal organizational and political dynamic and by the specific conditions it encounters, including the strategies pursued by local and regional groups.

\section{Evolving a set of basic analytical concepts}

In order to explore these issues it becomes essential to work out a conceptual approach that can assist in developing an appropriate methodology for orienting data collection and analysis.

I start from the conviction that the central task is first of all to sample the life-worlds of social actors occupying different social locations with in the area under study. The latter will vary depending upon one's particular research topic, i.e. "the area of study" might be an administrative unit or field of action of SARH (Ministry of Agriculture and water Resources), a specific production zone consisting of different types and scales of producers, an ejido made up of households exhibiting different patterns of economic activity, or an arena within which certain economic and/or political entrepreneurs compete for control over resources. 
The concept of life-world is taken from Schutz. It simultaneously implies both action and meaning. It is a "lived-in and largely taken-for-granted world" (Schutz and Luckmann, 1973). It is actor rather than observer defined. Everyday life is experienced as an ordered reality, shared with others (i.e. it is inter-subjective). This "order" appears both in the ways in which people manage their social relationships and in how they problematize their situations. Even a brief conversation with an individual quickly reveals some aspects of $\mathrm{his} /$ her effective or meaningful network of social relations that might even stretch as far as California. One will also get a glimpse of the personal constructs with which the person categorizes, codes, processes and imputes meaning to $\mathrm{h}$ is or her experiences (past and present).

The first research task then is to devise ways of encountering and entering the life-worlds of specific actors. Since I assume that social reality is differentiated and heterogeneous, we must aim, in the first place, to sample contrasting views of the immediate, or what Schutz calls the "here-and-now", social situations confronted by particular individuals. This can be done in a number of ways: by arranging to meet and discuss with persons of different social positions, encountering people casually in a corner shop, at the market, bus stop, or cooperative store, or by arranging to attend meetings organized by special interest groups (such as the church or Lions' Club) or by a public body (such as the farmers' association, the municipio or political party PRI). It will be important at this stage to spread one's net somewhat wide so as to sample a range of contrasting opinions and situations. one possible strategy is deliberately to seek out those groups and individuals who, in the eyes of some locals, are "oddballs" or "deviants". Meeting the latter will put into perspective the views and observed behaviour of the others.

All this, of course, is bread and butter to the field anthropologist. Nevertheless it needs re-emphasizing that this process of plunging into the social reality should be informed by some kind of theoretically-based approach that will help identify critical dimensions.

An actor-oriented perspective gives priority (a) to identifying the problems and concepts as presented by particular actors, with a view to isolating similarities or differences in social interpretation and cultural values or styles, and (b) to learning something about the 
types and contents of important social relationships and activity fields that involve these individuals.

This first encounter with the life-worlds of particular individuals will necessarily be somewhat superficial, although it will, I believe, provide a better entrada (entrance) into the life circumstances and problematic situations of individuals and social groups than "structured" social surveys could achieve. It is critically important to obtain as much detailed ethnography as possible in these fleeting encounters; otherwise it will be difficult to develop a sound appreciation of the variations in world views and social strategies upon which to build the case studies which will form the central pillar of the research.

At this point, it is necessary to reflect carefully upon the research data and issues raised in order to identify promising lines of enquiry. It should be possible, for example, at this stage to map out some of the recurring conceptual schema or personal and collective constructs used and to give a rough picture of the predominant social groupings and social relationships.

After this one should aim to select some strategic cases for more detailed systematic analysis, using case-study methods. Here it is important to make clear the significance of the case-study method. Cases are not examples in the sense of illustrating the basic principles of social structure: that is a structural-functionalist conception. Nor are they necessarily locality-based: that belongs to a simple "community studies" approach. Nor should they simply be built upon interview material gathered from key informants: observation of specific social situations and follow-up interviews with various persons are essential.

The chief advantage of case studies is that they provide the opportunity to highlight and analyze the processes by which social actors actually manage their everyday social worlds and attempt to resolve certain problematic situations. Case studies often reveal the fragility of the so-called existing social order or patterns of social legitimacy. A systematic series of case studies can also tell us a lot about the processes of social reproduction and transformation, and can show how human agents (individuals and social groups) play an active role in this process. Case studies, which often provide insight into ongoing social dramas or conflicts, make transparent certain aspects of every- 
day Iife that are not otherwise immediately apparent (Turner, 1957:9193). Even case studies that bring out the more regular, "uneventful" processes of everyday peasant or bureaucratic life tell us a lot about the management, organization and culture of social life.

It is difficult to determine the precise criteria for the selection of the cases (or how many) without specifying the particular research problem and area of study to be investigated. Also it is probable that each researcher will wish to apply different types of case studies that focus upon different units of study, such as the household, economic enterprise, individual career, government development agency, or "broker" institutions, such as the associations of producers and committees dealing with agricultural development and water distribution or municipal affairs.

However, given the main themes of the project, it would seem important to choose cases which bring out the following processes:

i) how individuals and groups deal organizationally and cognitively with intervention by outside authorities or interests;

ii) how individuals or groups develop their own strategies for improving their life circumstances or for pursuing their own social "projects":

iii) how "intermediate" personnel (e.g. técnicos (technicians), canaleros (ditch-tenders), cabos de compañias (chargehands of companies), delegados municipales (municipal representatives)) attempt to deal with the double pressures on them, interpret their tasks, and relate their formal obligations to personal career or political aspirations;

iv) how specific planned interventions are transformed in the process of implementation as a result of the negotiations between intervening parties (e.g. SARH (Ministry of Agriculture and water Resources), BANRURAL (Agricultural Bank), or the Companies) and local groups;

v) how "intermediate" institutions or formal forums (e.g. Comite Técnico Cañero (Sugar Committee), Asambleas de UNPH (Assemblies of the National Union of Vegetable Producers), Comite de Desarrollo Integral Municipal (Committee for Municipal Integrated Development), Comité Directivo de Distrito (Management Comittee for the District) reflect wider socio-political negotiations and processes and affect different social interests; 
vi) how different types of households respond to internal and wider environmental forces and devise 'survival' strategies when faced by scarcity of resources;

vii) how individual economic or political careers and family-based enterprises are developed over time;

viii) how persons utilize public resources and institutions to further their own personal and political careers;

ix) how groups of producers react to the incorporation into wider national and international markets and institutions, or respond to major changes in cropping patterns (e.g. the shift from tomatoes to sunflower and other crops), land use (e.g. the encroachment of agricultural land by urban expansion) or water use - (e.g. the conflicts over water for agriculture, industry or domestic consumption);

x) how different social groups operate within the context of differing social and economic fields, some being oriented to the immediate locality and region, whilst others operate within fields of action that reach out to Guadalajara and "al norte" (i.e. the United States).

The kinds of research techniques that can be utilized to build up these case studies.

I cannot lay out the details of these, only offer a thumbnail sketch of each. Those methods that are likely to be less familiar are spelt out in a little more detail.

1) Life Histories focusing upon critical life experiences of the individuals concerned. See Plumer (1983) on "Documents of Life" and Bertaux's (1981) collection of papers for examples of different ways of collecting them. Balan, Browning and Jelin (1973) on Monterrey and Long and Roberts (1984) on central Peru have designed more structured interviewing schedules for looking at residential, family and work histories;

2) Social Network Analysis. See Mitchell's (1969) Introduction to "Social Networks in Urban Situations" for an overview of the techniques (quantitative and qualitative) and analytical concepts that can be 
employed. The chapter in the same book by Boswell on the mobilization of help in critical situations uses a social network approach to analyze the sets of relationships involved. Long's (1972) paper on transporters in Peru might also be useful;

3) Study of Careers (individual and enterprise). This can of course be combined with the use of life history and social network methods. Long's (1979) "Multiple Enterprise in the Highlands of Peru" is an example of how to $100 \mathrm{k}$ at long-term economic careers and suggests how one might relate changes in individual careers to the broader chronology of regional and national change. See Grindle's (1977) book on CONASUPO, Smith's (1979) "Labyrinths of Power" and Arce (1986) for methods of studying the careers of bureaucrats and politicos;

4) The Analysis of Social Situations (Extended Case Method). The best introduction to this is Van Velsen (1967). Turner's (1957:91-94) concept of social drama is important and also Moore (1978). Gluckman's (1958) original paper on "An Analysis of a Social Situation in Modern Zululand" is a classic. Long's book (1968) on Zambia provides a number of examples of social situational analysis. As Gluckman and others (Garbett, 1970; Mitchel1, 1983) make abundantly clear this case-study method is not to be interpreted as a mode of "apt illustration". It aims to provide a close-up view of social interaction and confrontation in order to elucidate how structural forms and processes. (reproduction and transformation) work themselves out in everyday situations. The ways in which individuals manipulate norms, values and develop strategies to create space for their "own projects" is a central interest in this literature.

5) Discourse Analysis and Actor's Accounts of Social Bvents. This takes us into the literature on ethnomethodology and phenomenology. I would not suggest immersing oneself totally in this, but Mihan and Wood (1975) give a reasonable introduction to the literature. See also Douglas's "Understanding Everyday Life", and Weigert (1981). Discourse analysis connects up with Foucault's writings (for a summary overview of his work, see Wuthnow, et.al, 1984), although he manifests a strong structuralist bent. The volune edited by Gudykunst, stewart and Ting-Toomey, "Communication, Culture, and Organizational Processes" (1985) contains some papers that indicate how one might use certain insights from "interpretative" sociology to explore organizational issues and what is called "the management of meaning". I am not sure 
what potential this type of actor-oriented perspective has for the present project. It needs further exploration.

6) Activity Fields and Social Field Analysis. Work on "activity fields" (Joan Vincent's term, 1977) and "social fields" takes us back once more to the original Manchester studies. Mitchell, (1969), Kapferer (1972) and Long (1968) all utilise the notion of "social field" in order to go beyond institutional types of analysis. The main point here is that it is argued that individuals and groups do not operate in clearly defined institutional frameworks but rather construct fields of action which often cross-cut formal organizational boundaries and normative systems. In order therefore to understand the nature of ongoing social systems and how they are transformed it becomes crucial to adopt a social field, actor/strategy approach. Long's Introductory chapter to "Social Change and the Individual" (1968) provides a brief discussion of the theoretical and methodological importance of the concept of social field and the rest of the book uses it to analyze social and agricultural change in Zambia. In considering the notion of "activity" /"social" field it is necessary to compare this with other similar concepts, such as "arena" used by strauss in his books on hospitals (the best is on "Psychiatric Ideologies"), and "power domain" used by Adams (1975:68-93). Another useful cross-reference might be the notion that Giddens (1984:118-144) has of time-space "locales". Again there is the connection with Schutz's concept of "life-worlds". Schutz argues that an individual's body of knowledge is organized in zones stretching out spatially and temporally from the individual (Schutz and Luckmann, 1973). This, it seems, implies that different fields of social relationships underpin the organization of this stock of knowledge, which will vary according to the particular individual or social category.

7) Personal Constructs, Folk Models, Cognitive Maps and Knowledge systems. As we indicated earlier, an actor perspective must attempt to tie together in some way action and meaning. This can be done by approaching the issue from the point of view of "the sociology of everyday life" (see Berger and Luckmann, "The Social Construction of Reality", 1973, first sections on the foundations of everyday knowledge; and Schutz and Luckmann (1973) on Life-Worlds). In many respects Giddens (1984, 1987) provides the best theoretical statement on the relevance of studying in detail day-to-day activities of individuals for the reproduction of structure (what he calls "structuration") and 
for analyzing practical consciousness (the tacit knowledge that people have about how to "go on" in social life without articulating it verbally).

In order to probe individuals' ways of construing the world around them one needs to develop techniques for isolating the kinds of concepts, assumptions, and dimensions they work with. There are several possible methods available for attempting this, ranging from Kelly's personal construct theory (see Bannister, 1977, and Bannister and Fransella, 1971), which although intended for psychologists can be adapted to explore sociological questions; to cognitive maps which aim to identify the category systerns of individuals and groups (see Spradley's (1972) study of tramps for an application of this method, although he places rather too much emphasis on semantic and taxonomic analysis); to Gudeman and Penn's (1982) treatment of what they call "local models" which enable people to categorize and impute meaning to their physical and cultural milieu; to the study of knowledge systems along the lines of Schutz, Berger and Luckmann, and Knorr-Cetina ("The Manufacture of Knowledge", 1981).

It remains open as to which of these methods for exploring the conceptual worlds of social actors is the most appropriate when dealing with particular types of case studies. Also one may wish to draw insights from them without committing oneself either to the underlining theoretical thinking or to the precise methods recommended. For example, in our knowledge interface paper (Arce and Long, 1987) we drew upon various discussions on how knowledge is generated and transformed to develop our own analysis of the interaction between the worlds of the técnico and the peasant, although theoretically we espoused a strong actor perspective.

The above discussion on research methods was designed to provoke researchers into thinking more systematically about how to carry out the various kinds of case studies necessary for achieving the objectives of the project. Obviously a case-study methodology needs to be complemented with other forms of data collection, and perhaps, later, one will need to consider the question of how to sample the larger universe in order to contextualize or test out our case-study and qualitative data. 
Given our interest in the co-existence and interpenetration of different life-worlds and in the struggles that take place between local producer groups and intervening parties, then much of our case-study and general observational material should be directed towards the critical points of linkage or confrontation between groups or social units. The concept of interface can contribute to the analysis of these processes. Interface conveys the idea of some kind of face-to-face encounter between individuals or groups representing different interests, resources and levels of power. Analyzing interface situations aims to bring out the dynamic and emergent character of the interactions that take place and to show how the goals, perceptions, interests, and relationships of the various actors are reshaped as a result of the interactions, leading to a "new" interface encounter the next time round.

Interfaces contain within them many levels and forms of social linkage and also different, and often conflicting, value systems or rationalities. Also, although the methodology of interface studies focuses upon specific social interactional processes and draws upon the types of case-study research methods described above, analysis should situate these within broader institutional and power fields. One way of contextualizing actor strategies within a broader structural framework of analysis is by adopting a modified political economy approach (see Long and Roberts, 1984). At this stage in our research it would be premature to anticipate the final theoretical product. However, one thing is clear: in order to understand the complexities of intervention and actor strategies in the area of research we need to penetrate the life-worlds of different social groups and individuals who make up the complex mosaic of changing agrarian and social relations in the region.

As I see it, these various case-study methods should contribute to a better understanding of interface phenomena and to developing a systematic methodology for analyzing intervention processes and the ways in which individuals or groups attempt to create space for pursuing their own social projects or for resisting the imposition of other more powerful actors or social sectors. 
By way of concluding: two critical problems

These notes are not written with the intention of spelling out the details of the methodology for particular research topics with in the overall project. Rather the aim has been to outline the kinds of general theoretical ideas that should guide the choice of research methods to be used.

If this general theoretical approach is followed then it seems to me that there are a number of difficult methodological problems to be resolved. Among these, the following are perhaps the most challenging:

1) The problem of how to study the process by which external intervention enters the life-worlds of the individuals and groups affected and thus comes to form part of the resources and constraints of the social strategies they develop. Hence so-called "external" factors are internalized and may come to mean quite different things to different interest groups or actors. The implication of this is that the notion of "intervention" by outside agencies needs "deconstructing" so that we recognize the process as a many-headed hydra (even if it belongs to the same body) which develops different social practices in relation to different contexts and actors. A further implication of this is that through this process local groups come to define and recognize their own social spaces, cultural boundaries and positions within the wider power structure.

2) The problem of how to relate field observations on social action to the notion of "practical consciousness". This entails stepping beyond the usual simple assumption about congruence between articulated ideas or ideology and action to recognizing the reflexive capacities of the human actor (i.e. "the capacity to understand what they do while they do it") (see Giddens, 1984:xxii-xxiii). This runs counter to much sociological theorizing on, for example, forms of peasant resistance to state intervention which normally assume some form of articulated, often collective, consciousness (for a critique of this assumption, see scott, 1986). Clearly there are many situations (this area of study included), where this is not so evidently the case; yet it would be incorrect to assume that peasants do not internalize the problems they face due to state intervention or transnational exploitation. The way they go about 
dealing with their daily affairs and devising modes of "sabotaging" or implicitly "questioning" the manner in which they are dealt with, or the strategies they employ to extract what they can from

"the system" or "patrón", reveal the importance of taking serious account of the notion of practical consciousness.

\section{Notes}

1. This document was prepared especially for members of the Mexican research team. It was written in July 1987 in close discussion with Alberto Arce, who called my attention to the need for such an overview and who made several highly pertinent suggestions. 


\section{BIBLIOGRAPHY}

Adams, R.N. 1975 .

Energy and structure: A theory of social power. Austin and London: University of Texas Press.

Alavi, H. 1973.

Peasant classes and primordial loyalties. The Journal of Peasant Studies, Vol.1, No. 1: 22-62.

Allott, A.N, and G.R. Woodman, (eds). 1985.

People's law and state law: The Bellagio Papers. Dordrecht: Foris.

Apthorpe, R. 1984 .

Agriculture and strategies: The language of development policy. In: $\mathrm{Clay,}$ E.J. and B.B. Schaffer (eds), Room of Manoeuvre: An exploration of public policy in agriculture and rural development. London: Heinemann Educational Books.

Arce, A. 1986.

Agricultural policy administration in a less developed country: The case of SAM in Mexico. Ph.D. thesis, University of Manchester.

Arce, A. 1987.

Bureaucratic conflict and public policy: Rainfed agriculture in Mexico. Boletin de Estudios Latinoamericanos y del Caribe, 42, June: 3-24.

Arce, A. and Long, N. 1987.

The dynamics of knowledge interfaces between Mexican agricultural bureaucrats and peasants : a case study from Jalisco. Boletin de Estudios Latinoamericanos y del Caribe, 43, December: 5-30.

Bailey, F, 1969.

Stratagems and spoils: A social anthropology of politics. Oxford: Basil Blackwell.

Balán, J., Browning, H. and E. Jelin. 1973.

Men in a developing society: Geographic and social mobility in Monterey. Austin, Texas: University of Texas Press.

Bannister, D. (ed). 1977.

New perspectives in personal construct theory. London, New York and San Francisco: Academic Press.

Bannister, D. and F. Fransella, (eds). 1971.

Inquiring man: The theory of personal constructs. Harmondsworth: Penguin Books.

Barnett, T. 1977 .

The Gezira Scheme. An illusion of development. London: Frank Cass.

Barth, F. 1981 .

Process and form in social life. Selected essays of Fredrik Barth: Volume I. London, Boston and Henley: Routledge and Kegan Paul. 
Batley, R. 1983.

Power through bureaucracy: Urban political analysis in Brazil. Aldershot:

Gower.

Benda-Beckmann, F, von, 1979.

Property in social continuity: Continuity and change in the maintenance of property relationships through time in Minangkabau, west Sumatra. The Hague: M. Nijhoff.

Benda-Beckmann, F. von, 1983a. Op zoek naar het kleinere euvel in de jungle van het rechtspluralisme. Inaugural Lecture, Wageningen: The Agricultural

University.

Benda-Beckmann, F. von, 1983b.

Why law does not behave: Critical and constructive reflections on the social scientific perception of the social significance of law. In: $H$. Finkler (ed), Proceedings of the Symposium on Folk Law and Legal Pluralism, XIth IUAES Congress, 1983, Vancouver. Ottawa.

Benda-Beckmann, F, von, 1984.

Law out of context: A comment on the creation of customary law discussion. Journal of African Law, 28: 28-33.

Benda-Beckmann, F. von, 1985.

Some comparative generalizations about the differential use of state and folk institutions of dispute settlement. In: A. Allott and G. Woodman (eds.), People's law and state law - The Bellagio Papers. Dordrecht: Foris.

Benda-Beckmann, F. von, 1986.

Anthropology and comparative law. In $K$. von Benda-Beckmann and $F$. Strijbosch (eds), Anthropology of law in the Netherlands. Dordrecht: Foris.

Benda-Beckmann, F. von, 1987a.

De ijsjes van de rechter: een verkenning van complexe sociale zekerheidssystemen. Recht der Werkelijkheid, I: 69-82.

Benda-Beckmann, F. von, 1987b.

Magic charm and scape-goat: Law in development theory and practice. Paper for the International Seminar on "The impacts of development". Padang, December 1987.

Benda-Beckmann, F. von, 1988. Sociale zekerheid en plattelandsontwikkeling in Indonesië. Studium Generale Papers. Wageningen: The Agricultural University.

Benda-Beckmann, $F$, and $K$, von, 1985.

Transformation and change in Minangkabau. In: L. Thomas and F. von BendaBeckmann (eds), Change and continuity in Minangkabau. Athens: Ohio University Monographs in International Studies.

Benda-Beckmann, F, von, 1986. Verwantschap tussen dorp en staat. Paper for the VIth KOTA-conference, Amsterdam 20-21 May. 
Benda-Beckmann, F. von, et.al. 1988.

Introduction: Between kinship and the state. In: F. von Benda-Beckmann et al. (eds), Between kinship and the state: Social security and law in developing countries. Dordrecht: Foris.

Benda-Beckmann, K. von, 1982.

Traditional law in a non-traditional context. Indonesia Circle, 27: 39-50.

Benda-Beckmann, K. von, 1984.

The broken stairways to consensus: Village justice and state courts in

Minangkabau. Dordrecht: Foris.

Benda-Beckmann, K. von, 1987.

Overheidskoöperaties als particuliere ondernemingen. Recht der

Werkelijkheid, 1987, Vol.I: 54-68.

Benda-Beckmann, K. von, 1988.

Social security and small-scale enterprises in islamic Ambon. In: F. von Benda-Beckmann et al. (eds), Between kinship and the state: Social security and law in developing countries. Dordrecht: Foris.

Benvenuti, B. 1975 .

General systems theory and entrepreneurial autonomy in farming: towards a new feudalism or towards democratic planning. Sociologia Ruralis, Vol.xV, No.1/2: 47-62.

Benvenuti, B., E. Bolhuis and J.D. van der Ploeg, 1982.

I problemi dell'imprenditorialitá agricola nella integrazione cooperative. Rome: AIPA.

Berger, P.L, and T. Luckmann, 1966.

The social construction of reality: A treatise in the sociology of knowledge. Harmondsworth; Peguin Books.

Berry, S. 1985.

Fathers work for their sons: Accumulation, mobility and class formation in an extended Yoruba community. Berkeley, Los Angeles and London: University of California Press.

Bertaux, 1981 .

Biography and society: The life history approach in the social sciences. Beverly Hills and London: Sage Publications.

Black, M. 1962.

Models and metaphors: Studies in language and philosophy. Ithaca: Cornell University Press.

Blau, P.M. 1967.

Exchange and power in social life. New York and London: John wiley and Sons.

Bolhuis, E.E. and J.D. van der Ploeg, 1985.

Boerenarbeid en stijlen van landbouw beoefening. Leiden: Leiden Development Studies. 
Boserup, E. 1965.

The conditions of agricultural growth: The economics of agrarian change under population pressure. Chicago: Aldine.

Botchway, J. 1988 .

The lack of agricultural knowledge networks and institutional frameworks in rural development projects: the case of Weija irrigation project. M.Sc. thesis Wageningen, The Agricultural University.

Bottra11, A. 1981 .

Comparative study of the management and organization of irrigation projects. Washington: World Bark Staff Working Paper

Bourdieu, P. 1980.

Le sens pratique. Paris: Les Editions de Minuit.

Box, L. 1981.

Cultivation and adaptation: An essay on the sociology of agriculture. Sociologia Ruralis, XXI, 2: 160-176.

Box, L. 1982.

Food, feed or fuel? Agricultural development alternatives and the case for technological innovation in cassava (manihot esculenta crantz) cultivation. Quarterly Journal of International Agriculture, Special Issue: 34-48.

Box, L. 1984a.

Cassava cultivators and their cultivars: Preliminary results of case studies in the sierra region of the Dominican Republic. Proceedings of the 6th Symposium of the International Society for Tropical Root Crops. Lima: International Potato Center.

Box, L. 1984b.

Reverse transfer: Adapting agricultural research to smallholder conditions: The case of cassava cultivation in the Dominican Republic. Paper presented to the Caribbean Studies Association Conference on Strategies for Progress in the Post-Independence Caribbean. Saint Kitts.

Box, L, 1984C.

Survey on trail: Sociological contributions to adaptive agricultural research. Paper presented to the world Congress of Rural Sociology, Manilla.

Box, L. and F.J. Doorman, 1985.

The adaptive farmer: sociological contributions to adaptive agricultural research on cassava and rice cultivation in the Dominican Republic (1981-1984). Wageningen: Department of the Sociology of Rural Development, The Agricultural University.

Box, L. and F. J. Doorman, 1986.

Adaptive agricultural research in the Dominican Republic: Collected reports and papers. Leiden and Geneva: International Documentation Company - Microfiche.

Brammer, H. 1980.

Some innovations don't wait for experts. Ceres, 13(2): 24-28. 
Brokensha, D. et al. 1980.

Indigenous knowledge systems and development. Lanham, Maryland: University Press of America.

Brown, L.D. 1983.

Managing conflict at organizational interfaces. Reading, Mass.: Addisonwesley.

Brush, S.B., J.C. Heath and Z. Huaman, 1981.

Dynamics of andean potato agriculture. Economic Botany, 35, 1: 70-88.

Castatios, C.M. 1987.

Organización campesina: La estrategia truncada. Chapingo, Mexico: Agrocomunicación Saenz Colin.

Castellanos, V. H. and L. Box, 1981.

Investigación de yuca en la Repüblica Dominicana. Santiago: CENDA - Investigación Agrosociológica.

Chambers, R. and J. Moris, 1973.

Mwea: An irrigated rice settlement in Kenya, Munich: Weltforum Verlag.

Chambers, R. 1983.

Rural development: putting the last first. London: Longman.

Chanock, M. 1978.

Neo-traditionalism and the customary law in Malawi. African Law Studies, $16: 80-91$.

Chiba, M. (ed), 1986.

Asian indigenous law: In interaction with received law. London and New York: Kegan Paul.

Clay, E.J, and Schaffer, B.B. 1984.

Room for manoevure: An exploration of public policy in agriculture and rural development. London: Heinemann Educational Books.

Cock, J. 1985.

Cassava: New potential for a neglected crop. Boulder, Colorado: Westview Press.

Cohen, A.P. 1985.

The symbolic construction of community. London and New York: Tavistock Publications and Ellis Horwood Limited.

Cole, J.W. and E.R. Wolf, 1974 .

The hidden frontier, ecology and ethnicity in an Alpine Valley. New York.

Collins, R. 1981.

Micro-translation as a theory-building strategy. In: K. Knorr-Cetina and A.V. Cicourel (eds), Advances in social theory and methodology. Boston, London and Henley: Routledge and Kegan Paul.

Coward, F.w. 1977.

Irrigation management alternatives: themes from indigenous irrigation systems. Agricultural Administration, 4:223-237. 
Coward, E.w. 1980.

Irrigation and agricultural development in Asia. Ithaca and London: Cornell University Press.

Crouch, L. A. 1981.

The development of capitalism in Dominican agriculture. Berkeley: University of California, Ph.D. Dissertation.

Darre, J.P. 1985.

La Parole et la technique, l'univers de pensêe des éleveurs du Ternois. Paris: L'Harmattan.

Dewalt, B. 1975.

Modernization in a Mexican ejido. A study in economic adaptation. Cambridge: Cambridge University Press.

Diemer, G. 1988.

Paradigms in irrigation development: A view from Africa. Paper presented to the World Congress for Rural Sociology held in Bologna. Wageningen: Department of Irrigation and Civil Engineering, The Agricultural University.

Doorman, F. J. and A. Naut, 1986.

Què pasa? Evaluación del sistema de generación y transferencia de tecnología en la producción arrocera en la República Dominicana. Santiago: CENDA - Investigación Agrosociológica.

Douglas, J.D. (ed) 1971. Understanding everyday life: Towards the reconstruction of sociological knowledge. London: Routledge and Kegan Paul.

Drijver, C.A., F. Toornstra and S.S.A.L. Siriwardena, 1985. Mahaweli Ganga Project, Sri Lanka: Evaluation of environmental problems and the role of settler housholds in conservation. Leiden: Centre for Environmental Studies, University of Leiden.

Eggink, J.W. and J. Ubels. 1984.

Irrigation peasants and development: An attempt to analyze the role of irrigation in social change in Third world societies. Wageningen: The Agricul tural University.

Eldijk, A, van, 1986.

Tussen volksrecht en overheidsrecht: Over zelfregulering van marktaktiviteiten in Sierra Leone. In: w. Brussaard et al., Recht in ontwikkeling: Tien agrarisch-rechtelijke opstellen. Deventer: Kluwer.

Eldijk, A, van, 1987.

Markthoofden en kleinhandel in Sierra Leone: Het bestuur in kwestie. In: K. von Benda-Beckmann and A. Hoekema (eds), Horizontaal bestuur. Den Haag: vuga.

Elwert, G. and Bierschenk, T. 1988.

Aid and development. Special Issue of Sociologia Ruralis, XXVIII, $2 / 3$. 
Esman, M.J. and Uphoff, N.T. 1984.

Local organizations: Intermediaries in rural development. Ithaca and London: Cornell University Press.

Fardon, R. (ed) 1985 .

Power and knowledge: Anthropological and sociological approaches. Edinburgh: Scottish Academic Press.

Feeley, M. 1976.

The concept of law in social science: A critique and notes on an expanded view. Law and Society Review, 10: 497-523.

Fitzpatrick, P. 1984.

Traditionalism and traditional law. Journal of African Law, 28: 20-27.

Fleer, H. 1987.

Irrigatie en systeemrehabilitatie in Gal Oya, Sri Lanka. Wageningen: Department of Irrigation and Civil Engineering, The Agricultural University

Fleuret, P. 1985.

The social organisation of water control in the Taita Hills, Kenya. American Ethnologist, 12, 1: 103-118

Foucault, M. 1972.

The archaeology of knowledge. New York: Randon House.

Foucault, M. 1980.

Power/knowledge: Selected interviews and other writings 1972-1977. Colin Gordon (ed), New York: Pantheon Books.

Foucault, M. 1981.

The history of sexuality. Volume I: An introduction. Harmondsworth; Penguin.

Freeman, D.M. and M.K. Lowdermilk, 1981.

Sociological analysis of irrigation water management: A perspective and approach to assist decision making. In: C. Russel and N.K. Nicholson (eds), Public choice and rural development. Baltimore: John Hopkins University Press.

Fresco, L.0. 1986.

Cassava in shifting cultivation: a systems approach to agricultural technology development in Africa. Royal Tropical Institute, Amsterdam.

Galanter, M. 1981.

Justice in many rooms. Journal of Legal Pluralism, 19: 1-47.

Garbett, G.K. 1970.

The analysis of social situations. Man (N.S.), 5:214-227.

Geertz, C. 1967.

Tihingan: a Balinese village. In: Villages in Indonesia. Koetjaraningrat (ed). Ithaca: Cornell University Press

Geertz, C. 1.973.

The interpretation of cultures. New York: Basic Books. 
Geschiere, P. 1984.

Segmentary societies and the authority of the state: problems of implementing rural development in the Maka villages in south-eastern Caneroon. Sociologia Ruralis, XXIV, 1: 10-29.

Giddens, A. 1979 .

Central problems in social theory: Action, structure and contradiction in social analysis. London: Macmillan.

Giddens, A. 1981 .

Agency, institution and time-space analysis. In: K. Knorr-Cetina and A.V. Cicourel (eds), Advances in social theory and methodology. Boston, London and Henley: Routledge and Kegan Paul.

Giddens, A. 1984 .

The constitution of society: Outline of the theory of structuration. Cambridge: Polity Press.

Giddens, A. 1987.

Social theory and modern sociology. Oxford: Polity Press in association with Basil Blackwell.

Glantz, S. 1979 .

Manuel: Una biografía politica. Mexico: Editorial Nueva Imagen.

Glick, T. 1970.

Irrigation and society in medieval Valencia. Cambridge Massachusetts: Harvard University Press.

Gluckman, M. 1958 (1940 and 1942). Analysis of a social situation in modern zululand. Rhodes-Livingstone Paper, No. 28. Originally published in Bantu Studies, 1940 and African Studies, 1942 .

Gluckman, M. 1968.

The utility of the equilibrium model in the study of social change. American Anthropologist, 70: 219-237.

Gluckman, M., MitchelI, J.C. and Barnes, J. 1949.

The village headman in British Central Africa. Africa, XIX, 2: 89-106.

Goldschmidt, w. 1966.

Comparative Functionalism. Berkeley: University of California Press.

Gonzalez, N.L. 1972 .

Patron-client relationships at the international level. In: A. Strickon and S.M. Greenfield (eds), Structure and process in Latin America. Albuquerque: University of New Mexico Press.

Gray, R.F. 1963.

The Sonjo of Tanganyika: An anthropological study of an irrigation based society. Oxford: Oxford University Press.

Griffiths, J. 1986.

What is Legal Pluralism? Journal of Legal Pluralism, 24: 1-55. 
Grindle, M. 1977.

Bureaucrats, peasants and politicians in Mexico: A case study in policy. Berkeley and Los Angeles: University of California Press.

Grindle, M. 1980. (ed).

Politics and policy implementation in the Third World. Princeton, New Jersey: Princeton University Press.

Gudeman, S. and M. Penn, 1982.

Models, meaning and reflexivity. In: D. Parkin (ed), Semantic anthropology. London and New York: Academic Press.

Gudykunst, W.B., L.P. Stewart and S. Ting-Toomey. 1985 Communication, culture and organizational processes. Beverly Hills and London: Sage Publications.

Guzman Arias, L. 1983.

La yuca: Tècnicas de cultivo. Santo Domingo: Secretaria del Estado de Agricultura. Serie Raices y Tuberculos, No. 1.

Habermas, J. 1981 ,

The theory of communicative action. 2 Vols (English edition for the 1st volume, 1984; second volume, 1987). London: Heinemann.

Handelman, D. 1976.

Bureaucratic transactions: The development of official-client relationships in Israel. In: Kapferer, B. (ed), Transaction and meaning. Philadelphia: ISHI.

Handelman, D. 1978.

Introduction: A recognition of Bureacracy. In: Handelman, D. and Leyton, E. (eds), Bureaucracy and world view: Studies in the logic of official interpretation. St. John's, Newfoundland: Institute of Social and Economic Research, Memorial University of Newfoundland.

Hardeman, J. 1984. Selectieve innovatie door kleine boeren in Mexico. Amsterdam: Free University, Krips Repro Meppel.

Harris, B. 1978.

Access and the cooperative: A study of an intermedium in structural change in Sri Lankan dry zone paddy production. Development and Change, Vol.9: 277-298.

Haudry, R, de Soucy, 1984.

Situación del programa de credito. Proderm al 31/XII/83, y propuestas de acción, Cuzco.

Hayami, Y. and V. Ruttan, 1985.

Agricultural development: An international perspective. Baltimore: Johns Hopkins University Press.

Heijdra, H. 1988.

Local organizations: Outside interventions and peasant strategies. A case study at the intermediate level in an export-oriented irrigation zone of western Mexico. M.Sc. thesis, The Agricultural University, Wageningen. 
Herrera, A. de, 1980.

Agricultura general (1513). Re-edited by Servicio de Publicaciones del Ministerio de Agricultura y Pesca, Madria.

Hesse, M. 1978.

Theory and value in the social sciences. In: Hookway $\mathrm{C}$. and $\mathrm{Ph}$. Pettit (eds). Action and interpretation. Studies in Philosophy of the Social Sciences. Cambridge: Cambridge University Press.

Hesse, M. 1983.

The cognitive claims of metaphor. In: Van Noppen, J.P., (ed). Metaphor and Religion, Theolinguistics 2. Brussels: Study Series of the Free University of Brussels.

Hibon, A. 1981.

Transfert de technologie et agriculture paysanne en zone Andine: Le cas de la culture du mais dans les systemes de production du Cusco (Perou). Tome I et II, Toulouse.

Hildebrand, P. 1984.

Researcher/farmer linkage. In: Workshop on Agricultural Research Policy and Organization in Small Countries. Wageningen and The Hague: International Service for National Agricultural Research.

Hill, P. 1970.

A plea for indigenous agronomics: the West African example. In: P. Hill, (ed), Studies in rural capitalism in West Africa. Cambridge: Cambridge University Press.

Hindess, B. 1986.

Actors and social relations. In: Wardell, M.L, and Turner, S.P. (eds), Sociological theory in transition. Boston, London and Sydney: Allen and Unwin.

Hofstee, E.W. 1985.

Groningen van grasland naar bouwland 1750-1930. Wageningen: The Agricultural University.

Hooker, B. M. 1975.

Legal Pluralism: An introduction to colonial and neo-colonial laws. Oxford: Oxford University Press.

Horst, L. 1983.

Irrigation systems, alternative design concepts. ODI Irrigation Management Network Paper, No $7 \mathrm{c}$.

ISNAR, 1983.

El sistema de investigación agropecuaria en la República Dominicana. The Hague: International Service for National Agricultural Research.

Janvry, A. de, 1981.

The agrarian question and reformism in Latin America. Baltimore and London: Johns Hopkins University Press.

Johnson, A. W. 1972.

Individuality and experimentation in traditional agriculture. Human Ecology, 1(2):149-159. 
Kapferer, B. 1972.

Strategy and transaction in an African factory. Manchester: Manchester University Press.

Kapferer, B. (ed), 1976.

Transaction and meaning: Directions in the anthropology of exchange and symbolic behaviour. Philadelphia: ISHI.

Kidder, R. F. 1979.

Towards an integrated theory of imposed law. In: S.B. Burman and B. Harrel1-Bond, (eds), The imposition of law. New York: Academic Press.

Knorr-Cetina, K.D. 1981 .

The manufacture of knowledge: Towards a constructivist and contextual theory of science. Oxford: Pergamon Press.

Knorr-Cetina, K.D. and A. V. Cicourel, (eds), 1981. Advances in social theory: Toward an integration of micro- and macrosociologies. Boston, London and Henley: Routledge and Kegan Paul.

Koningsveld, H. 1986.

wat is landbouwwetenschap? op zoek naar een identiteit. In: Landbouwkundig Tijdschrift, $98,9: 45-47$.

Krimmel, $T$, and B. Massler. 1982.

Social differentiation and peasant colonisation: the impact of the new technology under conditions of compulsory relocation. A village study of the resettlement of reservoir area evacuees in the Mahaweli development area, Sri Lanka. Minchen: Technical University.

Kurin, R. 1983.

Indigenous agronomics and agricultural development in the Indus Basin. Human Organization, 42(4): 283-294.

Lacroix, A. 1981 .

Transformations du proces de travail agricole: Incidences de l'industrialisation sur les conditions de travail paysannes. Grenoble: INRA/IREP.

Lampe, K. 1983.

Contemplative introduction. Man and technology in irrigated agriculture. Symposium 1982, DVWK-bulletin No. 8. Hamburg/Berlin: Verlag Paul Parey.

Leach, E.R. 1961 .

Pul Eliya: a village in Ceylon. A study of land tenure and kinship. Cambridge: Cambridge University Press.

Lipsky, M. 1980 .

Street-Level bureaucracy: Dilemmas of the individual in public service. New York: Russell Sage.

Long, N. 1968.

Social change and the individual: a study of the social and religious responses to innovation in a Zambian rural community. Manchester: Manchester University Press. 
Long, N. 1972.

Kinship and associational networks among transporters in rural Peru: The problem of the "local" as against the "cosmopolitan" entrepreneur. Paper presented to seminar on "Kinship and social networks", Institute of Latin American Studies, London University. See shortened version in Long and Roberts, $1984: 181-195$.

Long, N. 1977.

An introduction to the sociology of rural development. London: Tavistock Publications Limited.

Long, N. 1979.

Multiple enterprise in the central highlands of Peru. In: S.M. Greenfield, et. al. (eds), Entrepreneurs in cultural context. Albuquerque: University of New Mexico Press.

Long, N. 1984.

Creating space for change: a perspective on the sociology of development. Inaugural Lecture, Wageningen: The Agricultural University. A shortened version is also published in Sociologia Ruralis, XXIV, No.3/4:168-184.

Long, N. 1986.

Contrasting patterns of irrigation organization, peasant strategies and planned intervention: A research proposal. Department of the Sociology of Rural Development, The Agricultural University, Wageningen.

Long, N. 1988.

Sociological perspectives on agrarian development and state intervention. In: A. Hall and J. Midgley (eds), Development policies: sociological perspectives. Manchester: Manchester University Press.

Long, N. et.al, 1986.

The comoditization debate: Labour process, strategy and social network. Wageningen: The Agricultural University.

Jong, N. and J.D. van der Ploeg, 1988.

New challenges in the sociology of rural development. Sociologia Ruralis, XXVIII, 1: 30-41.

Long, N. and B. Roberts, (eds), 1978.

Peasant cooperation and capitalist expansion in the central Peru. Austin, Texas: Texas University Press.

Long, N. and B. Roberts, 1984.

Miners, peasants and entrepreneurs: Regional development in the central highlands of Peru. Cambridge: Cambridge University Press.

Marte, D. 1984.

Planteamientos prácticos sobre el desarrollo agropecuario del país. Santo Domingo: Secretaria del Estado de Agricultura.

Martinez, S.T. 1983.

Los campesinos y el estado en Mexico. Ph.D. thesis, Universidad Iberoanericana, Mexico. 
Marx, K. 1962 (originally published 1852).

The eighteenth Brumaire of Louis Bonaparte. In: Selected works (two volumes). Moscow: Foreign Languages Publishing House.

Mayer, E.Y. 1981 .

Uso de la tierra en los Andes. Lima: International Potato Center (CIP).

Mazijk, R. van and S. Scheer, 1988.

Spate-irrigatie in Tunesië: een overheidsinterventie in een traditioneel irrigatiesysteem, beschouwd vanuit een interface perspectief. Wageningen: Department of Irrigation and Civil Engineering, The Agricultural University .

Mehan, H. and H. Wood, 1975.

The reality of ethnomethodology. New York and London: John Wiley and Sons.

Mendras, H. 1970.

The vanishing peasant: innovation and change in French agriculture. Cambridge: Cambridge University Press.

Merrey, D.J. 1986.

Reorganizing irrigation: local level management in the Punjab, Pakistan. IIMI Research Papers, 4. Digana Village, Sri Lanka.

Merryman, J.H. 1977.

Comparative law and social change: on the origins, style, decline and revival of the law and development movement. American Journal of Comparative Law, 25: 457-491.

Midgley, J. 1984.

Social security, inequality and the Third World. Chichester: John Wiley and Sons.

Mitchell, J.C. 1969.

Social networks in urban situations. Manchester: Manchester University Press.

Mitchell, J.C. 1983.

Case and situation analysis. Sociological Review (N.S.), 31,2:187-21I.

Moore, S.F. 1973.

Law and social change: The seni-autonomous social field as an appropriate subject of study. Law and Society Review, Summer: 719-746.

Moore, S.F. 1978.

Law as process: An anthropological approach. London: Routledge and Kegan Paul.

Moore, S.F. 1986.

Social facts and fabrications: "Customary" law on Kilimanjaro, 1880-1980. Cambridge: Cambridge University Press.

Morgan, G. 1986.

Images of organization. Beverly Hills and London: Sage Publications. 
Murray-Rust, H. and M. Moore 1983.

Formal and informal water management systems: cultivation meetings and water deliveries in two Sri Lankan villages. Ithaca: Cornell University.

Nader, L. and H. Todd (eds), 1978.

The disputing process - law in ten societies. New York: Columbia University Press.

Nage 1, U. 1980.

Institutionalization of knowledge flows: an analysis of the extension role of two agricultural universities in India. Quarterly Journal of International Agriculture, No.30.

Naut, C. A. and L. Box, 1984.

Yuqueros and yucologos. Santiago: CENDA - Investigación Agrosociológica.

Oasa, E.K. 1981 .

The international rice research institute and the green revolution: $A$ case study on the politics of agricultural research. Hawaii: University of Hawaii.

Ortiz, S. 1981

Models, reasoning and economic behaviour. In: L. Holy and M. Stuchlik, (eds), The structure of folk models. London and New York: Academic Press.

Ploeg, J. D. van der, 1985.

Patterns of farming logic: the structuration of labour and the impact of externalization: Changing dairy farming in Northern Italy. Sociologia Ruralis, $\mathrm{XXV}, 1: 5-25$.

Ploeg, J.D. van der, (forthcoming, 1989)

The art of farming: A comparative sociological analysis of commoditization processes in agriculture. Boulder, Colorado: Westview Press.

Plumner, K, 1983.

Documents of life: An introduction to the problems and literature of humanistic method. London: Allen and Unwin.

Polanyi, K. 1944.

The great transformation. New York: Rinehart and Company Inc.

Prigogine, I. 1976.

Order through fluctuation: Self-organization and social system. In: E. Jantsch and C.H. Waddington (eds), Evolution and consciousness: Human systems in transition. Reading, Mass.: Addison-Wesley.

Pusey, M. 1987.

Jürgen Habermas. London and New York: Tavistock Publications and Ellis Horwood Limited.

Raby, A,N. 1978 .

Bureaucracy, politics and society in a provincial town in Sri Lanka. Ph.D. thesis, San Diego, University of California.

Rees, S. 1978.

Social work face to face: Clients' and social workers' perceptions of the content and outcomes of their meetings. London: Edward Arnold. 
Rhoades R. E. and R. H. Booth, 1982.

Farmer back to farmer: A model for generating acceptable agricultural technology. Agricultural Administration, X1, 2: 127-137

Richards, P. 1985.

Indigenous agricultural revolution. London: Hutchinson.

Richards, P. 1987.

Agriculture as a performance. Paper given to the International Development Studies Workshop on Farmers and Agricultural Research: Complementary methods. Institute of Development Studies, Brighton.

Röling, N. 1985.

Extension science: Increasingly preoccupied with knowledge systems. Sociologia Ruralis, XXV, 3/4: 269-290.

Röling, N. 1987.

Extension science: Information systems for agricultural development. Cambridge: Cambridge University Press.

Schaffer, B.B. and G. Lamb, 1976.

Exit, voice and access. Social Science Information, 13, 6: 73-90.

Schaffer, B.B. 1984.

Towards responsibility: Public policy in concept and practice. In: E.J. Clay and B.B. Schaffer (eds), Room for manoeuvre. London: Heinemann Educational Books.

Schlippe, P. de, 1957.

Méthodes de recherches quantitatives dans l'économie rurale coutumière de 1'Afrique centrale. Bruxelles: Dir. de l'Agr. des Forêts et de 1'Elevage.

Schrijvers, J. 1985.

Blueprint for under-nourishment: the example of the Mahaweli river development scheme. Paper presented at the IWAES commission of women/Indian association of women's studies regional conference for Asia: Women and the household, New Delhi.

Schutz, A. 1962 .

The problem of social reality. The Hague: Mijhoff Publishers.

Schutz, A. and T. Luckmann, 1973.

The structures of the life-world. Evanston, Illinois: Northwestern University Press.

Scorza, M. 1977.

Garabombo, el Invisible. Caracas.

Scott, J. 1986.

Everyday forms of peasant resistance. The Journal of Peasant Studies, 13, $2: 5-35$.

Selwyn, P. 1984.

The allocation of resources: agricultural budgets in Mauritius. In: E.J. Clay and B.B. Schaffer (eds), Room for manoeuvre: An exploration of public policy in agriculture and rural development. London: Heinemann Educational Books. 
Siriwardena, S.S.A.L. 1983.

Smallholders in a large-scale irrigation settlement in Sri Lanka. Some experiences in the Mahaweli Irrigation Settlement Scheme. Paper presented to the International Seminar on Incorporation and Rural Development. Colombo, January.

Siriwardena, S.S.A.L. 1984.

Penetration of trade and the role of merchants in the Mahaweli irrigation settlement. Unpublished paper.

Skocpol, T. 1979.

States and social revolutions: A comparative analysis of France, Russia and China. Cambridge: Cambridge University Press.

Slicher van Bath, B.H. 1960.

De agrarische geschiedenis van west-Europa (500-1850). Het Spectrum, Utrecht, Antwerp.

Smith, G.A. 1984 .

Confederations of households: Extended domestic enterprises in city and country. In: N. Long and B. Roberts, Miners, peasants and entrepreneurs: Regional development in the central highlands of Peru. Cambridge: Cambridge University Press.

Smith, P. 1979 .

Labyrinths of power: Political recruitment in twentieth century Mexico. Princeton: Princeton University Press.

Snyder, F. 1981a.

Capitalism and legal change: An african transformation. New York: Academic Press.

Snyder, F. $1981 \mathrm{~b}$.

Colonialism and legal form: The creation of customary law in Senegal. Journal of Legal Pluralism, 19: 49-90.

Spiertz, J. 1984.

Het semi-autonome veld: wondermiddel of paardemiddel. Nieuwsbrief voor Nederlandstalige Rechtssociologen, Rechtsanthropologen en Rechtspsychologen, NNR: 283-289.

Spiertz, J. 1986.

Vreende gasten: Een casus uit Bali. In: W. Brussaard et al., Recht in ontwikkeling - Tien agrarisch-rechtelijke opstellen. Deventer: Kluwer.

Spradley, J.P. 1972.

Adaptive strategies in urban nomads: The ethnoscience of tramp culture. In: T. Weaver and D. White (eds), The anthropology of urban environments. Washington D.C.: The Society for Applied Anthropology Monographs Series, No.11.

Strauss, A. et.al. 1964.

Psychiatric ideologies and institutions. New York: Free Press.

Thompson, J.B. 1984 .

Studies in the theory of ideology. Cambridge: Polity Press. 
Turner, V. 1957.

Schism and continuity in an African society. Manchester: Manchester University Press.

Turner, V. 1974.

Dramas, fields and metaphors: Symbolic action in human society. Ithaca and London: Cornell University Press.

Uphoff, N, 1984.

Experience with people's participation in water management: Gal Oya, Sri Lanka. In: Garcia Zamor (ed), Public participation in development planning and management: cases from Africa and Asia. Boulder, Colorado: Westriew Press.

Uphoff, N. 1986.

Getting the process right: improving irrigation water management with farmer organisation and participation. Ithaca: Cornell University.

Vanderlinden, J, 1971 .

Le pluralisme juridique. In: J. Gillissen (ed), Le pluralisme juridique. Brussels: Université de Bruxelles.

Velsen, J. van, 1967.

Situational analysis and the extended-case method. In: A.L. Epstein (ed), The craft of anthropology. London: Tavistock Publications Limited.

Velzen, H.U.E. van, 1973. Robinson Crusoe and Friday: Strength and weakness of the big man paradigm. Man, 8, 2:592-612,

Velzen, H.U.E. van, 1977.

Staff, kulaks and peasants: A study of a political field. In: L. Cliffe, J.S. Coleman and M.R. Doornbos (eds), Government and rural development in east Africa. The Hague: The Institute of Social Studies.

Vincent, J. 1977.

Agrarian society as organized flow: processes of development, past and present. Peasant Studies, 6, 2:56-65.

Wachtel, N. 1976.

Los Vencidos: los indios del Peru frente a la conquista espanola (1530-1570). Madrid.

Wade, R. 1979.

The social response to irrigation: an Indian case study. Journal of Development Studies, 16, 1:3-26..

Wade, R, and R. Chambers, 1980 .

Managing the main system: canal irrigation's blind spot. Economic and Political Weekly: A107-112.

Wade, R. 1982.

The system of administrative and political corruption: canal irrigation in South India. The Journal of Development Studies, 18, 3: 287-329. 
Warwick, D. 1982.

Bitter pills: Population policies and their implementation in eight developing countries. Cambridge: Cambridge University Press.

Weigert, A.J. 1981.

Sociology of everyday life. New York and London: Longman.

Werbner, R.P. 1982.

The quasi-judicial and the experience of the absurd: Remaking land law in north-eastern Botswana. Journal of African Law, 24: 117-130.

Whetten, N. 1948.

Rural Mexico. Chigaco: University of Chicago Press.

Whitehead, A. 1981 .

I'm hungry mum: The politics of domestic budgeting. In: $K$. Young et.al., of marriage and the market. London: CSE Books.

Willet, J. and D. Jeldres, 1987.

Minifundio landbouw en irrigatie ontwikkeling in Ecuador. Wageningen: Department of Irrigation and Civil Engineering, The Agricultural University.

Wittfoge1, K. 1957.

Oriental despotism: A comparative study of total power. New Haven: Yale University Press.

Woodman, G.R. 1985.

Customary law, state courts, and the notion of institutionalization of norms in Ghana and Nigeria. In: A.N. Allott and G. R. Woodman (eds), People's law and state law - The Bellagio Papers. Dordrecht: Foris.

Worsley, P. 1965.

Bureaucracy and decolonization: democracy from the top. In: I. Horowitz (ed), The new sociology: Essays in social science and social theory in honor of C. Wright Mills. New York: Oxford University Press.

Wuthnow, R. et.al. 1984.

Cultural analysis. London and Boston: Routledge and Kegan Paul.

Zanden, J.L. van. 1985.

De economische ontwikkeling van de Nederlandse landbouw in de negentiende eeuw, 1800-1914. Wageningen: The Agicultural University. 
NORMAN LONG is Professor of the Sociology of Development, the Agricultural University, Wageningen. He was formerly Professor of Anthropology, the University of Durham, England. His main publications include: Social Change and the Individual, Manchester University Press, 1968; An Introduction to the Sociology of Rural Development, Tavistock, 1977; (with Bryan Roberts) Peasant Cooperation and Capitalist Expansion in Central Peru, Texas University Press, 1978, and Miners, Peasants and Entrepreneurs, Cambridge University Press, 1984; "Creating Space for Change: A Perspective on the Sociology of Development", Inaugural Lecture, Wageningen, 1984; (as editor) Family and Work in Rural Societies, 1984; and (with others) The Commoditization Debate, The Agricultural University, Wageningen, 1986.

ALBERTO ARCE is Lecturer in the Sociology of Development, the University of Hull. He was formerly Research Fellow, the Agricultural University, Wageningen. His publications include: "La asistencia técnica de un distrito de temporal: entre la grilla y la política", in Desarrollo Rural en Jalisco, Alcántara and Sánchez (eds), Guadalajara, 1985; "Bureaucratic conflict and public policy: rainfed agriculture in Mexico", in Boletin de Estudios Latinoamericanos y del Caribe, 1987; and (with Norman Long) "The dynamics of knowledge interfaces between Mexican agricultural bureaucrats and peasants", in Boletin de Estudios Latinoamericanos y del Caribe, 1987.

HAKS HEIJDRA recently graduated with the Ingenieur's degree (M.Sc.) in the Sociology of Rural Development, the Agricultural University, Wageningen. He participated in the Mexican irrigation project, and wrote a thesis, based on field research, entitled "Local Organizations: Outside Interventions and Peasant Strategies: A Case-study in an Export-oriented Irrigation Zone of Western Mexico", 1988.

MAGDALENA VILLARRKaL is currently studying for the M.Sc. in the Management of Agricultural Knowledge Systems at the Agricultural University, Wageningen. She worked on the Mexican irrigation project and is preparing a report on "The struggle for Identity and Space for Change: Women in a Mexican Ejido". Prior to this, she was involved in popular education and peasant organization programmes in western Mexico.

JAN DOUWE VAN DER PLOEG is Lecturer in Agrarian Sociology, the Agricultural University, wageningen. His main publications include: De Gestolen Toekomst: Landhervorming, Boerenstrijd en Imperialisme, 1977; (with E.E. Bolhuis) Boerenarbeid en Stijlen van Landbouwbeoefening (Peasant Labour and Styles of Farm Management), Leiden University, 1985; La Ristrutturazione del Lavoro Agricolo, Rome, 1986; De Verwetenschappelijking van de Landbouwbeoefening, The Agricultural University, Wageningen, 1987; (with Jaap Frouws), Automatisering in Land- en Tuinbouw: Een Agrarisch-sociologische Analyse, 1987; and (forthcoming) The Art of Farming: A Comparative Sociological Analysis of Commoditization Processes in Agriculture, Westview Press, 1989.

LOUK DE LA RIVE BOX is Director of the Department of Development Policy Preparation at the Netherlands Ministry of Foreign Affairs, on secondment from the Department of the Sociology of Rural Development, the Agricultural University, Wageningen. He has published extensively on the sociology of crop cultivation. His recent publications include: (with F. Doorman), The 
Adaptive Farmer, The Agricultural University, Wageningen, 1982; Adaptive Agricultural Research in the Dominican Republic: Collected Reports and Papers, Leiden and Geneva, 1986; and (forthcoming) From Common Ignorance to Shared Knowledge: Knowledge Networks in the Atlantic Zone of Costa Rica, The Agricultural University, Wageningen, 1989.

JAN UBELS is a Lecturer at the Department of Irrigation and Civil Engineering, the Agricultural University, Wageningen. He is trained in both irrigation engineering and development sociology. He is presently one of the irrigation advisers for the Mexican irrigation project. His publications include: (with Jan Willem Eggink) Irrigation, Peasants and Development, Departments of Irrigation and Civil Engineering and Rural Sociology, The Agricultural University, Wageningen, 1984; and a number of reports on water management problems in differing Third World contexts.

FRANZ VON BENDA-BECKMANN is Professor of Agrarian Law at the Agricultural University, Wageningen. He was formerly Lecturer in Legal Anthropology at the University of Zurich. His main publications include: Rechtspluralismus in Malawi, Westforum Verlag, 1970; Property and Social Continuity, Nijhoff, 1979; (as co-editor) Change and Continuity in Minangkabau, Ohio University Monographs, 1985, and Between Kinship and the State: Social Security and Law in Developing Countries, Foris, 1988. He has also published numerous articles on problems of legal anthropology, legal pluralism, and law and social change in Africa and Indonesia.

AB VAN El.DIJK is Lecturer in Non-western Law at the Department of Agrarian Law, the Agricultural University, Wageningen. He originally studied law at Leiden University. His publications include: Tussen volkrecht en overheidsrecht: Over zelfregulering van marktaktiviteiten in Sierra Leone, in Brussaard et.a.l., Recht in Ontwikkeling, Kluwer, Deventer, 1986; Markthoofden en kleinhandel in Sierra Leone: Het bestuur in kwestie, in von Benda-Beckmann and Hoekema (eds), Horizontaal Bestuur, Vuga, Den Haag, 1988. His primary research interest is legal and institutional aspects of economic change.

JOEP SPIERTZ is Lecturer in Non-Western Law at the Department of Agrarian Law, the Agricultural University, Wageningen. He studied law at Nijmegen Catholic University, after which he became interested in the legal and institutional aspects of land use and water management in community-based irrigation systems. He has published on the social significance of adat law and on legal anthropological approaches to irrigation research. He recently published: "Het semi-autonome veld: wondermiddel of paardemiddel", in Nieuwsbrief voor Nederlandstalige Rechtssociologen, Rechtsantropologen en Rechtspsychologen, 1984; and "Vreemde gasten: een casus uit Bali", in Brussaard et.al., Recht in Ontwikkeling, Kluwer, Deventer, 1986.

FIETJE HUBER is a researcher at the Department of Agrarian Law, the Agricultural University, Wageningen. She is currently researching law and the distribution of land in Peru. Prior to this, she spent three years in Peru working on rural development, and earlier worked as a lawyer specializing in the legal problems of different immigrant groups in the Netherlands. She recently published an article on "Farmers, Land and Security in Caqui, Peru", in Recht der Werklijkheid, 1988. 


\section{Already published in this series}

Differentiële sociologie in kort bestek. Schets van de differentiële sociologie en haar functie in het concrete sociaal-wetenschappeijjk onderzoek (out of print)

E. W. Hofstee. 1982, 54 blz., ing., (nr. I)

Migratie uit de steden. Een literatuurstudie (out of print)

Lily Harm. 1982, 82 blz., ing. (nr. 2)

Man and manihot. Vol. I: Case studies on cassava cultivators (out of print)

L. Box and F. Doorman. 1982, 185 blz., ing., (nr. 3)

Over vriendschap. Verslag van een hypothesenvormend sociologisch onderzoek naar een bijzondere betrekking tussen mensen (out of print)

G. A. Kooy. 1982, 130 blz., ing., (nr. 4)

Man and manihot. Vol. II: An annotated bibliography on cassava cultivation and processing among Amerindians (out of print)

B. de la Rive Box-Lasocki. 1982, 170 blz., ing.. (nr. 5)

Van huwelijk tot echtscheiding; een regenboog van ervaringen (out of print)

Iteke Weeda. 1983, 502 blz., ing. (nr. 6)

Rekreatiegedrag en ekonomische crisis (out of print)

Henk de Jong. 1983, 154 blz., ing. (nr. 7)

Planning voor vrijheid. Een historisch-sociologische studie van de overheidsinterventie in rekreatie en vrije tijd (out of print)

Theo Beckers. 1983, 456 blz., ing.. (nr. 8)

Volksonderwijs in de Welingerigte Maatschappij. Een inhoudsanalyse van prijsverhandelingen van de Maatschappij tot Nut van 't Algemeen (out of print)

Dick van der Wouw en Jo Louvenberg. 1982, 135 blz., ing., (nr. 9)

Over de welzijnstaal. Een onderzoek naar de psy-normering

Ernst Meijer. 1983, 95 blz., ing., (nr. 10)

Paddy farmers, irrigation and agricultural services in Malaysia. A case study in the Kemubu Scheme

G. Kalshoven, J. R. V. Daane, L. J. Fredericks, F. van der Steen van Ommeren and A. van Tilburg. 1984, 205 pp., paperback, (nr. II), ISBN 90-6754-055-2

De woongroep verlaten. Een verkennend sociologisch onderzoek naar uittreding uit woongroepen na conflicten.

Adri Bolt. 1984, III Pp., paperback, (nr. 12), ISBN 90-6754-056-0

Huwelijkswelslagen in Nederland. Een vergelijking tussen 1967 en 1983

G. A. Kooy. 1984, 164 pp., paperback, (nr. 13), ISBN 90-6754-057-9

Anthony Giddens. Een kennismaking met de structuratietheorie

Q. J. Munters, Ernst Meijer, Hans Mommaas, Hugo van der Poel, René Rosendal en Gert Spaargaren.

1985, 137 pp., paperback, (nr. 14), ISBN 90-6754-061-7

Handelen, Handelingscontext en Planning. Een theoretisch-sociologische verkenning

Fer Kleefmann. 1985, 37। pp., paperback, (nr. I5), ISBN 90-6754-062-5

Irrigation and social organization in West Malaysia

H. J. Hoogstraten. 1985, I48 pp., paperback, (nr. 16), ISBN 90-6754-067-6

The commoditization debate: labour process, strategy and social network Norman Long, Jan Douwe van der Ploeg. Chris Curtin and Louk Box. 1986, 123 pp., paperback, (nr. 17), ISBN 90-6754-087-0 
Rood en Zwart: Bedrijfsstrategieën en kennismodellen in de Nederlandse melkveehouderij

Benjo Maso. 1986, 135 pp., paperback, (nr. 18), ISBN 90-6754-094-3

Benaderingen van organisaties vergeleken. Een kritische bespreking van theorievorming over de relatie tussen strategie en structuur van organisaties

Henk ten Holt. 1987, I 15 pP., paperback, (nr. 19), ISBN 90-6754-098-6

Landbouw, landbouwwetenschap en samenleving. Filosofische opstellen

H. Koningsveld, J. Mertens, S. Lijmbach en J. Schakel. 1987, 200 pp., paperback, (nr. 20), ISBN 90-6754-115-X

De verwetenschappelijking van de landbouwbeoefening Jan Douwe van der Ploeg. 1987, 344 pp., paperback, (rr. 21), ISBN 90-6754-I20-6

Automatisering in land- en tuinbouw. Een agrarisch-sociologische analyse Jaap Frouws en Jan Douwe van der Ploeg. 1988, xvii + 110 pp., paperback, (nr. 22), ISBN 90-6754-123-0

Illegale recreatie. Nederlandse radiopiraten en hun publiek J. H. W. Lijfering. 1988, 128 PP., paperback, (nr. 23), ISBN 90-6754-128-I

De boer als buitenstaander? Sociologische studies over marginalisering en integratie

A. T. J. Nooij, R. E. van Broekhuizen, H. J. de Haan, Q. J. Munters en K. Verrips. 1989, vi + 118 PP., paperback, (nr. 24), ISBN 90-6754-134-6

Organization and participation in Southeast Asian irrigation systems

Geert Kalshoven, Nenita E. Tapay and Aart Schrevel. 1989, vii + 118 pp., paperback, (nr. 25), ISBN 90-6754-136-2

Marginalization misunderstood. Different patterns of farm development in the West of Ireland Chris Leeuwis, 1989. xiv + I3I pp., paperback, (nr. 26), ISBN 90-6754-146-X

\section{Ordering address}

Your bookseller or

Pudoc

P.O. Box 4

6700 AA Wageningen

The Netherlands 